\title{
Photoredox Catalysis Mediated by Tungsten(0) Arylisocyanides
}

\author{
Javier Fajardo Jr., Alexandra T. Barth, Maryann Morales, Michael K. Takase, Jay R. Winkler,* \\ and Harry B. Gray* \\ Beckman Institute \\ California Institute of Technology \\ Pasadena, California 91125, United States \\ *email: winklerj@caltech.edu \\ *email: hbgray@ caltech.edu
}




\section{Experimental Methods}

\section{General Considerations}

All manipulations were carried out using standard Schlenk or glovebox techniques under an inert atmosphere (dinitrogen or argon). Solvents were deoxygenated and dried by thoroughly sparging with $\mathrm{N}_{2}$ gas followed by passage through an activated alumina column in the solvent purification system by SG Water USA, LLC. Non-halogenated solvents were tested with sodium benzophenone ketyl in tetrahydrofuran (THF) to confirm effective oxygen and moisture removal. Deuterated solvents were purchased from Cambridge Isotope Laboratories, Inc., degassed, and dried over activated $3 \AA$ molecular sieves prior to use.

$\mathrm{W}(\mathrm{CNDipp})_{6},{ }^{1} \mathrm{~W}\left(\mathrm{CNDippPh}{ }^{\mathrm{OMe} 2}\right)_{6},{ }^{1} \mathrm{~W}\left(\mathrm{CNDippPh}^{\mathrm{OMe} 3}\right)_{6},{ }^{1} \mathrm{~W}\left(\mathrm{CNDippPh}^{\mathrm{Ph}}\right)_{6},{ }^{1} \mathrm{~W}\left(\mathrm{CN}-1-\left(2-{ }^{i} \mathrm{Pr}\right)-\right.$ $\mathrm{Naph})_{6}{ }^{2} \mathrm{~W}\left(\mathrm{CNDipp}{ }^{\mathrm{CC}} \mathrm{Ph}^{\mathrm{OMe}}\right)_{6},{ }^{2}$ 1-(2-iodobenzyl)-pyrrole ${ }^{3}$, and 1-(2-bromobenzyl)-pyrrole ${ }^{4}$ were prepared according to literature methods. 2,2,6,6-Tetramethylpiperidine (TMP) was dried by refluxing over calcium hydride and purified by vacuum distillation. Iodobenzene was purified by vacuum distillation. All other reagents were purchased from commercial vendors and used without further purification.

\section{NMR Spectroscopy}

NMR measurements were performed at room temperature and spectra obtained on a Varian 400 $\mathrm{MHz}$ spectrometer. ${ }^{1} \mathrm{H}$ and ${ }^{13} \mathrm{C}$ NMR chemical shifts are reported in ppm relative to tetramethylsilane, using residual proton and ${ }^{13} \mathrm{C}$ resonances from solvent as internal standards.

\section{IR Spectroscopy}

IR spectra were obtained on thin films, formed by evaporation of solutions, using a Bruker Alpha Platinum ATR spectrometer with OPUS software in a nitrogen-filled glovebox.

\section{UV-visible Spectroscopy}

UV-visible absorption measurements were performed under an $\mathrm{N}_{2}$ atmosphere at room temperature using a Cary $50 \mathrm{UV}$-visible spectrophotometer. Samples were prepared in dry, degassed solvents inside a nitrogen-filled glovebox, placed into the cell of a high-vacuum $1 \mathrm{~cm}$ path length fused quartz cuvette (Starna Cells), and isolated from atmosphere by a high-vacuum Teflon valve (Kontes). All samples were stored in the dark before measurement and had a blank solvent background subtraction applied.

\section{Luminescence Spectroscopy}

Steady-state and time-resolved luminescence measurements were carried out in the Beckman Institute Laser Resource Center at Caltech and performed under an $\mathrm{N}_{2}$ atmosphere at room temperature. Samples were prepared in dry, degassed solvents inside a nitrogen-filled glovebox, and, unless otherwise stated, placed into the cell of a high-vacuum $1 \mathrm{~cm}$ path length fused quartz cuvette (Starna Cells), and isolated from atmosphere by a high-vacuum Teflon valve (Kontes). All samples were stored in the dark before measurement.

Steady-state emission spectra were recorded on a modified Jobin Yvon Spex Fluorolog-3. Sample excitation was achieved via a xenon arc lamp with wavelength selection provided by a monochromator. Luminescence was collected at $90^{\circ}$ to the excitation direction and directed by a bifurcated optical fiber bundle to two Ocean Optics QEPro CCD spectrometers spanning 300 to 
$930 \mathrm{~nm}$. Spectra were corrected for instrument response.

For time-resolved measurements, laser excitation was provided by $8 \mathrm{~ns}$ pulses from a Q-switched Nd:YAG laser (Spectra-Physics Quanta-Ray PRO-Series) operating at $10 \mathrm{~Hz}$. The second harmonic was used to provide laser pulses at $532 \mathrm{~nm}$. Scattered excitation light was rejected by suitable long pass and short pass filters, and probe wavelengths were selected for detection by a double monochromator (Instruments SA DH-10) with $1 \mathrm{~mm}$ slits. All instruments and electronics in these systems were controlled by software written in LabVIEW (National Instruments). Timeresolved Stern-Volmer quenching measurements were performed in NMR tubes (total sample volume of $310 \mu \mathrm{L}$ ) and mixed manually between subsequent cycles of data collection. Luminescence decay traces were fit to a single exponential (after an appropriate time delay to remove scattered excitation light).

Initial quenching yields $\left(\phi_{\mathrm{q}}\right)$ were calculated according to the equation

$$
\phi_{q}=\frac{1}{1+\frac{1}{\tau_{0} k_{\mathrm{q}}[\mathrm{Q}]}}
$$

where $\tau_{0}$ is the lifetime of $* \mathrm{~W}(\mathrm{CNAr})_{6}$ in deaerated room temperature benzene solution, $k_{\mathrm{q}}$ is the bimolecular quenching constant extracted from the corresponding Stern-Volmer plot, and [Q] is the initial quencher (1-(2-iodobenzyl)-pyrrole or 1-(2-bromobenzyl)-pyrrole) concentration (50 $\mathrm{mM}$ in BHAS photoredox catalysis reactions).

Laser excitation for two-photon luminescence measurements was provided by a regeneratively amplified Ti:Sapphire femtosecond laser operating at $810 \mathrm{~nm}$ (Spectra Physics, Tsunami, Spitfire, $1 \mathrm{kHz}, \sim 200 \mathrm{fs})$. Luminescence was measured using a fiber-coupled CCD spectrometer (500-1000 $\mathrm{nm}$, Melles Griot).

As in our previous study, ${ }^{5}$ absolute two-photon absorption (TPA) cross sections $(\delta)$ were measured relative to fluorescein in $\mathrm{H}_{2} \mathrm{O}(\mathrm{pH} 11)$ as a standard. To account for variations in the laser power over the course of experiments, the power was measured prior to two-photon luminescence data acquisition for each individual sample, and $\delta$ were calculated according to the equation

$\frac{\delta_{\text {dye }}}{\delta_{\text {fluorescein }}}=\frac{<F_{\text {dye }}>}{\phi_{\text {dye }} C_{\text {dye }} \eta_{\text {dye }}<P_{\text {dye }}>^{2}} * \frac{\phi_{\text {fluorescein }} C_{\text {fluorescein }} \eta_{\text {fluorescein }}<P_{\text {fluorescein }}>^{2}}{<F_{\text {fluorescein }}>}$

where $\langle\mathrm{F}\rangle$ is the luminescence intensity integrated across the full band profile (omitting scattered $810 \mathrm{~nm}$ excitation light and normalized with respect to integration time), $\phi$ is the photoluminescence quantum yield, $\mathrm{C}$ is the concentration (determined using extinction coefficients and UV-visible absorbance spectra), $\eta$ is the index of refraction of the solvent, and $\langle\mathrm{P}\rangle$ is the laser power measured prior to collection of the two-photon luminescence spectrum of the sample.

The fluorescein (ACROS Organics, 99\%, pure, laser grade) standard was prepared under ambient atmosphere as described previously; ${ }^{5}$ neither the MilliQ water used to prepare the sample, nor the 
final sample solution, was degassed. UV-visible absorbance spectra were collected before and after two-photon luminescence measurements to make sure there was no significant sample decomposition. All two-photon luminescence spectra were an average of 10 scans and corrected for instrument response.

\section{Transient Absorption Spectroscopy}

Transient absorption measurements were carried out in the Beckman Institute Laser Resource Center at Caltech and performed under an $\mathrm{N}_{2}$ atmosphere at room temperature. Samples were prepared in dry, degassed solvents inside a nitrogen-filled glovebox, and placed into the cell of a high-vacuum $1 \mathrm{~cm}$ path length fused quartz cuvette (Starna Cells), and isolated from atmosphere by a high-vacuum Teflon valve (Kontes).

Laser excitation for $* \mathrm{~W}(\mathrm{CNAr})_{6}$ generation was provided by $8 \mathrm{~ns}$ pulses from a Q-switched Nd:YAG laser (Spectra-Physics Quanta-Ray PRO-Series) operating at $10 \mathrm{~Hz}$. The second harmonic was used to provide laser pulses at $532 \mathrm{~nm}$. Probe light for transient absorption spectra was provided by white light flash lamp sources with either nanosecond or microsecond durations. Probe light was transported via optical fiber and split by a partial reflector. Approximately $70 \%$ of the probe light passed through the sample, the remainder directed around the sample as a reference beam. Laser beam excitation was collinear with the probe light. Sample and reference beams were coupled by optical fibers to a spectrograph and detected using two CCD arrays (Avantes AvaSpec dual channel CCD spectrometer), with scattered excitation light rejected by long pass filters. Timing synchronization of the laser fire, flashlamp fire, and photodiode array readout were controlled by a series of timing circuits triggered by either a Q-switch advance logic pulse for nanosecond (or a laser lamp sync pulse for microsecond) measurements. The photodiode readout was interfaced with a PC via a National Instruments multifunction input/output card. Measurements were made with and without excitation, corrected for dark readout, and corrected for fluorescence when necessary. Difference spectra were averaged over approximately 100 shots. All instruments and electronics in these systems were controlled by software written in MATLAB (MathWorks).

\section{Electrochemistry}

THF solutions of electrolyte $\left(0.1 \mathrm{M}\left[{ }^{n} \mathrm{Bu}_{4}\right]\left[\mathrm{PF}_{6}\right]\right)$ and analyte (ca. $\left.1 \mathrm{mM}\right)$ were prepared inside a nitrogen-filled glovebox. Subsequent electrochemical measurements were performed at room temperature in the glovebox in a one compartment cell using a Biologic SP-200 potentiostat. A platinum disk was used as the working electrode and a carbon rod was used as the auxiliary electrode. A silver pseudoreference electrode was used with the cobaltocenium couple $\left(\mathrm{Cp}_{2} \mathrm{Co}^{[+/ 0]}\right.$; $\mathrm{Cp}=$ cyclopentadienide) as an internal reference. Under these conditions, the $\mathrm{Cp}_{2} \mathrm{Co}^{[+/ 0]}$ redox couple was experimentally determined to be $-1.33 \mathrm{~V}_{\text {versus }} \mathrm{Fc}^{[+/ 0]}(\mathrm{Fc}=$ ferrocene; Figure S137), consistent with previous literature reports. This value was used to reference cyclic voltammograms $(\mathrm{CVs}) \mathrm{vs} \mathrm{Fc}^{[+/ 0]}$.

\section{X-Ray Crystallography}

XRD studies were carried out at the Caltech Beckman Institute X-ray Crystallography Facility on a Bruker AXS KAPPA APEXII (Mo K $\alpha$ radiation) diffractometer. The structure of $\mathrm{WI}_{2}(\mathrm{CNDipp})_{5}$ was solved by direct methods using SHELXS ${ }^{6}$ and refined against $F^{2}$ on all data by full-matrix least squares with SHELXL-2017 ${ }^{7}$ using established refinement techniques. ${ }^{8}$ All non-hydrogen 
atoms were refined anisotropically. All hydrogen atoms were included into the model at geometrically calculated positions and refined using a riding model. The isotropic displacement parameters of all hydrogen atoms were fixed to 1.2 times the $U$ value of the atoms they are linked to (1.5 times for methyl groups).

$\mathrm{WI}_{2}$ (CNDipp) 5 crystallizes in the triclinic space group $P-1$ with one molecule in the asymmetric unit.

\section{Synthetic Details and Characterization Data}

1-(2-iodobenzyl)-pyrrole. Since BHAS photoredox reactions were performed in $\mathrm{C}_{6} \mathrm{D}_{6},{ }^{1} \mathrm{H}$ NMR data for this compound were acquired in this solvent.

${ }^{1} \mathrm{H}$ NMR (400 MHz, $\left.\mathrm{C}_{6} \mathrm{D}_{6}\right): \delta(\mathrm{ppm}) 4.59$ (s, 2H, $\left.\mathrm{C}_{\text {aryl }}-\mathrm{CH}_{2}-\mathrm{N}_{\text {pyrrole }}\right), 6.32$ (t, 2H, Pyrrole- $H$ ), 6.35 $(\mathrm{m}, 1 \mathrm{H}, \mathrm{Ar}-H), 6.37(\mathrm{t}, 2 \mathrm{H}$, Pyrrole-H), $6.44(\mathrm{t}, 1 \mathrm{H}, \mathrm{Ar}-H), 6.75(\mathrm{t}, 1 \mathrm{H}, \mathrm{Ar}-H), 7.54(\mathrm{~d}, 1 \mathrm{H}, \mathrm{Ar}-$ $H)$.
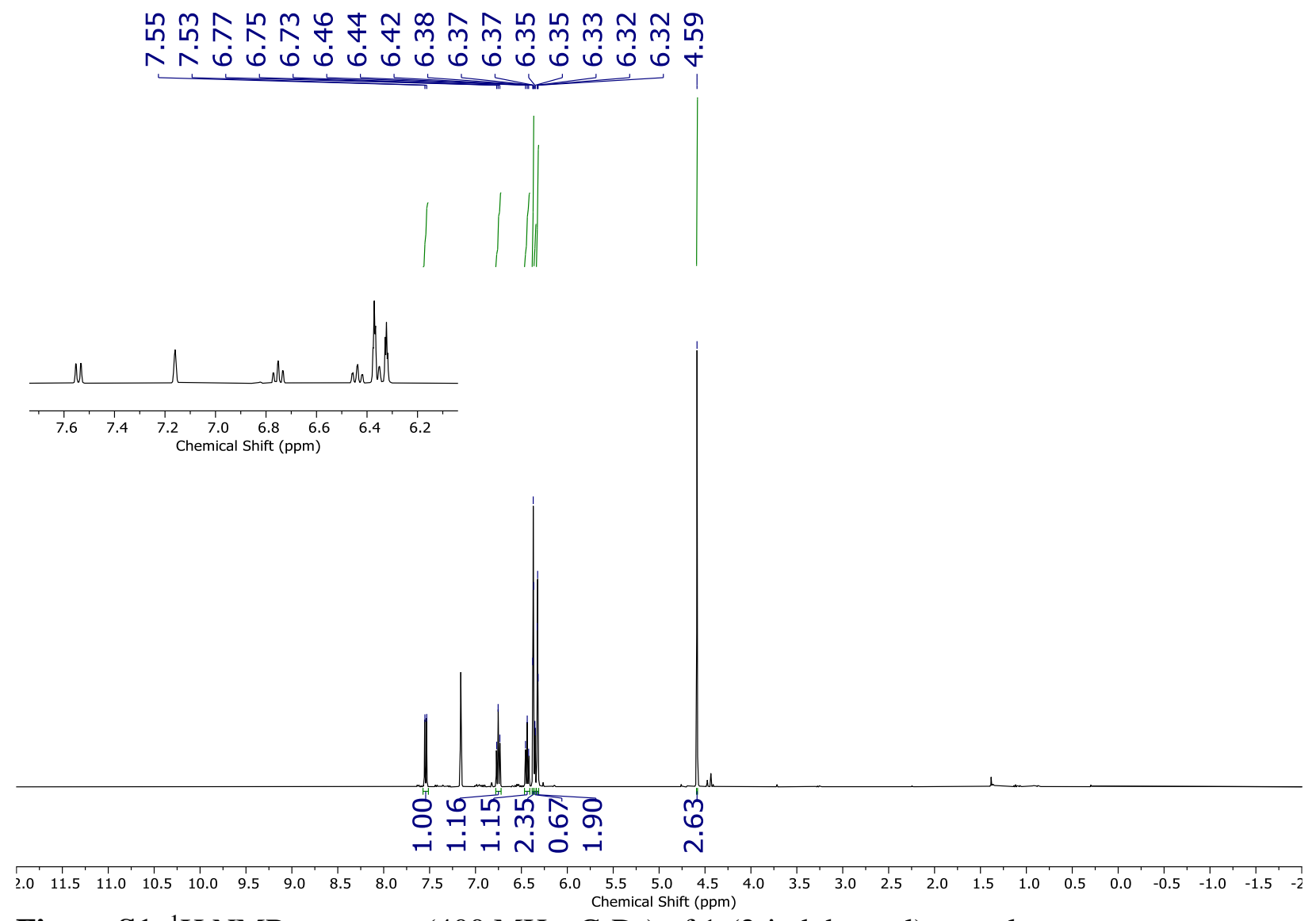

Figure S1. ${ }^{1} \mathrm{H}$ NMR spectrum (400 MHz, $\mathrm{C}_{6} \mathrm{D}_{6}$ ) of 1-(2-iodobenzyl)-pyrrole. 
1-(2-bromobenzyl)-pyrrole. Since BHAS photoredox reactions were performed in $\mathrm{C}_{6} \mathrm{D}_{6},{ }^{1} \mathrm{H}$ NMR data for this compound were acquired in this solvent.

${ }^{1} \mathrm{H}$ NMR (400 MHz, $\left.\mathrm{C}_{6} \mathrm{D}_{6}\right): \delta(\mathrm{ppm}) 4.64\left(\mathrm{~s}, 2 \mathrm{H}, \mathrm{C}_{\text {aryl }}-\mathrm{CH}_{2}-\mathrm{N}_{\text {pyrrole }}\right), 6.33$ (t, 2H, Pyrrole- $H$ ), 6.38 $(\mathrm{t}, 2 \mathrm{H}$, Pyrrole-H), $6.41(\mathrm{~m}, 1 \mathrm{H}, \mathrm{Ar}-H), 6.59(\mathrm{t}, 1 \mathrm{H}, \mathrm{Ar}-H), 6.72(\mathrm{t}, 1 \mathrm{H}, \mathrm{Ar}-H), 7.25(\mathrm{~d}, 1 \mathrm{H}, \mathrm{Ar}-$ $H)$.

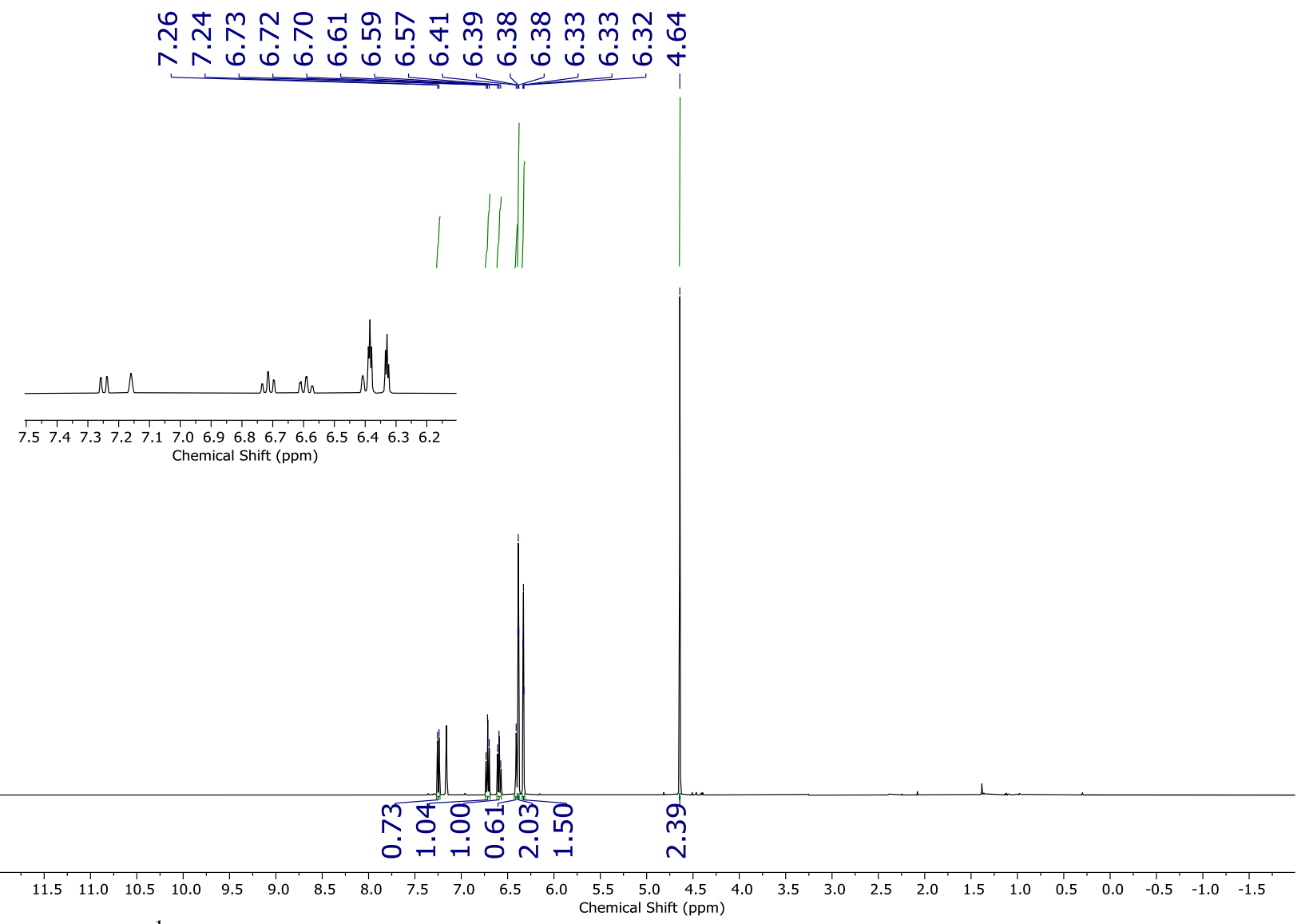

Figure S2. ${ }^{1} \mathrm{H}$ NMR spectrum (400 MHz, $\mathrm{C}_{6} \mathrm{D}_{6}$ ) of 1-(2-bromobenzyl)-pyrrole.

TMP. Since BHAS photoredox reactions were performed in $\mathrm{C}_{6} \mathrm{D}_{6},{ }^{1} \mathrm{H}$ NMR data for this compound were acquired in this solvent. ${ }^{1} \mathrm{H}$ and ${ }^{13} \mathrm{C}\left\{{ }^{1} \mathrm{H}\right\} \mathrm{NMR}$ data in $\mathrm{CDCl}_{3}$ was also acquired for comparison with [H-TMP][I]. Both data are in good agreement with that previously reported in the literature. ${ }^{9}$

${ }^{1} \mathrm{H}$ NMR (400 MHz, $\left.\mathrm{C}_{6} \mathrm{D}_{6}\right): \delta(\mathrm{ppm}) 0.31$ (br s, 1H, N-H), 1.07 (s, 12H, CH3), 1.23-1.26 (m, 4H, $\left.\mathrm{CH}_{2}-\mathrm{CH}_{2}-\mathrm{CH}_{2}\right), 1.51-1.57\left(\mathrm{~m}, 2 \mathrm{H}, \mathrm{CH}_{2}-\mathrm{CH}_{2}-\mathrm{CH}_{2}\right)$.

${ }^{1} \mathrm{H}$ NMR $\left(400 \mathrm{MHz}, \mathrm{CDCl}_{3}\right)$ : $\delta(\mathrm{ppm}) 0.65$ (br s, $\left.1 \mathrm{H}, \mathrm{N}-\mathrm{H}\right), 1.12(\mathrm{~s}, 12 \mathrm{H}, \mathrm{CH}), 1.30-1.33(\mathrm{~m}, 4 \mathrm{H}$, $\left.\mathrm{CH}_{2}-\mathrm{CH}_{2}-\mathrm{CH}_{2}\right), 1.62-1.68\left(\mathrm{~m}, 2 \mathrm{H}, \mathrm{CH}_{2}-\mathrm{CH}_{2}-\mathrm{CH}_{2}\right)$.

${ }^{13} \mathrm{C}\left\{{ }^{1} \mathrm{H}\right\} \mathrm{NMR}\left(101 \mathrm{MHz}, \mathrm{CDCl}_{3}\right): \delta(\mathrm{ppm}) 18.5\left(\mathrm{CH}_{2}-\mathrm{CH}_{2}-\mathrm{CH}_{2}\right), 31.7\left(\mathrm{CH}_{3}\right), 38.7\left(\mathrm{CH}_{2}-\mathrm{CH}_{2}-\right.$ $\left.\mathrm{CH}_{2}\right), 49.8\left(\mathrm{~N}-\mathrm{C}\left(\mathrm{CH}_{3}\right)_{2}-\mathrm{CH}_{2}\right)$. 


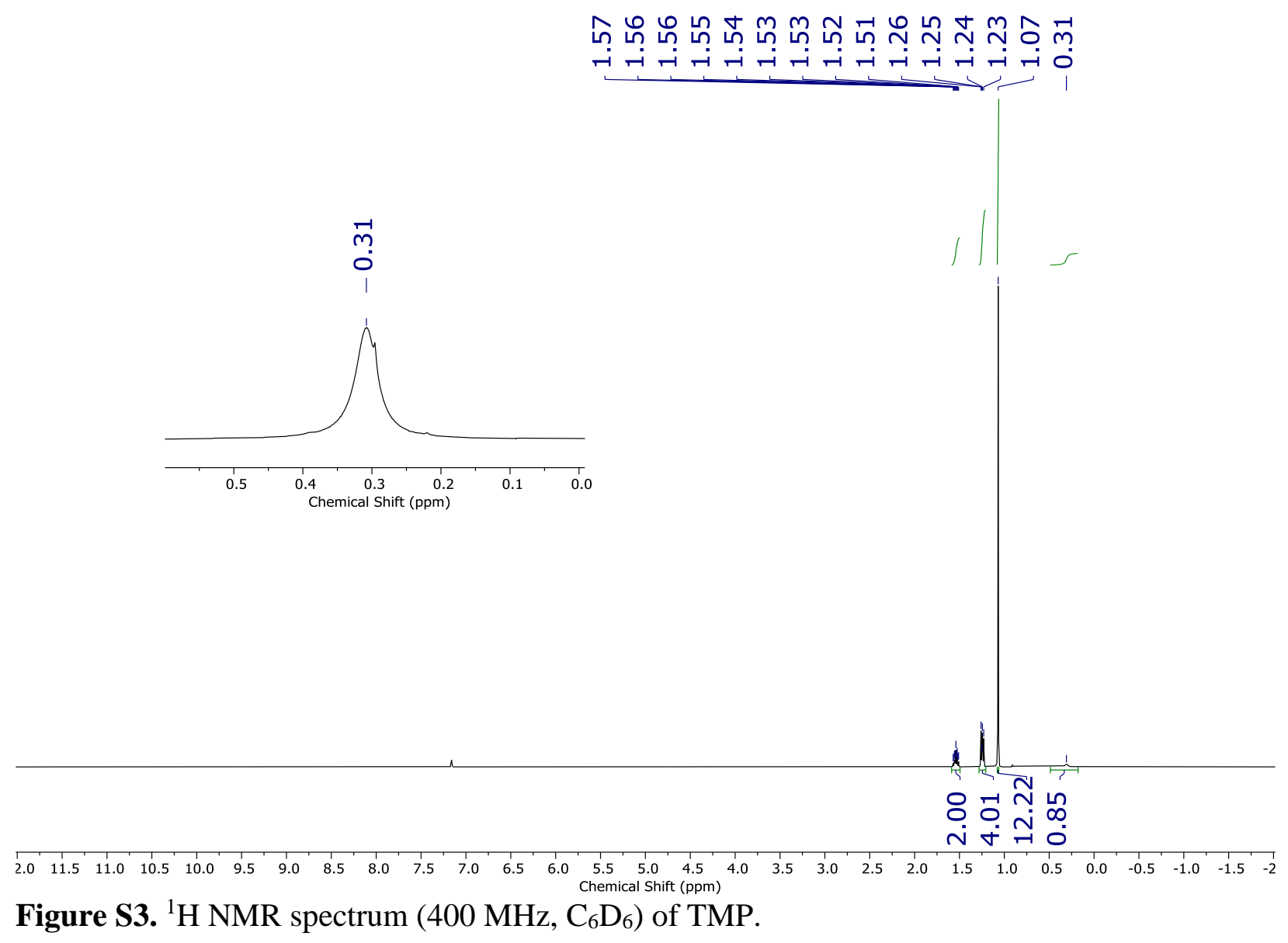




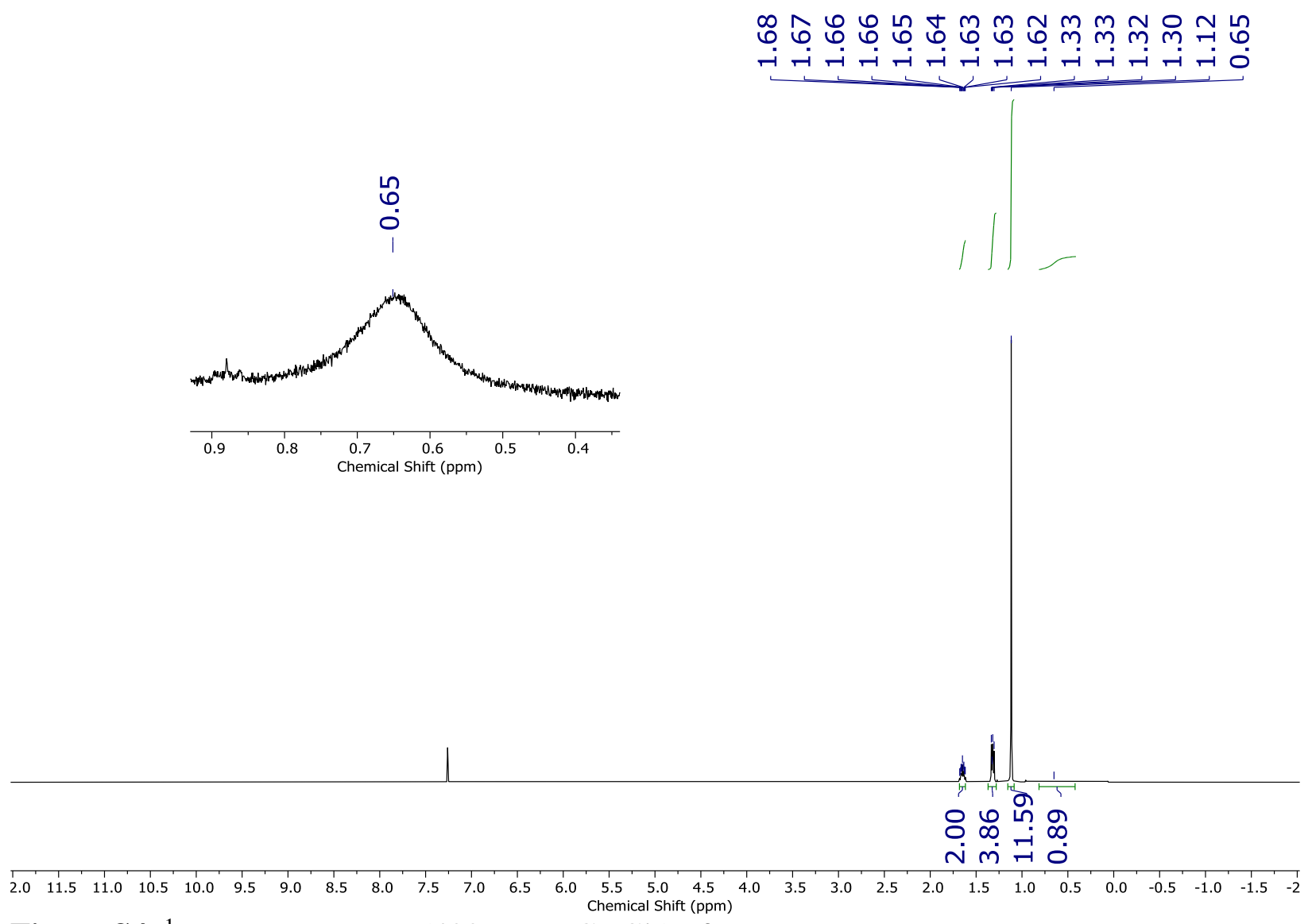

Figure S4. ${ }^{1} \mathrm{H}$ NMR spectrum $\left(400 \mathrm{MHz}, \mathrm{CDCl}_{3}\right)$ of TMP. 


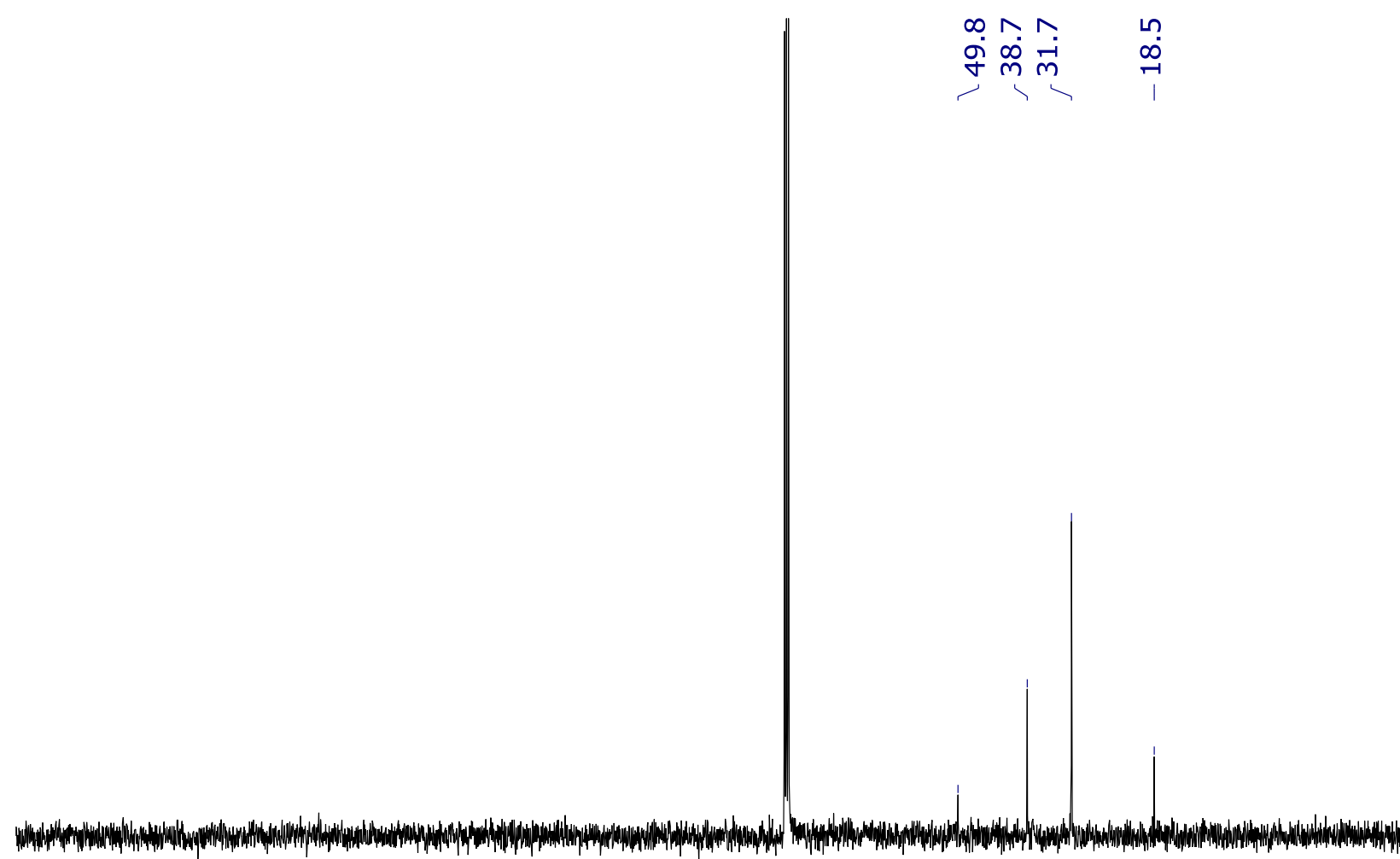

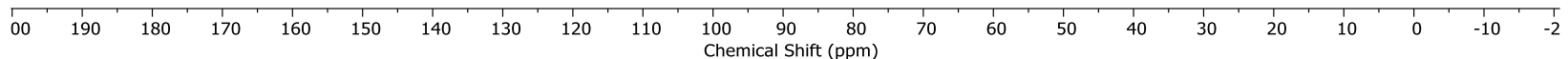

Figure S5. ${ }^{13} \mathrm{C}\left\{{ }^{1} \mathrm{H}\right\}$ NMR spectrum $\left(101 \mathrm{MHz}, \mathrm{CDCl}_{3}\right)$ of TMP. 


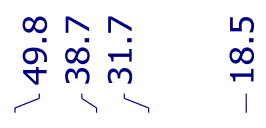

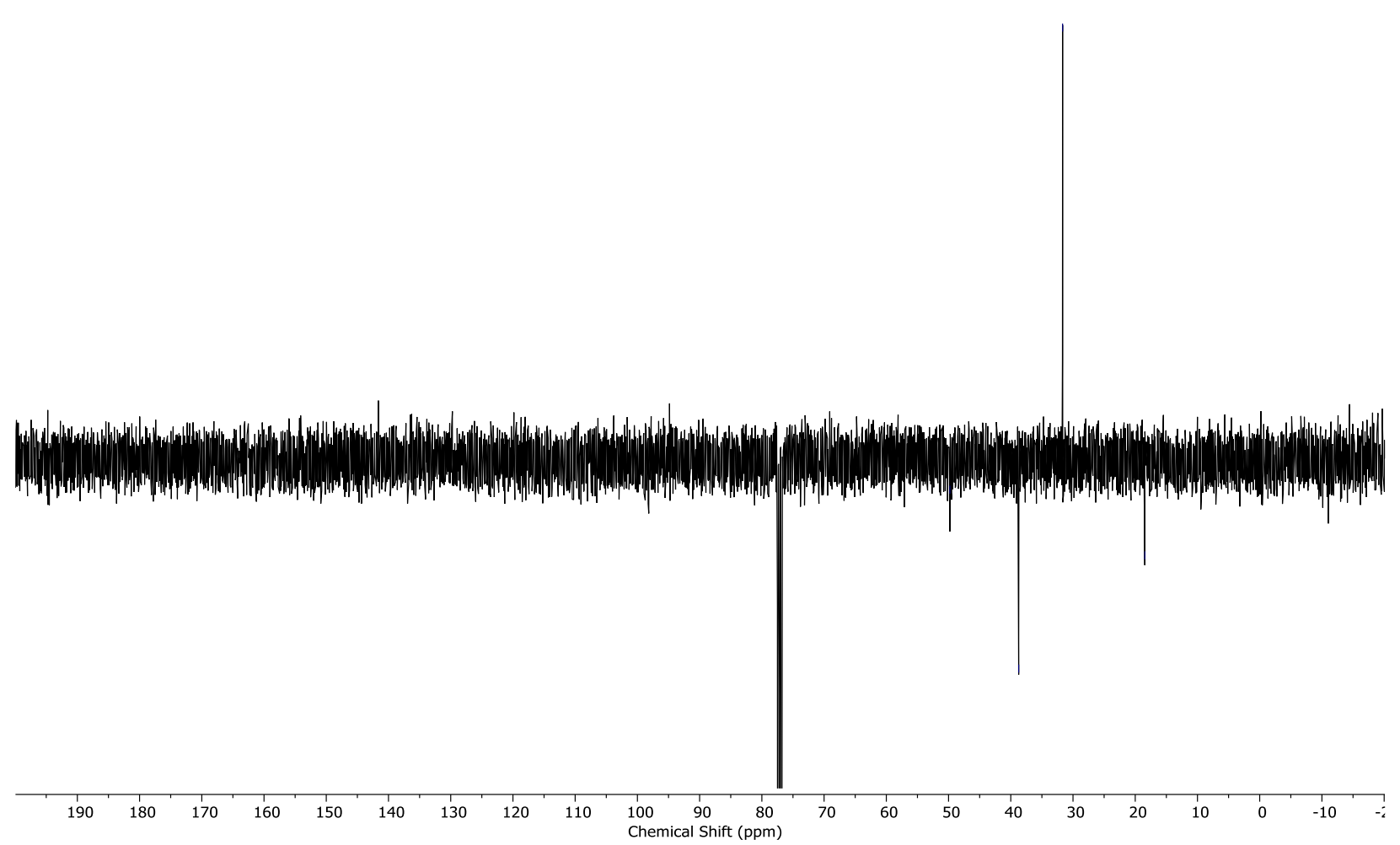

Figure S6. ${ }^{13} \mathrm{C}\left\{{ }^{1} \mathrm{H}\right\}$ APT NMR spectrum $\left(101 \mathrm{MHz}, \mathrm{CDCl}_{3}\right)$ of TMP.

[H-TMP][I]. Over the course of BHAS photoredox catalytic reactions, a colorless crystalline solid was observed to precipitate from $\mathrm{C}_{6} \mathrm{D}_{6}$ solution. This solid was isolated by filtration, washed with benzene, and dried under vacuum. ${ }^{1} \mathrm{H}$ and ${ }^{13} \mathrm{C}\left\{{ }^{1} \mathrm{H}\right\}$ NMR data acquired in $\mathrm{CDCl}_{3}$ confirmed the product to be [H-TMP][I]. The latter is also in good agreement with that reported for [H-TMP][Cl] in the literature. ${ }^{9}$

${ }^{1} \mathrm{H}$ NMR (400 MHz, $\left.\mathrm{CDCl}_{3}\right): \delta(\mathrm{ppm}) 1.70\left(\mathrm{~s}, 12 \mathrm{H}, \mathrm{CH}_{3}\right), 1.79\left(\mathrm{~s}, \mathrm{gH}, \mathrm{CH}_{2}-\mathrm{CH}_{2}-\mathrm{CH}_{2}\right.$ ), 7.91 (br s, $\left.2 \mathrm{H}, \mathrm{N}-\mathrm{H}_{2}\right)$.

${ }^{13} \mathrm{C}\left\{{ }^{1} \mathrm{H}\right\} \mathrm{NMR}\left(101 \mathrm{MHz}, \mathrm{CDCl}_{3}\right): \delta(\mathrm{ppm}) 16.3\left(\mathrm{CH}_{2}-\mathrm{CH}_{2}-\mathrm{CH}_{2}\right), 27.7\left(\mathrm{CH}_{3}\right), 35.6\left(\mathrm{CH}_{2}-\mathrm{CH}_{2}-\right.$ $\left.\mathrm{CH}_{2}\right), 59.1\left(\mathrm{~N}-\mathrm{C}\left(\mathrm{CH}_{3}\right)_{2}-\mathrm{CH}_{2}\right)$. 


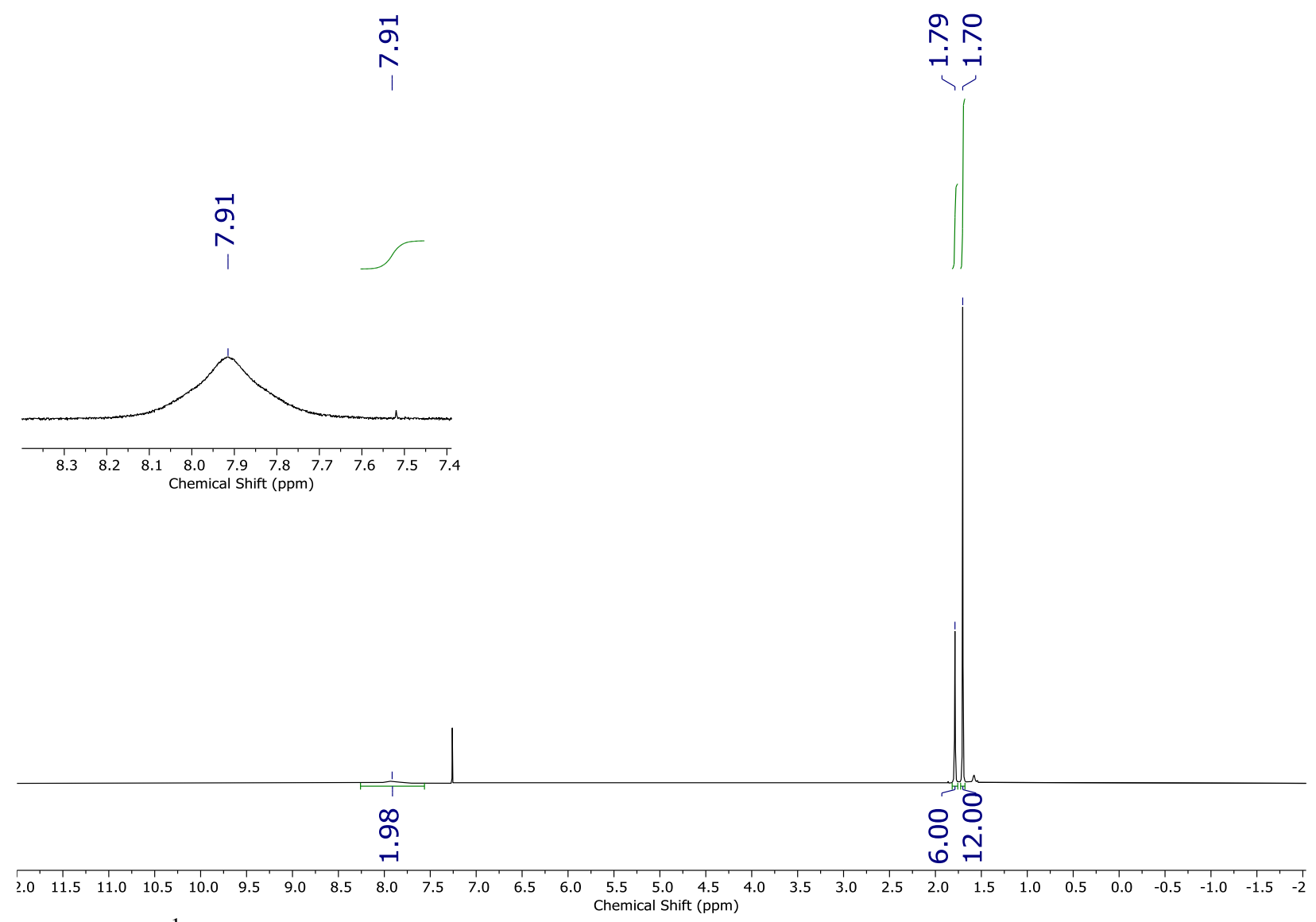

Figure S7. ${ }^{1} \mathrm{H}$ NMR spectrum $\left(400 \mathrm{MHz}, \mathrm{CDCl}_{3}\right)$ of $[\mathrm{H}-\mathrm{TMP}][\mathrm{I}]$. 


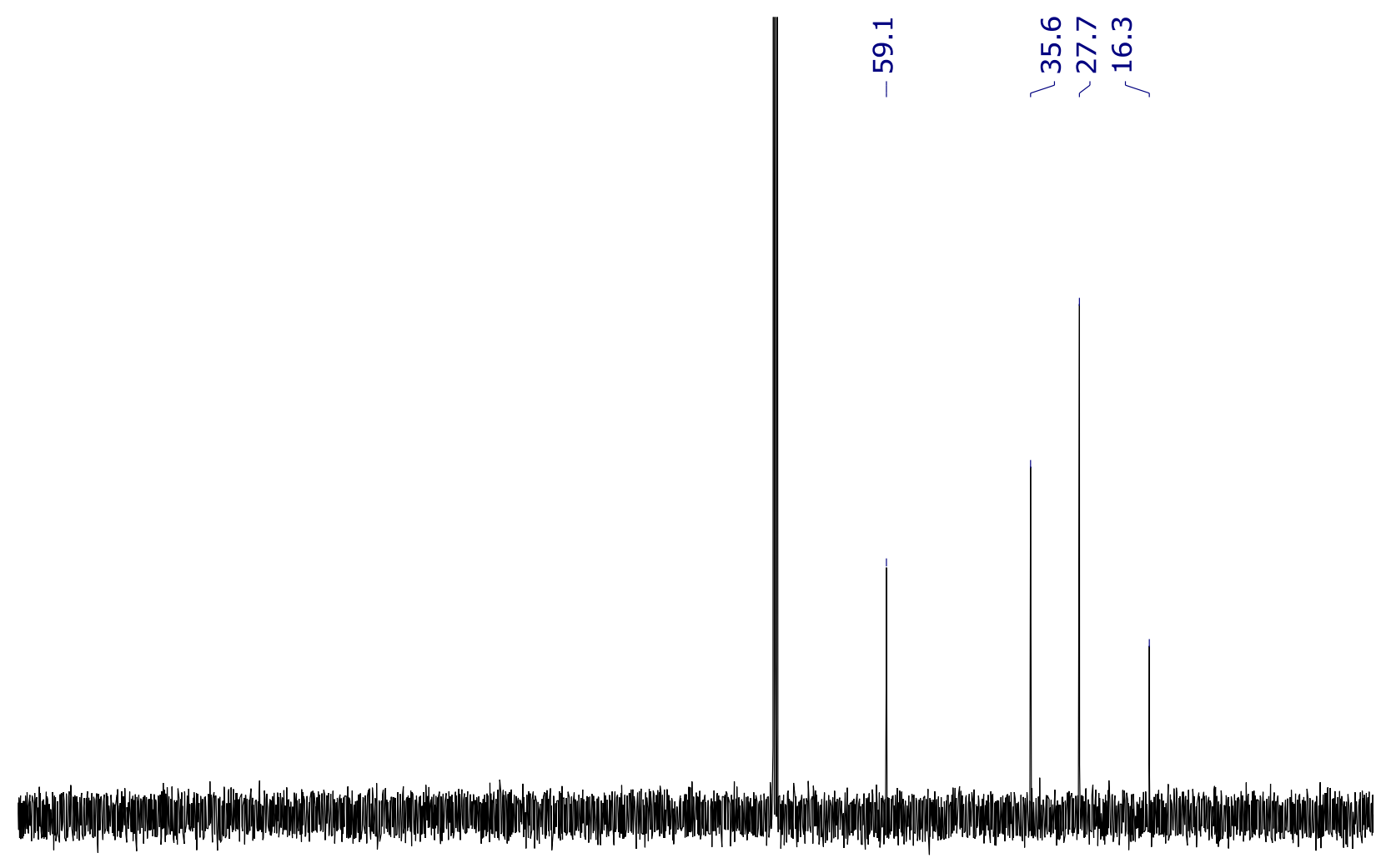

\begin{tabular}{lllllllllllllllllllllllll}
\hline 00 & 190 & 180 & 170 & 160 & 150 & 140 & 130 & 120 & 110 & 100 & 90 & 80 & 70 & 60 & 50 & 40 & 30 & 20 & 10 & 0 & -10 & -4 \\
Chemical Shift (ppm)
\end{tabular}

Figure S8. ${ }^{13} \mathrm{C}\left\{{ }^{1} \mathrm{H}\right\}$ NMR spectrum $\left(101 \mathrm{MHz}, \mathrm{CDCl}_{3}\right)$ of $[\mathrm{H}-\mathrm{TMP}][\mathrm{I}]$. 


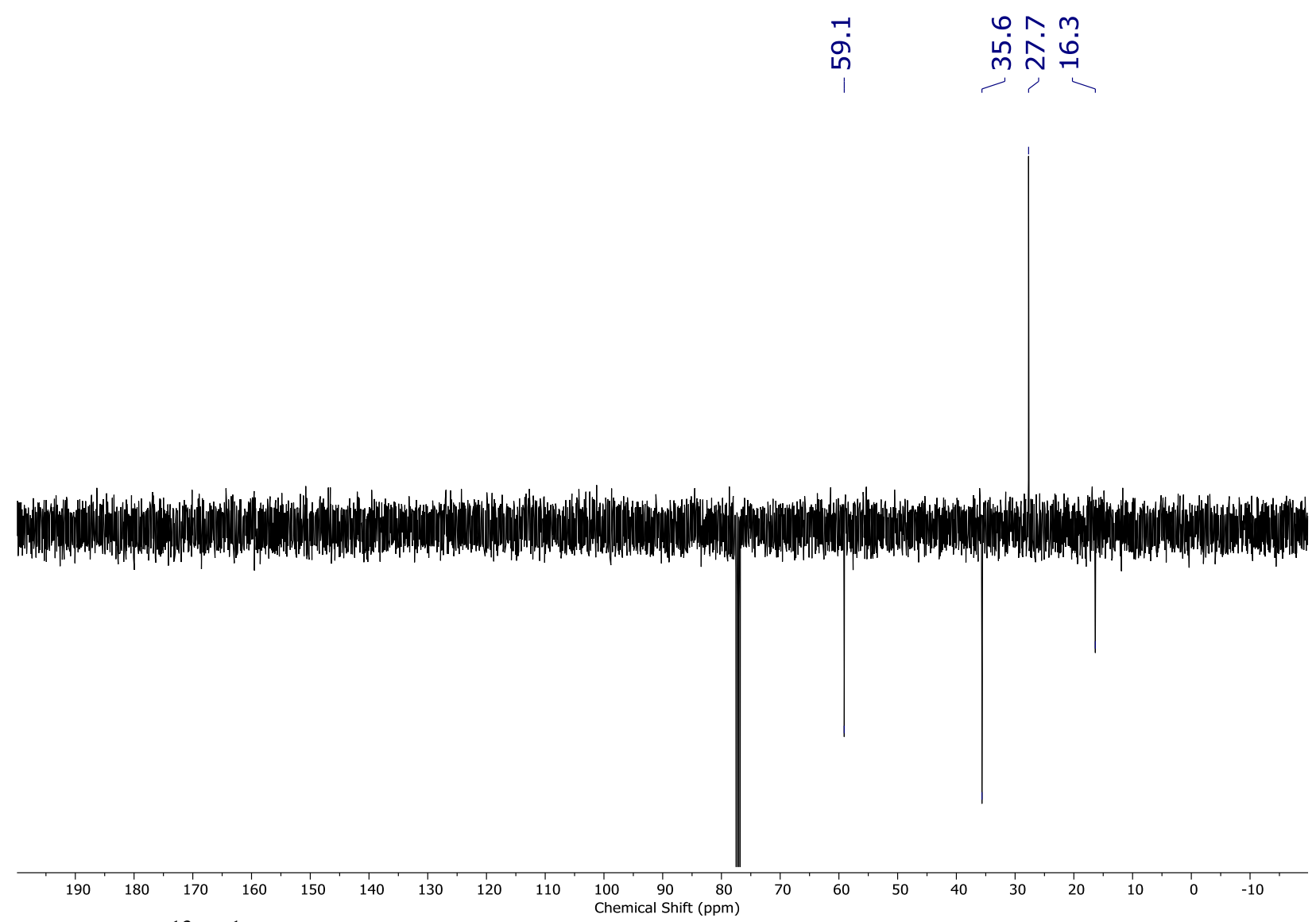

Figure S9. ${ }^{13} \mathrm{C}\left\{{ }^{1} \mathrm{H}\right\}$ APT NMR spectrum $\left(101 \mathrm{MHz}, \mathrm{CDCl}_{3}\right)$ of $[\mathrm{H}-\mathrm{TMP}][\mathrm{I}]$.

WI $_{2}$ (CNDipp)5. To a solution of W(CNDipp) 6 (1.00 equiv, $\left.0.0419 \mathrm{~g}, 0.0320 \mathrm{mmol}\right)$ in benzene ( 8 $\mathrm{mL}$ ) was added iodobenzene ( 4.00 equiv, $0.128 \mathrm{mmol}, 14.3 \mu \mathrm{L}$ ) via micropipette. This solution was transferred to a $25 \mathrm{~mL}$ Schlenk tube equipped with a stir bar and then sealed with a Teflon valve (Kontes). The tube was brought out of the glovebox and the mixture was irradiated overnight with a $40 \mathrm{~W}$ Kessil blue LED, using a stream of compressed air directed over the reaction vessel to maintain an ambient temperature during irradiation.

After irradiating overnight, the Schlenk tube was cycled into the glovebox. Consistent with the loss of sample luminescence, a UV-visible absorbance spectrum of the crude reaction mixture confirmed complete consumption of $\mathrm{W}(\mathrm{CNDipp})_{6}$, signaling the reaction was complete. The reaction solution was transferred to a $20 \mathrm{~mL}$ scintillation vial, frozen, and lyophilized. The remaining brown-orange residue was washed with pentane $(3 \times 2 \mathrm{~mL})$, dissolved in a minimal amount of benzene, and filtered into a $4 \mathrm{~mL}$ vial. Slow concentration of the benzene solution at room temperature in a sealed $20 \mathrm{~mL}$ scintillation vial containing HMDSO as the antisolvent then afforded crystals of $\mathrm{WI}_{2}(\mathrm{CNDipp})_{5}$. The crystals were washed with pentane $(3 \times 2 \mathrm{~mL})$, dissolved in a minimal amount of benzene, and filtered into a tared vial. Lyophilization then yielded $\mathrm{WI}_{2}(\mathrm{CNDipp})_{5}$ as an orange solid in quantitative yield $(0.0438 \mathrm{~g})$. The isolated material was stored at room temperature in the dark. 
Crystals suitable for XRD analysis were obtained by slow concentration of a concentrated $\mathrm{C}_{6} \mathrm{D}_{6}$ solution of $\mathrm{WI}_{2}(\mathrm{CNDipp})_{5}$ in a closed vessel containing HMDSO at room temperature in the dark.

${ }^{1} \mathrm{H}$ NMR (400 MHz, $\left.\mathrm{C}_{6} \mathrm{D}_{6}\right): \delta(\mathrm{ppm}) 1.18\left(\mathrm{~d}, J=7.0 \mathrm{~Hz}, 60 \mathrm{H}, \mathrm{CH}\left(\mathrm{CH}_{3}\right)_{2}\right), 3.87$ (sept, $J=6.9 \mathrm{~Hz}$, $\left.10 \mathrm{H}, \mathrm{CH}\left(\mathrm{CH}_{3}\right)_{2}\right), 6.90-6.96(\mathrm{~m}, 15 \mathrm{H}, \mathrm{Ar}-\mathrm{H})$.

${ }^{13} \mathrm{C}\left\{{ }^{1} \mathrm{H}\right\}$ NMR $\left(101 \mathrm{MHz}, \mathrm{C}_{6} \mathrm{D}_{6}\right): \delta(\mathrm{ppm}) 23.5\left(\mathrm{CH}\left(\mathrm{CH}_{3}\right)_{2}\right), 29.8\left(C \mathrm{CH}\left(\mathrm{CH}_{3}\right)_{2}\right), 123.6\left(C_{\text {aryl }}\right), 126.8$ $\left(C_{\text {aryl }}\right), 128.5\left(C_{\text {aryl }}\right), 145.0\left(C_{\text {aryl }}\right), 171.3\left(C_{\text {isocyanide }}=\mathrm{N}\right)$.

IR (thin film from $\left.\mathrm{C}_{6} \mathrm{D}_{6}\right): v(\mathrm{CN})=2050 \mathrm{~cm}^{-1}$ (centroid).
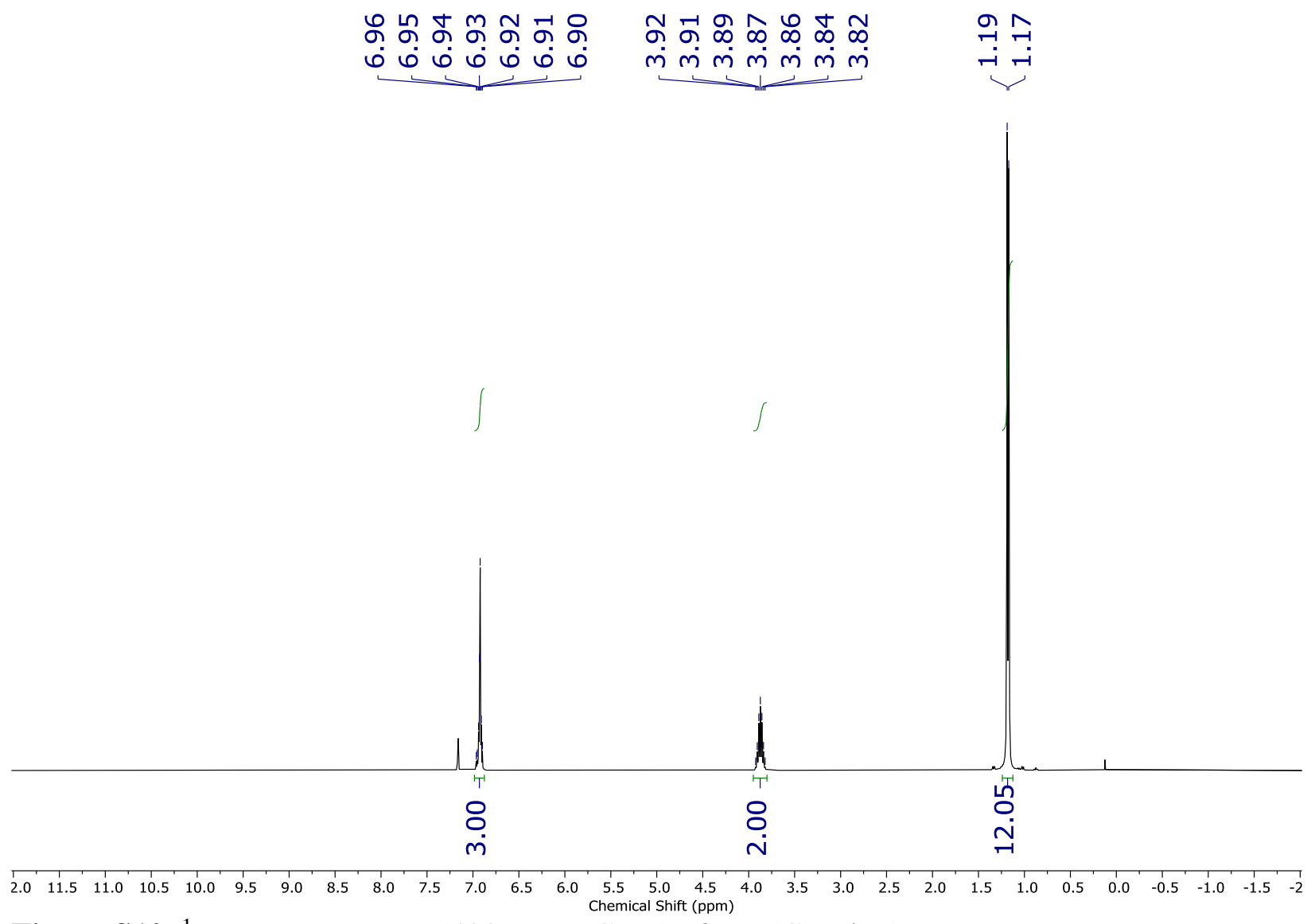

Figure S10. ${ }^{1} \mathrm{H}$ NMR spectrum $\left(400 \mathrm{MHz}, \mathrm{C}_{6} \mathrm{D}_{6}\right)$ of $\mathrm{WI}_{2}(\mathrm{CNDipp})_{5}$. 


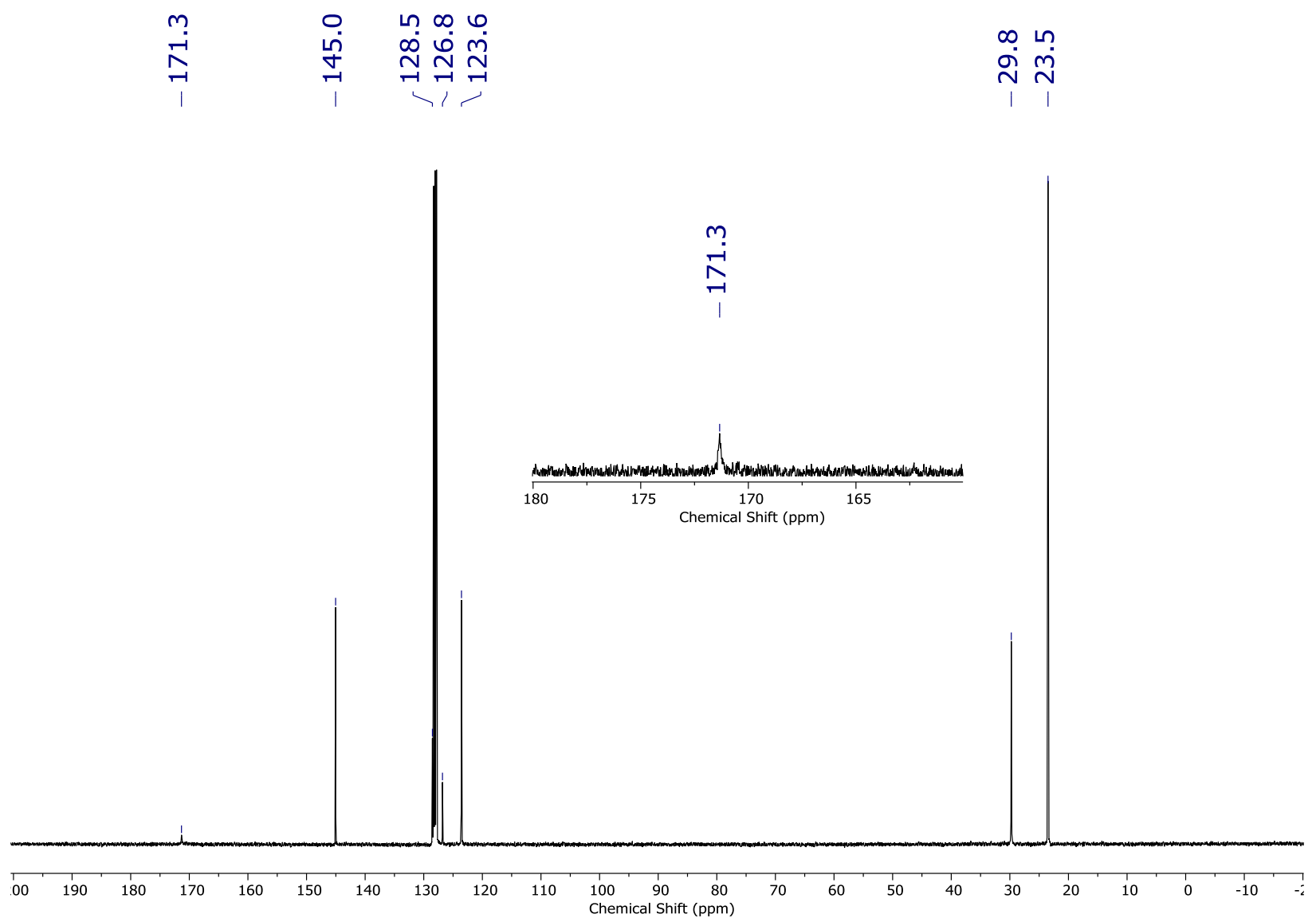

Figure S11. ${ }^{13} \mathrm{C}\left\{{ }^{1} \mathrm{H}\right\}$ NMR spectrum (101 MHz, $\left.\mathrm{C}_{6} \mathrm{D}_{6}\right)$ of $\mathrm{WI}_{2}(\mathrm{CNDipp})_{5}$. 


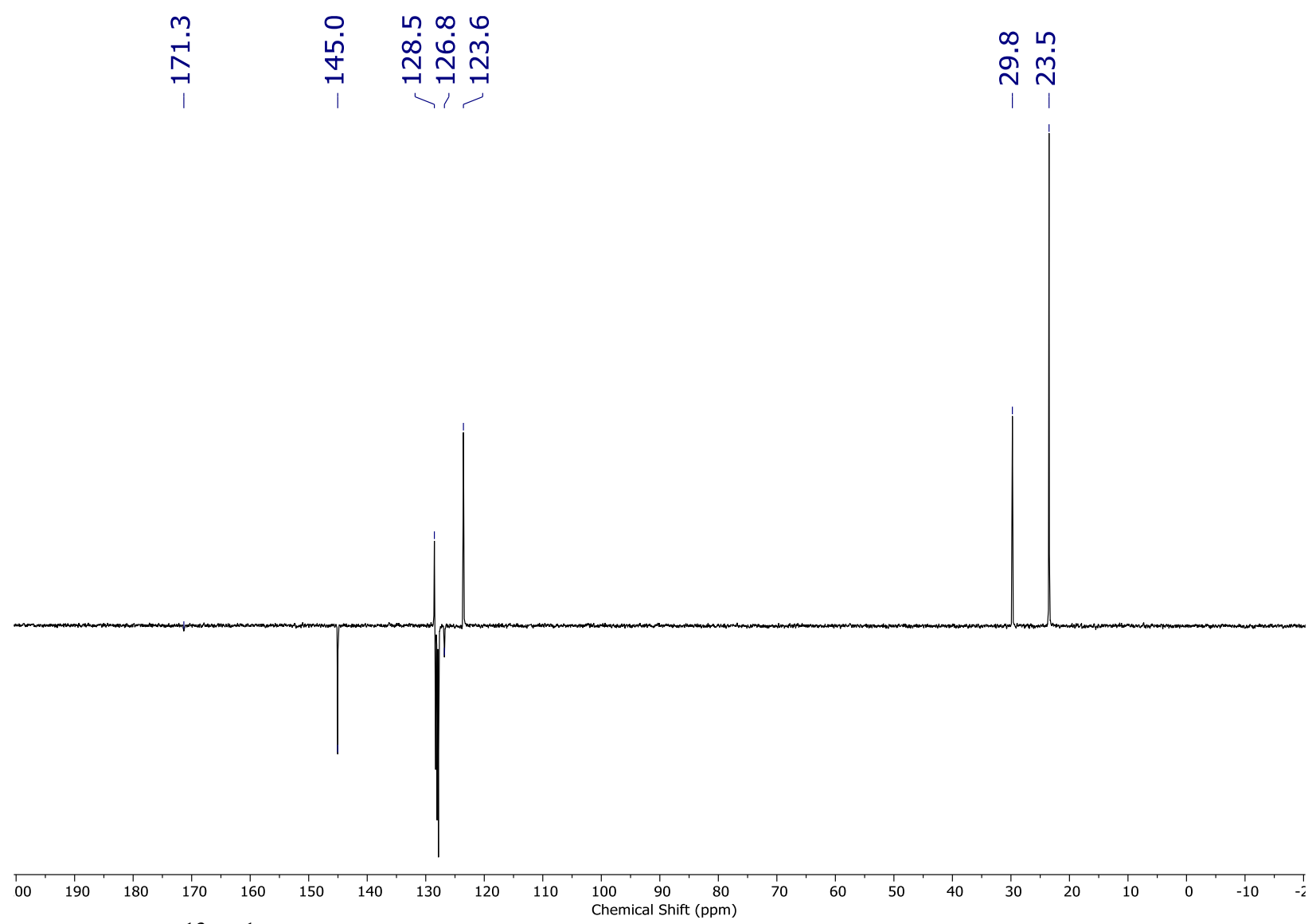

Figure S12. ${ }^{13} \mathrm{C}\left\{{ }^{1} \mathrm{H}\right\}$ APT NMR spectrum (101 MHz, $\left.\mathrm{C}_{6} \mathrm{D}_{6}\right)$ of $\mathrm{WI}_{2}(\mathrm{CNDipp})_{5}$.

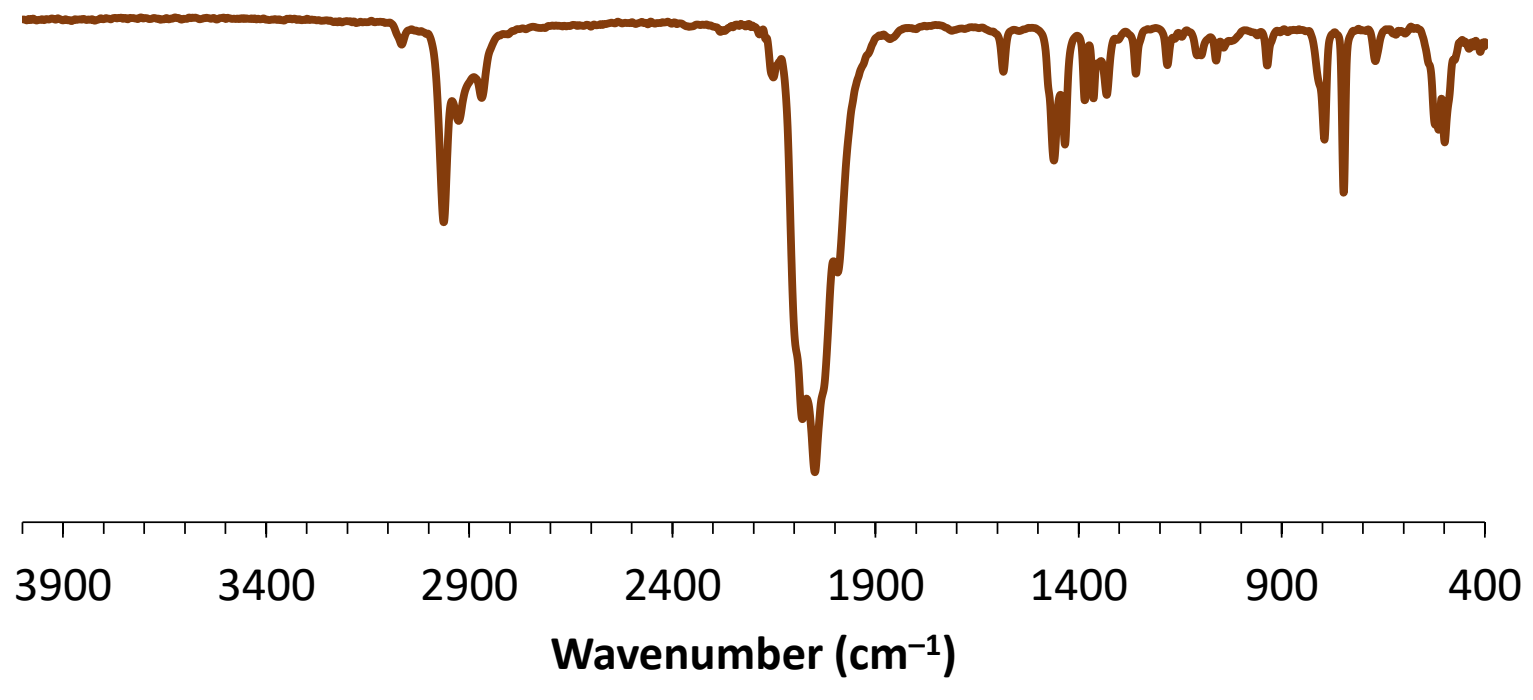

Figure S13. IR spectrum of $\mathrm{WI}_{2}(\mathrm{CNDipp})_{5}$ deposited as a thin film from $\mathrm{C}_{6} \mathrm{D}_{6}$. 


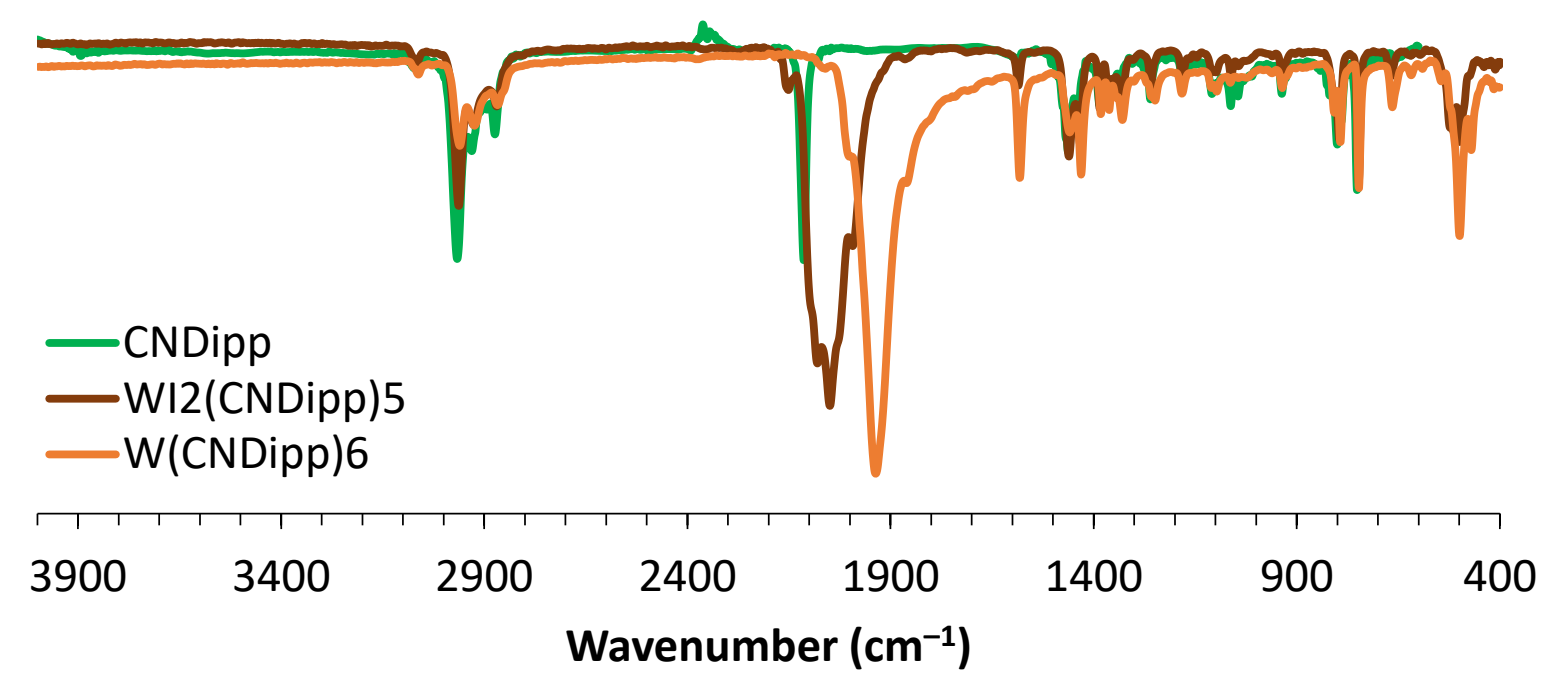

Figure S14. Overlaid IR spectra of CNDipp, $\mathrm{WI}_{2}(\mathrm{CNDipp})_{5}$, and $\mathrm{W}(\mathrm{CNDipp})_{6}$ deposited as thin films from $\mathrm{CDCl}_{3}(\mathrm{CNDipp})$ or $\mathrm{C}_{6} \mathrm{D}_{6}\left(\mathrm{WI}_{2}(\mathrm{CNDipp})_{5}\right.$ and $\left.\mathrm{W}(\mathrm{CNDipp})_{6}\right)$.

$\mathrm{WI}_{2}$ (CNDippPh $\left.{ }^{\mathrm{OMe}}\right)_{5}$. To a solution of $\mathrm{W}\left(\mathrm{CNDippPh}{ }^{\mathrm{OMe} 3}\right)_{6}(1.00$ equiv, $0.0285 \mathrm{~g}, 0.0124 \mathrm{mmol})$ in benzene $(12 \mathrm{~mL})$ was added iodobenzene ( 8.00 equiv, $0.0989 \mathrm{mmol}, 11.1 \mu \mathrm{L})$ via micropipette. This solution was transferred to a $25 \mathrm{~mL}$ Schlenk tube equipped with a stir bar and then sealed with a Teflon valve (Kontes). The tube was brought out of the glovebox and the mixture was irradiated overnight with a $40 \mathrm{~W}$ Kessil blue LED, using a stream of compressed air directed over the reaction vessel to maintain an ambient temperature during irradiation.

After irradiating overnight, the Schlenk tube was cycled into the glovebox. Consistent with the loss of sample luminescence, a UV-visible absorbance spectrum of the crude reaction mixture confirmed complete consumption of $\mathrm{W}\left(\mathrm{CNDippPh}{ }^{\mathrm{OMe}}\right)_{6}$, signaling the reaction was complete. The reaction solution was transferred to a $20 \mathrm{~mL}$ scintillation vial, frozen, and lyophilized. The remaining brown residue was washed with pentane $(3 \times 2 \mathrm{~mL})$, dissolved in a minimal amount of toluene, and filtered into a $20 \mathrm{~mL}$ scintillation vial. Layering the remaining volume with pentane and storing in the freezer $\left(-32^{\circ} \mathrm{C}\right)$ overnight led to the precipitation of $\mathrm{WI}_{2}\left(\mathrm{CNDippPh}^{\mathrm{OMe}}\right)_{5}$. After decanting the supernatant, the solid was washed with pentane $(3 \times 2 \mathrm{~mL})$, dissolved in a minimal amount of benzene, and filtered into a tared vial. Lyophilization then yielded $\mathrm{WI}_{2}\left(\mathrm{CNDippPh}^{\mathrm{OMe}}\right)_{5}$ as an orange solid in $95 \%$ yield $(0.0259 \mathrm{~g})$. The isolated material was stored at room temperature in the dark.

*Note: $\mathrm{WI}_{2}\left(\mathrm{CNDippPh}{ }^{\mathrm{OMe} 3}\right)_{5}$ prepared in this fashion contains a minor impurity that could not be removed despite attempts to further purify the compound. Single crystals of the product suitable for XRD analysis could not be obtained.

${ }^{1} \mathrm{H}$ NMR $\left(400 \mathrm{MHz}, \mathrm{C}_{6} \mathrm{D}_{6}\right): \delta(\mathrm{ppm}) 1.44\left(\mathrm{~d}, J=6.8 \mathrm{~Hz}, 60 \mathrm{H}, \mathrm{CH}\left(\mathrm{CH}_{3}\right)_{2}\right), 3.41\left(\mathrm{~s}, 30 \mathrm{H}, \mathrm{OCH}_{3}\right)$, 3.89 (s, $\left.15 \mathrm{H}, \mathrm{OCH}_{3}\right), 4.16$ (sept, $\left.J=6.8 \mathrm{~Hz}, 10 \mathrm{H}, \mathrm{CH}\left(\mathrm{CH}_{3}\right)_{2}\right), 6.76(\mathrm{~s}, 10 \mathrm{H}, \mathrm{Ar}-H), 7.49$ (s, 10H, Ar- $H$ ). 
${ }^{13} \mathrm{C}\left\{{ }^{1} \mathrm{H}\right\}$ NMR $\left(101 \mathrm{MHz}, \mathrm{C}_{6} \mathrm{D}_{6}\right): \delta(\mathrm{ppm}) 23.7\left(\mathrm{CH}\left(\mathrm{CH}_{3}\right)_{2}\right), 30.2\left(\mathrm{CH}\left(\mathrm{CH}_{3}\right)_{2}\right), 56.1\left(\mathrm{OCH}_{3}\right), 60.7$ $\left(\mathrm{OCH}_{3}\right), 106.1\left(C_{\text {aryl }}\right), 122.8\left(C_{\text {aryl }}\right), 126.1\left(C_{\text {aryl }}\right), 136.9\left(C_{\text {aryl }}\right), 140.0\left(C_{\text {aryl }}\right), 142.6\left(C_{\text {aryl }}\right), 145.6$ $\left(C_{\text {aryl }}\right), 154.6\left(C_{\text {aryl }}\right), 172.3\left(C_{\text {isocyanide }}=\mathrm{N}\right)$.

IR (thin film from $\left.\mathrm{C}_{6} \mathrm{D}_{6}\right): v(\mathrm{CN})=2051 \mathrm{~cm}^{-1}$ (centroid).

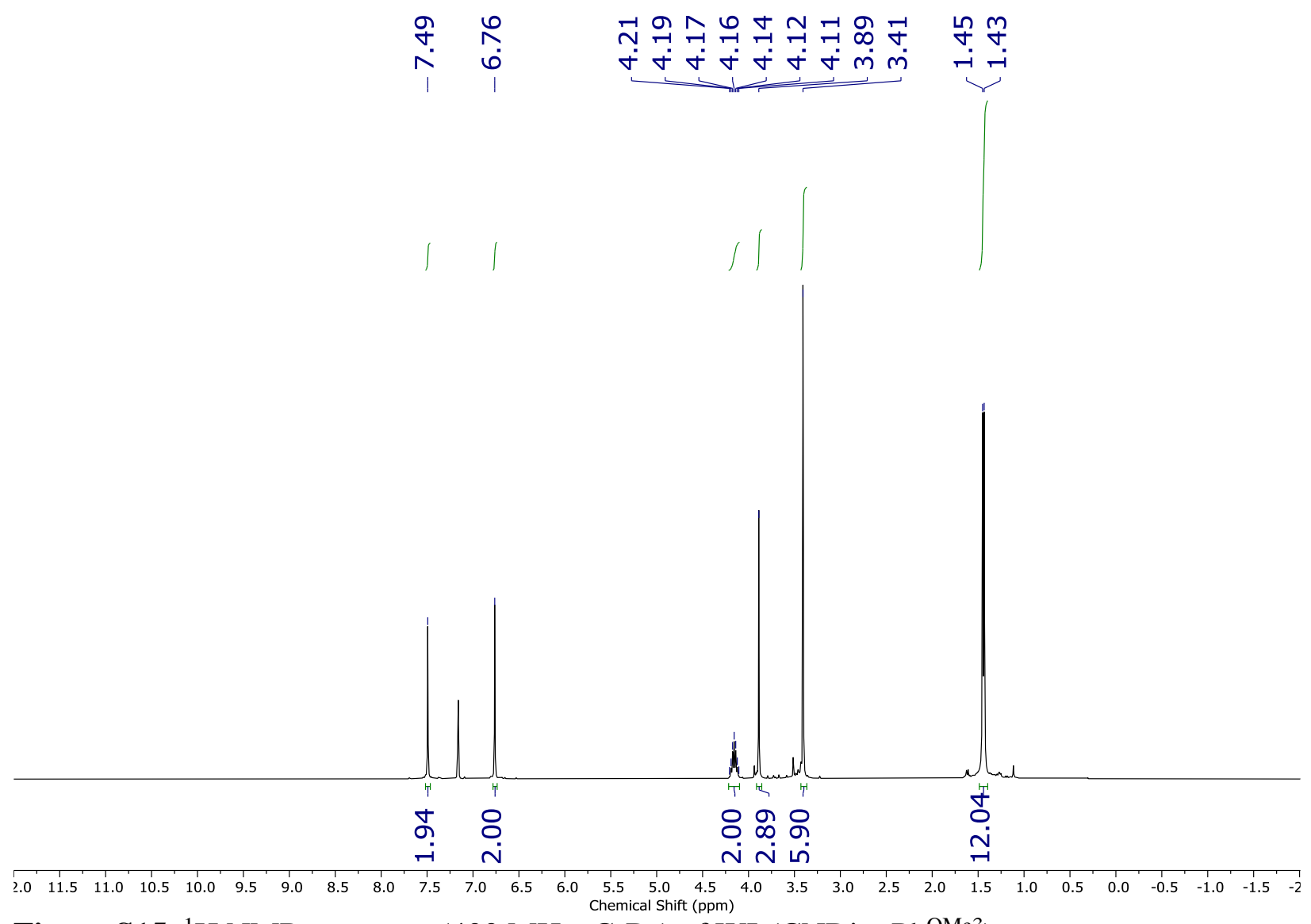

Figure S15. ${ }^{1} \mathrm{H}$ NMR spectrum (400 MHz, $\left.\mathrm{C}_{6} \mathrm{D}_{6}\right)$ of $\mathrm{WI}_{2}\left(\mathrm{CNDippPh}^{\mathrm{OMe}}\right)_{5}$. 


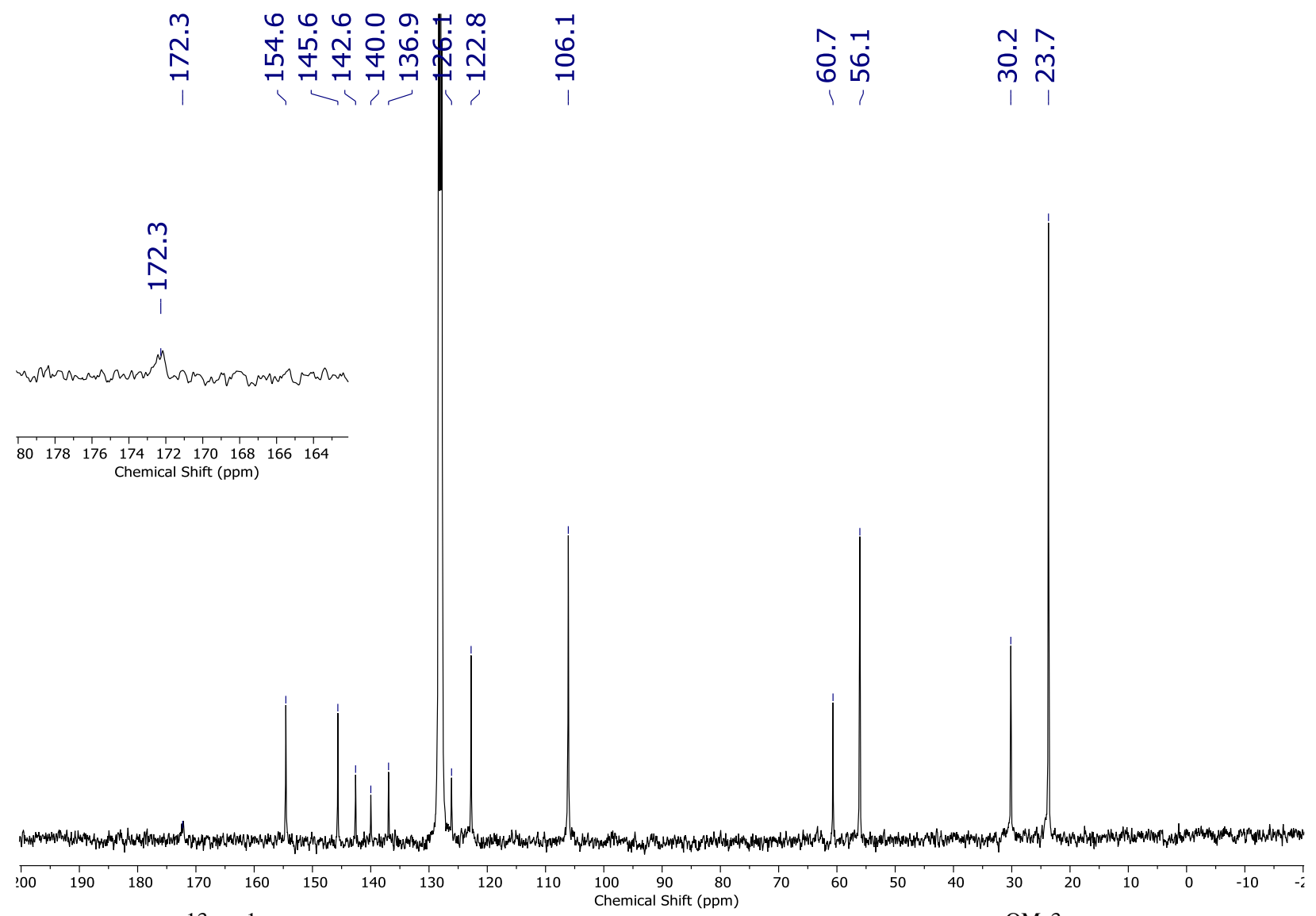

Figure S16. ${ }^{13} \mathrm{C}\left\{{ }^{1} \mathrm{H}\right\}$ NMR spectrum $\left(101 \mathrm{MHz}, \mathrm{C}_{6} \mathrm{D}_{6}\right)$ of $\mathrm{WI}_{2}\left(\mathrm{CNDippPh}^{\mathrm{OMe} 3}\right)_{5}$. 


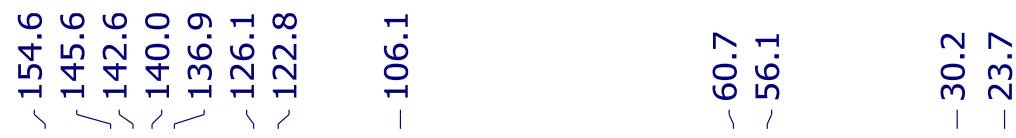

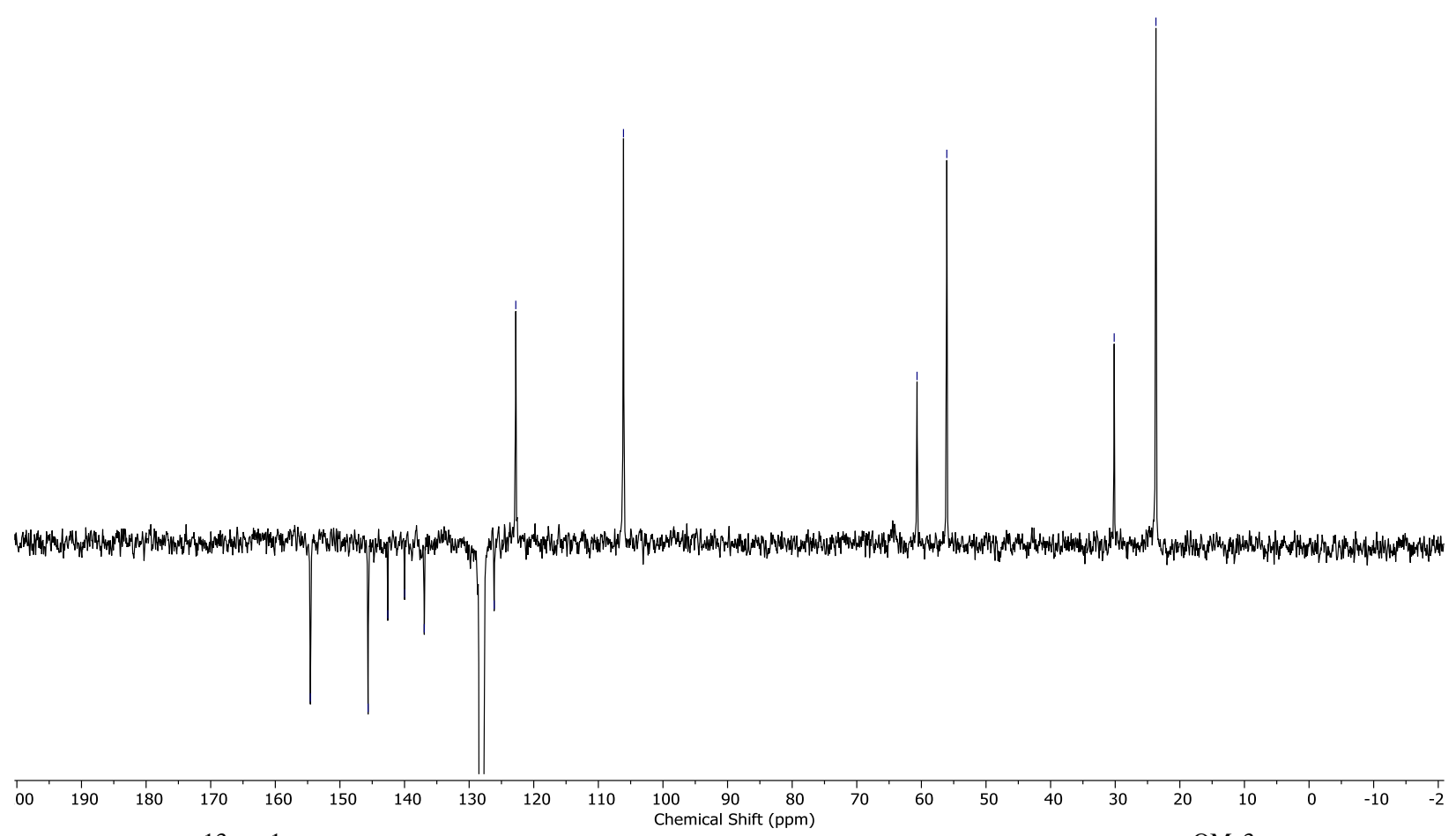

Figure S17. ${ }^{13} \mathrm{C}\left\{{ }^{1} \mathrm{H}\right\}$ APT NMR spectrum $\left(101 \mathrm{MHz}, \mathrm{C}_{6} \mathrm{D}_{6}\right)$ of $\mathrm{WI}_{2}\left(\mathrm{CNDippPh}^{\mathrm{OMe} 3}\right)_{5}$.
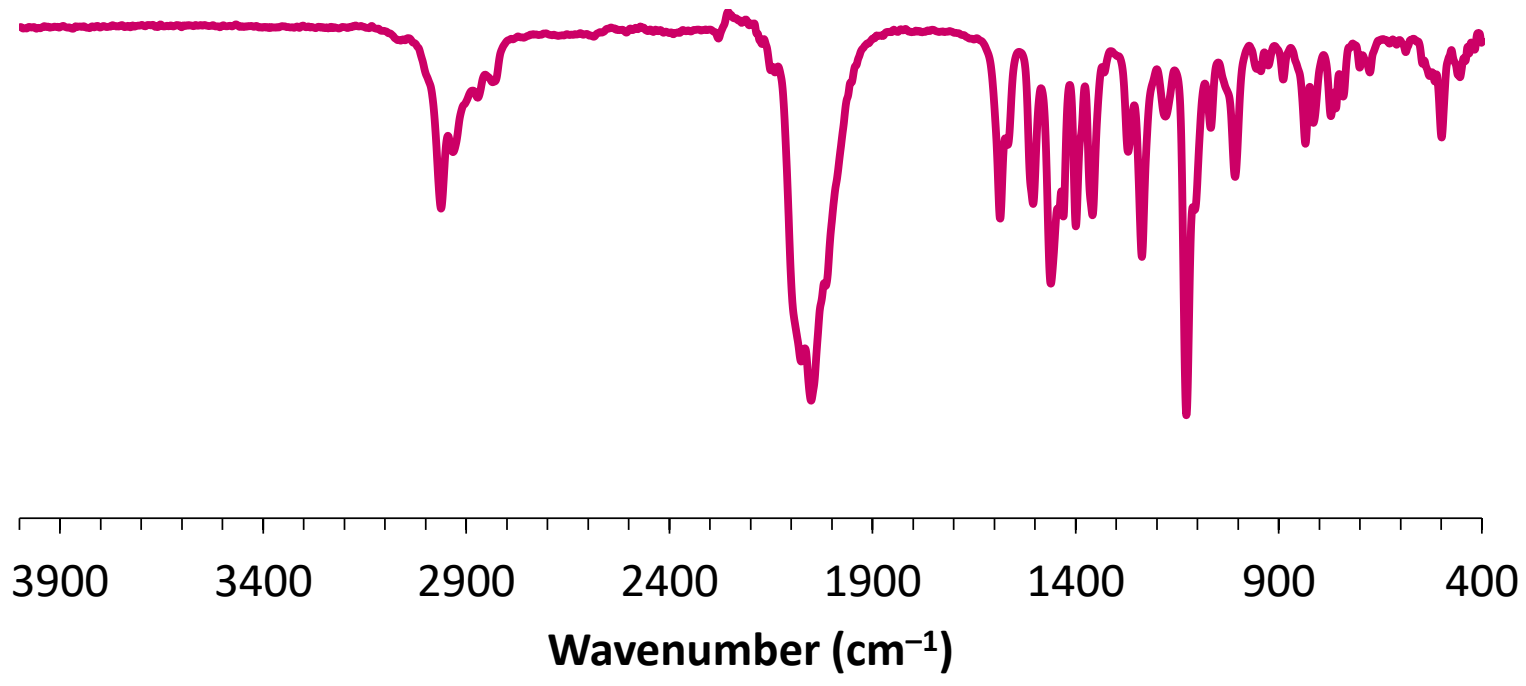

Figure S18. IR spectrum of $\mathrm{WI}_{2}\left(\mathrm{CNDippPh}{ }^{\mathrm{OMe} 3}\right)_{5}$ deposited as a thin film from $\mathrm{C}_{6} \mathrm{D}_{6}$. 


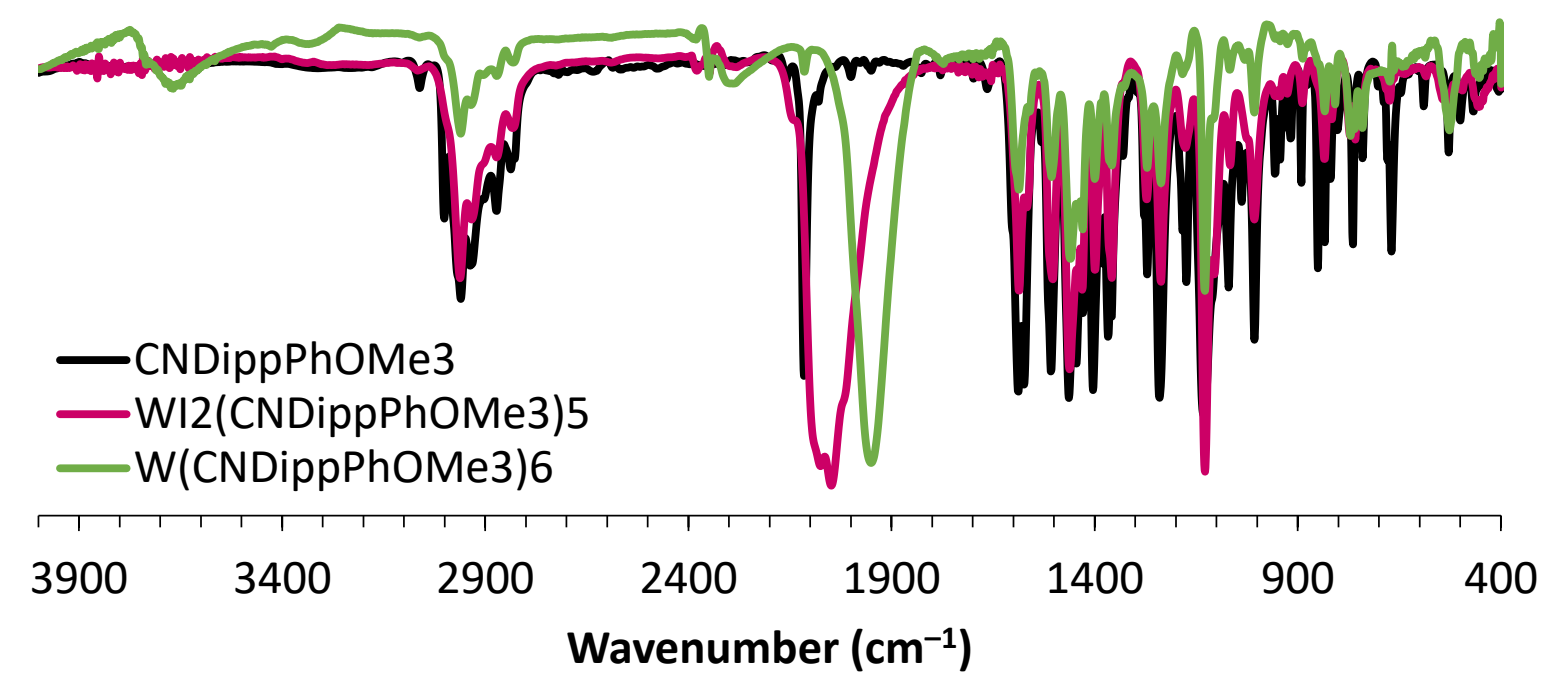

Figure S19. Overlaid IR spectra of $\mathrm{CNDippPh}{ }^{\mathrm{OMe} 3}, \quad \mathrm{WI}_{2}\left(\mathrm{CNDippPh}^{\mathrm{OMe}}\right)_{5}$, and $\mathrm{W}\left(\mathrm{CNDippPh}{ }^{\mathrm{OMe} 3}\right)_{6}(\mathrm{KBr}$ pellets $)$.
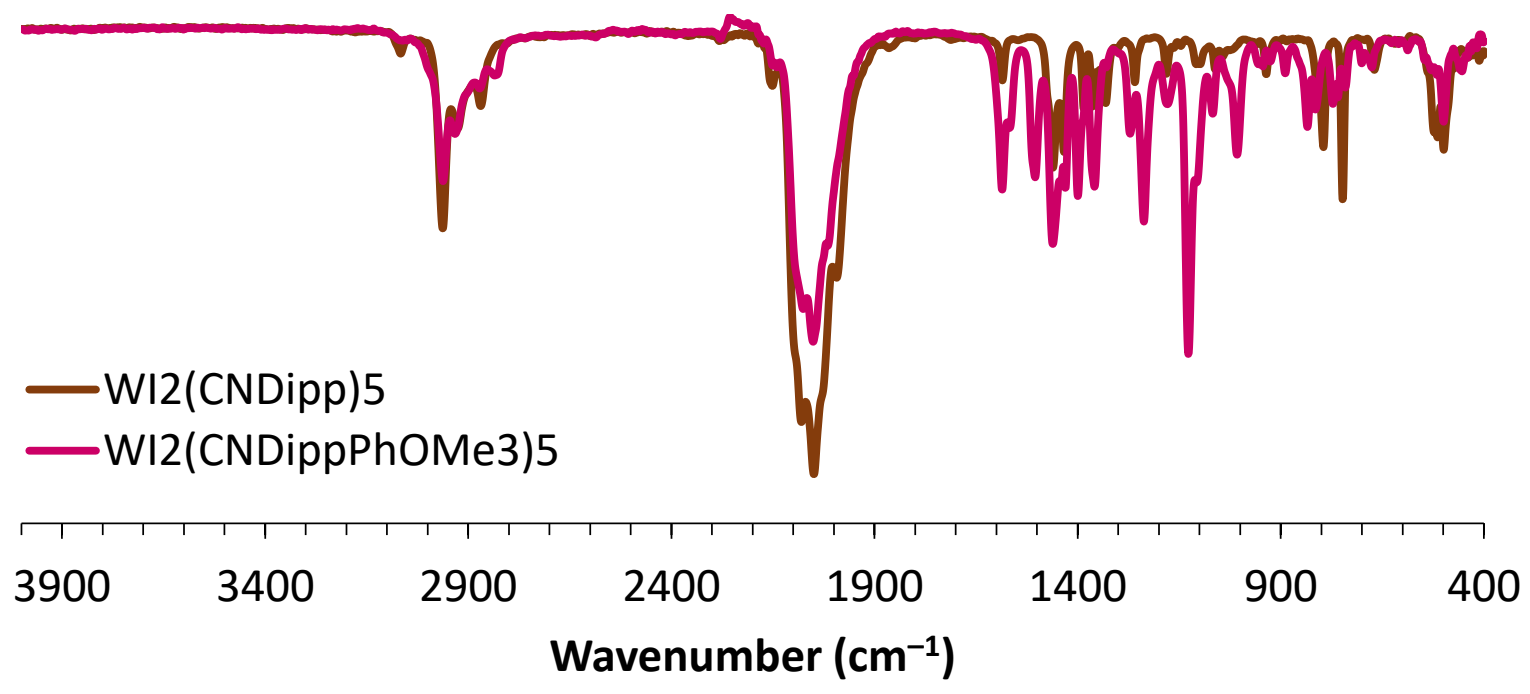

Figure S20. Overlaid IR spectra of $\mathrm{WI}_{2}(\mathrm{CNDipp})_{5}$ and $\mathrm{WI}_{2}\left(\mathrm{CNDippPh}^{\mathrm{OMe} 3}\right)_{5}$ deposited as thin films from $\mathrm{C}_{6} \mathrm{D}_{6}$. 


\section{UV-visible Spectroscopy}

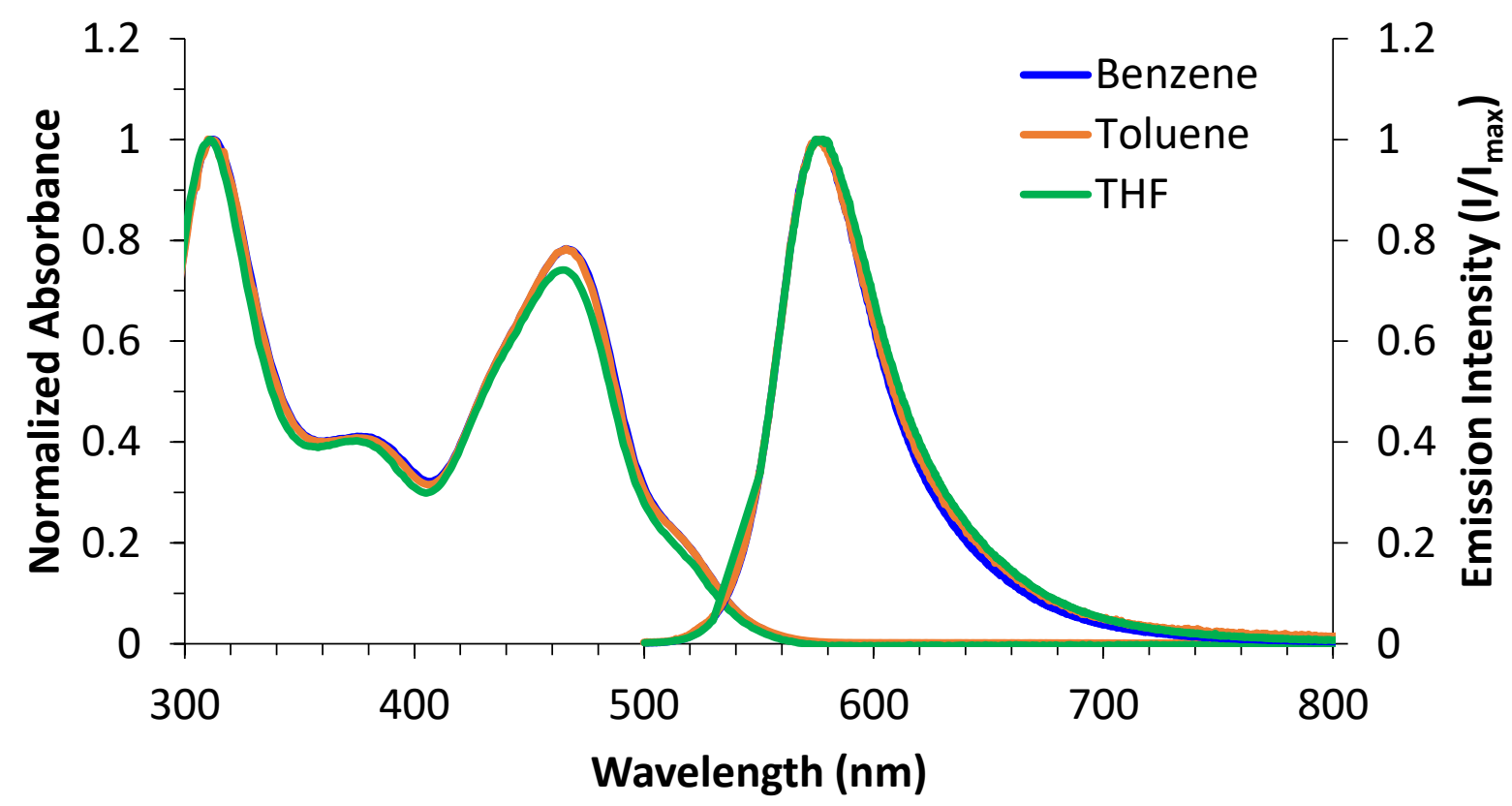

Figure S21. UV-visible absorbance and steady-state luminescence spectra of W(CNDipp) 6 in benzene, toluene, and THF solution.

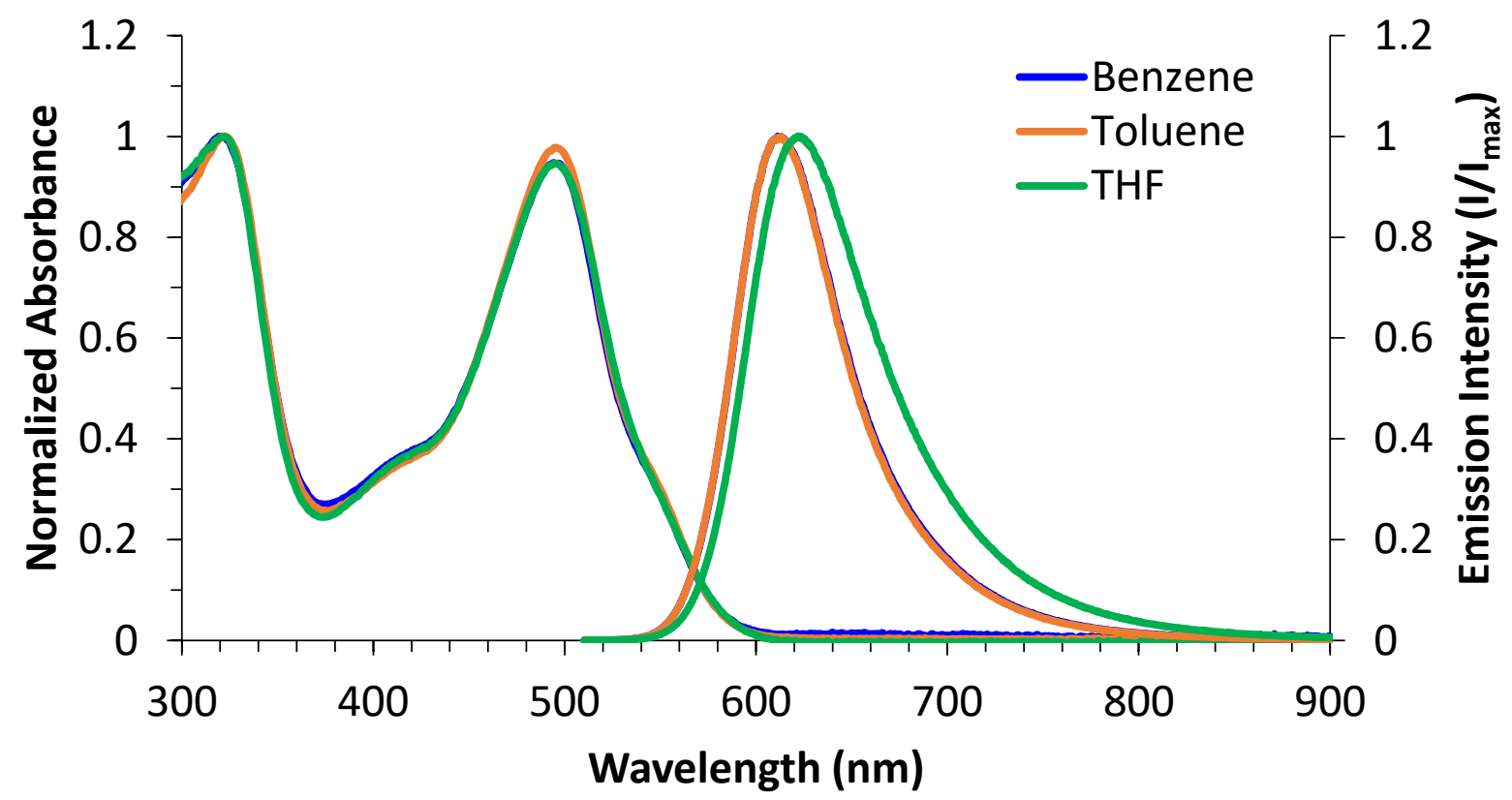

Figure S22. UV-visible absorbance and steady-state luminescence spectra of $\mathrm{W}\left(\mathrm{CNDippPh}{ }^{\mathrm{OMe} 3}\right)_{6}$ in benzene, toluene, and THF solution. 


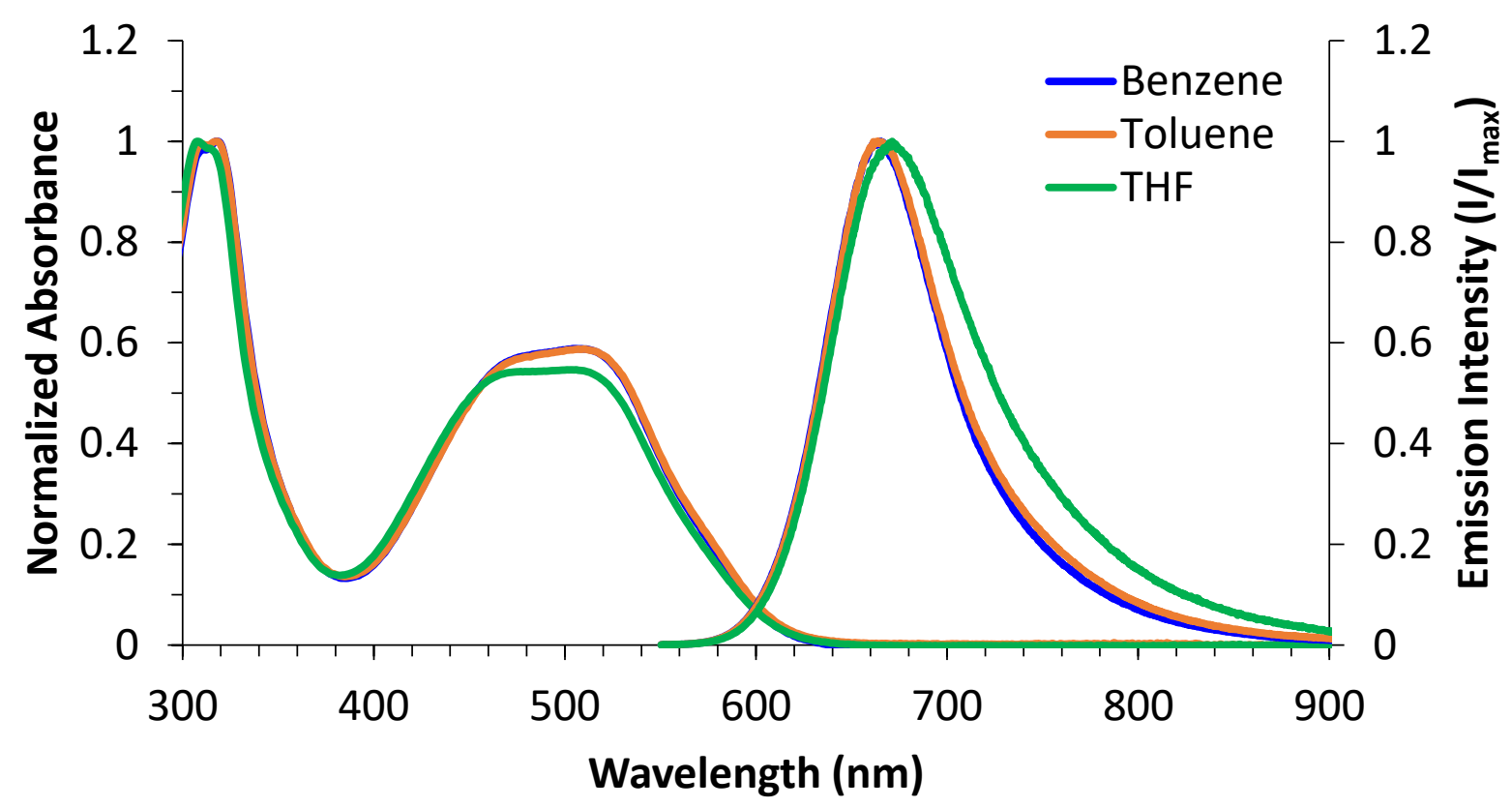

Figure S23. UV-visible absorbance and steady-state luminescence spectra of W(CN-1-(2- $\left.{ }^{i} \mathrm{Pr}\right)-$ Naph) 6 in benzene, toluene, and THF solution.

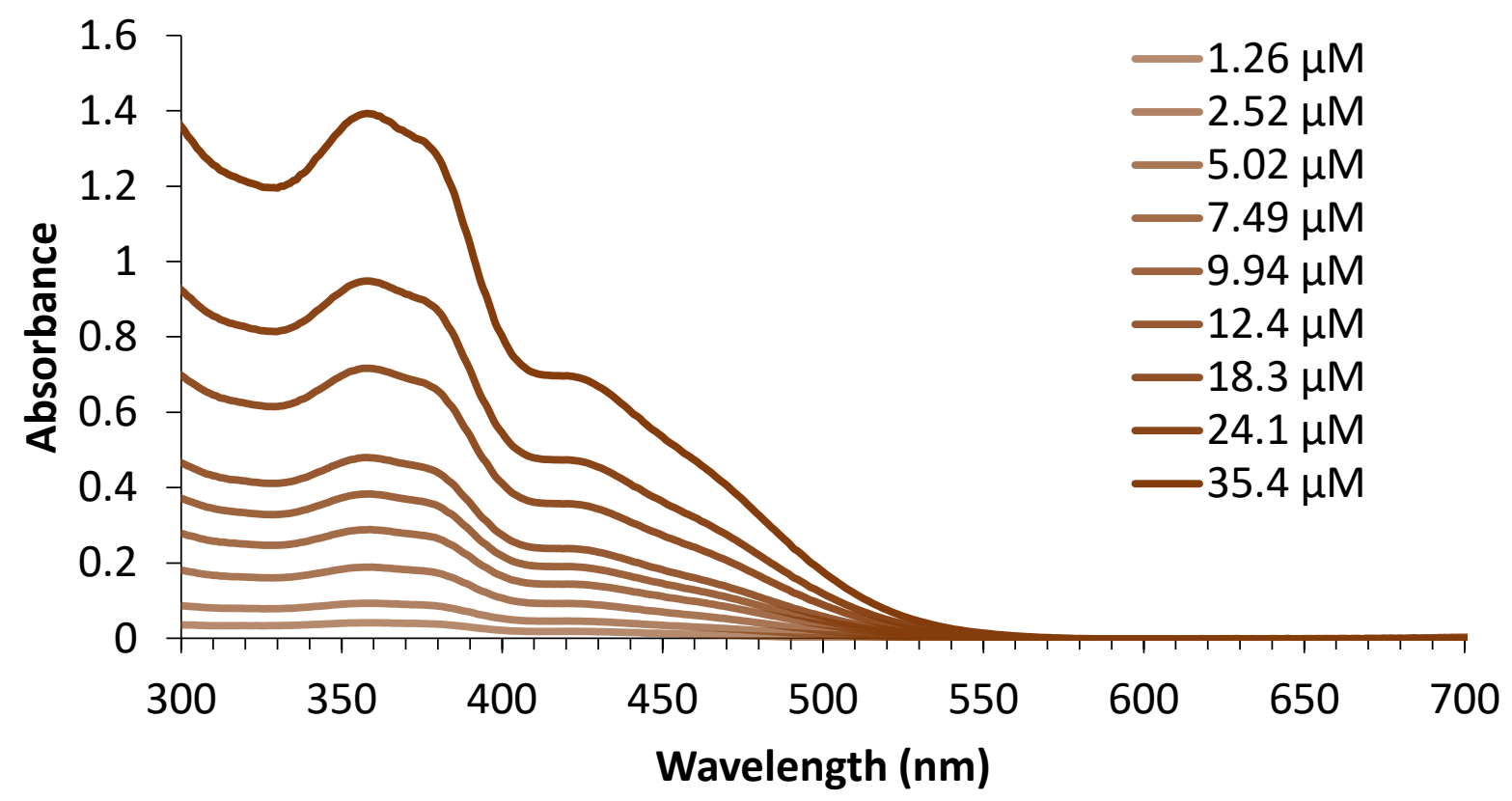

Figure S24. UV-visible absorbance spectra of $\mathrm{WI}_{2}(\mathrm{CNDipp})_{5}$ in benzene solution at different concentrations. 


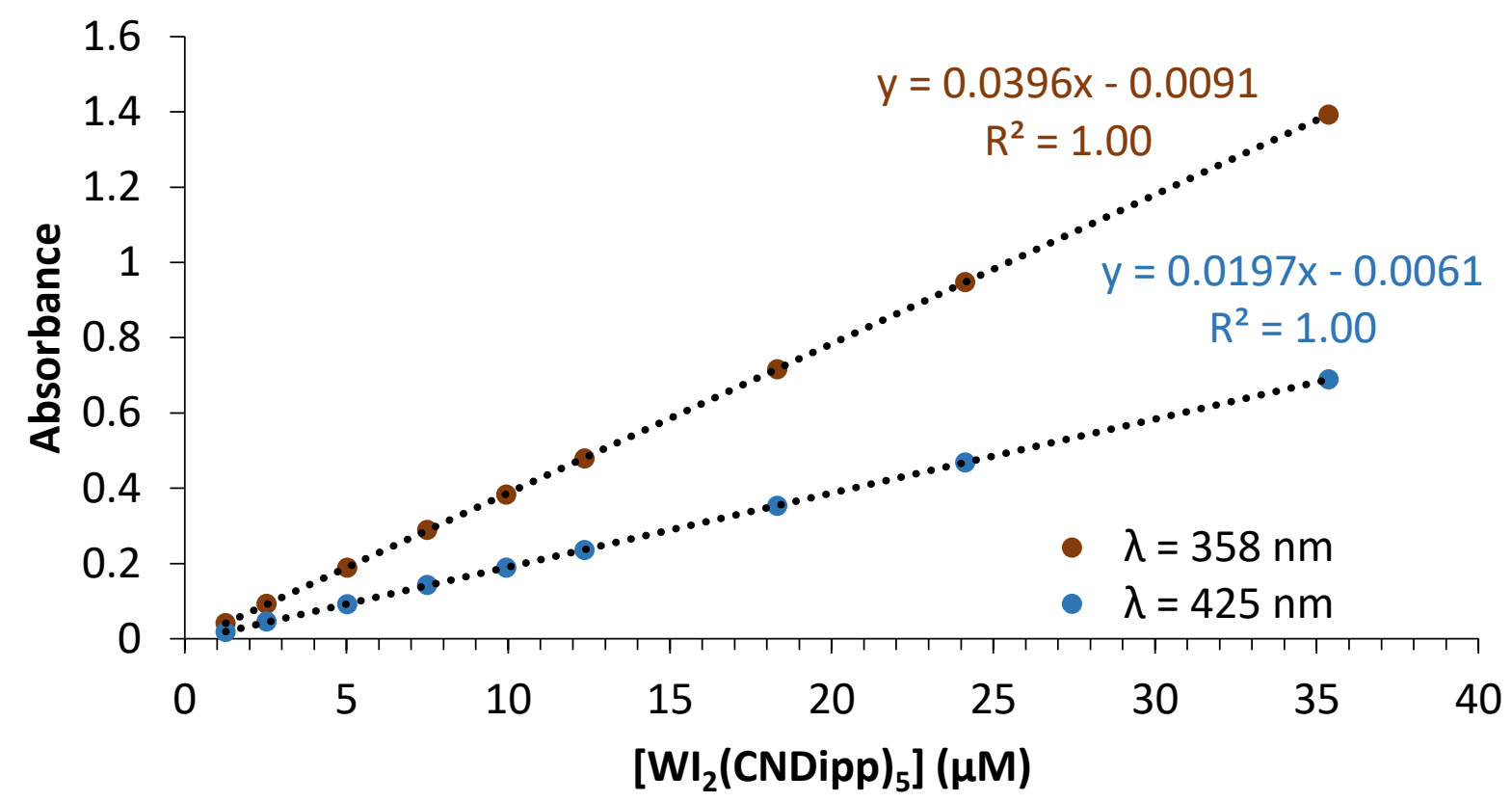

Figure S25. Plot of the absorbance at $\lambda=358$ and $425 \mathrm{~nm}$ versus the concentration of $\mathrm{WI}_{2}(\mathrm{CNDipp})_{5}$ in benzene solution. From the slope of the linear fits, $\varepsilon_{358}=4.0 \times 10^{4} \mathrm{M}^{-1} \mathrm{~cm}^{-1}$ and $\varepsilon_{425}=2.0 \times 10^{4}$ $\mathrm{M}^{-1} \mathrm{~cm}^{-1}$.

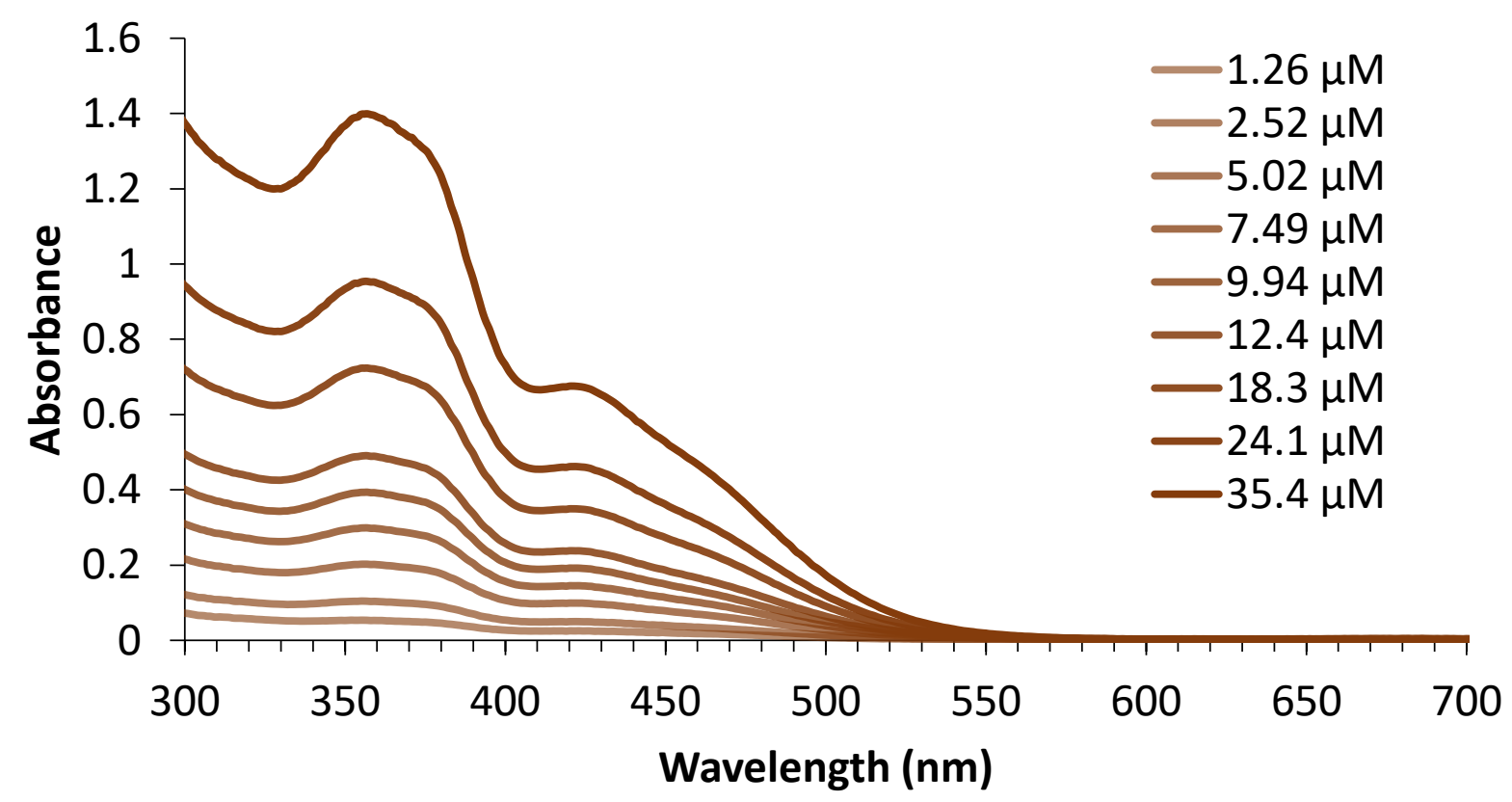

Figure S26. UV-visible absorbance spectra of $\mathrm{WI}_{2}(\mathrm{CNDipp})_{5}$ in $\mathrm{THF}$ solution at different concentrations. 


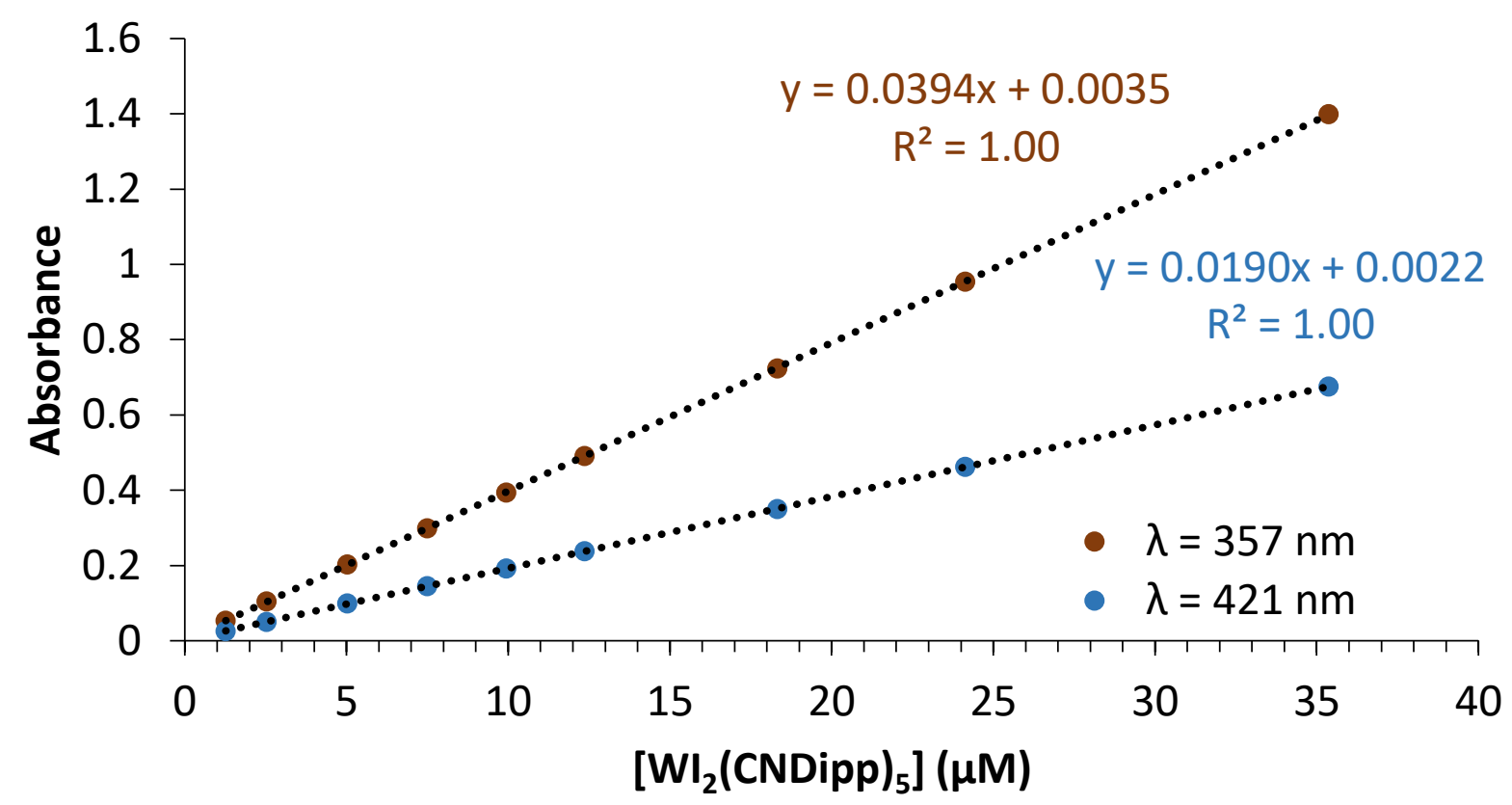

Figure S27. Plot of the absorbance at $\lambda=357$ and $421 \mathrm{~nm}$ versus the concentration of $\mathrm{WI}_{2}(\mathrm{CNDipp})_{5}$ in THF solution. From the slope of the linear fits, $\varepsilon_{357}=3.9 \times 10^{4} \mathrm{M}^{-1} \mathrm{~cm}^{-1}$ and $\varepsilon_{421}=1.9 \times 10^{4} \mathrm{M}^{-1}$ $\mathrm{cm}^{-1}$.

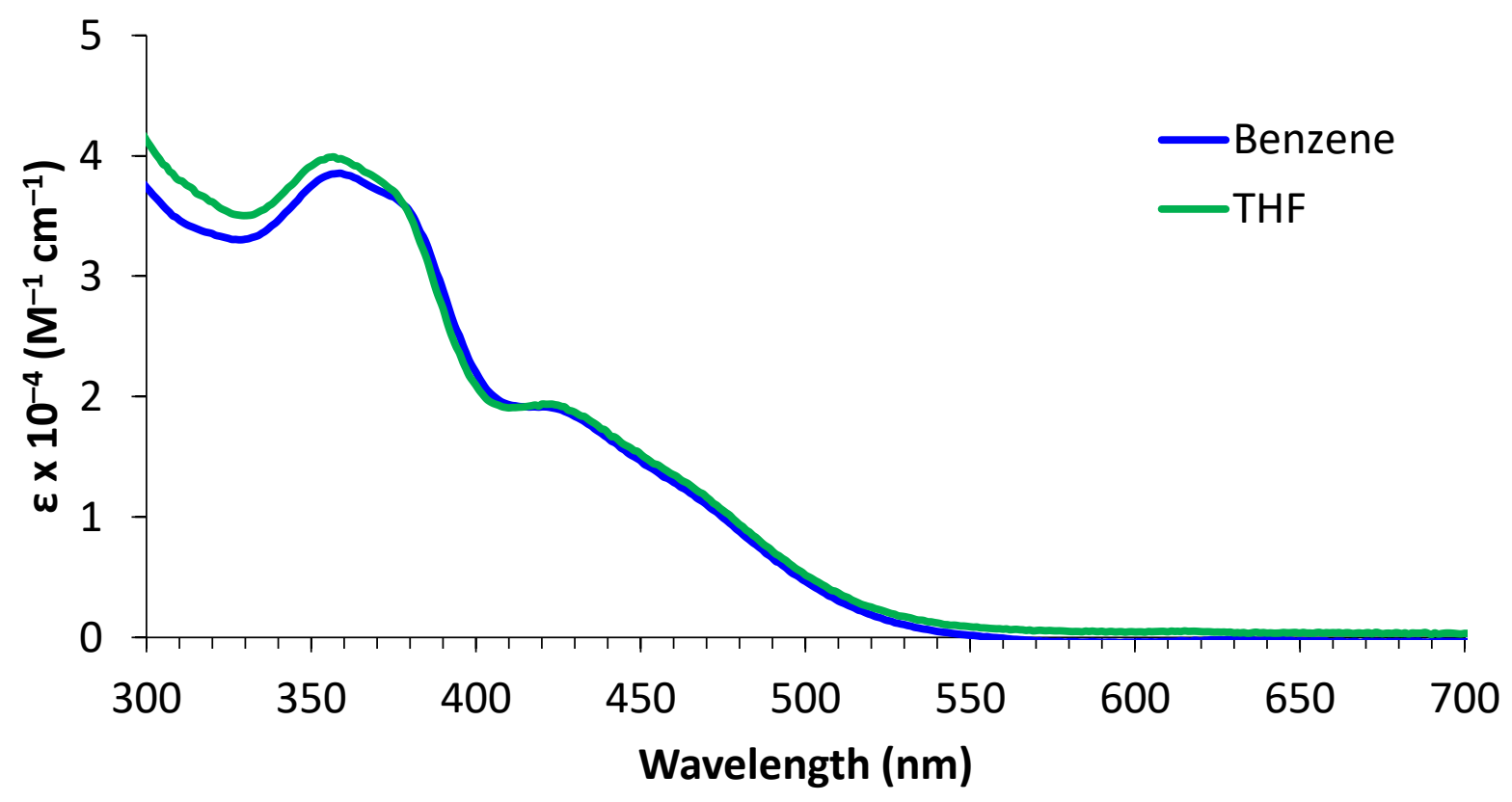

Figure S28. Overlaid UV-visible absorbance spectra of $\mathrm{WI}_{2}(\mathrm{CNDipp})_{5}$ in benzene and THF solution. 


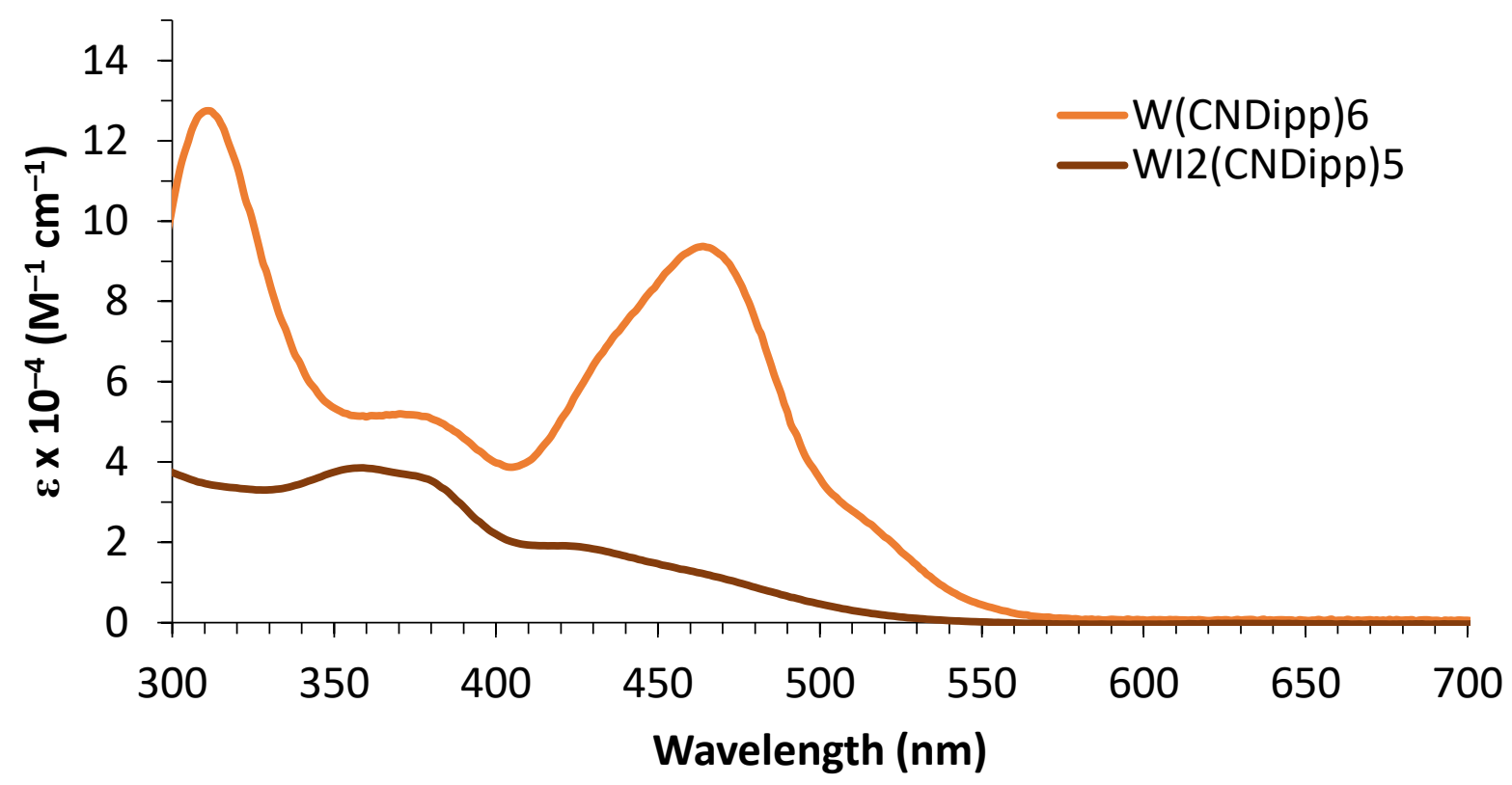

Figure S29. Overlaid UV-visible absorbance spectra of $\mathrm{WI}_{2}(\mathrm{CNDipp})_{5}$ (benzene) and $\mathrm{W}(\mathrm{CNDipp})_{6}$ (toluene).

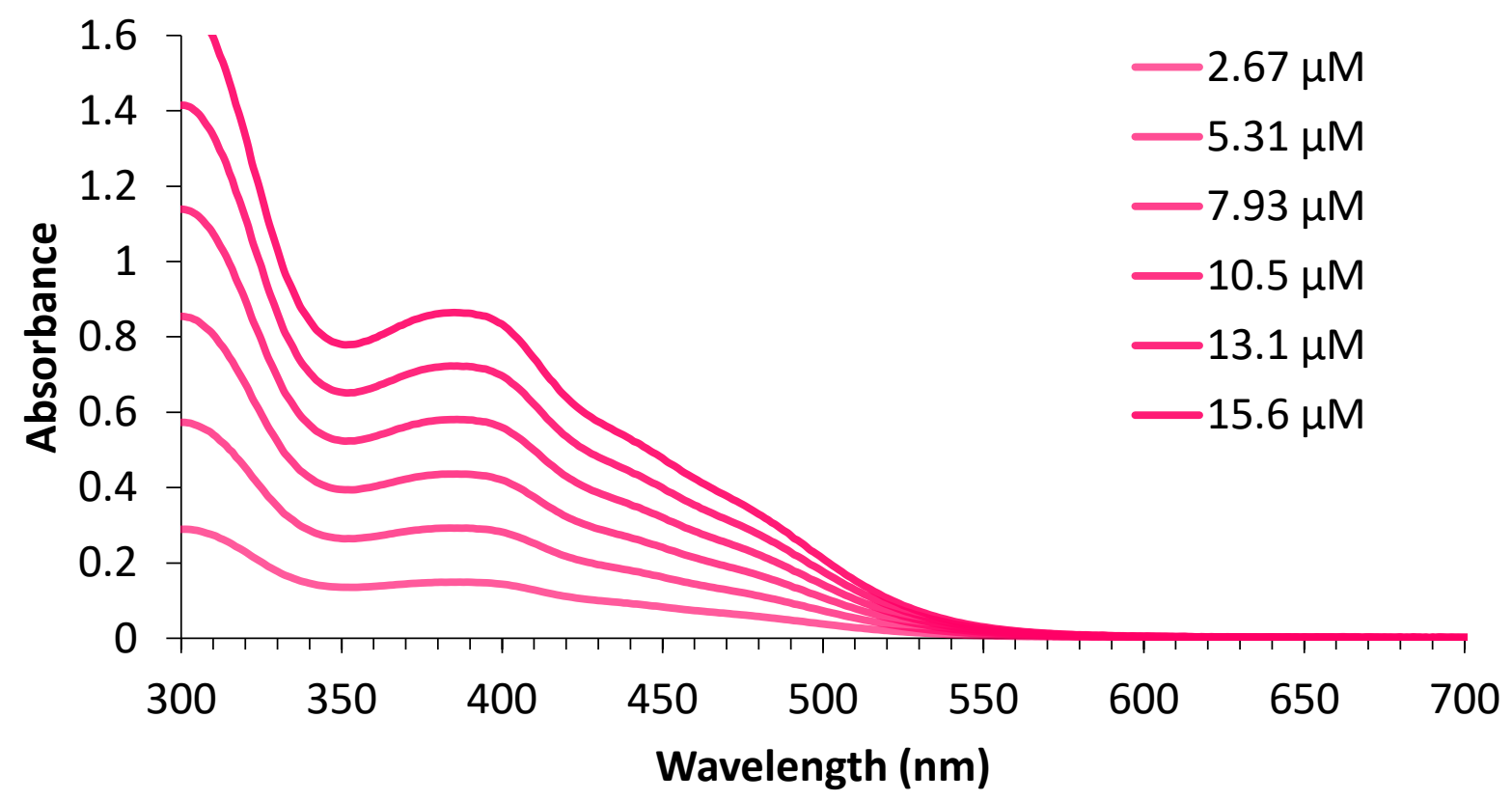

Figure S30. UV-visible absorbance spectra of $\mathrm{WI}_{2}\left(\mathrm{CNDipp}^{\mathrm{PhOMe} 3}\right)_{5}$ in benzene solution at different concentrations. 


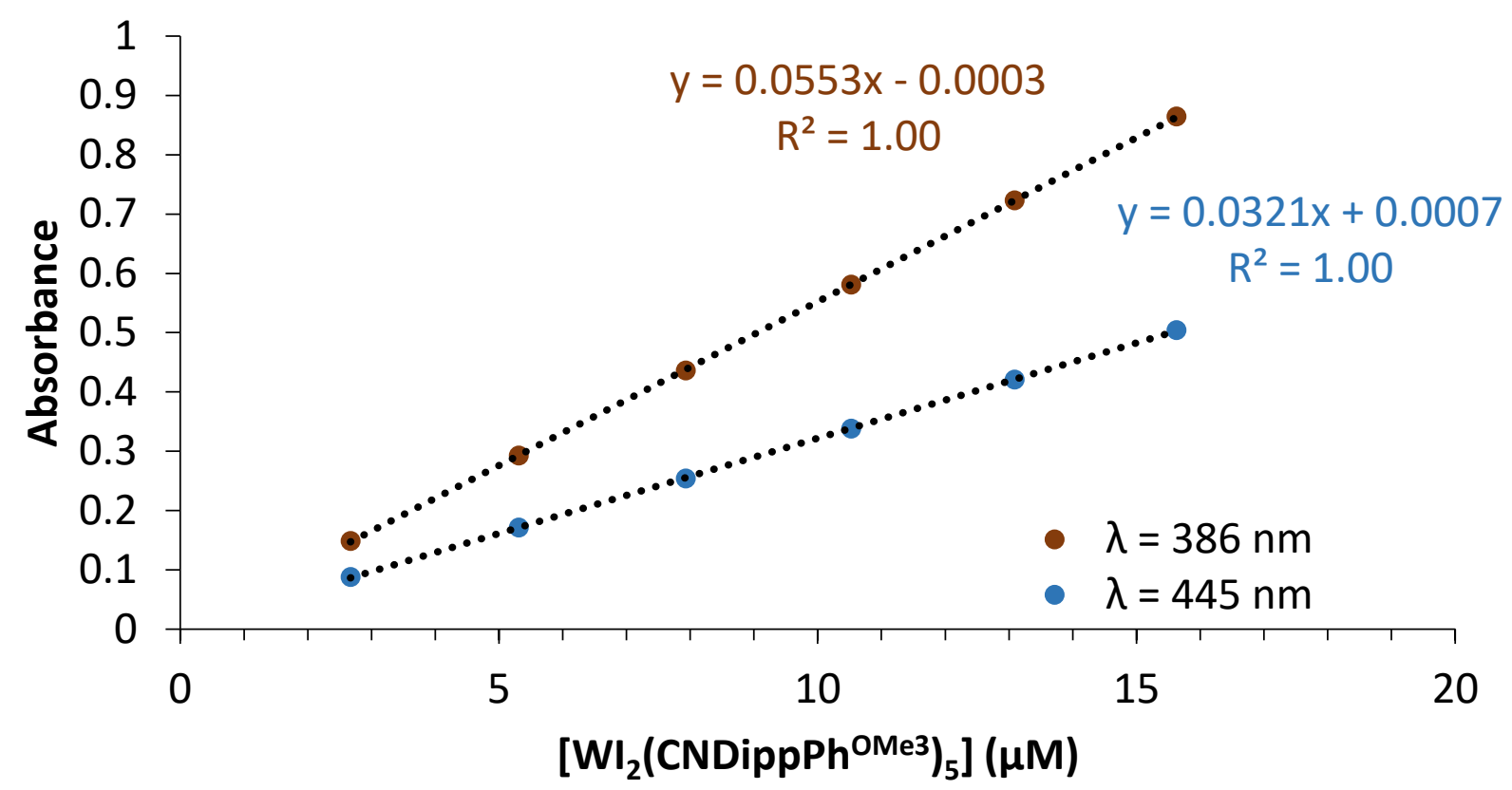

Figure S31. Plot of the absorbance at $\lambda=386$ and $425 \mathrm{~nm}$ versus the concentration of $\mathrm{WI}_{2}\left(\mathrm{CNDipp}^{\mathrm{PhOMe} 3}\right)_{5}$ in benzene solution. From the slope of the linear fits, $\varepsilon_{386}=5.5 \times 10^{4} \mathrm{M}^{-1} \mathrm{~cm}^{-}$ ${ }^{1}$ and $\varepsilon_{425}=3.2 \times 10^{4} \mathrm{M}^{-1} \mathrm{~cm}^{-1}$.

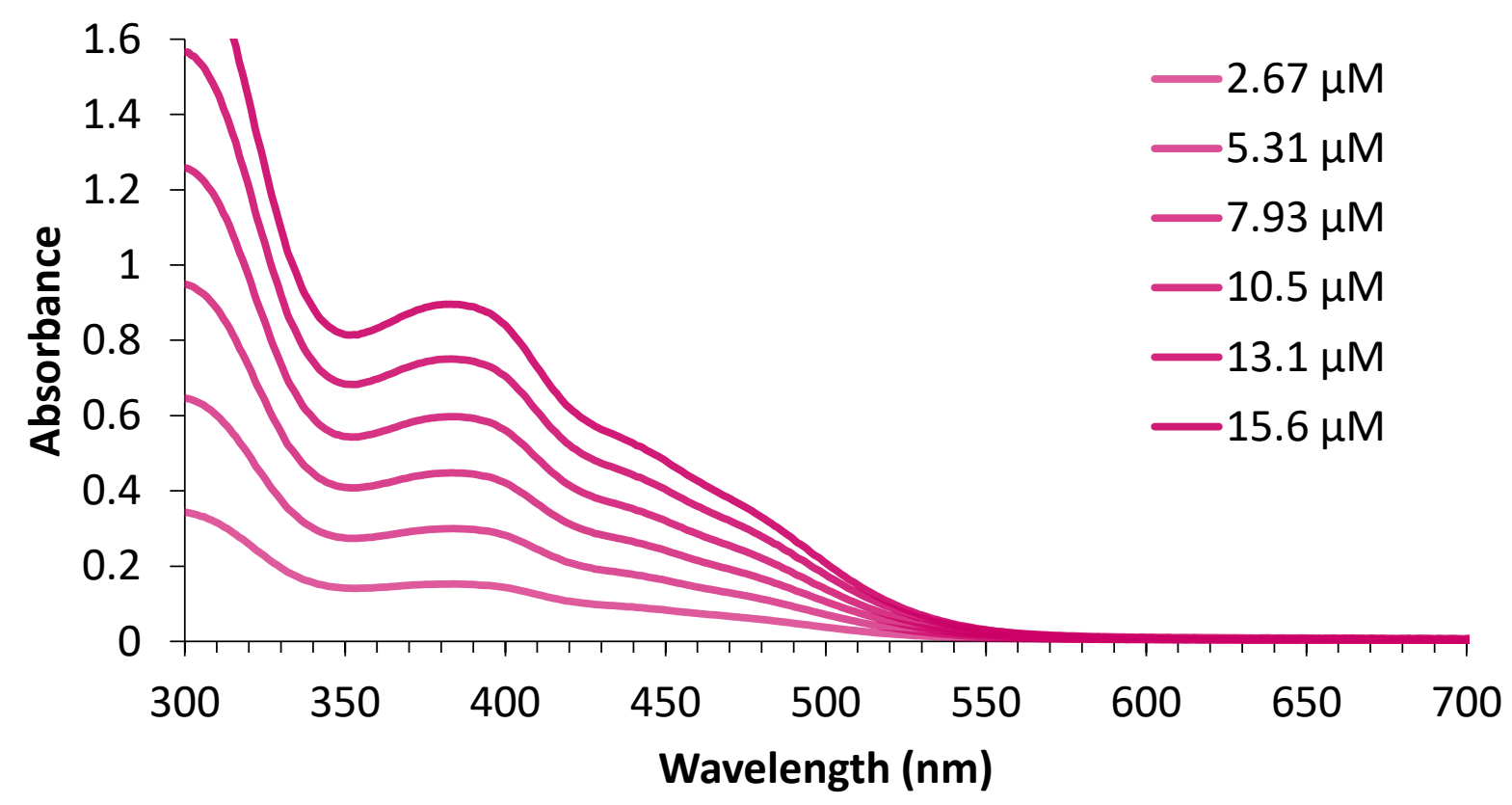

Figure S32. UV-visible absorbance spectra of $\mathrm{WI}_{2}\left(\mathrm{CNDipp}^{\mathrm{PhOMe}}\right)_{5}$ in THF solution at different concentrations. 


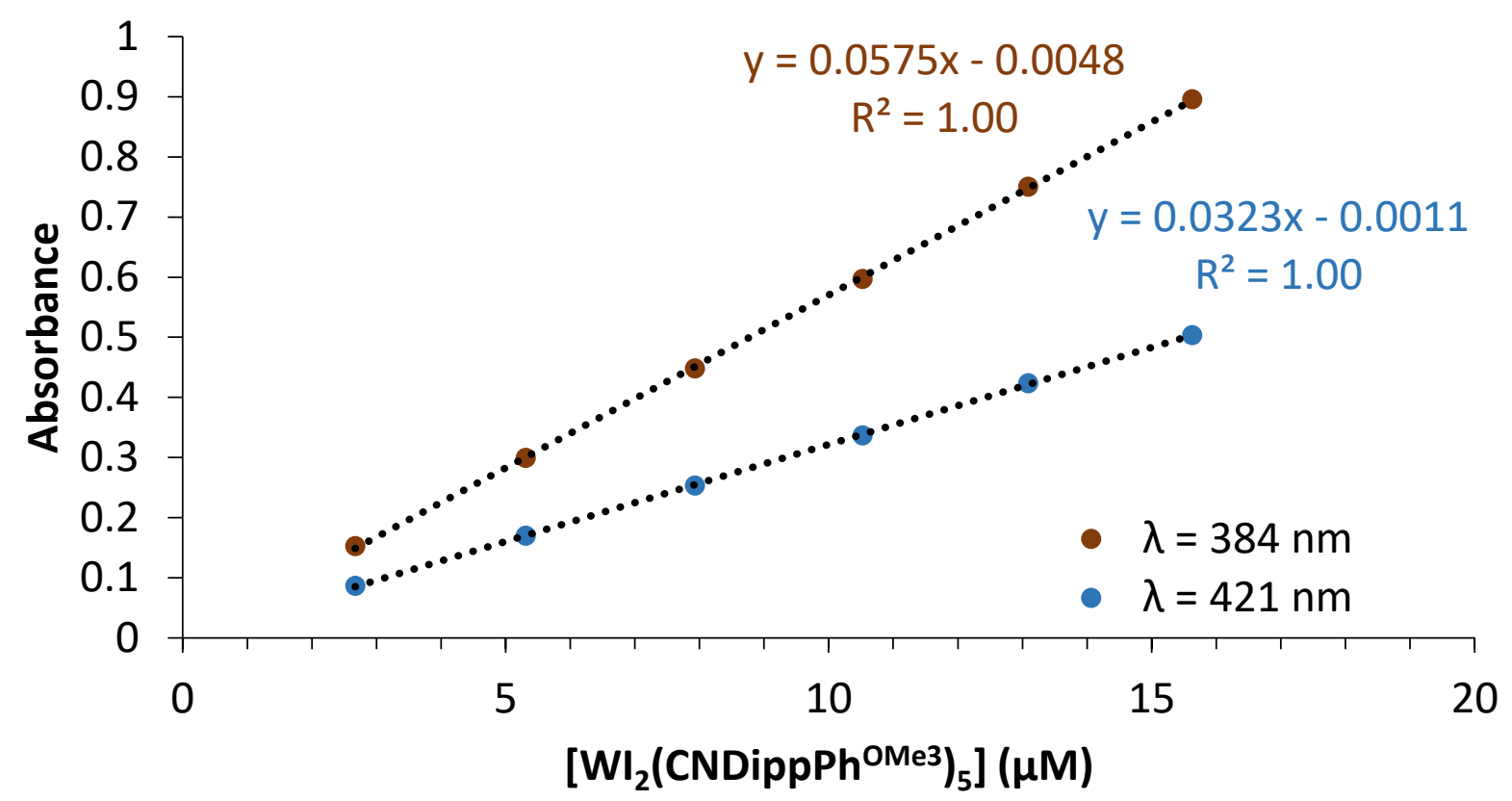

Figure S33. Plot of the absorbance at $\lambda=384$ and $421 \mathrm{~nm}$ versus the concentration of $\mathrm{WI}_{2}\left(\mathrm{CNDipp}^{\mathrm{PhOMe} 3}\right)_{5}$ in THF solution. From the slope of the linear fits, $\varepsilon_{384}=5.8 \times 10^{4} \mathrm{M}^{-1} \mathrm{~cm}^{-1}$ and $\varepsilon_{421}=3.2 \times 10^{4} \mathrm{M}^{-1} \mathrm{~cm}^{-1}$.

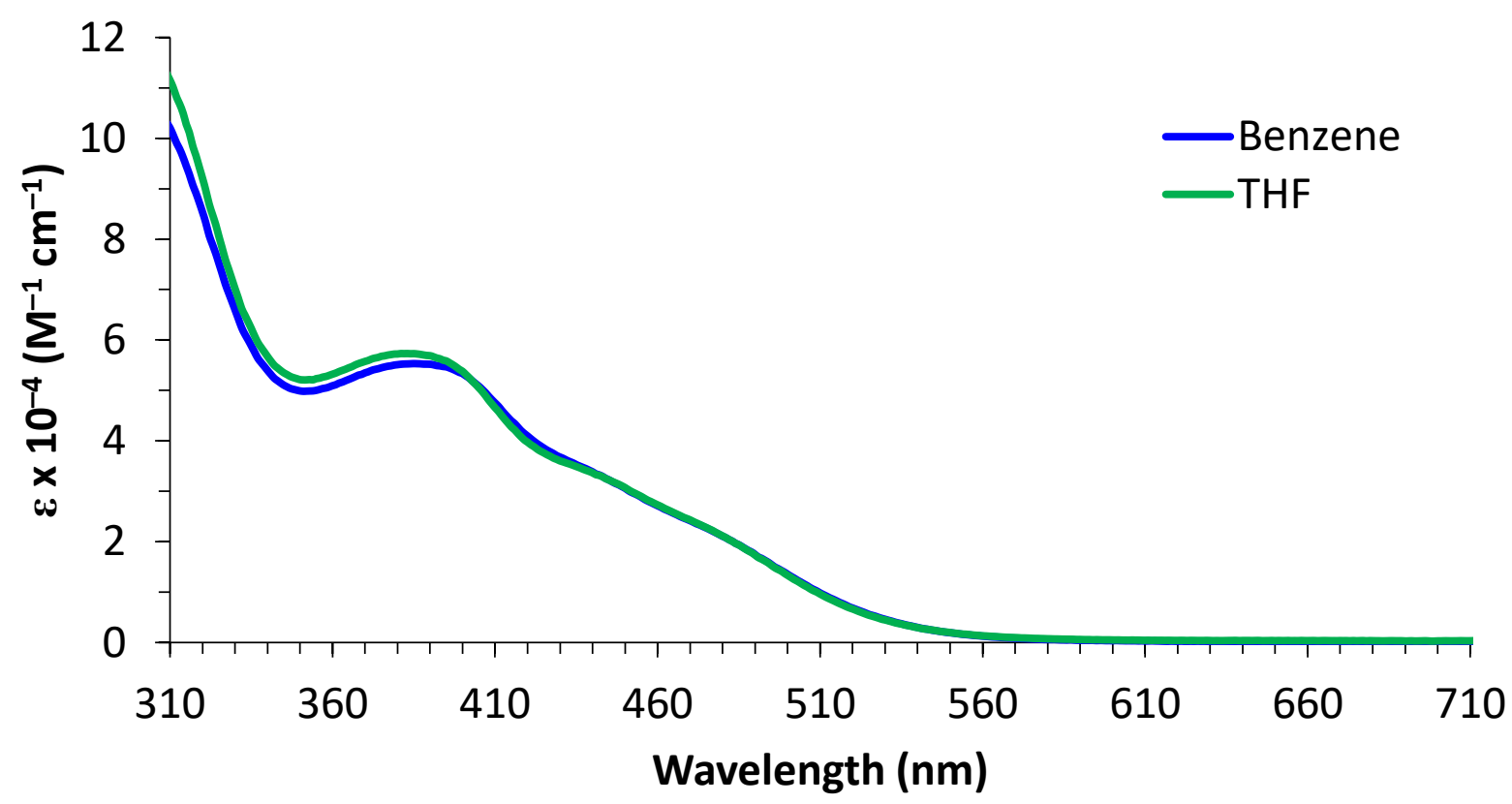

Figure S34. Overlaid UV-visible absorbance spectra of $\mathrm{WI}_{2}\left(\mathrm{CNDipp}^{\mathrm{PhOMe} 3}\right)_{5}$ in benzene and THF solution. 


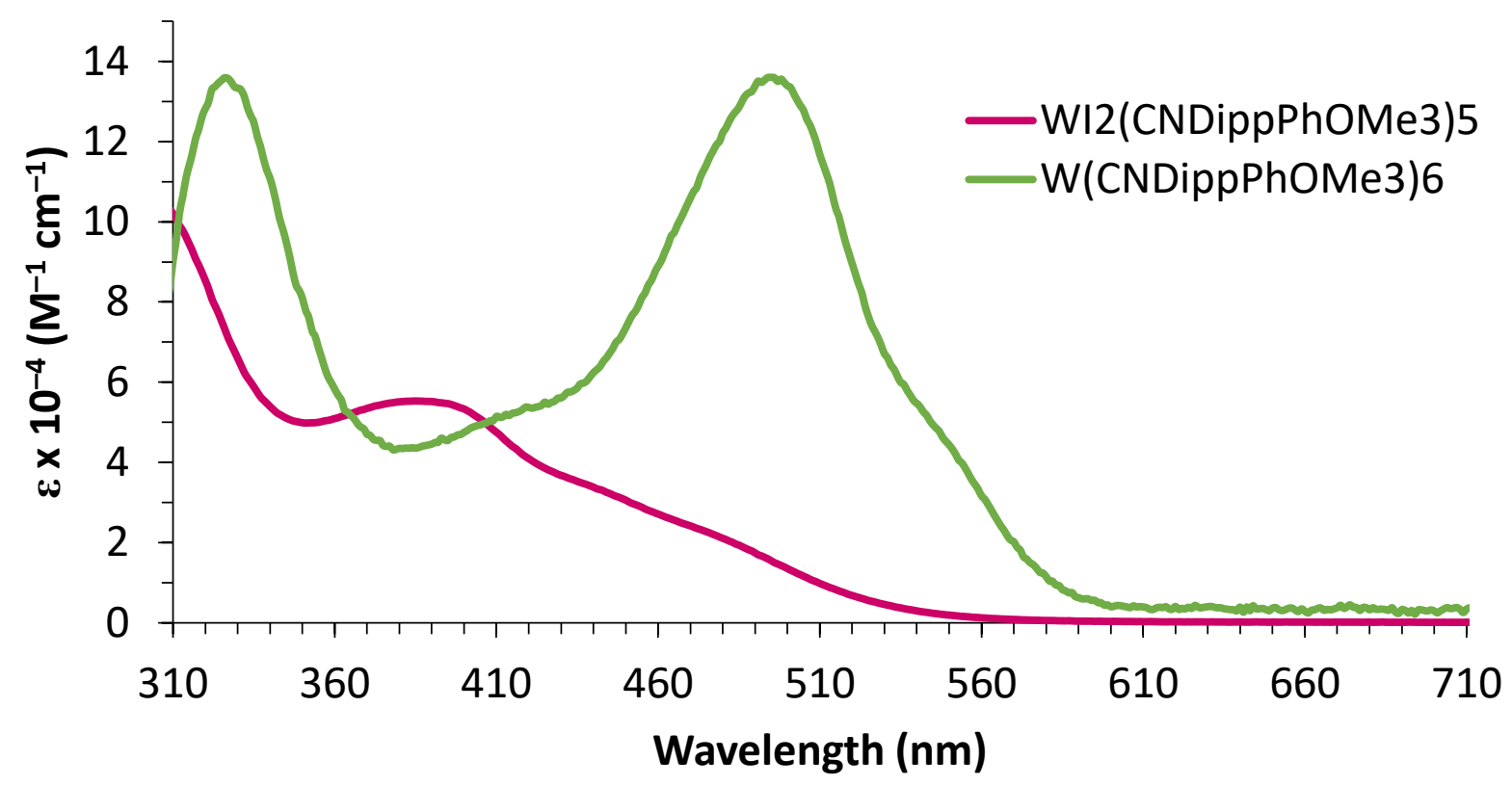

Figure S35. Overlaid UV-visible absorbance spectra of $\mathrm{WI}_{2}\left(\mathrm{CNDipp}^{\mathrm{PhOMe} 3}\right)_{5}$ (benzene) and $\mathrm{W}\left(\mathrm{CNDipp}^{\mathrm{PhOMe} 3}\right)_{6}$ (toluene).

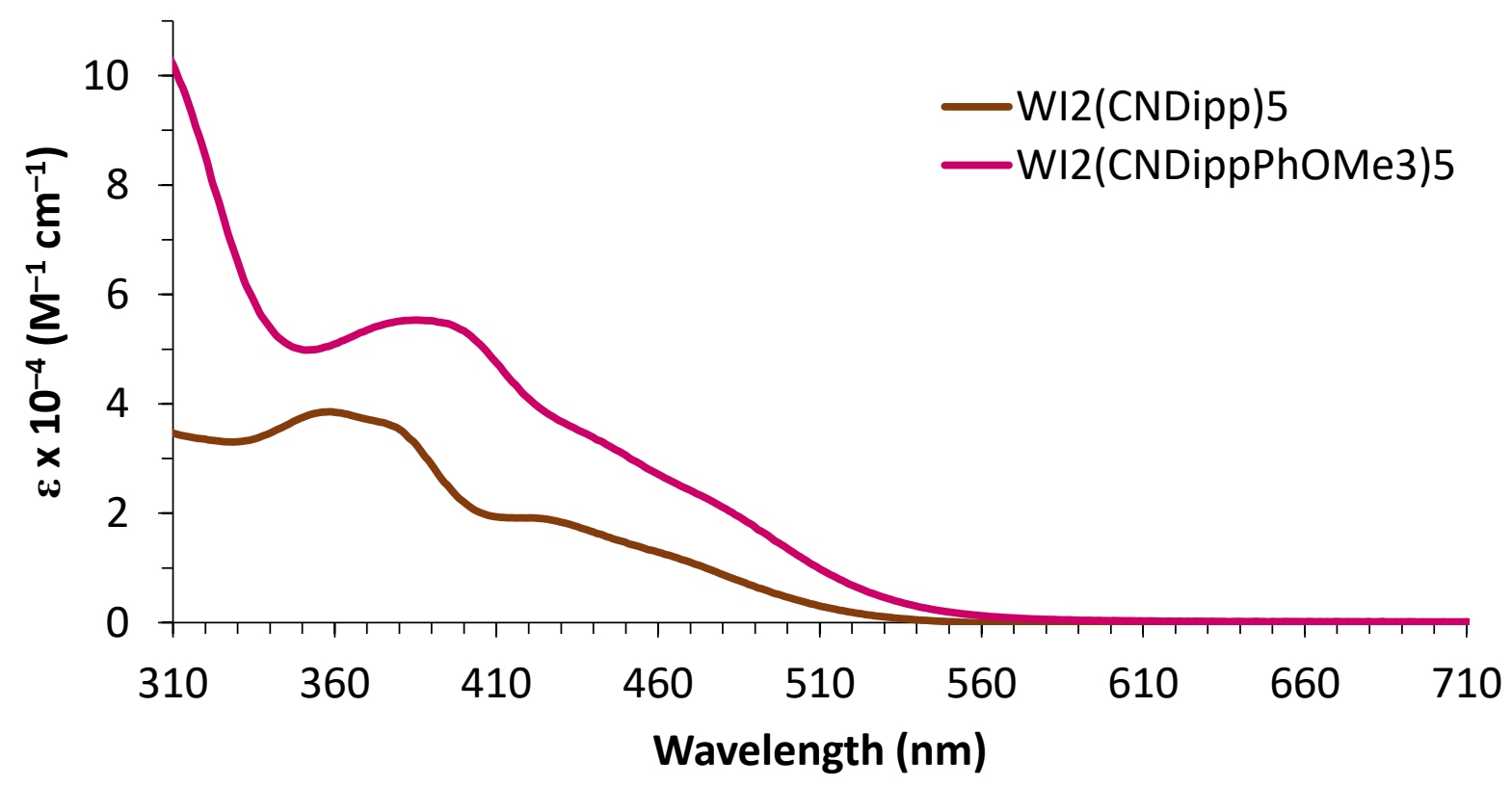

Figure S36. Overlaid UV-visible absorbance spectra of $\mathrm{WI}_{2}(\mathrm{CNDipp})_{5}$ and $\mathrm{WI}_{2}\left(\mathrm{CNDipp}^{\mathrm{PhOMe} 3}\right)_{5}$ in benzene solution. 


\section{$\underline{\text { Transient Absorption Spectroscopy }}$}

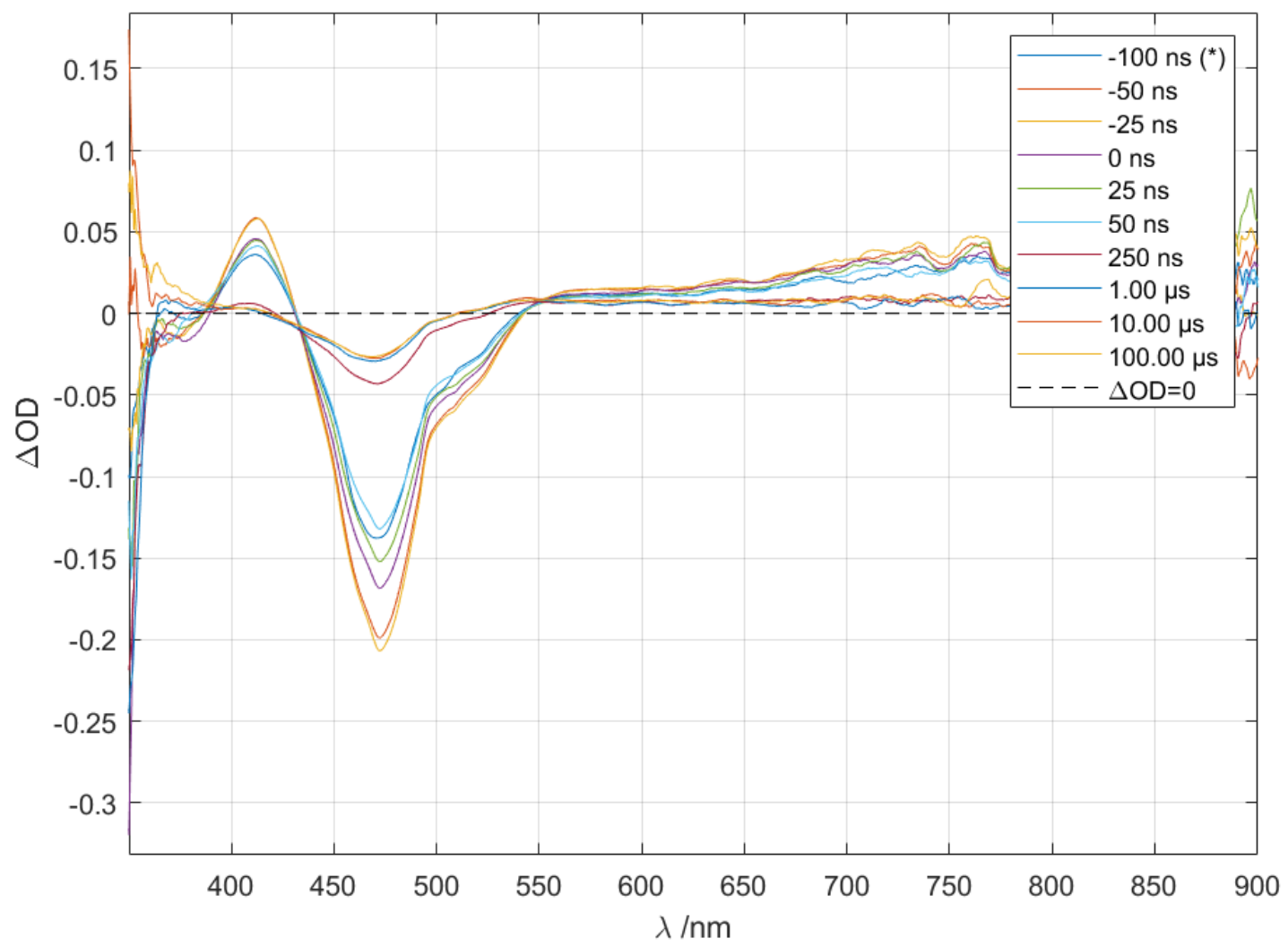

Figure S37. Transient absorption spectra of $\mathrm{W}(\mathrm{CNDipp})_{6}$ (ca. $\left.6.3 \mu \mathrm{M}\right)$ in benzene solution at specified delay times following $532 \mathrm{~nm}$ excitation. The spectra are reminiscent of those for the related complexes $\mathrm{Mo}\left(\mathrm{CN}^{\mathrm{R}} \mathrm{Ar}_{3} \mathrm{NC}\right)_{3}\left(\mathrm{R}=\mathrm{Me},{ }^{t} \mathrm{Bu}\right)^{4}$ and $\left[\mathrm{Ru}(\mathrm{bpy})_{3}\right]^{2+} \cdot{ }^{10} \mathrm{MLCT}$ bleach recovery $\left(\lambda_{\text {obs }}\right.$ $=450 \mathrm{~nm}$ ) yields an excited-state lifetime of $110 \mathrm{~ns}$, consistent with that obtained from time-resolved luminescence measurements (Table S2), and confirming *W(CNDipp)6 generation in benzene solution. 


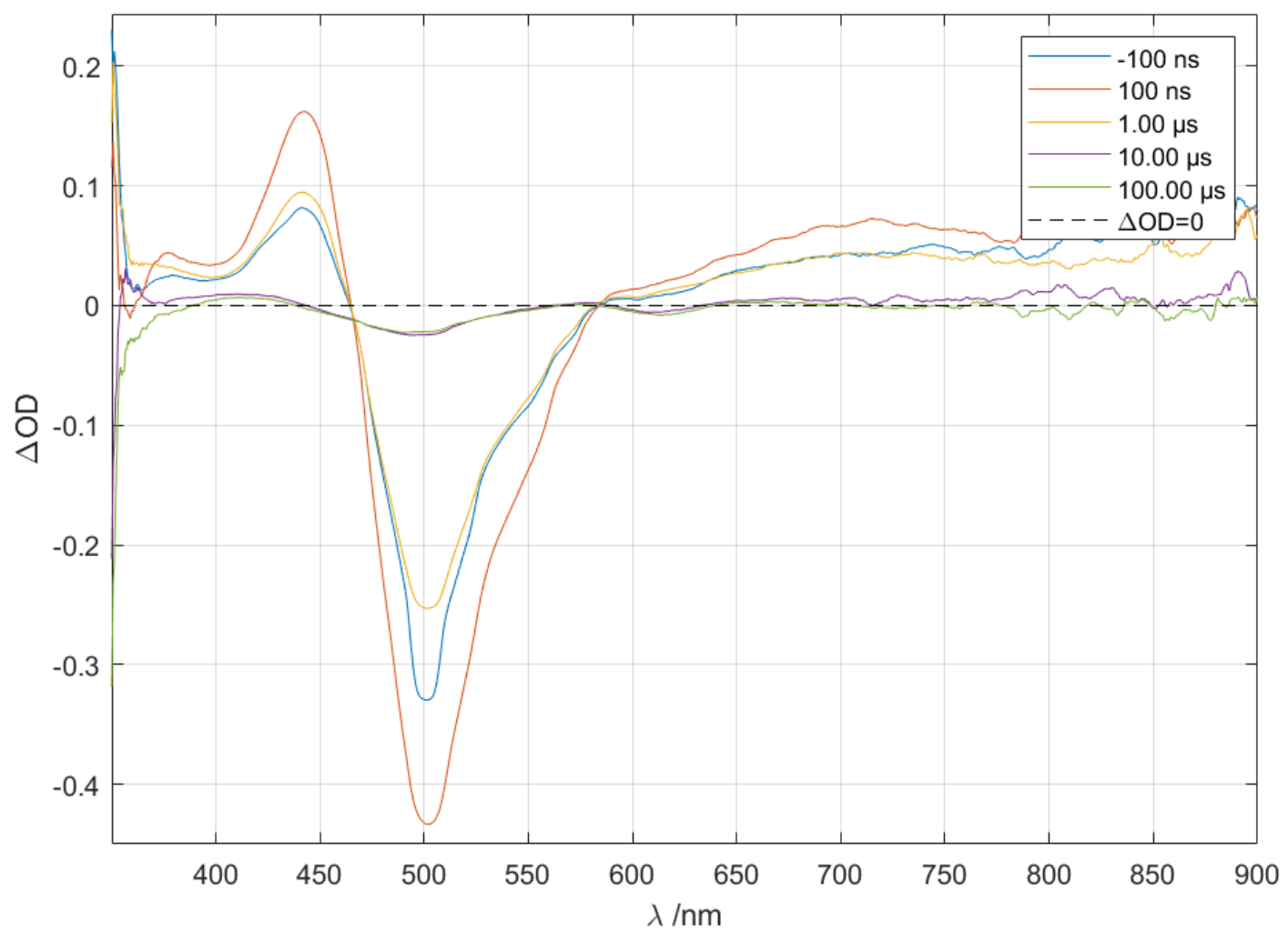

Figure S38. Transient absorption spectra of $\mathrm{W}\left(\mathrm{CNDippPh}^{\mathrm{OMe} 3}\right)_{6}(\mathrm{ca} .5 .7 \mu \mathrm{M})$ in benzene solution at specified delay times following $532 \mathrm{~nm}$ excitation. The spectra are reminiscent of those for the related complexes $\mathrm{Mo}\left(\mathrm{CN}^{\mathrm{R}} \mathrm{Ar}_{3} \mathrm{NC}\right)_{3}\left(\mathrm{R}=\mathrm{Me},{ }^{t} \mathrm{Bu}\right)^{4}$ and $\left[\mathrm{Ru}(\mathrm{bpy})_{3}\right]^{2+} \cdot{ }^{10} \mathrm{MLCT}$ bleach recovery $\left(\lambda_{\text {obs }}\right.$ $=475 \mathrm{~nm}$ ) yields an excited-state lifetime of $1.64 \mu \mathrm{s}$, consistent with that obtained from timeresolved luminescence measurements (Table $\mathrm{S} 4)$, and confirming $* \mathrm{~W}\left(\mathrm{CNDippPh}{ }^{\mathrm{OMe} 3}\right)_{6}$ generation in benzene solution. 
Two-Photon Luminescence Spectroscopy

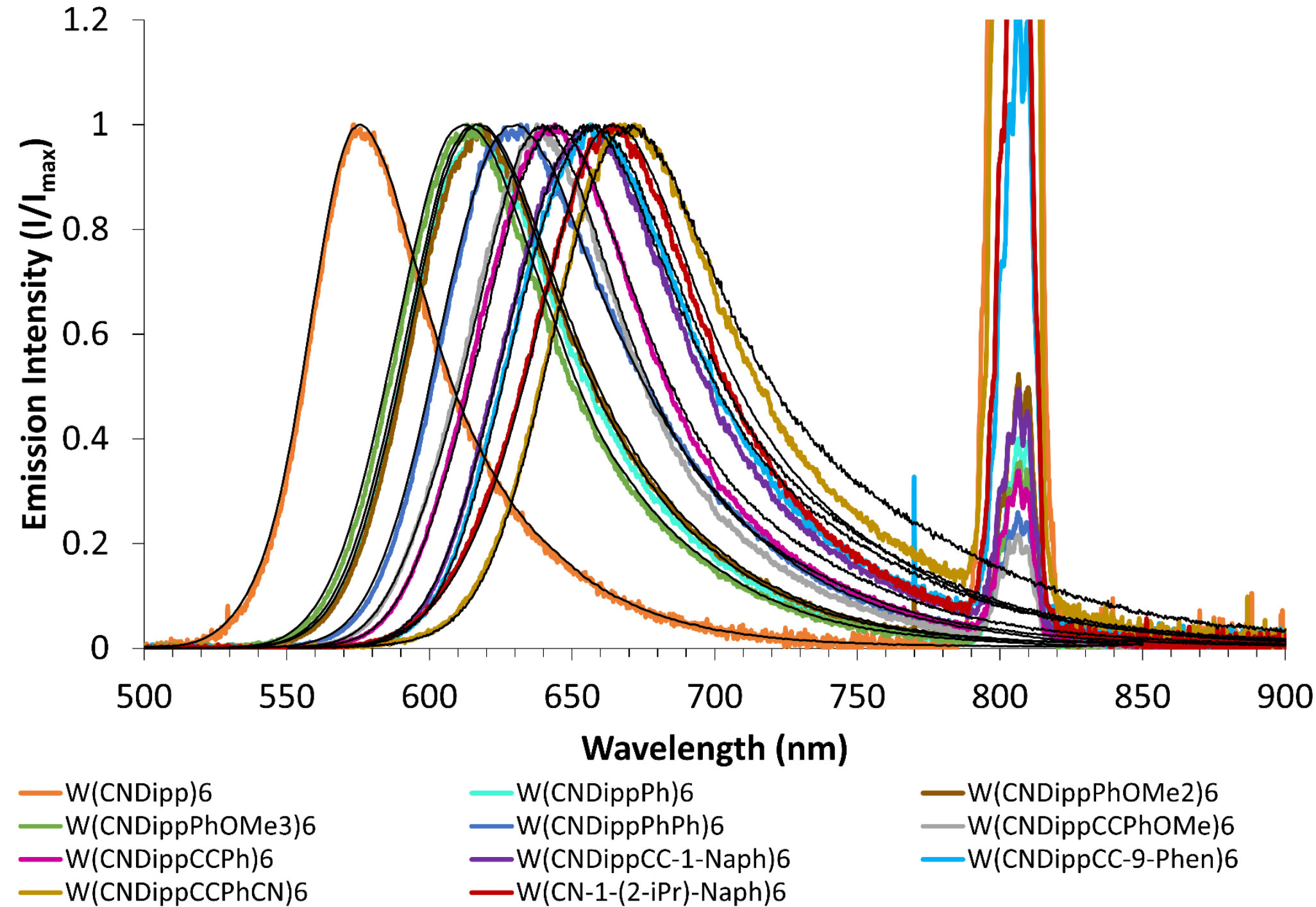

Figure S39. Luminescence spectra collected upon two-photon $(810 \mathrm{~nm})$ excitation of W(CNAr) 6 in room temperature toluene solution. The signal at $810 \mathrm{~nm}$ corresponds to scattered excitation light from the femtosecond-pulsed Ti:Sapphire laser. The corresponding emission spectra obtained from one-photon excitation are underlaid in black. 
Table S1. Samples and results of two-photon luminescence experiments.

\begin{tabular}{|c|c|c|c|c|c|c|c|c|c|c|c|c|}
\hline Dye & Solvent & $\boldsymbol{\varepsilon}_{\lambda \max }{ }^{a}\left\{\lambda_{\max }\right\}^{b}$ & $\mathbf{A}_{\lambda \max }$ & {$[\mathrm{Dy} e]^{c}$} & $\langle\mathbf{F}\rangle$ & $\begin{array}{c}\text { Integration } \\
\text { Time }^{d}\end{array}$ & $\phi P L$ & $\eta$ & $\begin{array}{l}\text { Laser } \\
\text { Power }\end{array}$ & $\delta_{810}^{f}$ & $\begin{array}{l}\text { Avg. } \\
\delta_{810}^{f}\end{array}$ & $\begin{array}{c}\text { Std. } \\
\text { Deviation }\end{array}$ \\
\hline Fluorescein & $\mathrm{H}_{2} \mathrm{O}(\mathrm{pH} 11)$ & $8.7 \times 10^{3}\{322\}^{g}$ & 0.637 & 73.2 & ---- & ----- & $0.97^{h}$ & 1.334 & ----- & 21 & ----- & ----- \\
\hline $\mathrm{W}(\mathrm{CNDipp})_{6}{ }^{i}$ & Toluene & $9.5 \times 10^{4}\{465\}$ & $\begin{array}{l}2.675 \\
2.675 \\
2.322 \\
3.150\end{array}$ & $\begin{array}{l}28.2 \\
28.2 \\
24.4 \\
33.2\end{array}$ & $\begin{array}{l}69478 \\
76507 \\
19011 \\
46148\end{array}$ & $\begin{array}{l}3500 \\
3500 \\
6000 \\
2000\end{array}$ & 0.03 & 1.496 & $\begin{array}{l}72 \\
72 \\
32 \\
89\end{array}$ & $\begin{array}{l}221 \\
244 \\
212 \\
227\end{array}$ & 230 & 14 \\
\hline $\mathrm{W}(\mathrm{CNDippPh})_{6}{ }^{i}$ & Toluene & $1.3 \times 10^{5}\{495\}$ & $\begin{array}{l}1.356 \\
0.895 \\
1.128\end{array}$ & $\begin{array}{l}10.4 \\
6.88 \\
8.67\end{array}$ & $\begin{array}{l}138303 \\
139976 \\
170055\end{array}$ & $\begin{array}{c}200 \\
3000 \\
500\end{array}$ & 0.41 & 1.496 & $\begin{array}{l}82 \\
33 \\
83\end{array}$ & $\begin{array}{c}1175 \\
763 \\
1077\end{array}$ & 1000 & 220 \\
\hline $\mathrm{W}\left(\mathrm{CNDippPh}{ }^{\mathrm{OMe} 2}\right)_{6}^{i}$ & Toluene & $1.3 \times 10^{5}\{495\}$ & $\begin{array}{l}0.955 \\
1.223 \\
1.639\end{array}$ & $\begin{array}{l}7.35 \\
9.41 \\
12.6\end{array}$ & $\begin{array}{l}150834 \\
134451 \\
174464\end{array}$ & $\begin{array}{c}300 \\
2000 \\
500\end{array}$ & 0.42 & 1.496 & $\begin{array}{l}81 \\
30 \\
68\end{array}$ & $\begin{array}{c}1213 \\
950 \\
1105\end{array}$ & 1100 & 130 \\
\hline $\mathrm{W}\left(\mathrm{CNDippPh}{ }^{\mathrm{OMe} 3}\right)_{6}{ }^{i}$ & Toluene & $1.3 \times 10^{5}\{495\}$ & $\begin{array}{l}1.663 \\
1.056 \\
1.376\end{array}$ & $\begin{array}{l}12.8 \\
8.12 \\
10.6\end{array}$ & $\begin{array}{l}100922 \\
139069 \\
168019\end{array}$ & $\begin{array}{c}150 \\
2000 \\
500\end{array}$ & 0.41 & 1.496 & $\begin{array}{l}78 \\
35 \\
77\end{array}$ & $\begin{array}{c}1030 \\
856 \\
1013\end{array}$ & 970 & 96 \\
\hline $\mathrm{W}\left(\mathrm{CNDippPh} \mathrm{Ph}^{\mathrm{Ph}}\right)_{6}{ }^{i}$ & Toluene & $1.6 \times 10^{5}\{506\}$ & $\begin{array}{l}1.693 \\
1.041 \\
1.728\end{array}$ & $\begin{array}{l}10.6 \\
6.51 \\
10.8\end{array}$ & $\begin{array}{l}178512 \\
135433 \\
260028\end{array}$ & $\begin{array}{c}150 \\
1000 \\
400\end{array}$ & 0.44 & 1.496 & $\begin{array}{l}78 \\
39 \\
72\end{array}$ & $\begin{array}{l}2052 \\
1563 \\
2046\end{array}$ & 1900 & 280 \\
\hline $\mathrm{W}\left(\mathrm{CNDipp}{ }^{\mathrm{CC}} \mathrm{Ph}^{\mathrm{OMe}}\right)_{6}{ }^{j}$ & Toluene & $1.6 \times 10^{5}\{518\}$ & $\begin{array}{l}1.660 \\
0.751 \\
1.641\end{array}$ & $\begin{array}{l}10.4 \\
4.69 \\
10.3\end{array}$ & $\begin{array}{l}192724 \\
116546 \\
215940\end{array}$ & $\begin{array}{c}150 \\
1000 \\
400\end{array}$ & 0.78 & 1.496 & $\begin{array}{l}81 \\
39 \\
76\end{array}$ & $\begin{array}{l}1182 \\
1052 \\
1088\end{array}$ & 1100 & 70 \\
\hline $\mathrm{W}\left(\mathrm{CNDipp}{ }^{\mathrm{CC}} \mathrm{Ph}\right)_{6}{ }^{j}$ & Toluene & $1.1 \times 10^{5}\{521\}$ & $\begin{array}{l}1.450 \\
0.860 \\
1.106\end{array}$ & $\begin{array}{l}13.2 \\
7.82 \\
10.1\end{array}$ & $\begin{array}{c}203036 \\
90658 \\
225996\end{array}$ & $\begin{array}{c}250 \\
1000 \\
800\end{array}$ & 0.37 & 1.496 & $\begin{array}{l}79 \\
40 \\
79\end{array}$ & $\begin{array}{c}1303 \\
984 \\
1132\end{array}$ & 1100 & 160 \\
\hline $\mathrm{W}\left(\mathrm{CNDipp}^{\mathrm{CC}}-1-\mathrm{Naph}\right)_{6}{ }^{j}$ & Toluene & $1.4 \times 10^{5}\{531\}$ & $\begin{array}{l}1.813 \\
0.698 \\
1.261\end{array}$ & $\begin{array}{l}13.0 \\
4.98 \\
9.01\end{array}$ & $\begin{array}{c}166982 \\
99778 \\
219307\end{array}$ & $\begin{array}{c}250 \\
2000 \\
1300\end{array}$ & 0.30 & 1.496 & $\begin{array}{l}81 \\
40 \\
79\end{array}$ & $\begin{array}{c}1280 \\
1048 \\
931\end{array}$ & 1100 & 180 \\
\hline 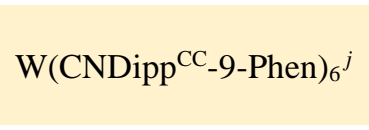 & Toluene & $1.4 \times 10^{5}\{533\}$ & $\begin{array}{l}0.671 \\
0.638 \\
0.436\end{array}$ & $\begin{array}{l}4.79 \\
4.56 \\
3.11\end{array}$ & $\begin{array}{c}177635 \\
82691 \\
220216\end{array}$ & $\begin{array}{c}800 \\
2000 \\
5000\end{array}$ & 0.26 & 1.496 & $\begin{array}{l}83 \\
40 \\
73\end{array}$ & $\begin{array}{c}1264 \\
1095 \\
951\end{array}$ & 1100 & 160 \\
\hline $\mathrm{W}\left(\mathrm{CNDipp}^{\mathrm{CC}} \mathrm{Ph}^{\mathrm{CN}}\right)_{6}{ }^{j}$ & Toluene & $1.3 \times 10^{5}\{544\}$ & $\begin{array}{l}0.780 \\
0.657 \\
0.923\end{array}$ & $\begin{array}{l}6.00 \\
5.06 \\
7.10\end{array}$ & $\begin{array}{c}192619 \\
90428 \\
183472\end{array}$ & $\begin{array}{l}2000 \\
5000 \\
5000\end{array}$ & 0.23 & 1.496 & $\begin{array}{l}80 \\
41 \\
70\end{array}$ & $\begin{array}{l}533 \\
465 \\
427\end{array}$ & 480 & 50 \\
\hline $\mathrm{W}\left(\mathrm{CN}-1-\left(2-{ }^{i} \mathrm{Pr}\right)-\mathrm{Naph}\right)_{6}{ }^{j}$ & Toluene & $5.7 \times 10^{4}\{509\}$ & $\begin{array}{l}1.607 \\
1.183 \\
1.193\end{array}$ & $\begin{array}{l}28.2 \\
20.8 \\
20.9\end{array}$ & $\begin{array}{l}168795 \\
159282 \\
184437\end{array}$ & $\begin{array}{l}1000 \\
5000 \\
5000\end{array}$ & 0.25 & 1.496 & $\begin{array}{l}74 \\
41 \\
68\end{array}$ & $\begin{array}{l}214 \\
184 \\
142\end{array}$ & 180 & 40 \\
\hline
\end{tabular}

${ }^{a} \mathrm{In} \mathrm{M}^{-1} \mathrm{~cm}^{-1} .{ }^{b}$ In nm. ${ }^{c}$ In $\mu \mathrm{M} .{ }^{d}$ In ms. ${ }^{e}$ In mW. ${ }^{.}$In GM. ${ }^{g}$ From ref. $11 .{ }^{h}$ From ref. $12 .{ }^{i}$ From ref. 1. ${ }^{j}$ From ref. 2. 


\section{Photoredox Catalysis}

All photoredox catalysis samples were prepared in a nitrogen-filled glovebox. Reactions were run in $0.6 \mathrm{~mL}$ of $\mathrm{C}_{6} \mathrm{D}_{6}$ in J-Young NMR tubes sealed with a Teflon valve. All samples were stored in the dark before commencing irradiation or analyzing by ${ }^{1} \mathrm{H}$ NMR spectroscopy.

Component concentrations/stoichiometries were determined by relative integrations from the ${ }^{1} \mathrm{H}$ NMR spectrum of the photoredox sample acquired prior to irradiation, setting the concentration of BHAS substrate (1-(2-iodobenzyl)-pyrrole or 1-(2-bromobenzyl)-pyrrole) equal to $50 \mathrm{mM}$ (1.00 equiv). The resonances (in $\mathrm{C}_{6} \mathrm{D}_{6}$ ) used for relative integrations to calculate component concentrations/stoichiometries and substrate conversion/turnover numbers (TONs) to the cyclized product are as follows:

$* 1$-(2-iodobenzyl)-pyrrole: benzyl protons at $\delta=4.59 \mathrm{ppm}$

$* 1$-(2-bromobenzyl)-pyrrole: benzyl protons at $\delta=4.64 \mathrm{ppm}$

*TMP: methyl protons at $\delta=1.07 \mathrm{ppm}$

$* \mathrm{~W}(\mathrm{CNAr})_{6}$ : isopropyl methine protons in the range $\delta=3.64-4.00 \mathrm{ppm}$ (depending on CNAr)

$*$ Cyclized organic product: benzyl protons at $\delta=4.04 \mathrm{ppm}$

For one-photon photoredox experiments, irradiation was achieved with a NUBM44 $445 \mathrm{~nm} 6 \mathrm{~W}$ High-Power Blue Laser Diode from Opt Lasers. To maintain an ambient temperature, a stream of compressed air was directed over the irradiated portion of the NMR tube during irradiation. A picture of the experimental setup is shown in Figure S40.

Laser excitation for two-photon photoredox experiments was provided by a regeneratively amplified Ti:Sapphire femtosecond laser operating at $810 \mathrm{~nm}$ (Spectra Physics, Tsunami, Spitfire, $1 \mathrm{kHz}, \sim 200 \mathrm{fs}$ ). The NMR sample was mixed manually every 30 minutes, and the laser power measured to account for variation of power over the course of the 12-h irradiation period. A picture of the experimental setup is shown in Figure S116. To optimize excitation in an NMR tube, the laser excitation beam was focused into a line using a cylindrical lens. It is difficult to estimate the precise excitation area in this situation. A rough estimate assuming a rectangular excitation profile $\left(10 \mathrm{~mm} \times 1 \mathrm{~mm}=0.1 \mathrm{~cm}^{2}\right)$ and average laser power of $150 \mathrm{~mW}$ gives a power density of $1.5 \mathrm{~W}$ $\mathrm{cm}^{-2}$. Assuming a $200 \mathrm{ps}$ pulse, the peak power density is approximately $750 \mathrm{MW} \mathrm{cm}{ }^{-2}$.

Owing to the poor optical properties of NMR tubes, it is also difficult to ascertain the precise excitation rate. We can provide a rough estimate for the two-photon excitation case assuming the geometric details given above. The estimated photon absorption rates for two-photon excitation are $(10 \pm 4) \times 10^{-6}$ einsteins $\mathrm{s}^{-1} \mathrm{~cm}^{-3}$. For the one-photon excitation, the excitation geometry did not permit calculation of the photon absorption rate.

For two-photon photoredox catalysis experiments, ${ }^{*} \mathrm{~W}(\mathrm{CNAr})_{6}$ production depends on the square of the incident intensity times the TPA cross section $(\delta)$. Since the W(CNDipp $)_{6}$ and $\mathrm{W}\left(\mathrm{CNDippPh}{ }^{\mathrm{OMe} 3}\right)_{6}$ concentrations and sample irradiation areas in these experiments were approximately the same, the relative rate of excited-state formation is given by

$$
\frac{\mathrm{P}_{810}^{2}\left(\mathrm{~W}\left(\mathrm{CNDippPh}^{\mathrm{OMe} 3}\right)_{6}\right) * \delta_{810}\left(\mathrm{~W}\left(\mathrm{CNDippPh}^{\mathrm{OMe} 3}\right)_{6}\right)}{\mathrm{P}_{810}^{2}\left(\mathrm{~W}(\mathrm{CNDipp})_{6}\right) * \delta_{810}\left(\mathrm{~W}(\mathrm{CNDipp})_{6}\right)}=\frac{(135 \mathrm{~mW})^{2} * 970 \mathrm{GM}}{(214 \mathrm{~mW})^{2} * 230 \mathrm{GM}}=1.7
$$


where $\mathrm{P}_{810}$ was the average power of the Ti:Sapphire laser over the 12-h irradiation period.

UV-visible absorbance spectra of the post-photoredox reaction mixture were obtained by cycling the J-Young NMR sample into the glovebox, diluting a drop of the sample with the appropriate solvent, and preparing the sample as described above.

In addition to the photoredox catalysis control reactions conducted in the absence of light (Table 1, entry 14) or $\mathrm{W}(\mathrm{CNAr})_{6}$ (Table 1 , entry 15$)$, monitoring a $\mathrm{C}_{6} \mathrm{D}_{6}$ solution of $\mathrm{W}(\mathrm{CNAr})_{6}$ of similar concentration by ${ }^{1} \mathrm{H}$ NMR spectroscopy after irradiation for comparable times showed no evidence of $\mathrm{W}(\mathrm{CNAr})_{6}$ decomposition.

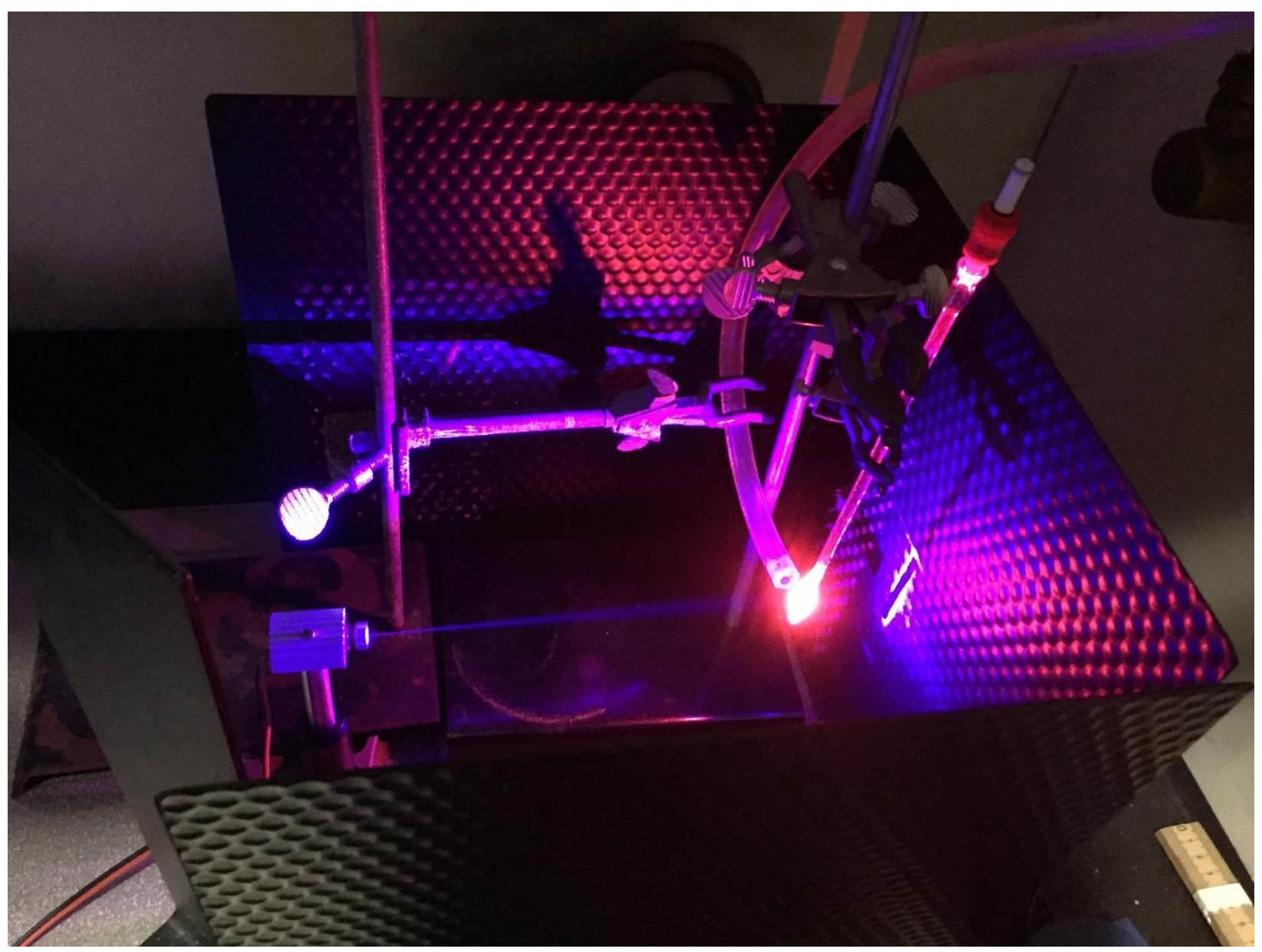

Figure S40. Experimental setup for one-photon photoredox catalysis experiments. 


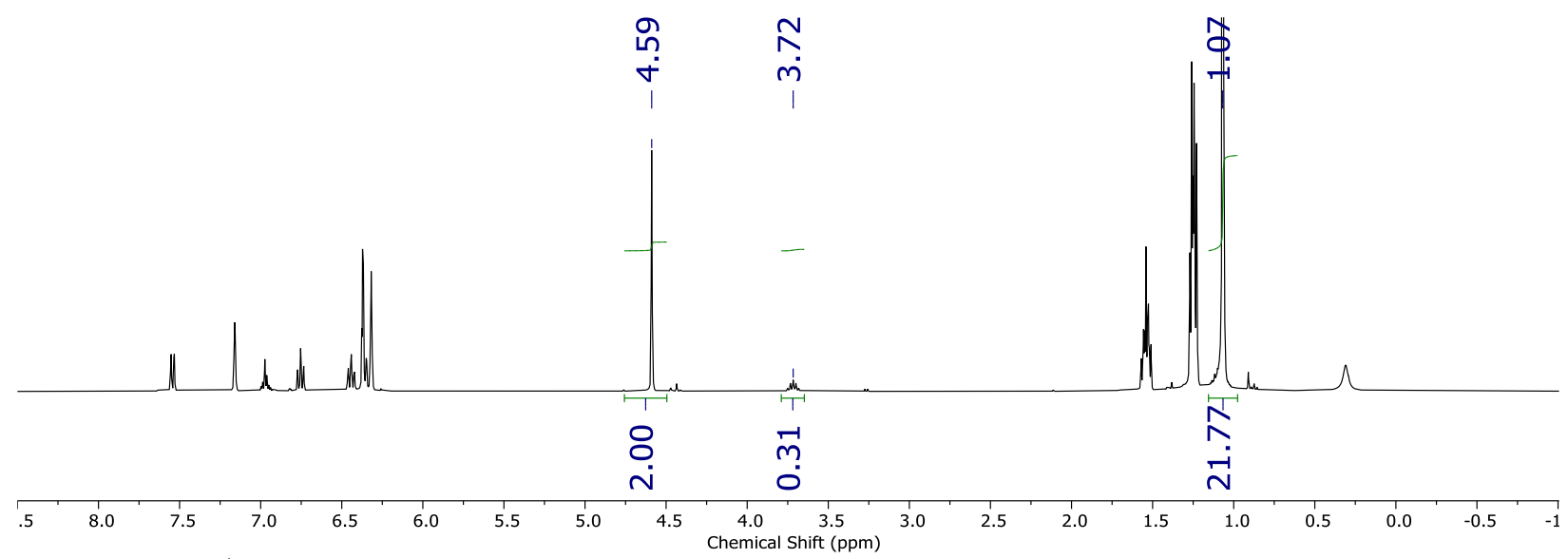

Figure S41. ${ }^{1} \mathrm{H}$ NMR spectrum $\left(400 \mathrm{MHz}, \mathrm{C}_{6} \mathrm{D}_{6}\right)$ of the one-photon photoredox catalysis sample for the reaction of ca. $2.5 \mathrm{~mol} \% \mathrm{~W}(\mathrm{CNDipp})_{6}$ and 1-(2-iodobenzyl)-pyrrole prior to irradiation. The following concentrations/stoichiometries were determined from relative integration: $\mathrm{W}(\mathrm{CNDipp})_{6}=$ $1.29 \mathrm{mM}, 2.58 \mathrm{~mol} \%$; TMP $=90.7 \mathrm{mM}, 1.81$ equiv.

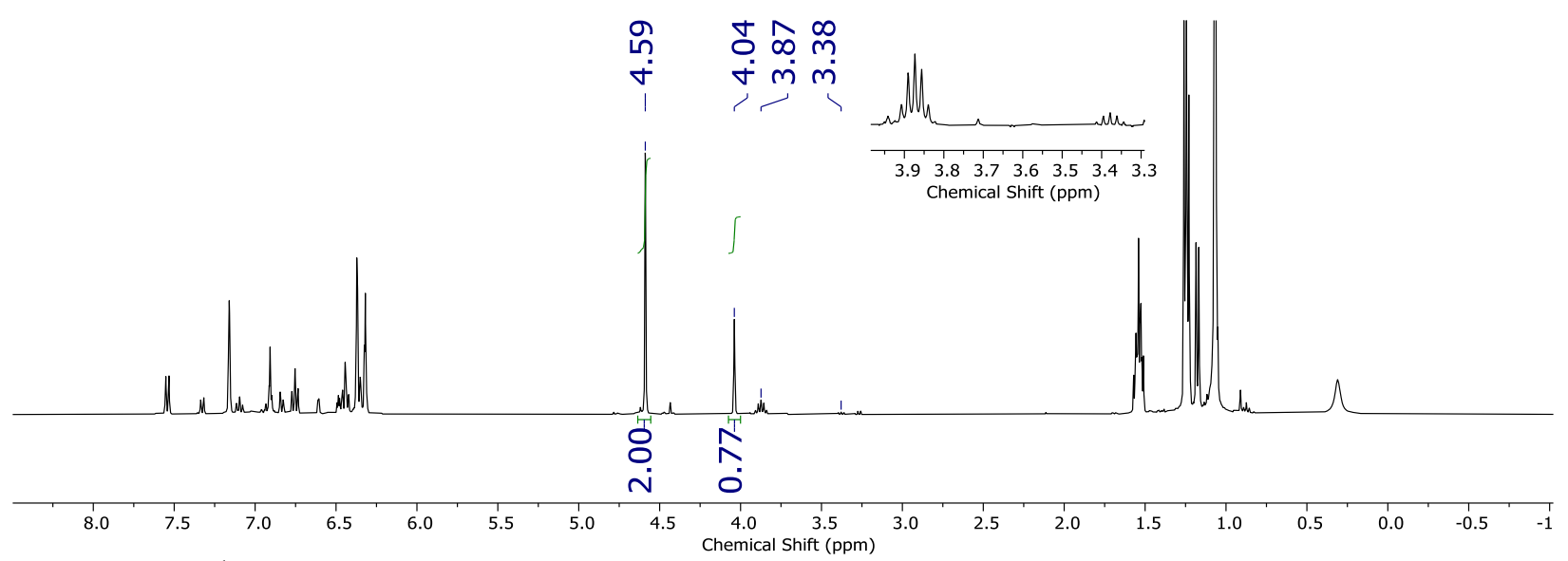

Figure S42. ${ }^{1} \mathrm{H}$ NMR spectrum $\left(400 \mathrm{MHz}, \mathrm{C}_{6} \mathrm{D}_{6}\right)$ of the one-photon photoredox catalysis sample for the reaction of ca. $2.5 \mathrm{~mol} \% \mathrm{~W}(\mathrm{CNDipp})_{6}$ and 1-(2-iodobenzyl)-pyrrole after 1-h irradiation. The following was determined from relative integration: $28 \%$ conversion, $\mathrm{TON}=11$. Isopropyl resonances for $\mathrm{W}(\mathrm{CNDipp})_{6}$ are no longer observed, but new isopropyl methine peaks are present that correspond to $\mathrm{WI}_{2}(\mathrm{CNDipp})_{5}(3.87 \mathrm{ppm})$ and free CNDipp (3.38 ppm). See Figures S47-48 for more details. 


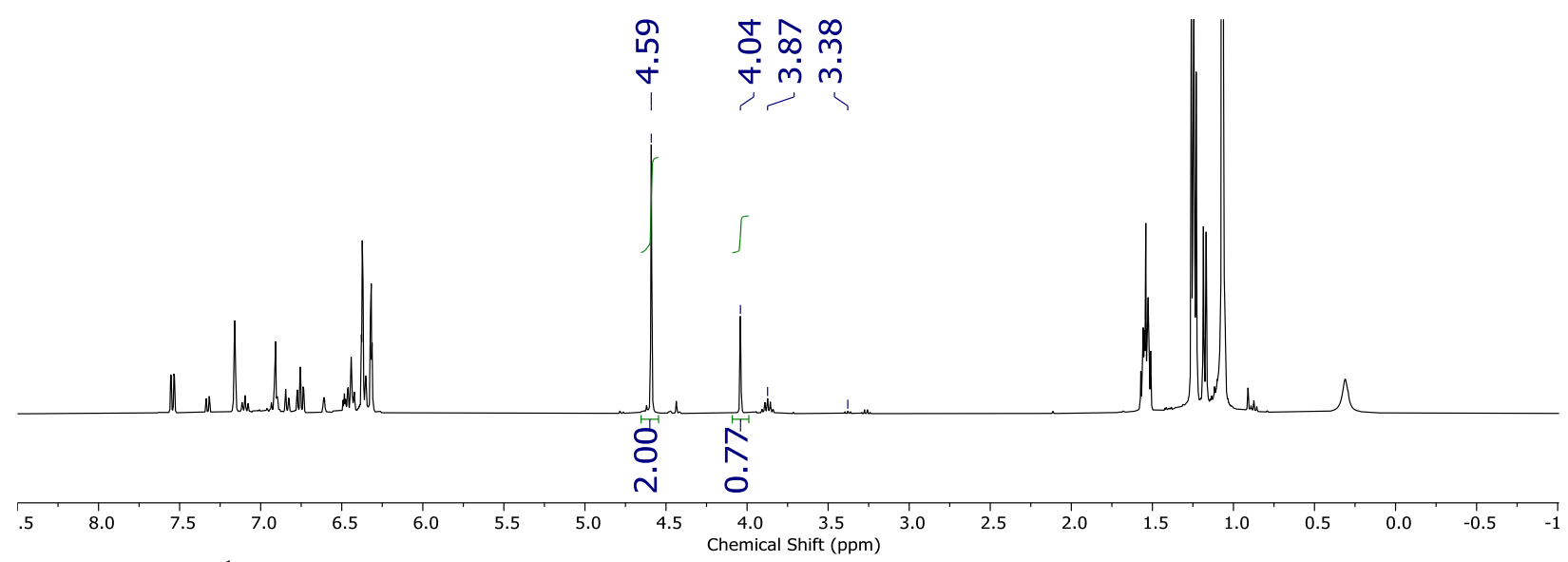

Figure S43. ${ }^{1} \mathrm{H}$ NMR spectrum $\left(400 \mathrm{MHz}, \mathrm{C}_{6} \mathrm{D}_{6}\right)$ of the one-photon photoredox catalysis sample for the reaction of ca. $2.5 \mathrm{~mol} \% \mathrm{~W}(\mathrm{CNDipp})_{6}$ and 1-(2-iodobenzyl)-pyrrole after 2-h irradiation. No further substrate conversion is observed, consistent with complete W(CNDipp)6 consumption as suggested by ${ }^{1} \mathrm{H}$ NMR spectroscopy (Figure S42) and loss of sample luminescence.

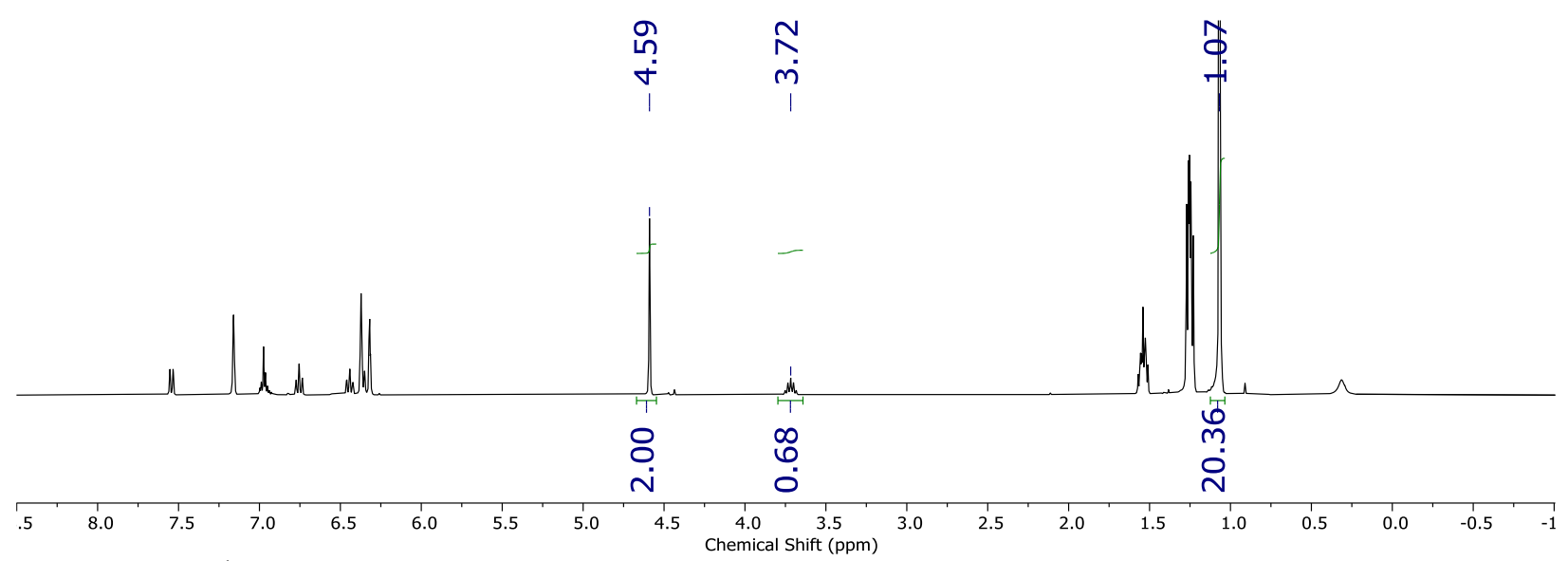

Figure S44. ${ }^{1} \mathrm{H}$ NMR spectrum $\left(400 \mathrm{MHz}, \mathrm{C}_{6} \mathrm{D}_{6}\right)$ of the one-photon photoredox catalysis sample for the reaction of ca. $5 \mathrm{~mol} \% \mathrm{~W}(\mathrm{CNDipp})_{6}$ and 1-(2-iodobenzyl)-pyrrole prior to irradiation. The following concentrations/stoichiometries were determined from relative integration: $\mathrm{W}(\mathrm{CNDipp})_{6}=$ $2.83 \mathrm{mM}, 5.67 \mathrm{~mol} \%$; TMP $=84.8 \mathrm{mM}, 1.70$ equiv. 


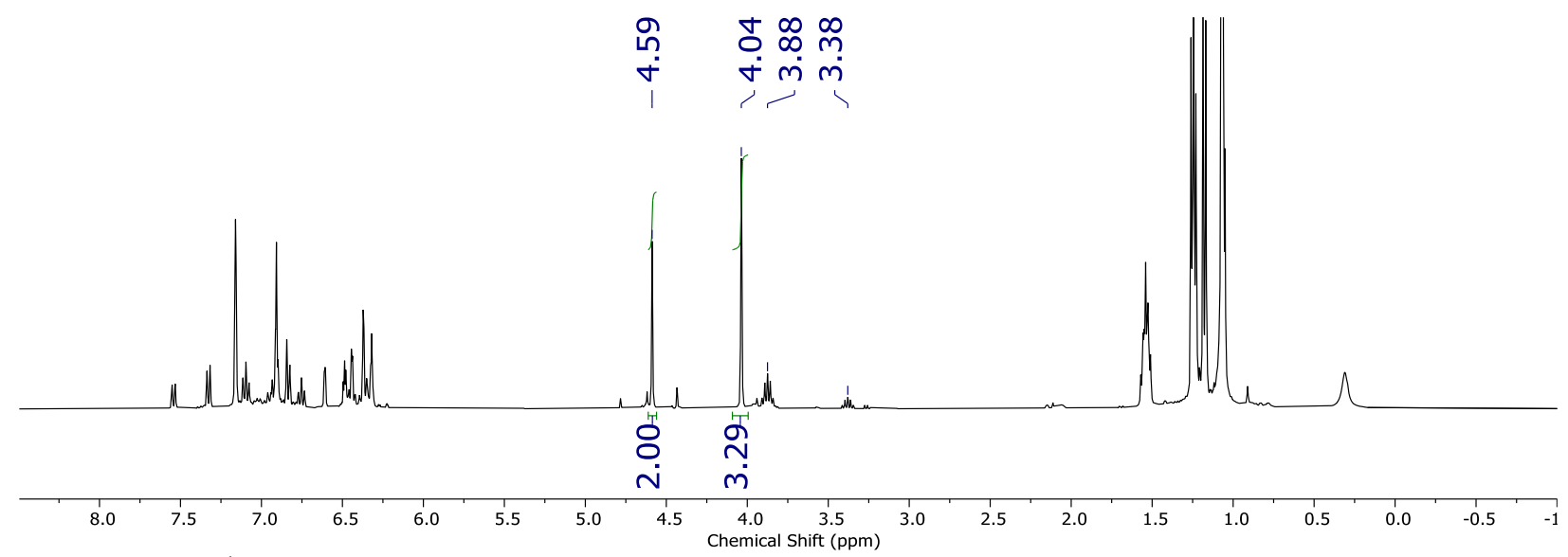

Figure S45. ${ }^{1} \mathrm{H}$ NMR spectrum $\left(400 \mathrm{MHz}, \mathrm{C}_{6} \mathrm{D}_{6}\right)$ of the one-photon photoredox catalysis sample for the reaction of ca. $5 \mathrm{~mol} \% \mathrm{~W}(\mathrm{CNDipp})_{6}$ and 1-(2-iodobenzyl)-pyrrole after 1-h irradiation. The following was determined from relative integration: $62 \%$ conversion, $\mathrm{TON}=11$. Isopropyl resonances for $\mathrm{W}(\mathrm{CNDipp})_{6}$ are no longer observed, but new isopropyl methine peaks are present that correspond to $\mathrm{WI}_{2}(\mathrm{CNDipp})_{5}(3.88 \mathrm{ppm})$ and free CNDipp (3.38 ppm). See Figures $\mathrm{S} 47-48$ for more details.

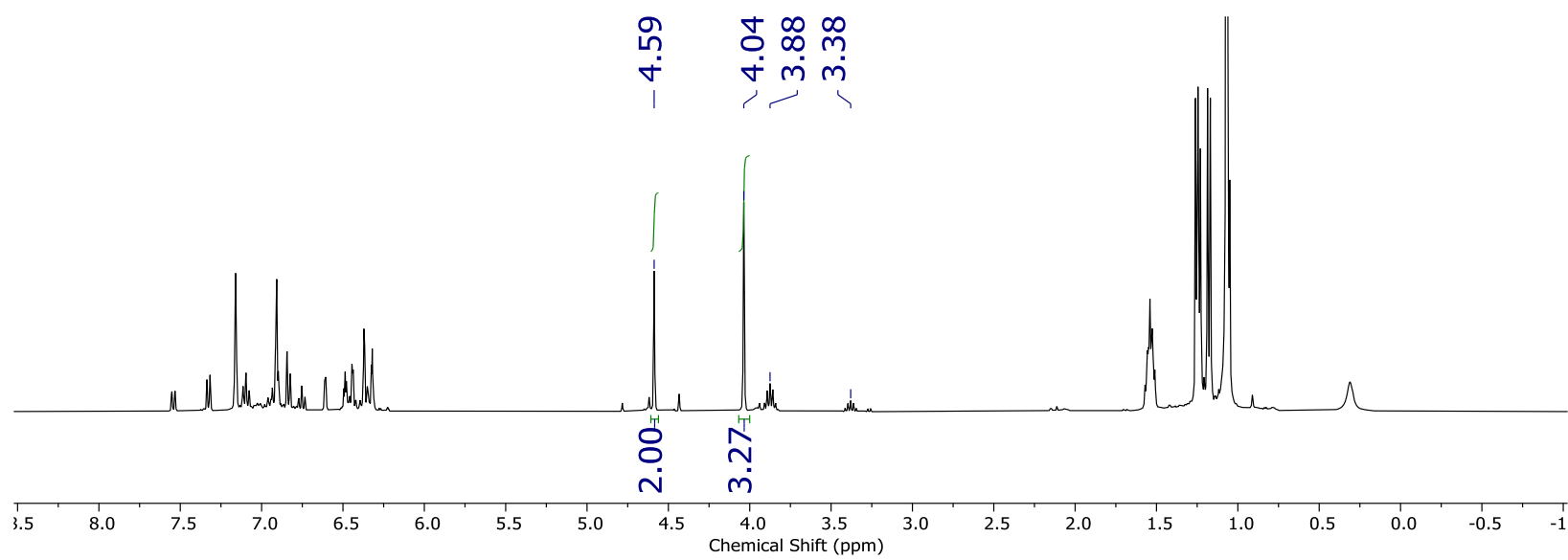

Figure S46. ${ }^{1} \mathrm{H}$ NMR spectrum $\left(400 \mathrm{MHz}, \mathrm{C}_{6} \mathrm{D}_{6}\right)$ of the one-photon photoredox catalysis sample for the reaction of ca. 5 mol \% W(CNDipp) 6 and 1-(2-iodobenzyl)-pyrrole after 2-h irradiation. No further substrate conversion is observed, consistent with complete W(CNDipp)6 consumption as suggested by ${ }^{1} \mathrm{H}$ NMR spectroscopy (Figure S45), UV-visible absorbance spectroscopy (Figure S49), and loss of sample luminescence. 

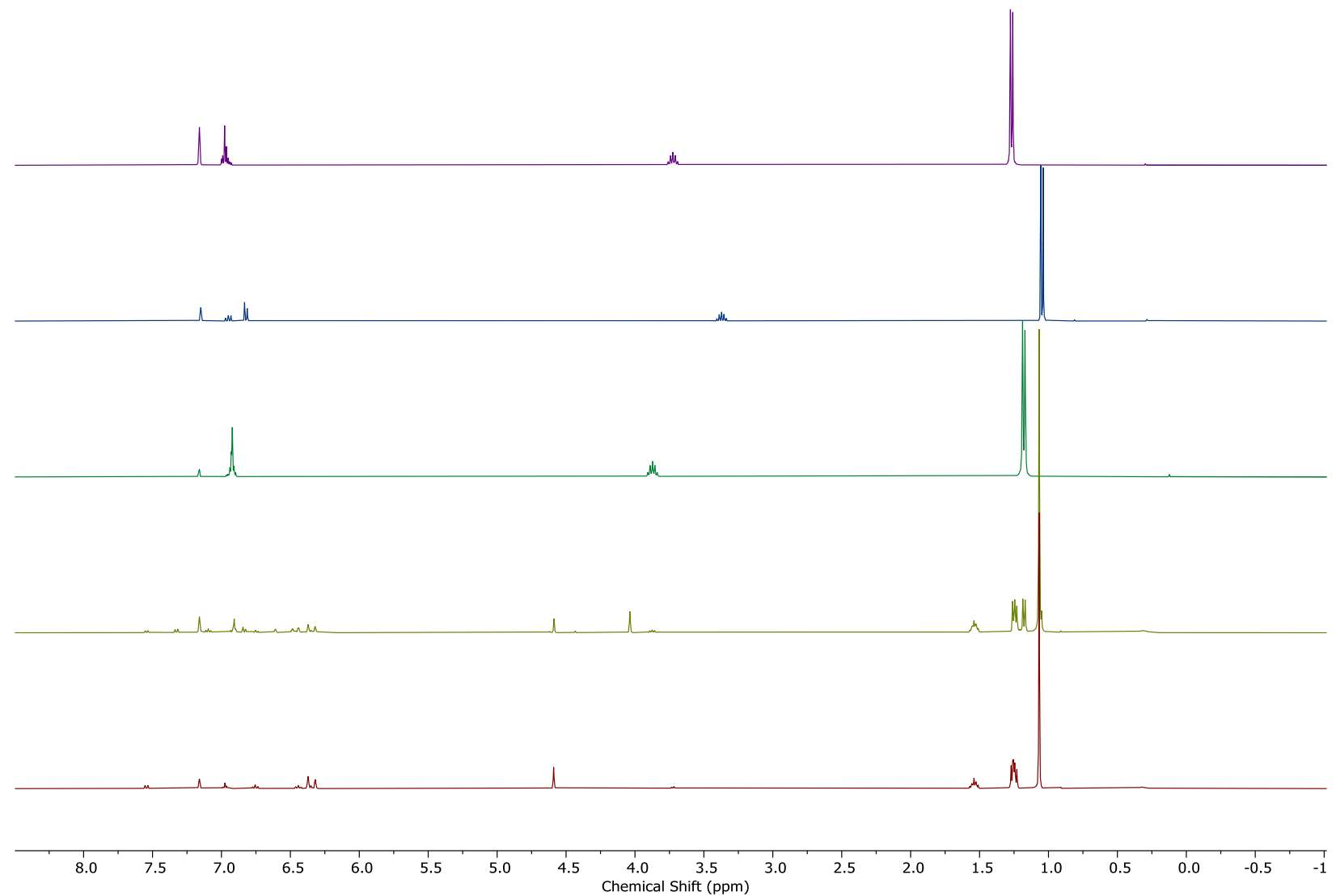

Figure S47. Stacked ${ }^{1} \mathrm{H}$ NMR spectra $\left(400 \mathrm{MHz}, \mathrm{C}_{6} \mathrm{D}_{6}\right)$ of an authentic sample of W(CNDipp) 6 (purple), an authentic sample of CNDipp (blue), an authentic sample of $\mathrm{WI}_{2}$ (CNDipp) 5 (green), the post-photoredox reaction mixture from Figure S45 (yellow-green), and the pre-irradiated photoredox reaction mixture from Figure S44 (red).
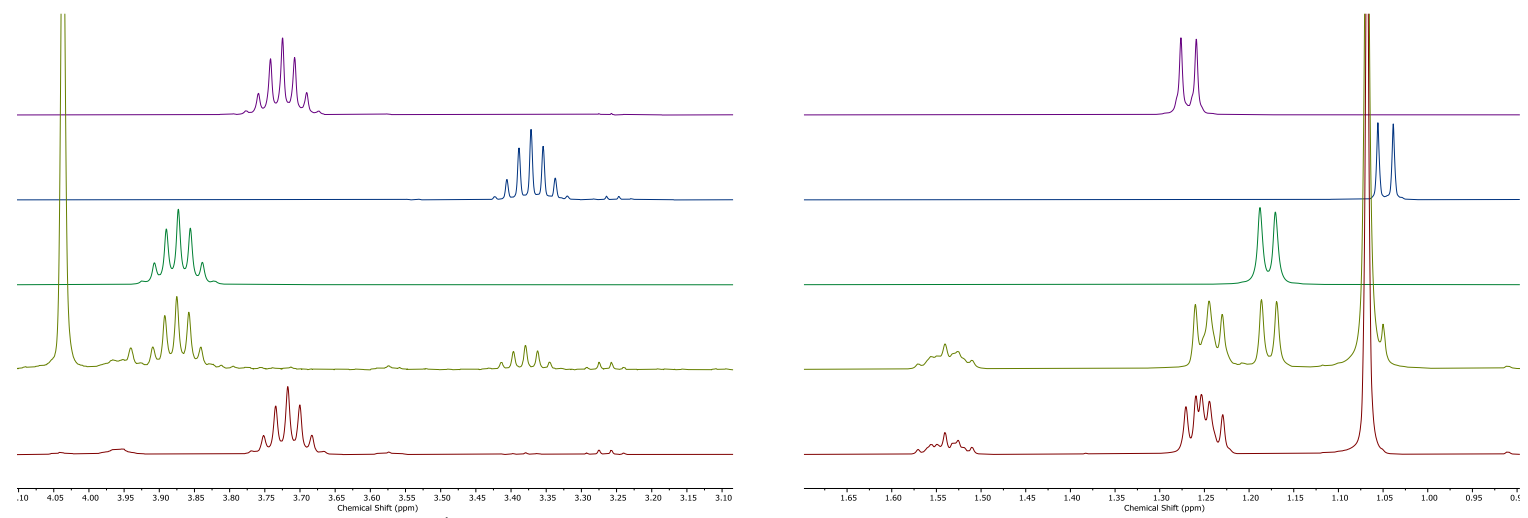

Figure S48. Zoom-ins of the ${ }^{1} \mathrm{H}$ NMR spectra from Figure S47 showing the isopropyl regions. 


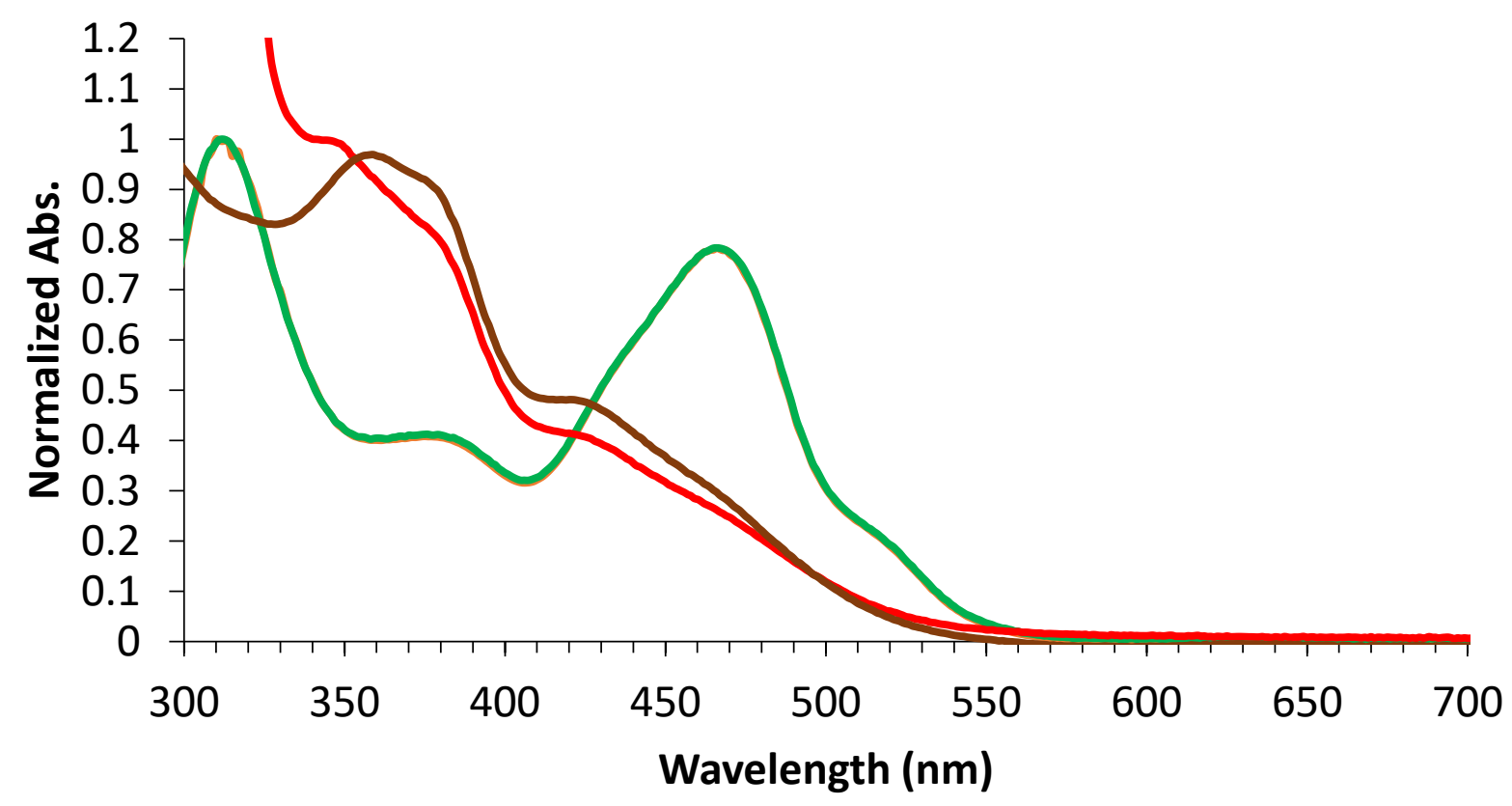

Figure S49. Overlaid UV-visible absorbance spectra of an authentic sample of W(CNDipp) 6 (orange, toluene), the pre-irradiated photoredox reaction mixture from Figure S44 (green, toluene), the post-photoredox reaction mixture from Figure S46 (red, toluene), and an authentic sample of $\mathrm{WI}_{2}$ (CNDipp) 5 (brown, benzene).

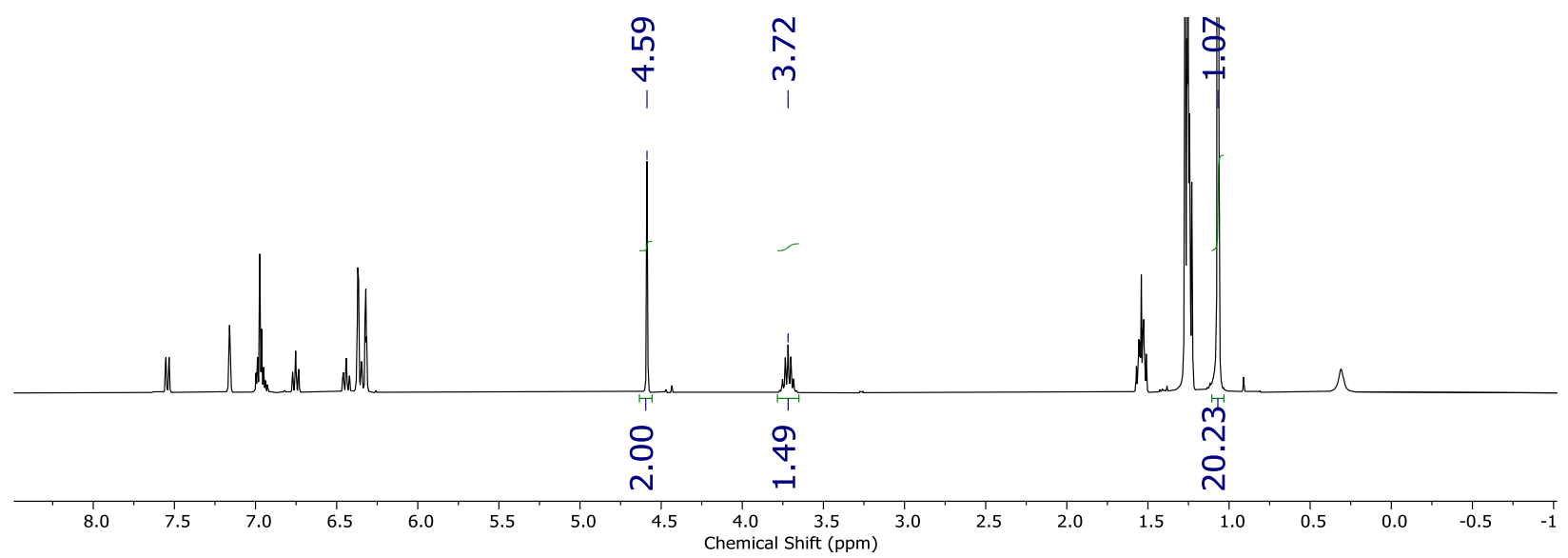

Figure S50. ${ }^{1} \mathrm{H}$ NMR spectrum $\left(400 \mathrm{MHz}, \mathrm{C}_{6} \mathrm{D}_{6}\right)$ of the one-photon photoredox catalysis sample for the reaction of ca. $10 \mathrm{~mol} \% \mathrm{~W}(\mathrm{CNDipp})_{6}$ and 1-(2-iodobenzyl)-pyrrole prior to irradiation. The following concentrations/stoichiometries were determined from relative integration: $\mathrm{W}(\mathrm{CNDipp})_{6}=$ $6.21 \mathrm{mM}, 12.4 \mathrm{~mol} \%$; TMP $=84.3 \mathrm{mM}, 1.69$ equiv. 


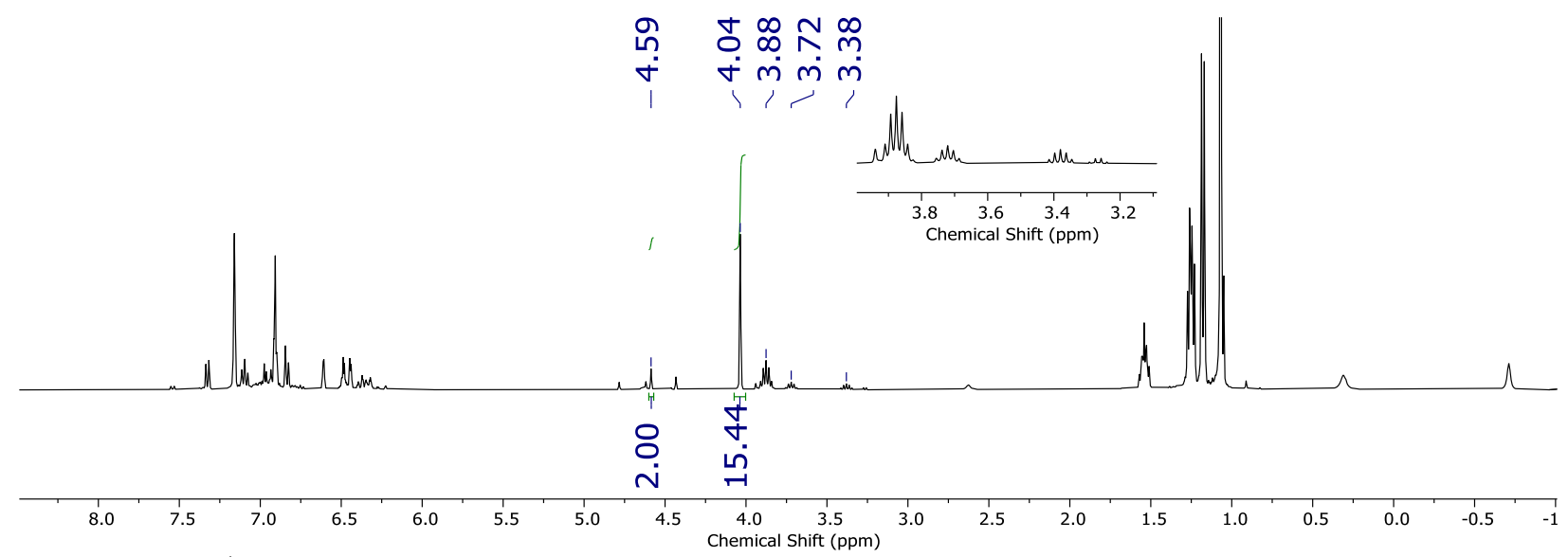

Figure S51. ${ }^{1} \mathrm{H}$ NMR spectrum $\left(400 \mathrm{MHz}, \mathrm{C}_{6} \mathrm{D}_{6}\right)$ of the one-photon photoredox catalysis sample for the reaction of ca. $10 \mathrm{~mol} \% \mathrm{~W}(\mathrm{CNDipp})_{6}$ and 1-(2-iodobenzyl)-pyrrole after 1-h irradiation. The following was determined from relative integration: $88 \%$ conversion, TON $=7.1$. The isopropyl methine resonance for $\mathrm{W}(\mathrm{CNDipp})_{6}$ is still present $(3.72 \mathrm{ppm})$, along with new isopropyl methine peaks that correspond to $\mathrm{WI}_{2}(\mathrm{CNDipp})_{5}(3.88 \mathrm{ppm})$ and free CNDipp (3.38 ppm). See Figures S4748 for more details.

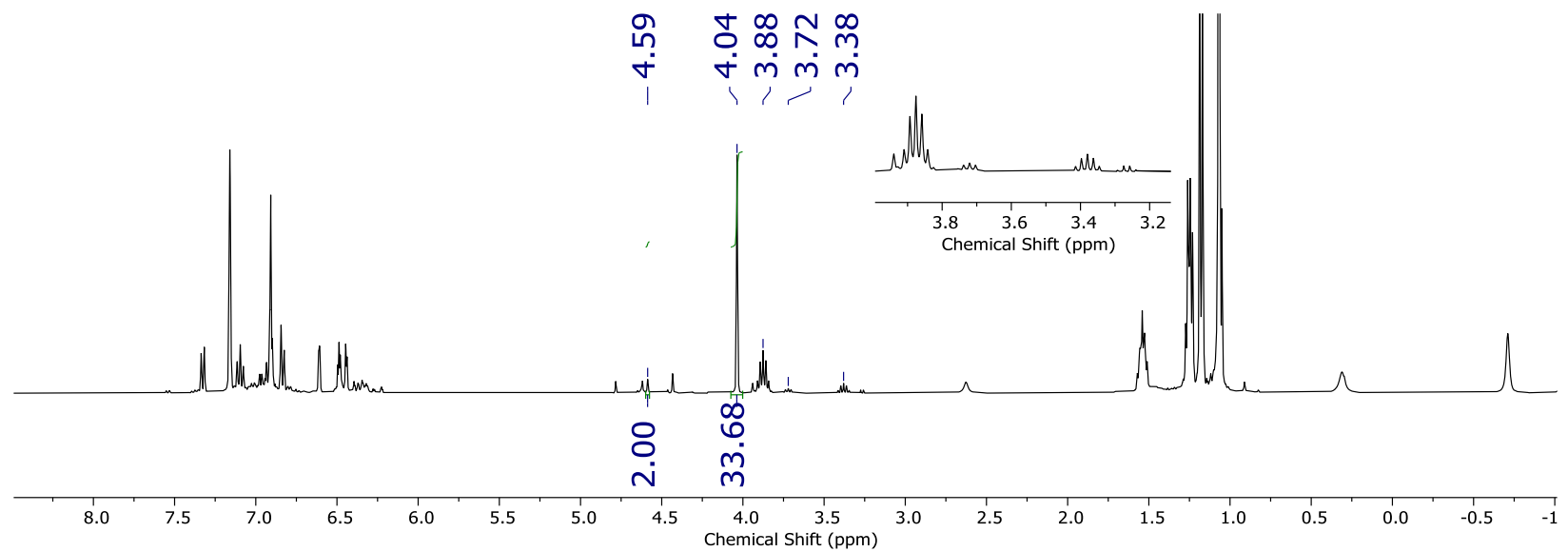

Figure S52. ${ }^{1} \mathrm{H}$ NMR spectrum $\left(400 \mathrm{MHz}, \mathrm{C}_{6} \mathrm{D}_{6}\right)$ of the one-photon photoredox catalysis sample for the reaction of ca. $10 \mathrm{~mol} \% \mathrm{~W}(\mathrm{CNDipp})_{6}$ and 1-(2-iodobenzyl)-pyrrole after 2-h irradiation. The following was determined from relative integration: $94 \%$ conversion, $\mathrm{TON}=7.6$. An isopropyl methine resonance for $\mathrm{W}(\mathrm{CNDipp})_{6}(3.72 \mathrm{ppm})$ suggests a small amount of the photocatalyst is still present. 


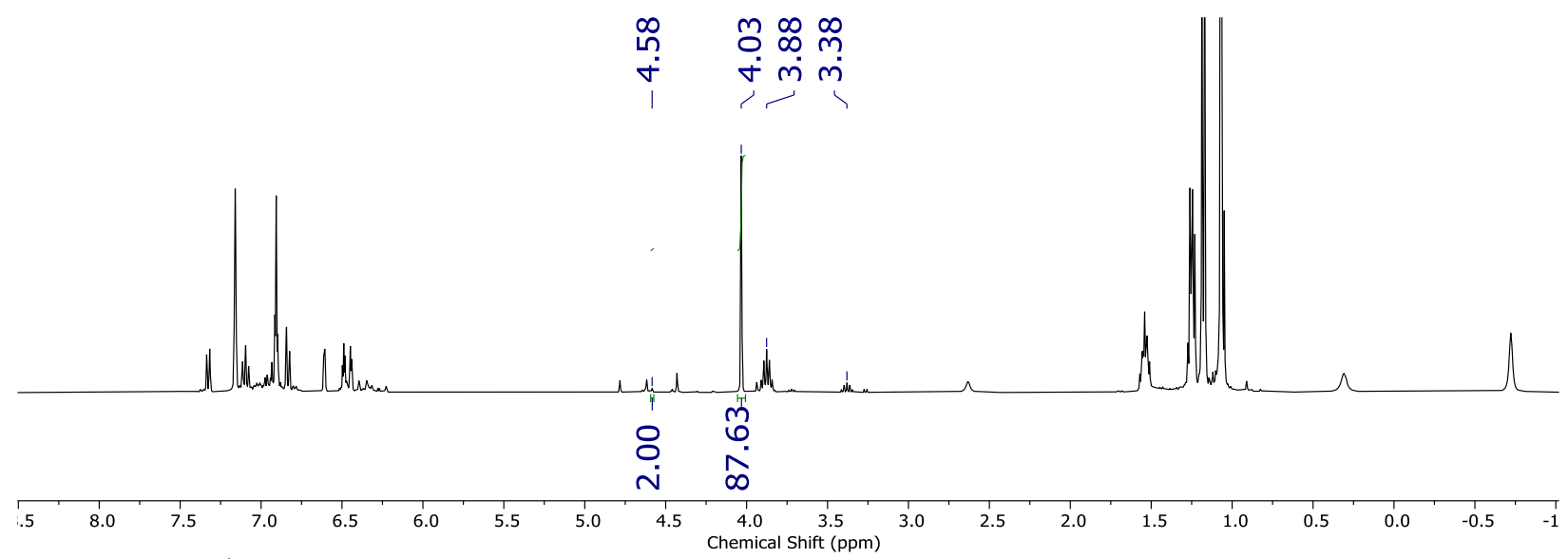

Figure S53. ${ }^{1} \mathrm{H}$ NMR spectrum $\left(400 \mathrm{MHz}, \mathrm{C}_{6} \mathrm{D}_{6}\right)$ of the one-photon photoredox catalysis sample for the reaction of ca. $10 \mathrm{~mol} \% \mathrm{~W}(\mathrm{CNDipp})_{6}$ and 1-(2-iodobenzyl)-pyrrole after 4-h irradiation. The following was determined from relative integration: $98 \%$ conversion, $\mathrm{TON}=7.9$. Isopropyl resonances for $\mathrm{W}(\mathrm{CNDipp})_{6}$ are no longer observed.

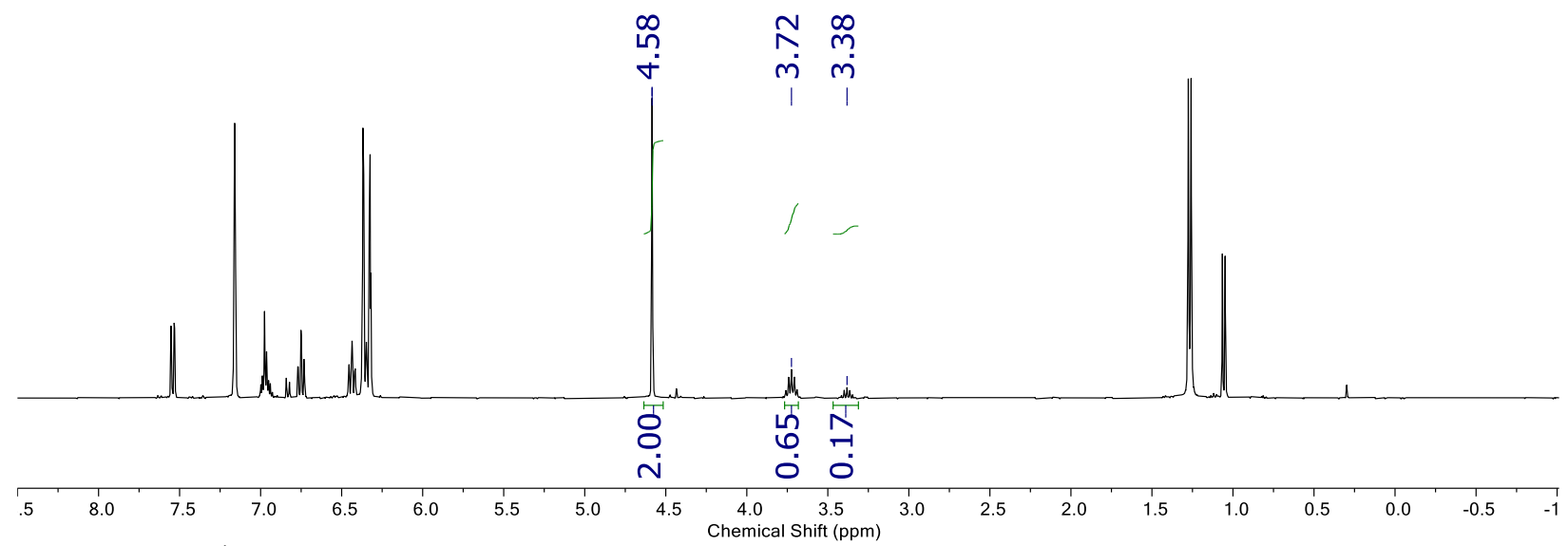

Figure S54. ${ }^{1} \mathrm{H}$ NMR spectrum $\left(400 \mathrm{MHz}, \mathrm{C}_{6} \mathrm{D}_{6}\right)$ of the one-photon redox catalysis sample for the reaction of ca. $5 \mathrm{~mol} \% \mathrm{~W}(\mathrm{CNDipp})_{6}$ and 1-(2-iodobenzyl)-pyrrole in the presence of ca. $9 \mathrm{~mol} \%$ CNDipp, and absence of TMP, prior to irradiation. The following concentrations/stoichiometries were determined from relative integration: $\mathrm{W}(\mathrm{CNDipp})_{6}=2.71 \mathrm{mM}, 5.42 \mathrm{~mol} \%$; CNDipp $=4.25$ $\mathrm{mM}, 8.50 \mathrm{~mol} \%$. 


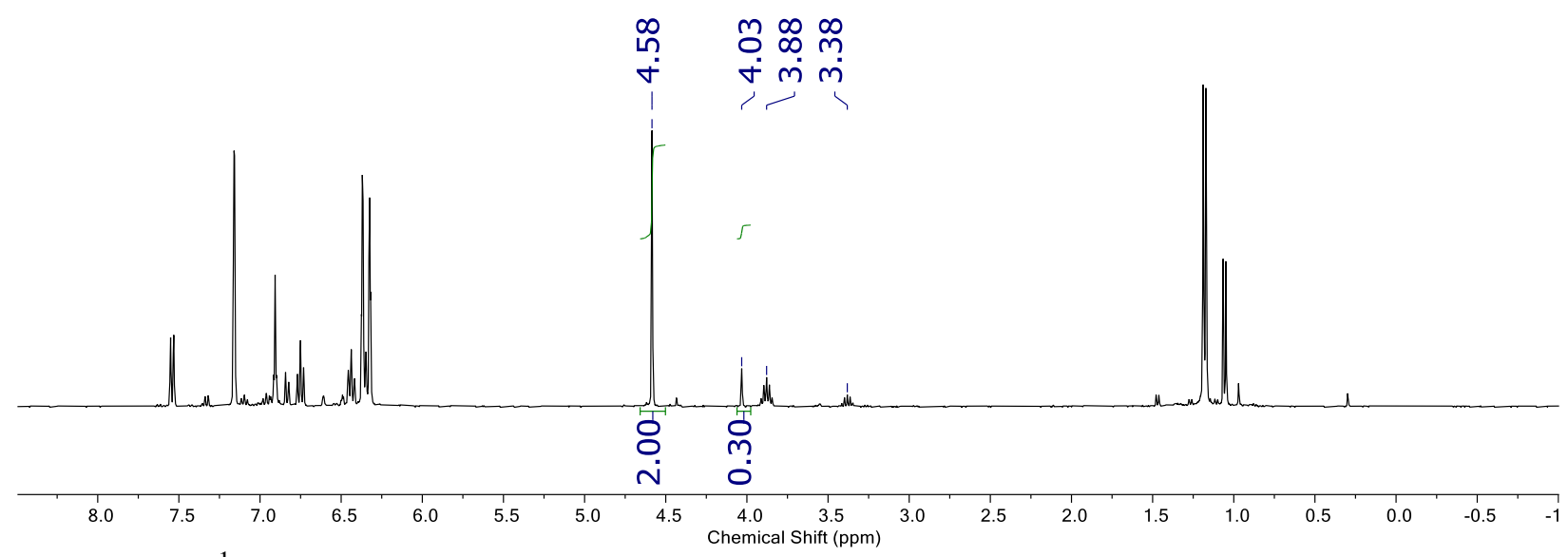

Figure S55. ${ }^{1} \mathrm{H}$ NMR spectrum $\left(400 \mathrm{MHz}, \mathrm{C}_{6} \mathrm{D}_{6}\right)$ of the one-photon redox catalysis sample for the reaction of ca. $5 \mathrm{~mol} \% \mathrm{~W}(\mathrm{CNDipp})_{6}$ and 1-(2-iodobenzyl)-pyrrole in the presence of ca. $9 \mathrm{~mol} \%$ CNDipp, and absence of TMP, after 1-hr irradiation. The following was determined from relative integration: $13 \%$ conversion, $\mathrm{TON}=2.4$. Conversion of $\mathrm{W}(\mathrm{CNDipp})_{6}$ to $\mathrm{WI}_{2}(\mathrm{CNDipp})_{5}(3.88 \mathrm{ppm})$ is observed.

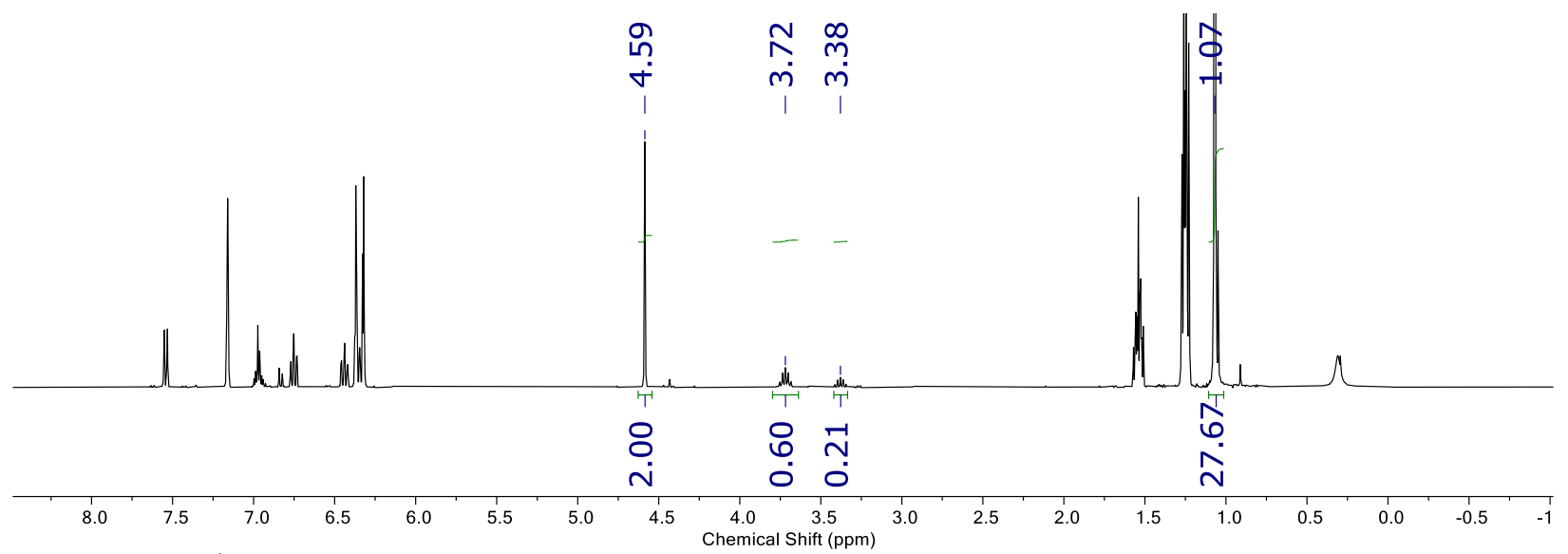

Figure S56. ${ }^{1} \mathrm{H}$ NMR spectrum $\left(400 \mathrm{MHz}, \mathrm{C}_{6} \mathrm{D}_{6}\right)$ of the one-photon redox catalysis sample for the reaction of ca. $5 \mathrm{~mol} \% \mathrm{~W}(\mathrm{CNDipp})_{6}$ and 1-(2-iodobenzyl)-pyrrole in the presence of ca. $11 \mathrm{~mol} \%$ CNDipp prior to irradiation. The following concentrations/stoichiometries were determined from relative integration: $\mathrm{W}(\mathrm{CNDipp})_{6}=2.50 \mathrm{mM}, 5.00 \mathrm{~mol} \%$; CNDipp $=5.25 \mathrm{mM}, 10.5 \mathrm{~mol} \%$; TMP $=115 \mathrm{mM}, 2.31$ equiv. 


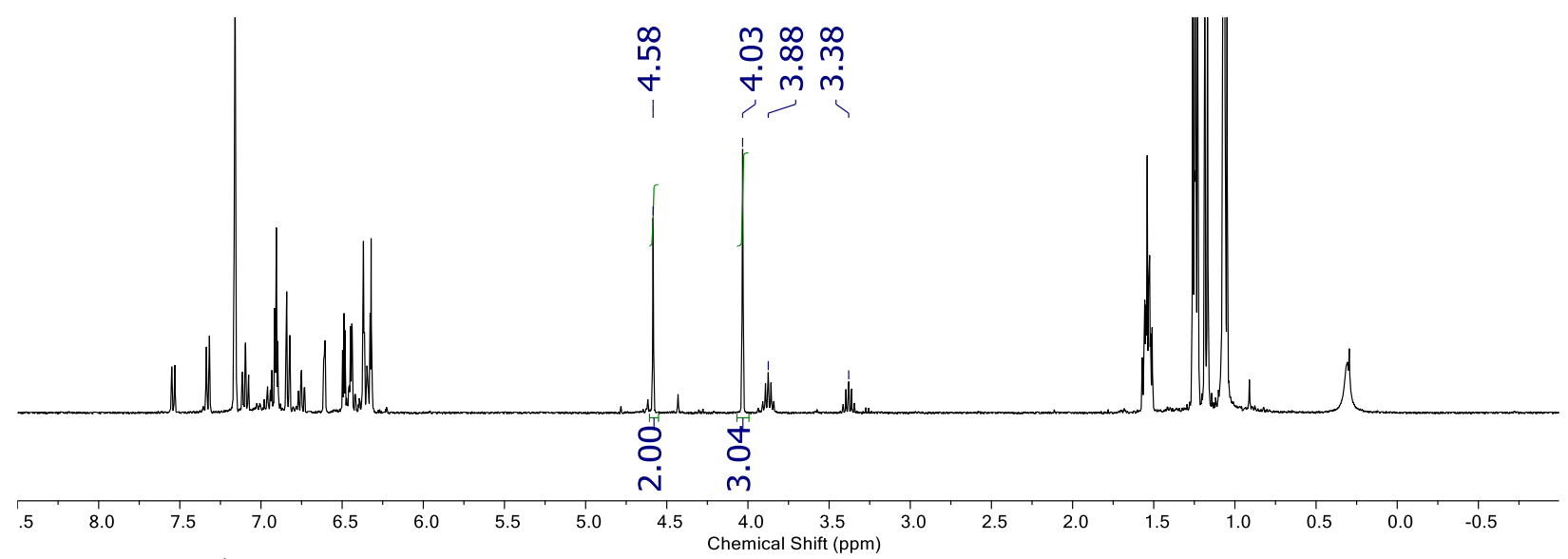

Figure S57. ${ }^{1} \mathrm{H}$ NMR spectrum $\left(400 \mathrm{MHz}, \mathrm{C}_{6} \mathrm{D}_{6}\right)$ of the one-photon redox catalysis sample for the reaction of ca. $5 \mathrm{~mol} \% \mathrm{~W}(\mathrm{CNDipp})_{6}$ and 1-(2-iodobenzyl)-pyrrole in the presence of ca. $11 \mathrm{~mol} \%$ CNDipp after 1-hr irradiation. The following was determined from relative integration: $60 \%$ conversion, $\mathrm{TON}=12$. Conversion of $\mathrm{W}(\mathrm{CNDipp})_{6}$ to $\mathrm{WI}_{2}(\mathrm{CNDipp})_{5}(3.88 \mathrm{ppm})$ is observed.

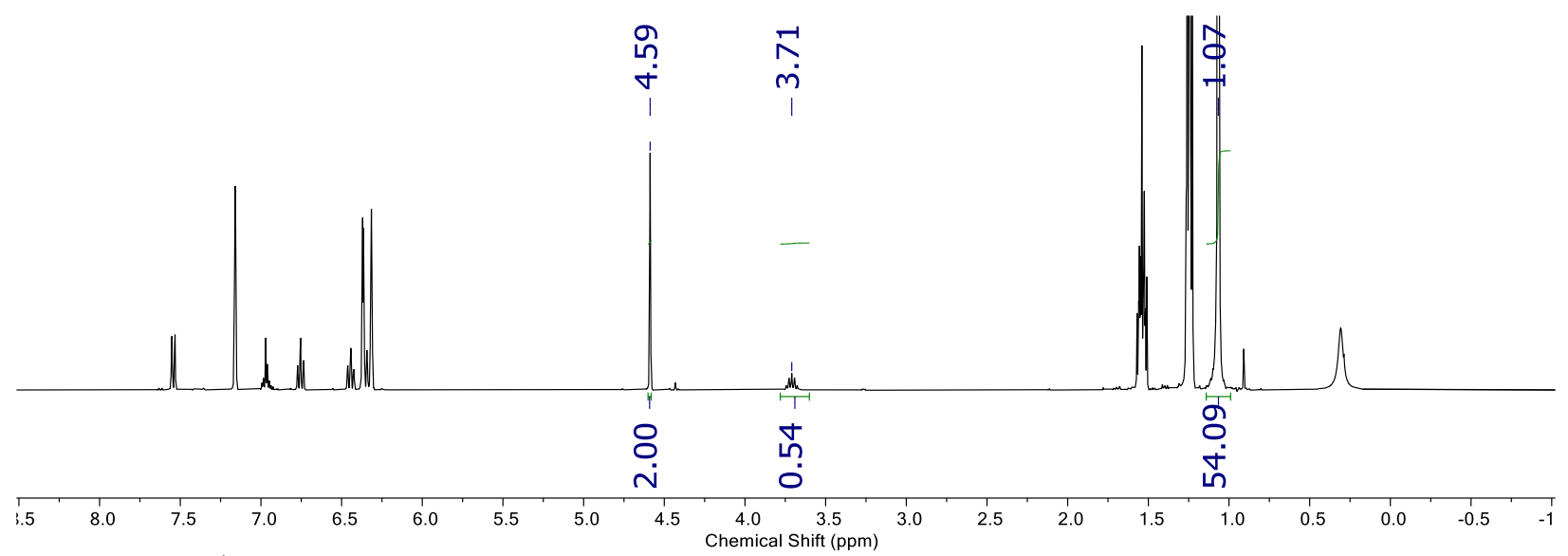

Figure S58. ${ }^{1} \mathrm{H}$ NMR spectrum $\left(400 \mathrm{MHz}, \mathrm{C}_{6} \mathrm{D}_{6}\right)$ of the one-photon redox catalysis sample for the reaction of ca. $5 \mathrm{~mol} \% \mathrm{~W}(\mathrm{CNDipp})_{6}$ and 1-(2-iodobenzyl)-pyrrole prior to irradiation. The following concentrations/stoichiometries were determined from relative integration: $\mathrm{W}(\mathrm{CNDipp})_{6}=$ $2.25 \mathrm{mM}, 4.50 \mathrm{~mol} \%$; TMP = $225 \mathrm{mM}, 4.51$ equiv. 


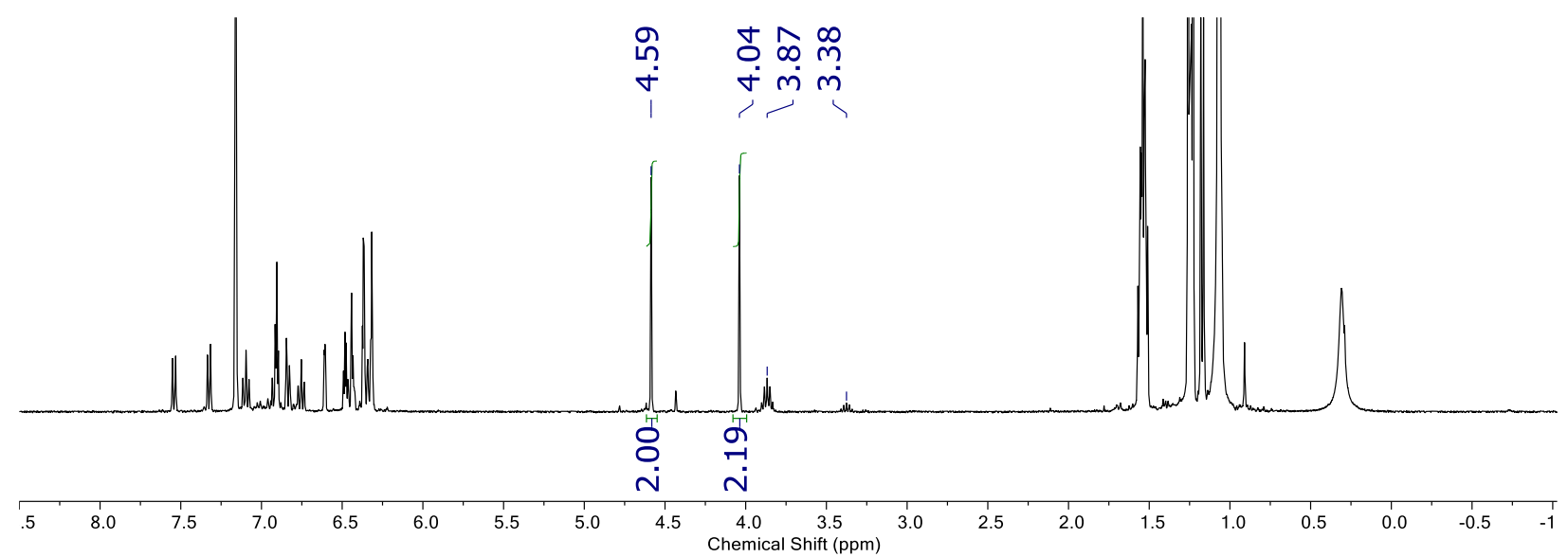

Figure S59. ${ }^{1} \mathrm{H}$ NMR $\left(400 \mathrm{MHz}, \mathrm{C}_{6} \mathrm{D}_{6}\right)$ spectrum of the one-photon redox catalysis sample for the reaction of ca. $5 \mathrm{~mol} \% \mathrm{~W}(\mathrm{CNDipp})_{6}$ and 1-(2-iodobenzyl)-pyrrole after 1-hr irradiation. The following was determined from relative integration: $52 \%$ conversion, $\mathrm{TON}=12$. Conversion of $\mathrm{W}(\mathrm{CNDipp})_{6}$ to $\mathrm{WI}_{2}(\mathrm{CNDipp})_{5}(3.87 \mathrm{ppm})$ is observed.

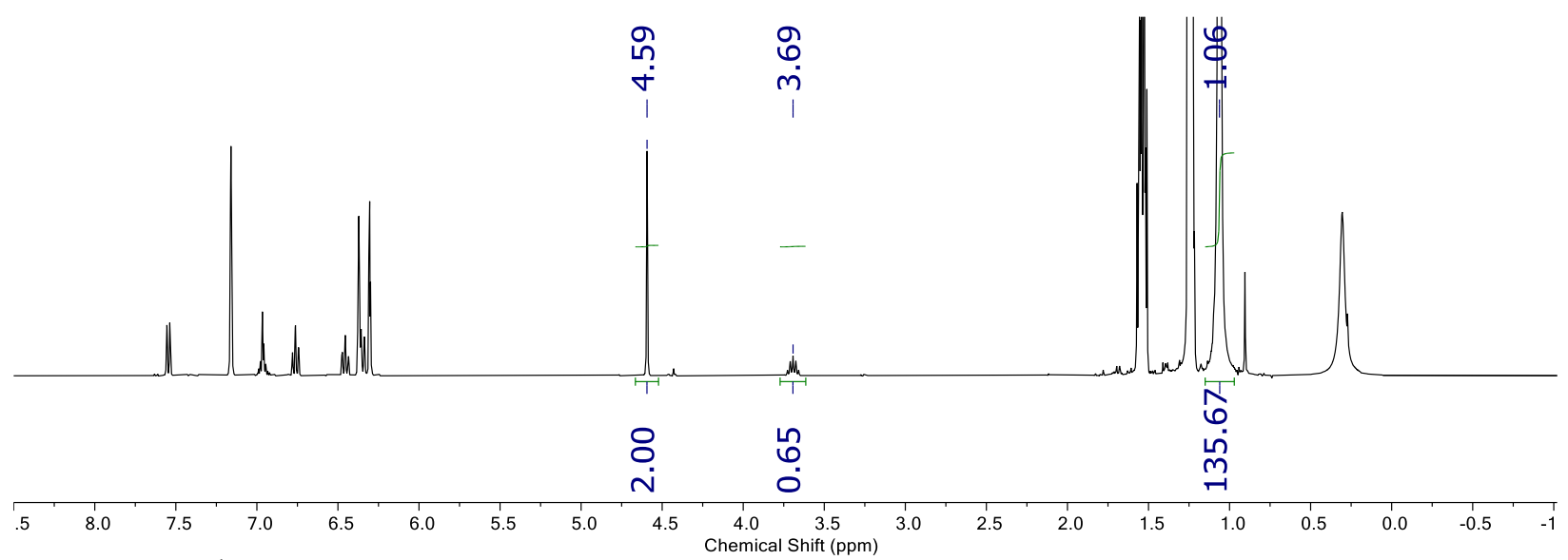

Figure S60. ${ }^{1} \mathrm{H}$ NMR spectrum $\left(400 \mathrm{MHz}, \mathrm{C}_{6} \mathrm{D}_{6}\right)$ of the one-photon redox catalysis sample for the reaction of ca. $5 \mathrm{~mol} \% \mathrm{~W}(\mathrm{CNDipp})_{6}$ and 1-(2-iodobenzyl)-pyrrole prior to irradiation. The following concentrations/stoichiometries were determined from relative integration: $\mathrm{W}(\mathrm{CNDipp})_{6}=$ $2.71 \mathrm{mM}, 5.42 \mathrm{~mol} \%$; TMP = $565 \mathrm{mM}, 11.3$ equiv. 


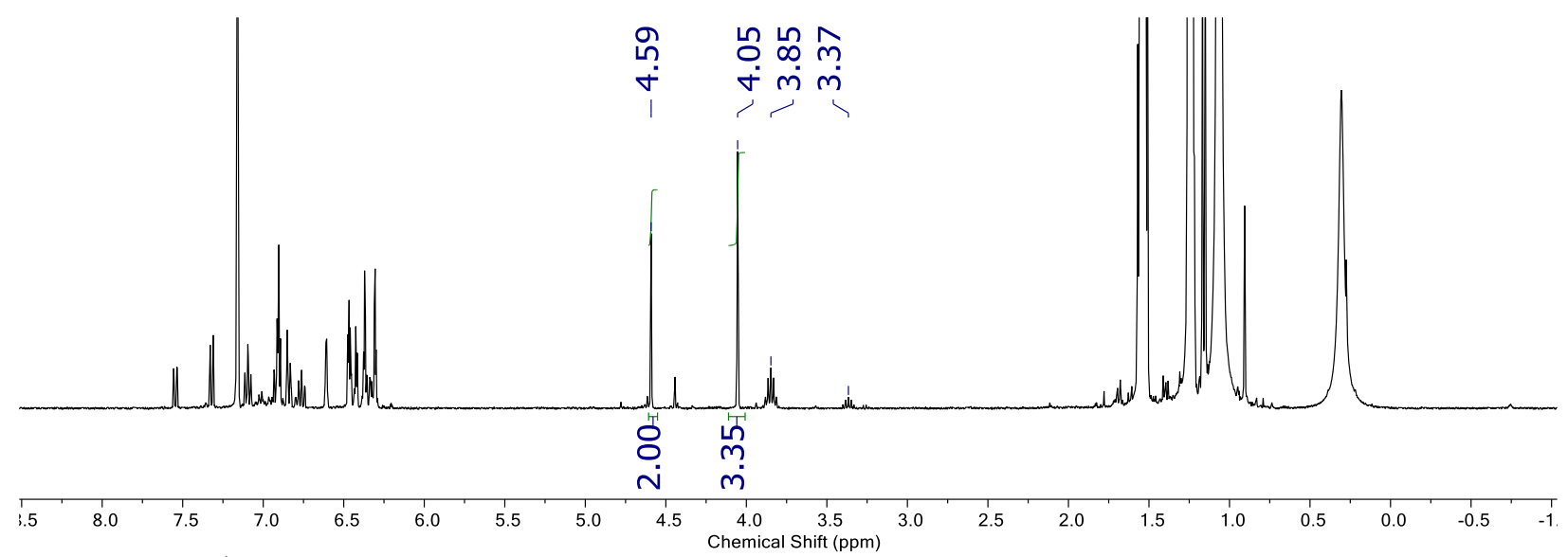

Figure S61. ${ }^{1} \mathrm{H}$ NMR spectrum $\left(400 \mathrm{MHz}, \mathrm{C}_{6} \mathrm{D}_{6}\right)$ of the one-photon redox catalysis sample for the reaction of ca. $5 \mathrm{~mol} \% \mathrm{~W}(\mathrm{CNDipp})_{6}$ and 1-(2-iodobenzyl)-pyrrole after 1-hr irradiation. The following was determined from relative integration: $63 \%$ conversion, $\mathrm{TON}=12$. Conversion of $\mathrm{W}$ (CNDipp) 6 to $\mathrm{WI}_{2}$ (CNDipp) 5 (3.85 ppm) is observed.

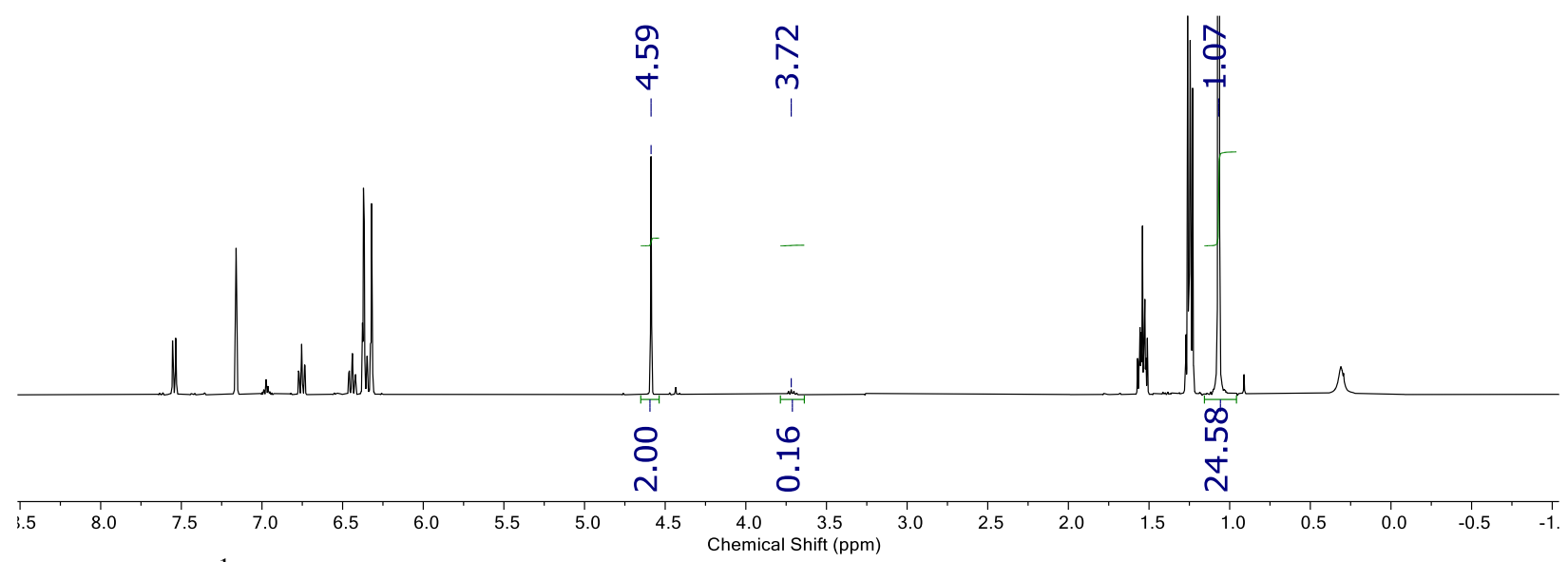

Figure S62. ${ }^{1} \mathrm{H}$ NMR spectrum $\left(400 \mathrm{MHz}, \mathrm{C}_{6} \mathrm{D}_{6}\right)$ of the one-photon redox catalysis sample for the reaction of ca. $1.3 \mathrm{~mol} \% \mathrm{~W}(\mathrm{CNDipp})_{6}$ and 1-(2-iodobenzyl)-pyrrole prior to irradiation. The following concentrations/stoichiometries were determined from relative integration: $\mathrm{W}(\mathrm{CNDipp})_{6}=$ $0.67 \mathrm{mM}, 1.33 \mathrm{~mol} \%$; TMP $=102 \mathrm{mM}, 2.05$ equiv. 


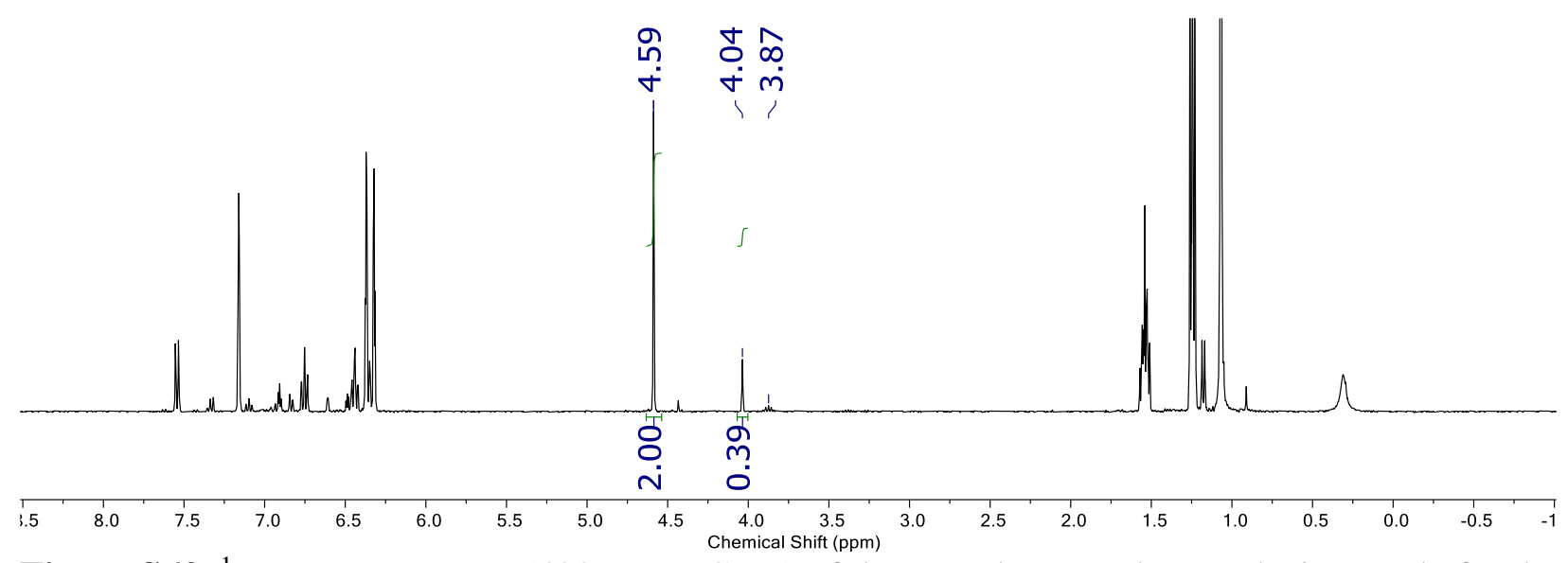

Figure S63. ${ }^{1} \mathrm{H}$ NMR spectrum $\left(400 \mathrm{MHz}, \mathrm{C}_{6} \mathrm{D}_{6}\right)$ of the one-photon redox catalysis sample for the reaction of ca. $1.3 \mathrm{~mol} \% \mathrm{~W}(\mathrm{CNDipp})_{6}$ and 1-(2-iodobenzyl)-pyrrole after 1-hr irradiation. The following was determined from relative integration: $16 \%$ conversion, $\mathrm{TON}=12$. Conversion of $\mathrm{W}(\mathrm{CNDipp})_{6}$ to $\mathrm{WI}_{2}$ (CNDipp) 5 (3.87 ppm) is observed.

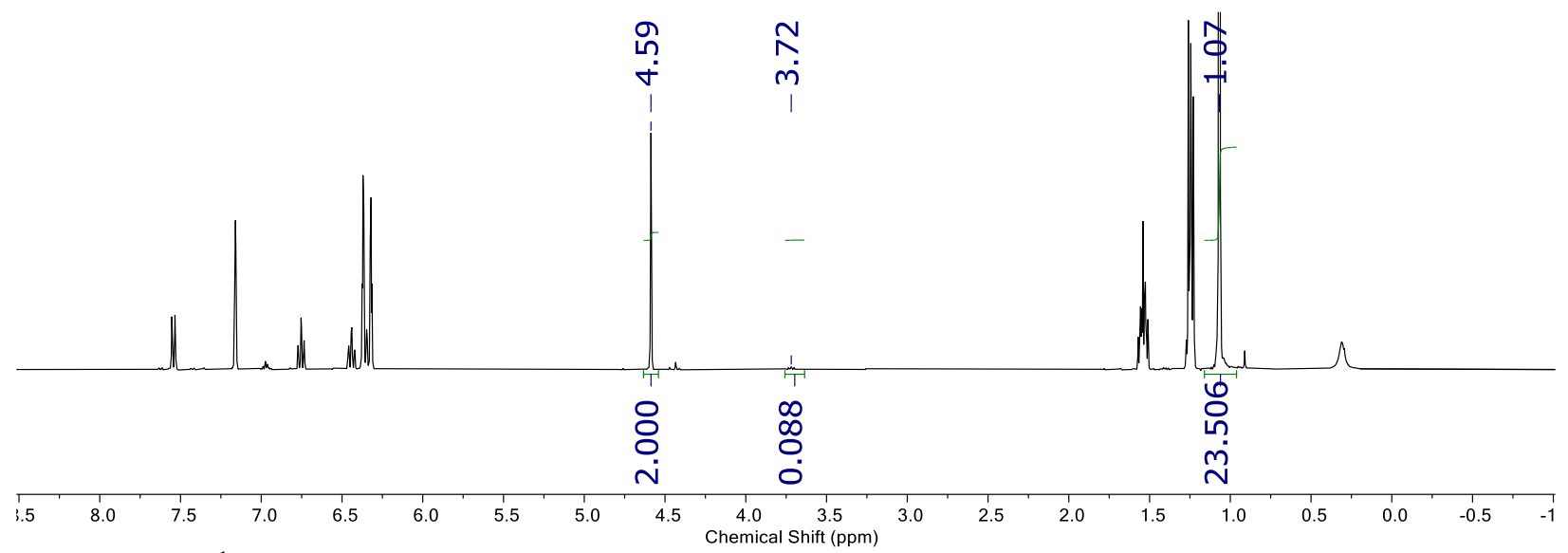

Figure S64. ${ }^{1} \mathrm{H}$ NMR spectrum $\left(400 \mathrm{MHz}, \mathrm{C}_{6} \mathrm{D}_{6}\right)$ of the one-photon redox catalysis sample for the reaction of ca. $0.7 \mathrm{~mol} \% \mathrm{~W}(\mathrm{CNDipp})_{6}$ and 1-(2-iodobenzyl)-pyrrole prior to irradiation. The following concentrations/stoichiometries were determined from relative integration: $\mathrm{W}(\mathrm{CNDipp})_{6}=$ $0.37 \mathrm{mM}, 0.73 \mathrm{~mol} \%$; TMP $=98.0 \mathrm{mM}, 1.96$ equiv. 


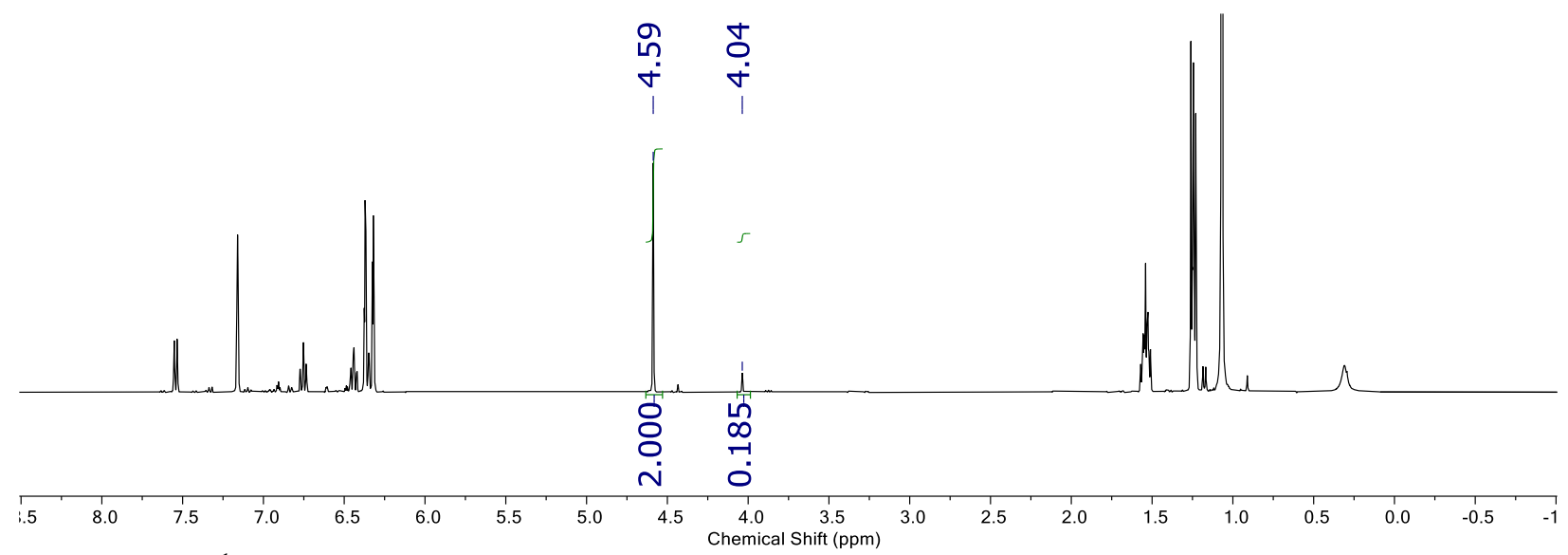

Figure S65. ${ }^{1} \mathrm{H}$ NMR spectrum $\left(400 \mathrm{MHz}, \mathrm{C}_{6} \mathrm{D}_{6}\right)$ of the one-photon redox catalysis sample for the reaction of ca. $0.7 \mathrm{~mol} \% \mathrm{~W}(\mathrm{CNDipp})_{6}$ and 1-(2-iodobenzyl)-pyrrole after 1-hr irradiation. The following was determined from relative integration: $8.5 \%$ conversion, $\mathrm{TON}=12$.

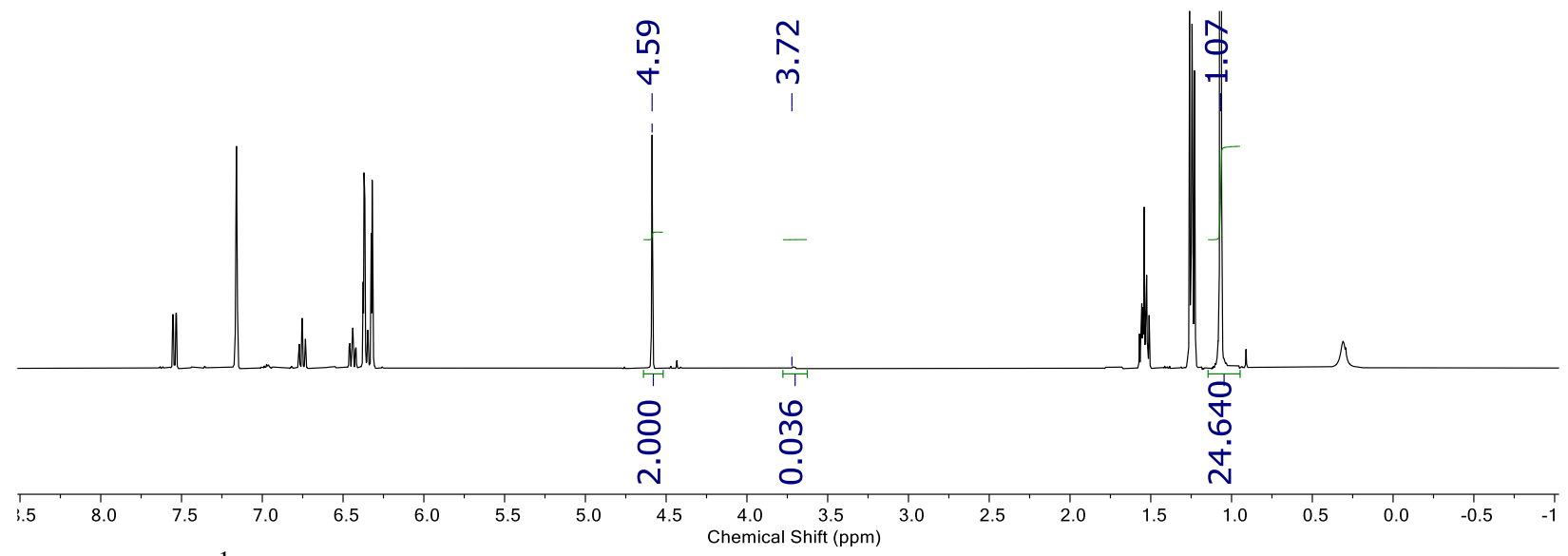

Figure S66. ${ }^{1} \mathrm{H}$ NMR spectrum $\left(400 \mathrm{MHz}, \mathrm{C}_{6} \mathrm{D}_{6}\right)$ of the one-photon redox catalysis sample for the reaction of ca. $0.3 \mathrm{~mol} \% \mathrm{~W}(\mathrm{CNDipp})_{6}$ and 1-(2-iodobenzyl)-pyrrole prior to irradiation. The following concentrations/stoichiometries were determined from relative integration: $\mathrm{W}(\mathrm{CNDipp})_{6}=$ $0.15 \mathrm{mM}, 0.30 \mathrm{~mol} \%$; TMP $=103 \mathrm{mM}, 2.05$ equiv. 


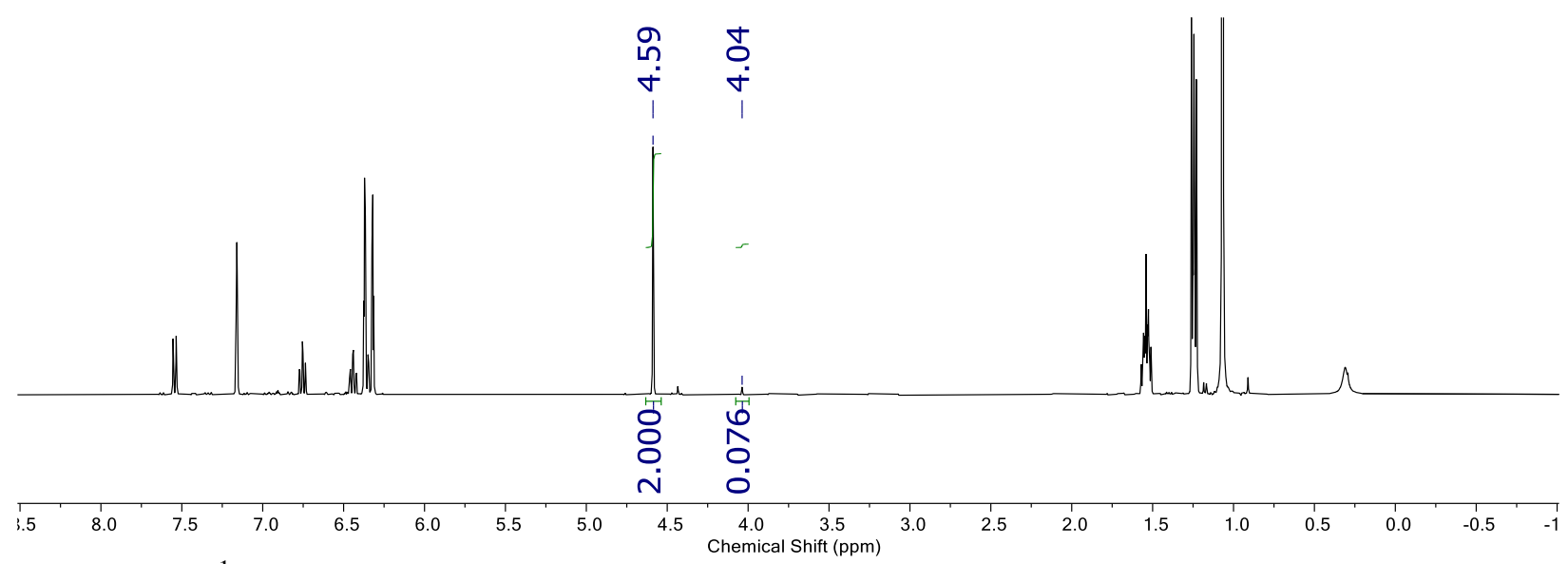

Figure S67. ${ }^{1} \mathrm{H}$ NMR spectrum $\left(400 \mathrm{MHz}, \mathrm{C}_{6} \mathrm{D}_{6}\right)$ of the one-photon redox catalysis sample for the reaction of ca. $0.3 \mathrm{~mol} \% \mathrm{~W}(\mathrm{CNDipp})_{6}$ and 1-(2-iodobenzyl)-pyrrole after 1-hr irradiation. The following was determined from relative integration: $3.7 \%$ conversion, $\mathrm{TON}=12$.

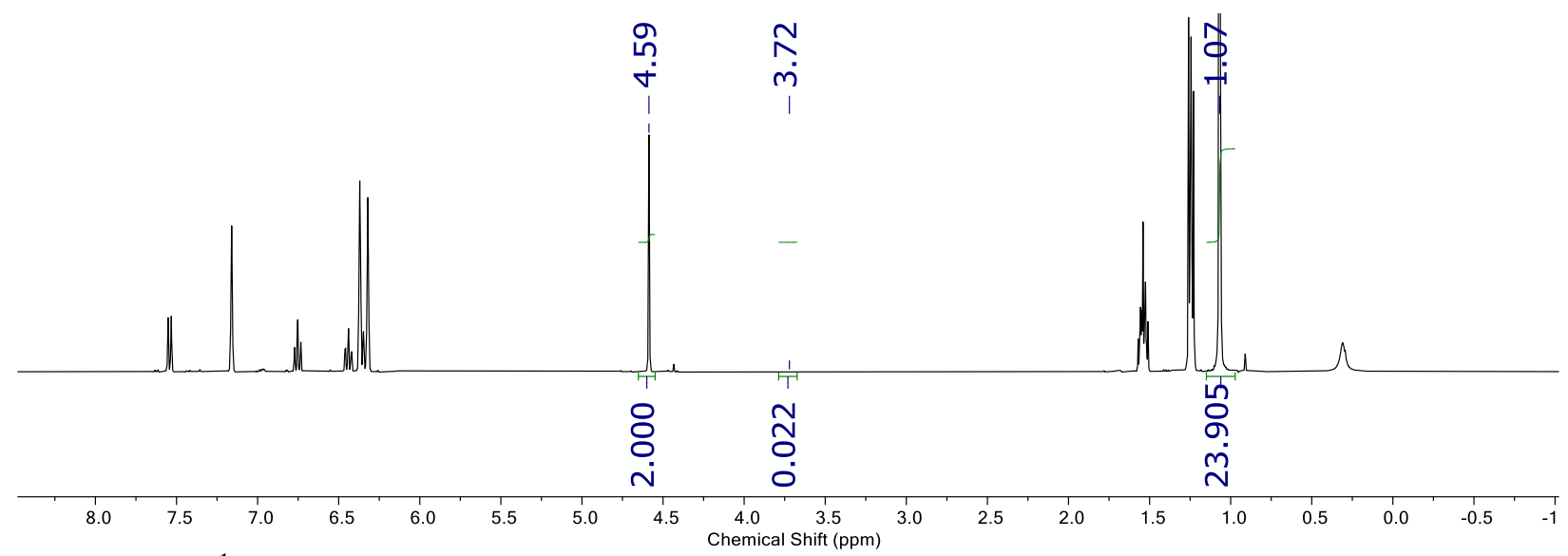

Figure S68. ${ }^{1} \mathrm{H}$ NMR spectrum $\left(400 \mathrm{MHz}, \mathrm{C}_{6} \mathrm{D}_{6}\right)$ of the one-photon redox catalysis sample for the reaction of ca. $0.2 \mathrm{~mol} \% \mathrm{~W}(\mathrm{CNDipp})_{6}$ and 1-(2-iodobenzyl)-pyrrole prior to irradiation. The following concentrations/stoichiometries were determined from relative integration: $\mathrm{W}(\mathrm{CNDipp})_{6}=$ $0.09 \mathrm{mM}, 0.18 \mathrm{~mol} \%$; TMP $=99.6 \mathrm{mM}, 1.99$ equiv. 


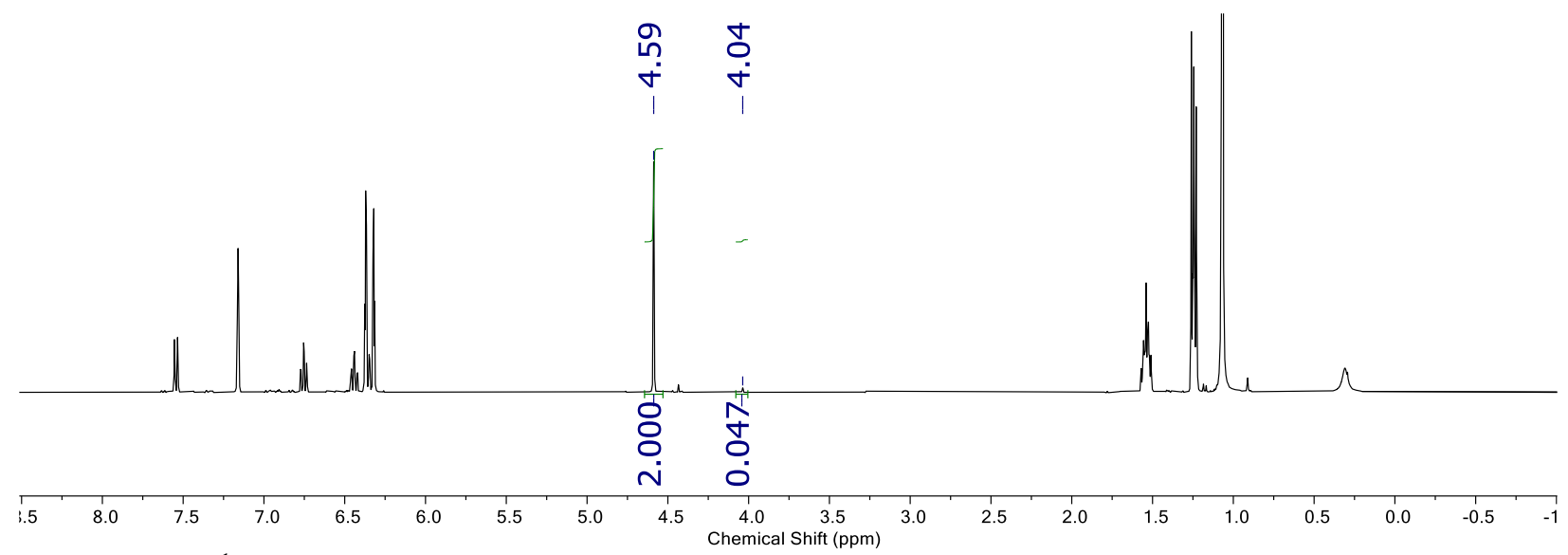

Figure S69. ${ }^{1} \mathrm{H}$ NMR spectrum $\left(400 \mathrm{MHz}, \mathrm{C}_{6} \mathrm{D}_{6}\right)$ of the one-photon redox catalysis sample for the reaction of ca. $0.2 \mathrm{~mol} \% \mathrm{~W}(\mathrm{CNDipp})_{6}$ and 1-(2-iodobenzyl)-pyrrole after 1-hr irradiation. The following was determined from relative integration: $2.3 \%$ conversion, $\mathrm{TON}=12$.

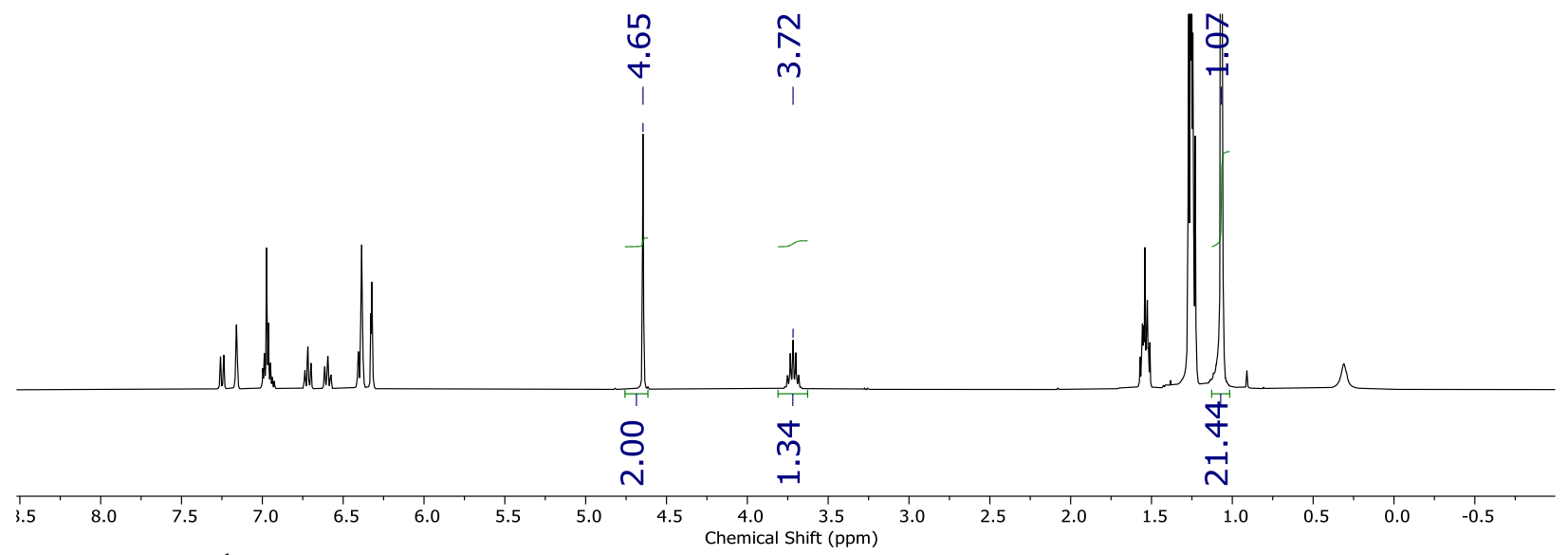

Figure S70. ${ }^{1} \mathrm{H}$ NMR spectrum $\left(400 \mathrm{MHz}, \mathrm{C}_{6} \mathrm{D}_{6}\right)$ of the one-photon photoredox catalysis sample for the reaction of ca. $10 \mathrm{~mol} \% \mathrm{~W}(\mathrm{CNDipp})_{6}$ and 1-(2-bromobenzyl)-pyrrole prior to irradiation. The following concentrations/stoichiometries were determined from relative integration: $\mathrm{W}(\mathrm{CNDipp})_{6}=5.58 \mathrm{mM}, 11.2 \mathrm{~mol} \%$; TMP $=89.3 \mathrm{mM}, 1.79$ equiv. 


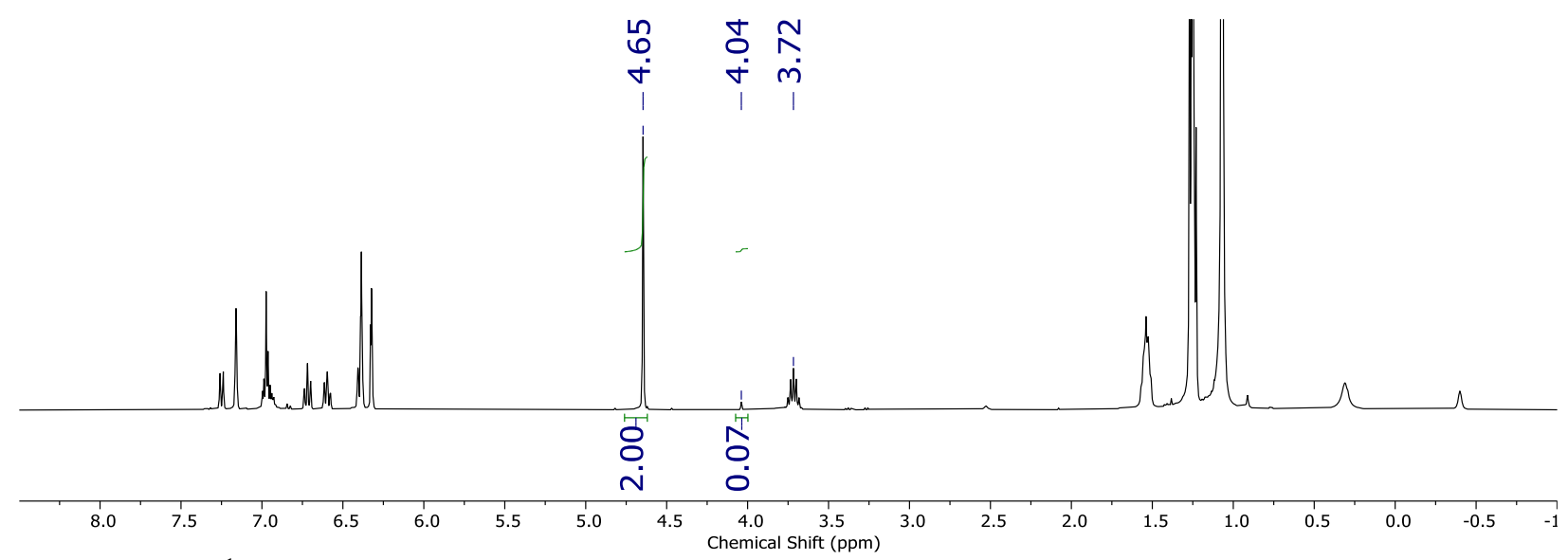

Figure S71. ${ }^{1} \mathrm{H}$ NMR spectrum $\left(400 \mathrm{MHz}, \mathrm{C}_{6} \mathrm{D}_{6}\right)$ of the one-photon photoredox catalysis sample for the reaction of ca. $10 \mathrm{~mol} \% \mathrm{~W}(\mathrm{CNDipp})_{6}$ and 1-(2-bromobenzyl)-pyrrole after 1-h irradiation. The following was determined from relative integration: $3.4 \%$ conversion, $\mathrm{TON}=0.3$. An intense isopropyl methine resonance for $\mathrm{W}(\mathrm{CNDipp})_{6}$ is still present $(3.72 \mathrm{ppm})$, with negligible decomposition observed.

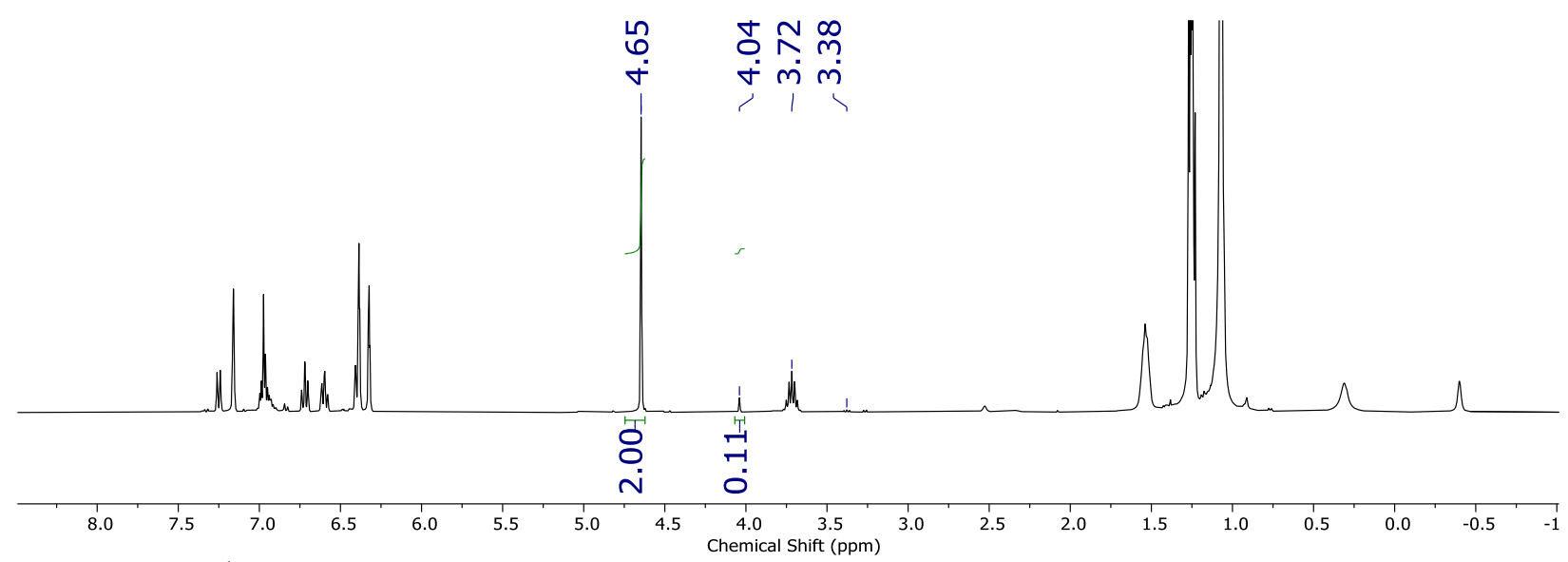

Figure S72. ${ }^{1} \mathrm{H}$ NMR spectrum $\left(400 \mathrm{MHz}, \mathrm{C}_{6} \mathrm{D}_{6}\right)$ of the one-photon photoredox catalysis sample for the reaction of ca. $10 \mathrm{~mol} \% \mathrm{~W}(\mathrm{CNDipp})_{6}$ and 1-(2-bromobenzyl)-pyrrole after 2-h irradiation. The following was determined from relative integration: $5.2 \%$ conversion, $\mathrm{TON}=0.5$. An intense isopropyl methine resonance for $\mathrm{W}(\mathrm{CNDipp})_{6}$ is still present $(3.72 \mathrm{ppm})$, with only a small amount of free CNDipp (3.38 ppm) observed. 


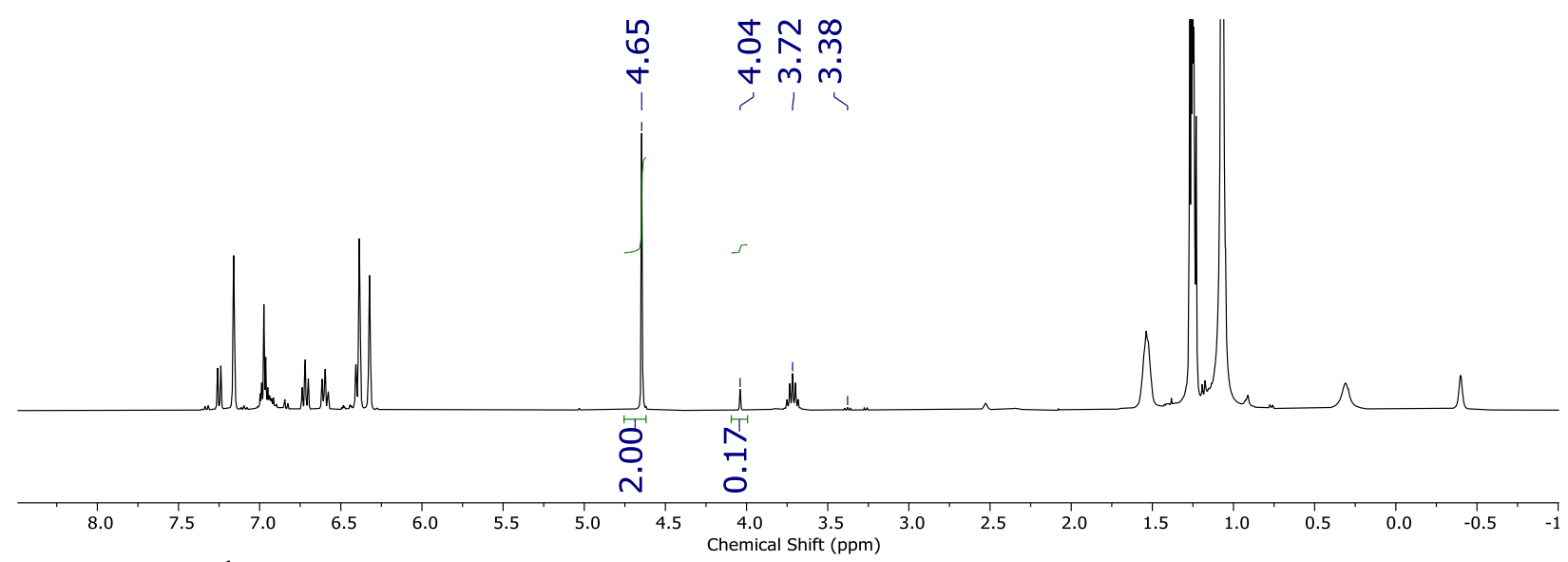

Figure S73. ${ }^{1} \mathrm{H}$ NMR spectrum $\left(400 \mathrm{MHz}, \mathrm{C}_{6} \mathrm{D}_{6}\right)$ of the one-photon photoredox catalysis sample for the reaction of ca. $10 \mathrm{~mol} \% \mathrm{~W}(\mathrm{CNDipp})_{6}$ and 1-(2-bromobenzyl)-pyrrole after 4-h irradiation. The following was determined from relative integration: $7.8 \%$ conversion, $\mathrm{TON}=0.7$. An intense isopropyl methine resonance for $\mathrm{W}(\mathrm{CNDipp})_{6}$ is still present $(3.72 \mathrm{ppm})$, with only a small amount of free CNDipp (3.38 ppm) observed.

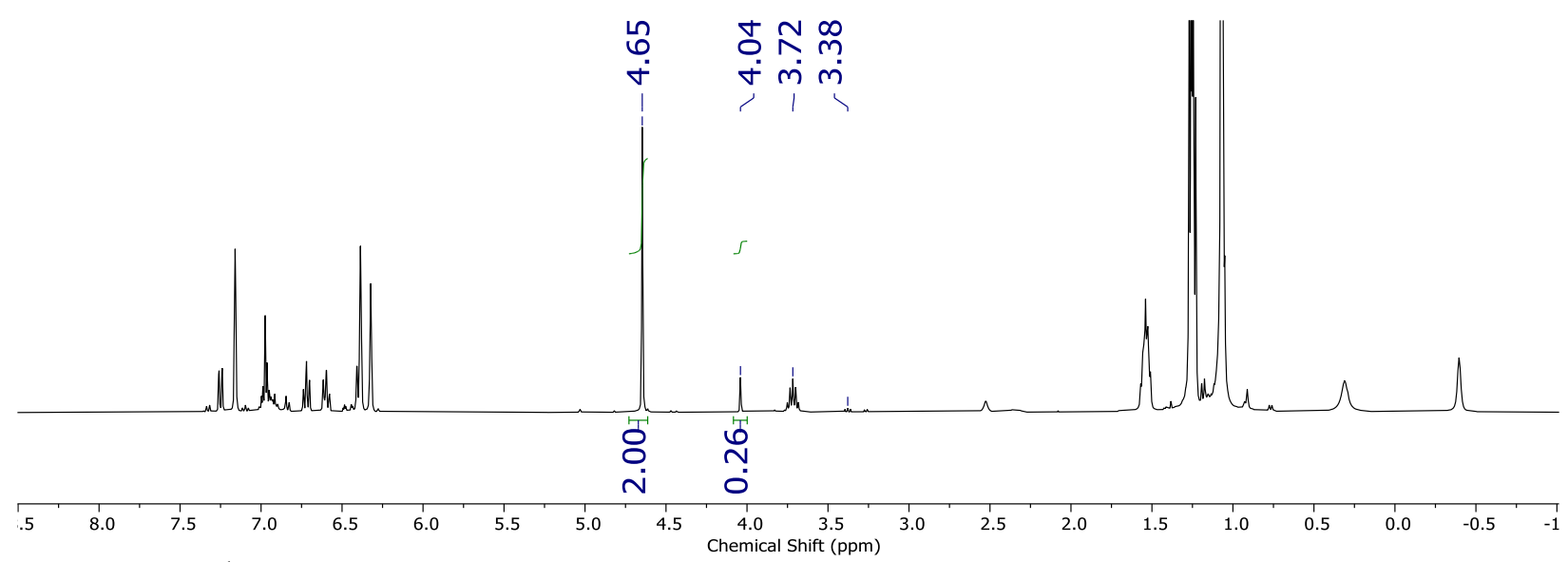

Figure S74. ${ }^{1} \mathrm{H}$ NMR spectrum $\left(400 \mathrm{MHz}, \mathrm{C}_{6} \mathrm{D}_{6}\right)$ of the one-photon photoredox catalysis sample for the reaction of ca. $10 \mathrm{~mol} \% \mathrm{~W}(\mathrm{CNDipp})_{6}$ and 1-(2-bromobenzyl)-pyrrole after 8-h irradiation. The following was determined from relative integration: $12 \%$ conversion, TON $=1.0$. An intense isopropyl methine resonance for $\mathrm{W}(\mathrm{CNDipp})_{6}$ is still present $(3.72 \mathrm{ppm})$, with only a small amount of free CNDipp (3.38 ppm) observed. 


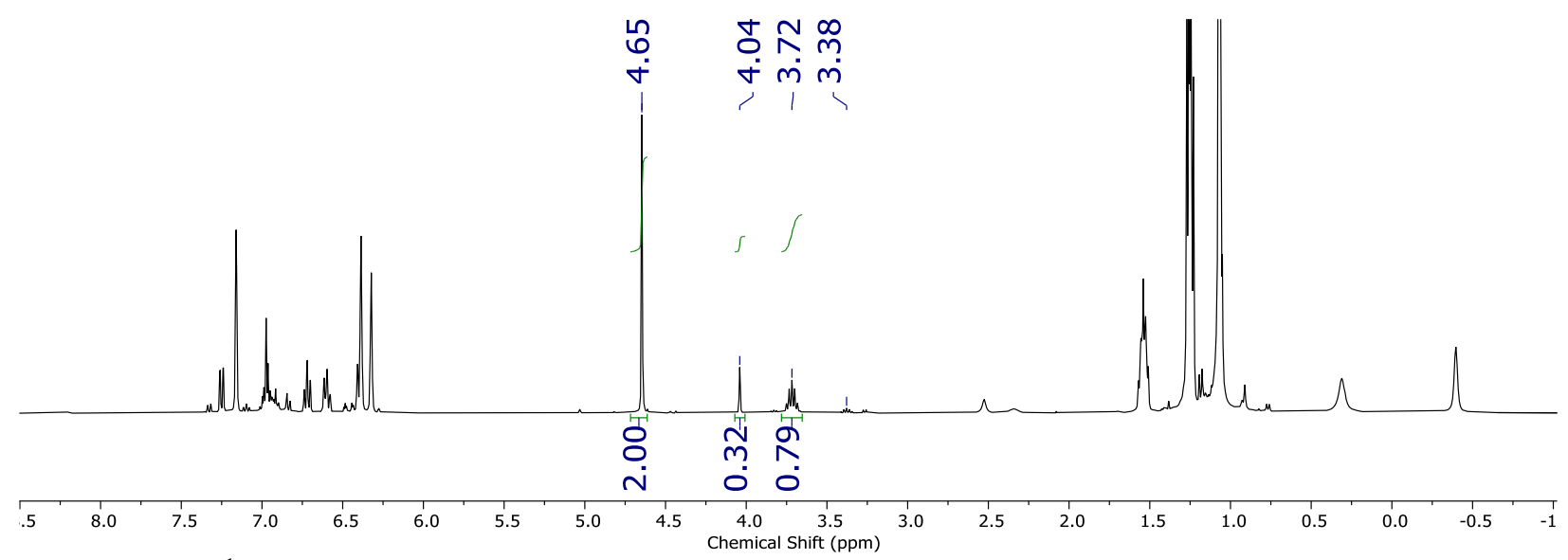

Figure S75. ${ }^{1} \mathrm{H}$ NMR spectrum $\left(400 \mathrm{MHz}, \mathrm{C}_{6} \mathrm{D}_{6}\right)$ of the one-photon photoredox catalysis sample for the reaction of ca. $10 \mathrm{~mol} \% \mathrm{~W}(\mathrm{CNDipp})_{6}$ and 1-(2-bromobenzyl)-pyrrole after 12-h irradiation. The following was determined from relative integration: $14 \%$ conversion, $\mathrm{TON}=1.2$. An intense isopropyl methine resonance for $\mathrm{W}(\mathrm{CNDipp})_{6}$ is still present $(3.72 \mathrm{ppm})$, with only a small amount of free CNDipp (3.38 ppm) observed.

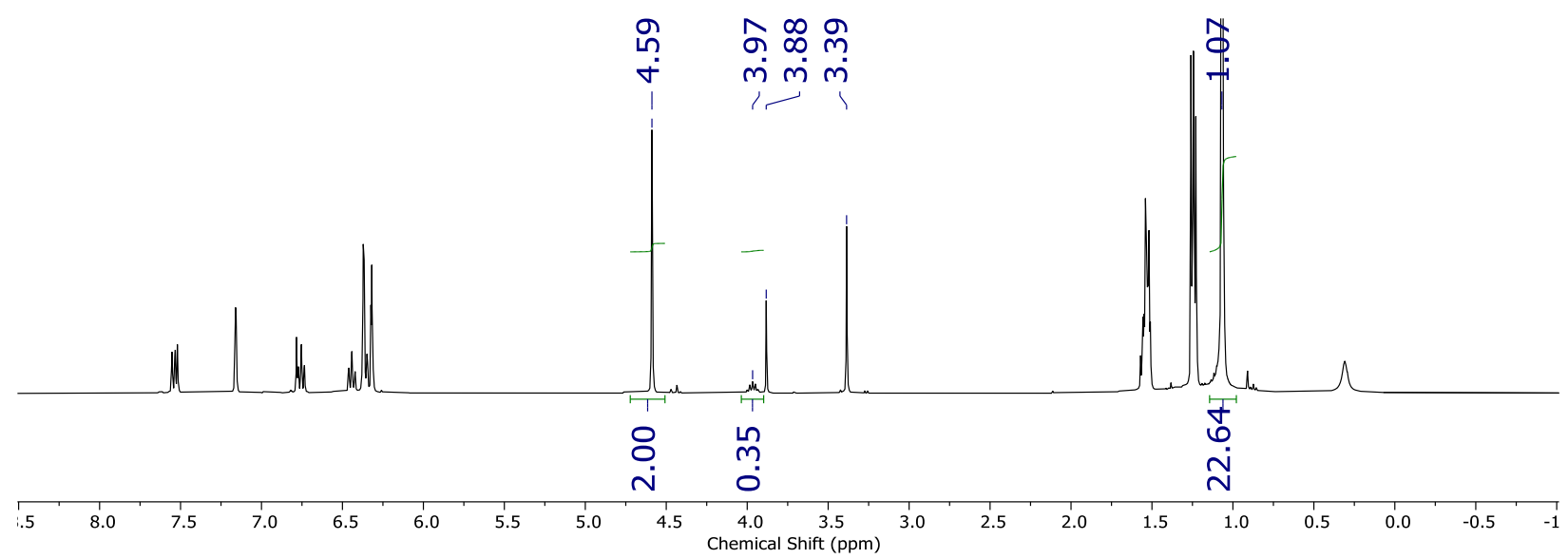

Figure S76. ${ }^{1} \mathrm{H}$ NMR spectrum $\left(400 \mathrm{MHz}, \mathrm{C}_{6} \mathrm{D}_{6}\right)$ of the one-photon photoredox catalysis sample for the reaction of ca. $2.5 \mathrm{~mol} \% \mathrm{~W}\left(\mathrm{CNDippPh}^{\mathrm{OMe} 3}\right)_{6}$ and 1-(2-iodobenzyl)-pyrrole prior to irradiation. The following concentrations/stoichiometries were determined from relative integration: $\mathrm{W}\left(\mathrm{CNDippPh}{ }^{\mathrm{OMe} 3}\right)_{6}=1.46 \mathrm{mM}, 2.92 \mathrm{~mol} \%$; TMP $=94.3 \mathrm{mM}, 1.89$ equiv. 


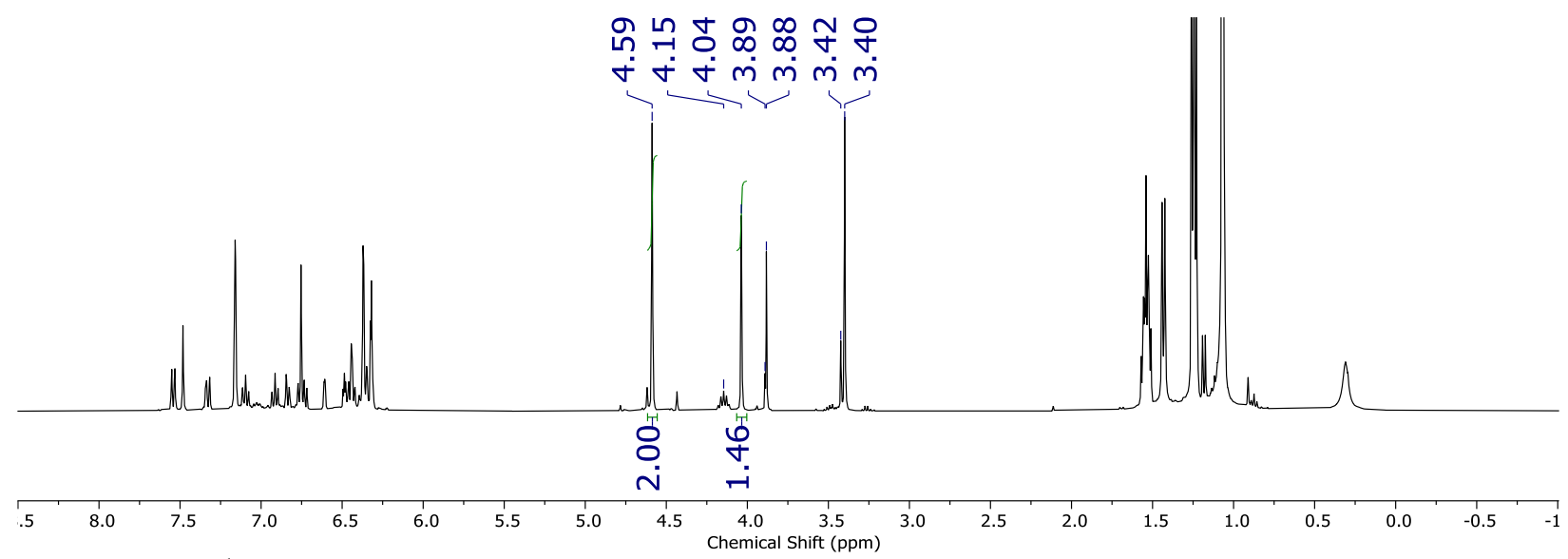

Figure S77. ${ }^{1} \mathrm{H}$ NMR spectrum $\left(400 \mathrm{MHz}, \mathrm{C}_{6} \mathrm{D}_{6}\right)$ of the one-photon photoredox catalysis sample for the reaction of ca. $2.5 \mathrm{~mol} \% \mathrm{~W}\left(\mathrm{CNDippPh}{ }^{\mathrm{OMe} 3}\right)_{6}$ and 1-(2-iodobenzyl)-pyrrole after 1-h irradiation. The following was determined from relative integration: $42 \%$ conversion, TON $=15$. Isopropyl resonances for $\mathrm{W}\left(\mathrm{CNDippPh}{ }^{\mathrm{OMe} 3}\right)_{6}$ are no longer observed, but new peaks are present that correspond to $\mathrm{WI}_{2}\left(\mathrm{CNDippPh}^{\mathrm{OMe} 3}\right)_{5}\left(3.40,3.88 \mathrm{ppm}\right.$ : $\mathrm{OCH}_{3}$; $4.15 \mathrm{ppm}$ : isopropyl methine) and free $\mathrm{CNDippPh}^{\mathrm{OMe} 3}$ (3.42, 3.89 ppm: $\left.\mathrm{OCH}_{3}\right)$. See Figures $\mathrm{S} 83-84$ for more details.

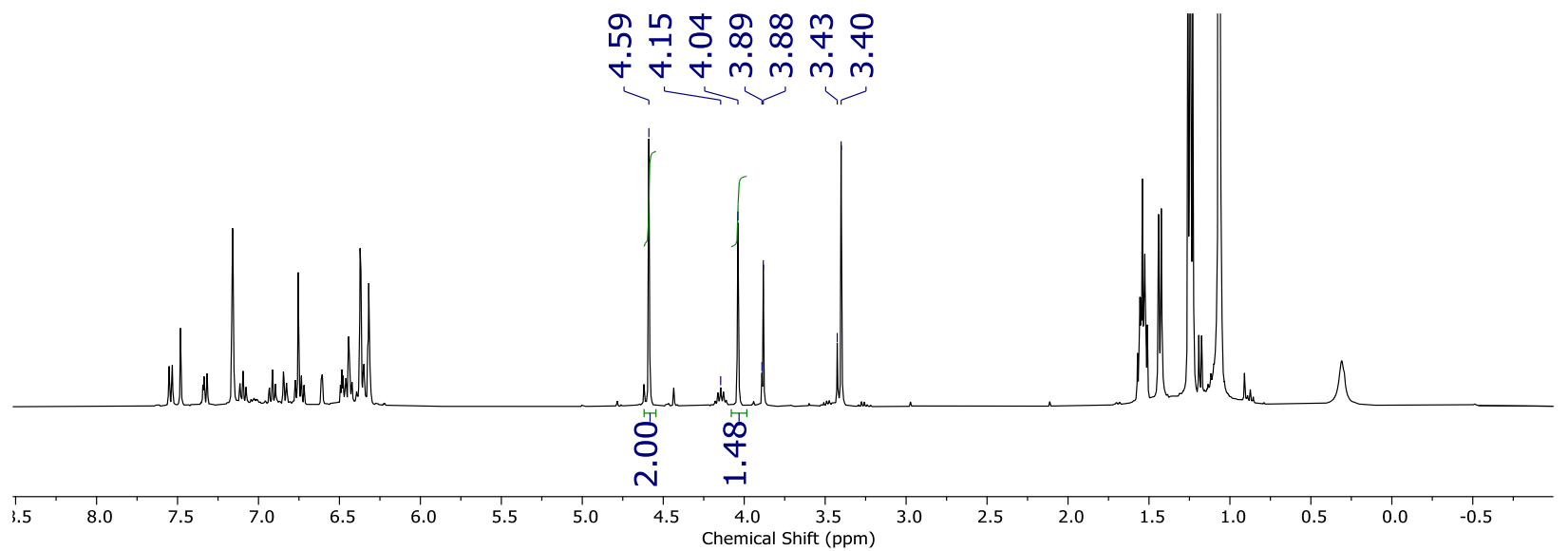

Figure S78. ${ }^{1} \mathrm{H}$ NMR spectrum $\left(400 \mathrm{MHz}, \mathrm{C}_{6} \mathrm{D}_{6}\right)$ of the one-photon photoredox catalysis sample for the reaction of ca. $2.5 \mathrm{~mol} \% \mathrm{~W}\left(\mathrm{CNDippPh}^{\mathrm{OMe} 3}\right)_{6}$ and 1-(2-iodobenzyl)-pyrrole after 2-h irradiation. No further substrate conversion is observed, consistent with complete $\mathrm{W}\left(\mathrm{CNDippPh}{ }^{\mathrm{OMe} 3}\right)_{6}$ consumption as suggested by ${ }^{1} \mathrm{H}$ NMR spectroscopy (Figure S77), UV-visible absorbance spectroscopy (Figure S79), and loss of sample luminescence. 


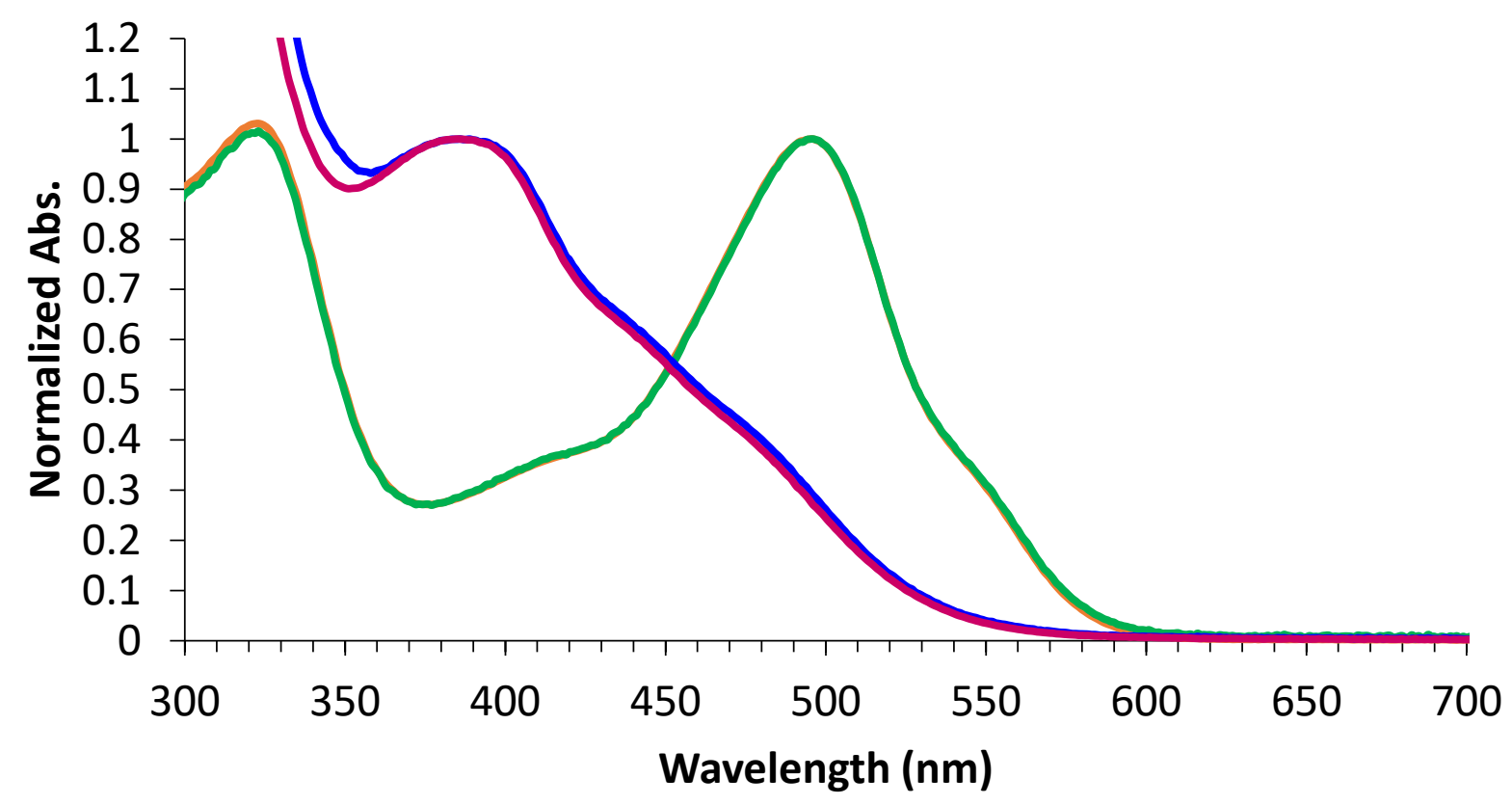

Figure S79. Overlaid UV-visible absorbance spectra of an authentic sample of W(CNDippPh $\left.{ }^{\mathrm{OMe} 3}\right)_{6}$ (orange, toluene), the pre-irradiated photoredox reaction mixture from Figure S76 (green, toluene), the post-photoredox reaction mixture from Figure S78 (blue, toluene), and an authentic sample of $\mathrm{WI}_{2}\left(\mathrm{CNDippPh}{ }^{\mathrm{OMe} 3}\right)_{5}$ (magenta, benzene).

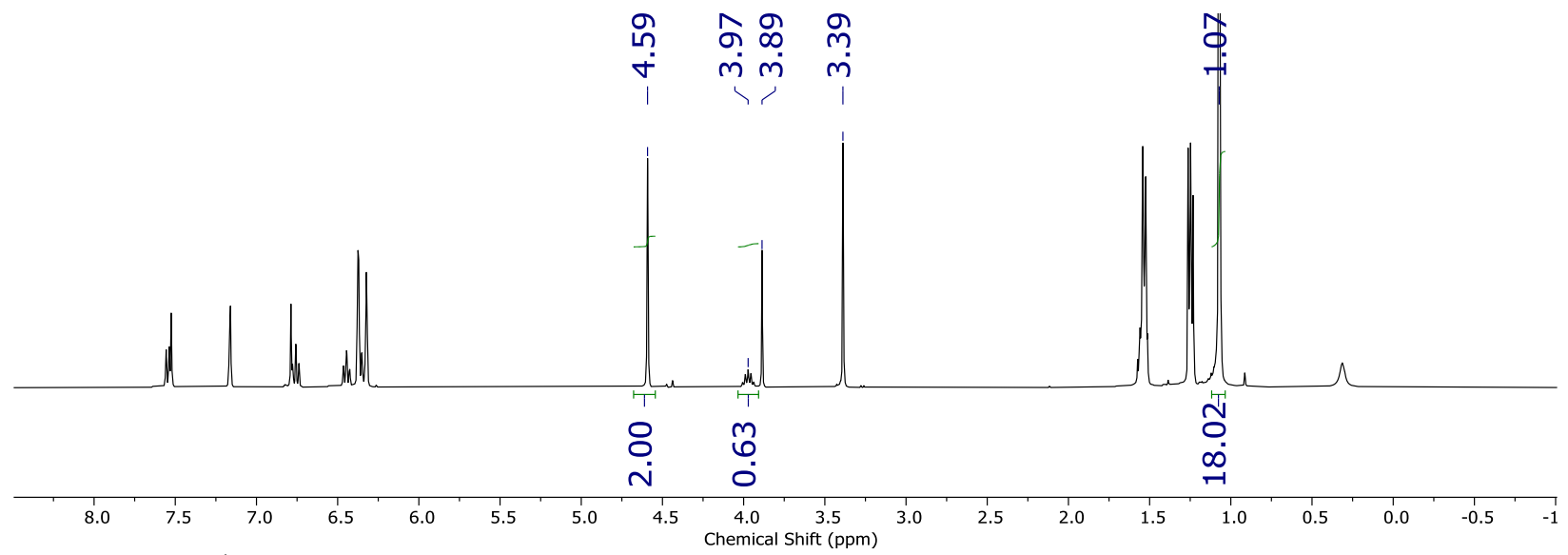

Figure S80. ${ }^{1} \mathrm{H}$ NMR spectrum $\left(400 \mathrm{MHz}, \mathrm{C}_{6} \mathrm{D}_{6}\right)$ of the one-photon photoredox catalysis sample for the reaction of ca. $5 \mathrm{~mol} \% \mathrm{~W}\left(\mathrm{CNDippPh}{ }^{\mathrm{OMe} 3}\right)_{6}$ and 1-(2-iodobenzyl)-pyrrole prior to irradiation. The following concentrations/stoichiometries were determined from relative integration: $\mathrm{W}\left(\mathrm{CNDippPh}{ }^{\mathrm{OMe} 3}\right)_{6}=2.63 \mathrm{mM}, 5.25 \mathrm{~mol} \%$; TMP $=75.1 \mathrm{mM}, 1.50$ equiv. 


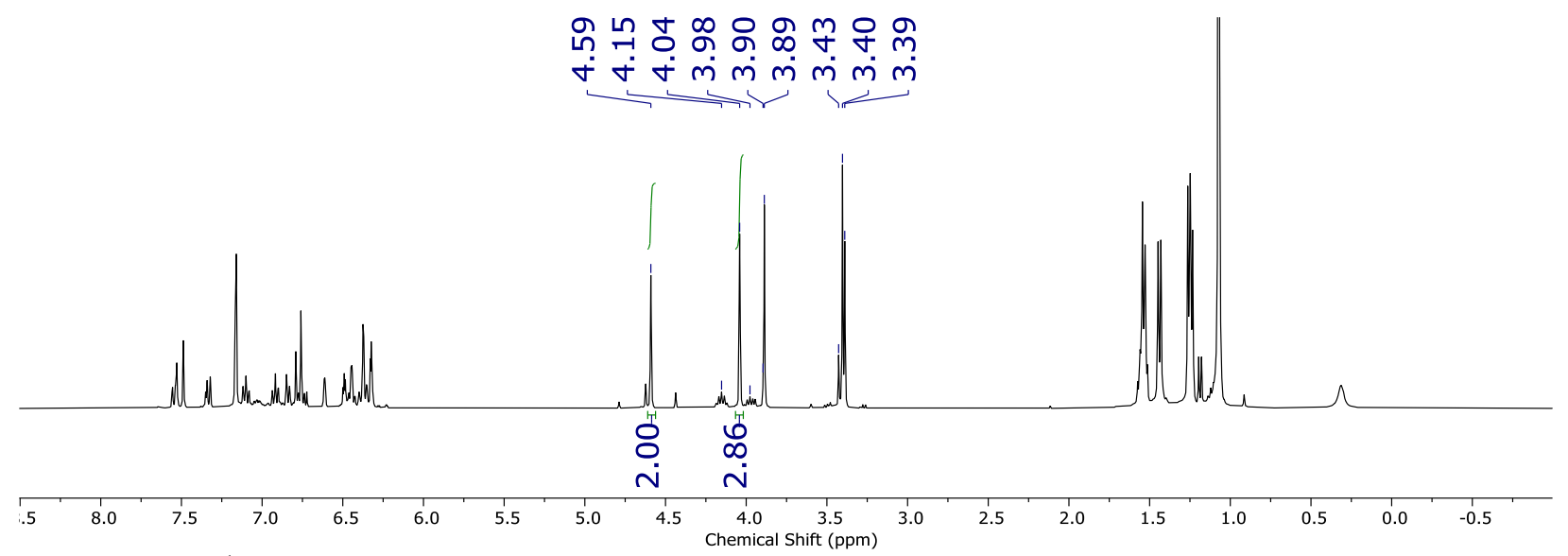

Figure S81. ${ }^{1} \mathrm{H}$ NMR spectrum $\left(400 \mathrm{MHz}, \mathrm{C}_{6} \mathrm{D}_{6}\right)$ of the one-photon photoredox catalysis sample for the reaction of ca. $5 \mathrm{~mol} \% \mathrm{~W}\left(\mathrm{CNDippPh}{ }^{\mathrm{OMe} 3}\right)_{6}$ and 1-(2-iodobenzyl)-pyrrole after 1-h irradiation. The following was determined from relative integration: 59\% conversion, TON $=11$. $\mathrm{W}\left(\mathrm{CNDippPh}{ }^{\mathrm{OMe} 3}\right)_{6}$ is still present $\left(3.39,3.89 \mathrm{ppm}\right.$ : $\mathrm{OCH}_{3} ; 3.98 \mathrm{ppm}$ : isopropyl methine $)$, but new peaks that correspond to $\mathrm{WI}_{2}\left(\mathrm{CNDippPh}^{\mathrm{OMe} 3}\right)_{5}\left(3.40,3.89 \mathrm{ppm}\right.$ : $\mathrm{OCH}_{3} ; 4.15 \mathrm{ppm}$ : isopropyl methine) and free $\mathrm{CNDippPh}^{\mathrm{OMe} 3}\left(3.43,3.90\right.$ ppm: $\left.\mathrm{OCH}_{3}\right)$ are also observed. See Figures S83-84 for more details.

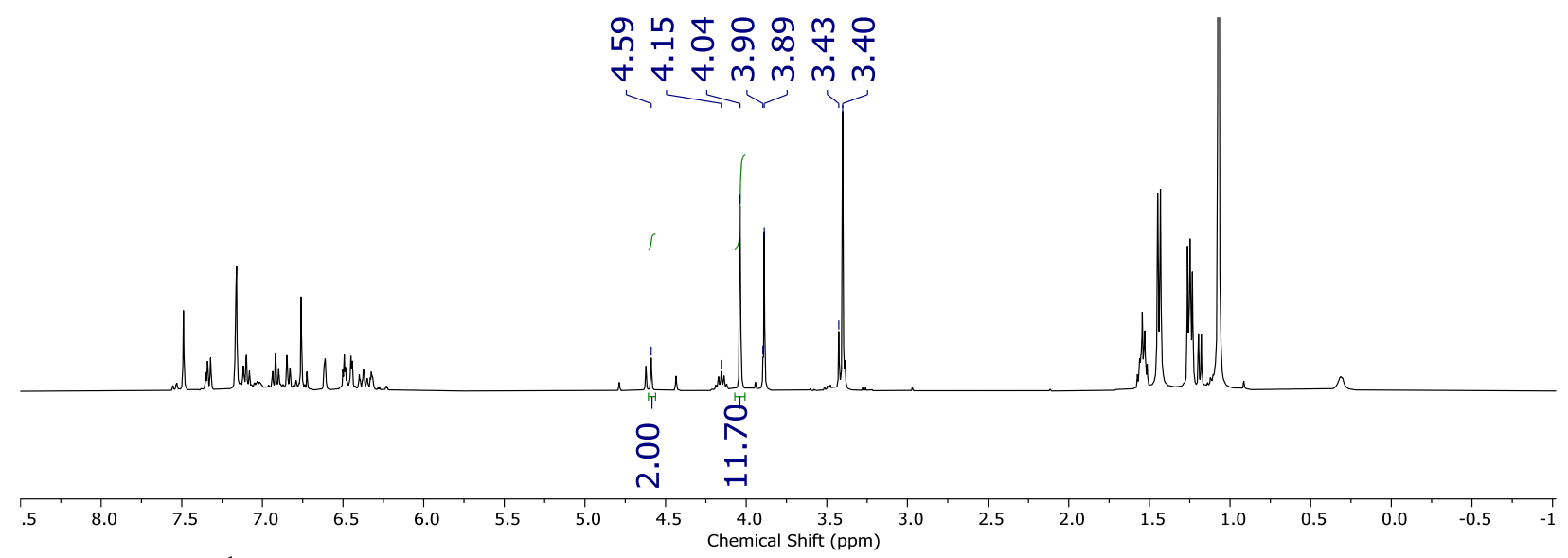

Figure S82. ${ }^{1} \mathrm{H}$ NMR spectrum $\left(400 \mathrm{MHz}, \mathrm{C}_{6} \mathrm{D}_{6}\right)$ of the one-photon photoredox catalysis sample for the reaction of ca. $5 \mathrm{~mol} \% \mathrm{~W}\left(\mathrm{CNDippPh}^{\mathrm{OMe} 3}\right)_{6}$ and 1-(2-iodobenzyl)-pyrrole after 4-h irradiation. The following was determined from relative integration: $85 \%$ conversion, TON $=16$. Resonances for $\mathrm{W}\left(\mathrm{CNDippPh}{ }^{\mathrm{OMe} 3}\right)_{6}$ are no longer observed, consistent with loss of sample luminescence. 


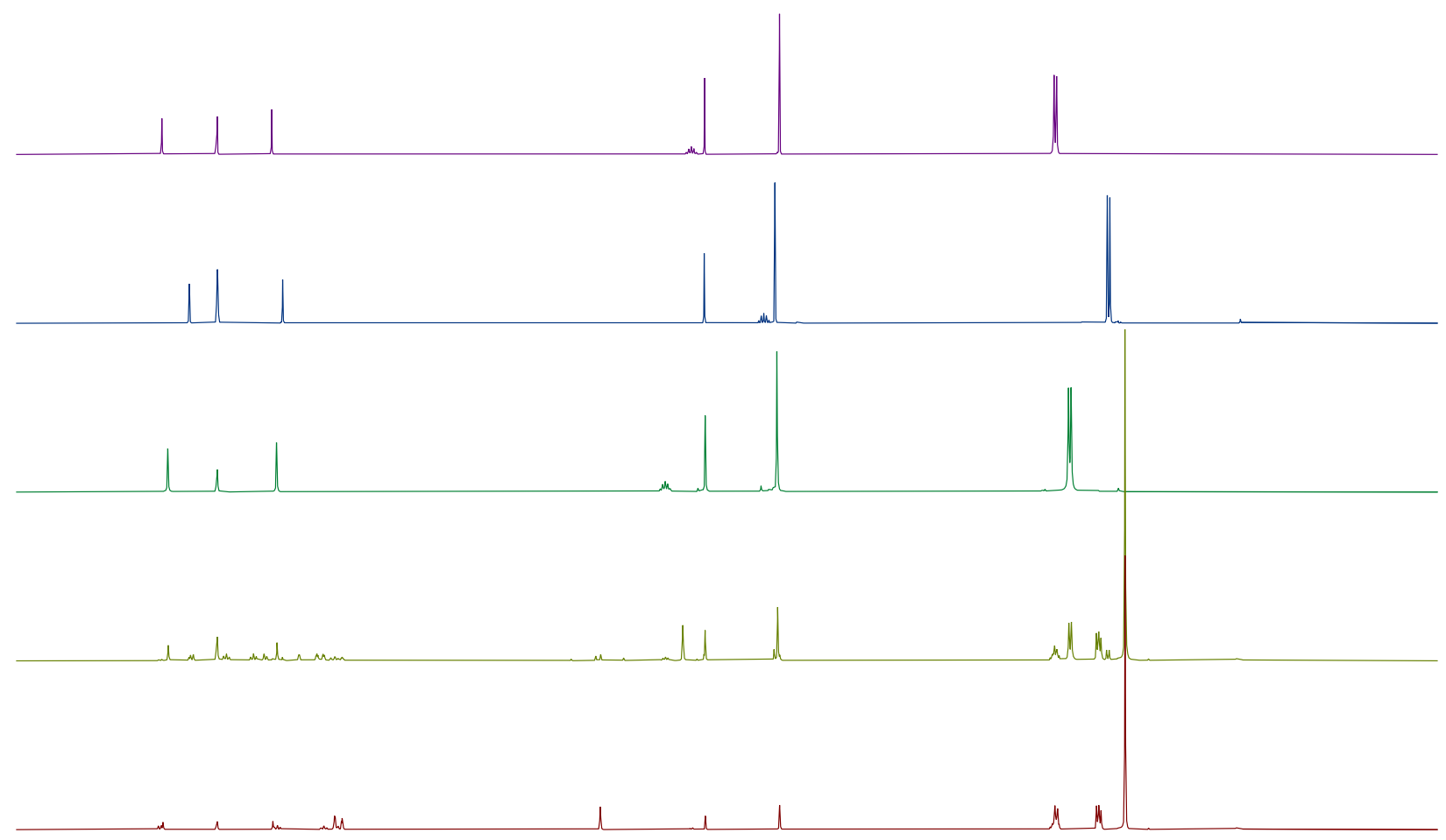

\begin{tabular}{lllllllllllllllllll}
\hline .5 & 8.0 & 7.5 & 7.0 & 6.5 & 6.0 & 5.5 & 5.0 & 4.5 & $\begin{array}{c}1 \\
\text { Chemical Shift (ppm) }\end{array}$ & 3.0 & 2.5 & 2.0 & 1.5 & 1.0 & 0.5 & 0.0 & -0.5 & -1
\end{tabular}

Figure S83. Stacked ${ }^{1} \mathrm{H}$ NMR spectra $\left(400 \mathrm{MHz}, \mathrm{C}_{6} \mathrm{D}_{6}\right)$ of an authentic sample of $\mathrm{W}\left(\mathrm{CNDippPh}{ }^{\mathrm{OMe} 3}\right)_{6}$ (purple), an authentic sample of $\mathrm{CNDippPh}^{\mathrm{OMe} 3}$ (blue), an authentic sample of $\mathrm{WI}_{2}\left(\mathrm{CNDippPh}^{\mathrm{OMe}}\right)_{5}$ (green), the post-photoredox reaction mixture from Figure S82 (yellowgreen), and the pre-irradiated photoredox reaction mixture from Figure S80 (red).
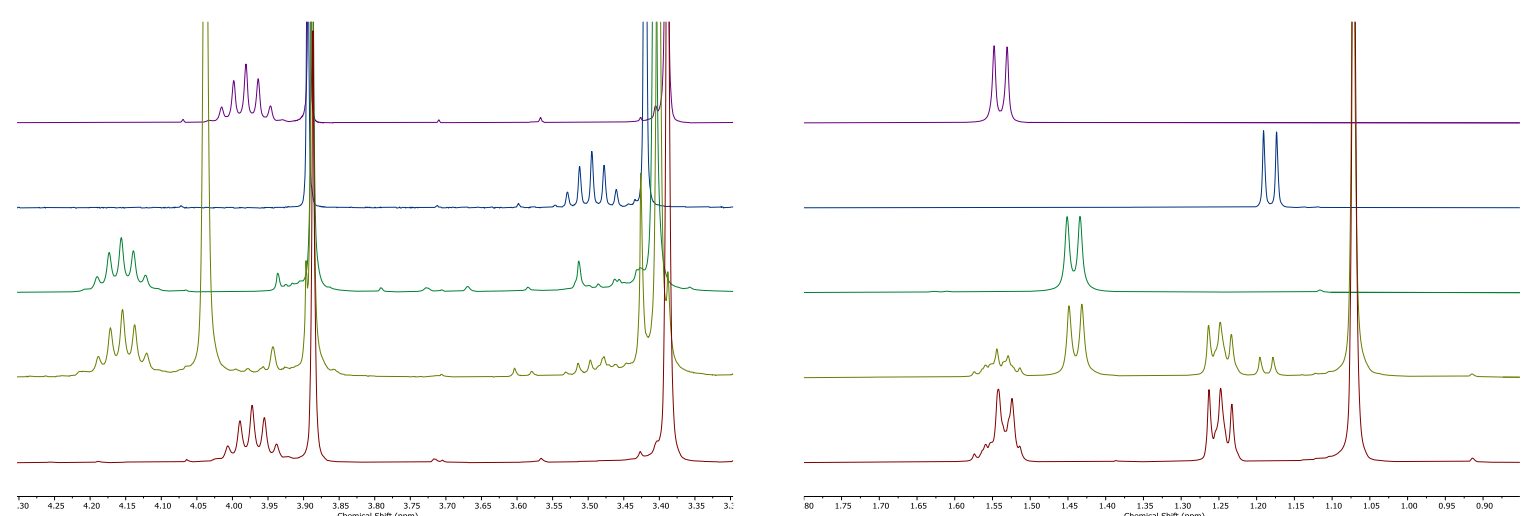

Figure S84. Zoom-ins of the ${ }^{1} \mathrm{H}$ NMR spectra from Figure S83 showing the isopropyl regions. 


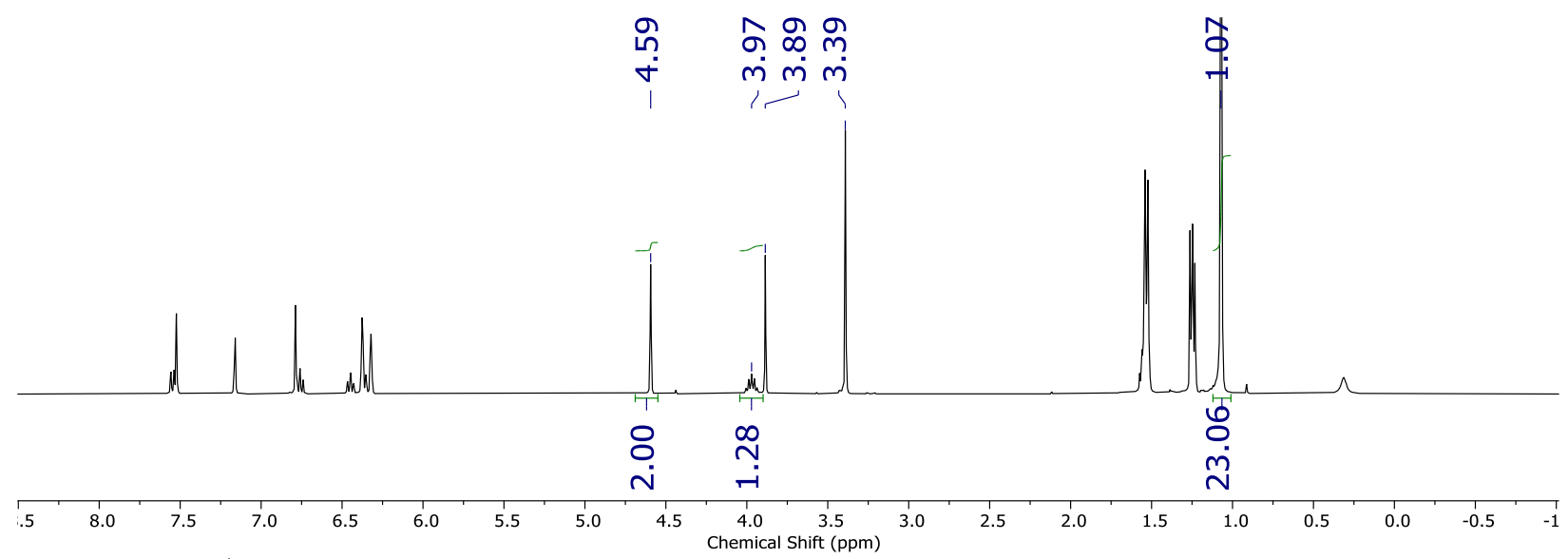

Figure S85. ${ }^{1} \mathrm{H}$ NMR spectrum $\left(400 \mathrm{MHz}, \mathrm{C}_{6} \mathrm{D}_{6}\right)$ of the one-photon photoredox catalysis sample for the reaction of ca. $10 \mathrm{~mol} \% \mathrm{~W}\left(\mathrm{CNDippPh}{ }^{\mathrm{OMe} 3}\right)_{6}$ and 1-(2-iodobenzyl)-pyrrole prior to irradiation. The following concentrations/stoichiometries were determined from relative integration: $\mathrm{W}\left(\mathrm{CNDippPh}{ }^{\mathrm{OMe} 3}\right)_{6}=5.33 \mathrm{mM}, 10.7 \mathrm{~mol} \%$; TMP $=96.1 \mathrm{mM}, 1.92$ equiv.

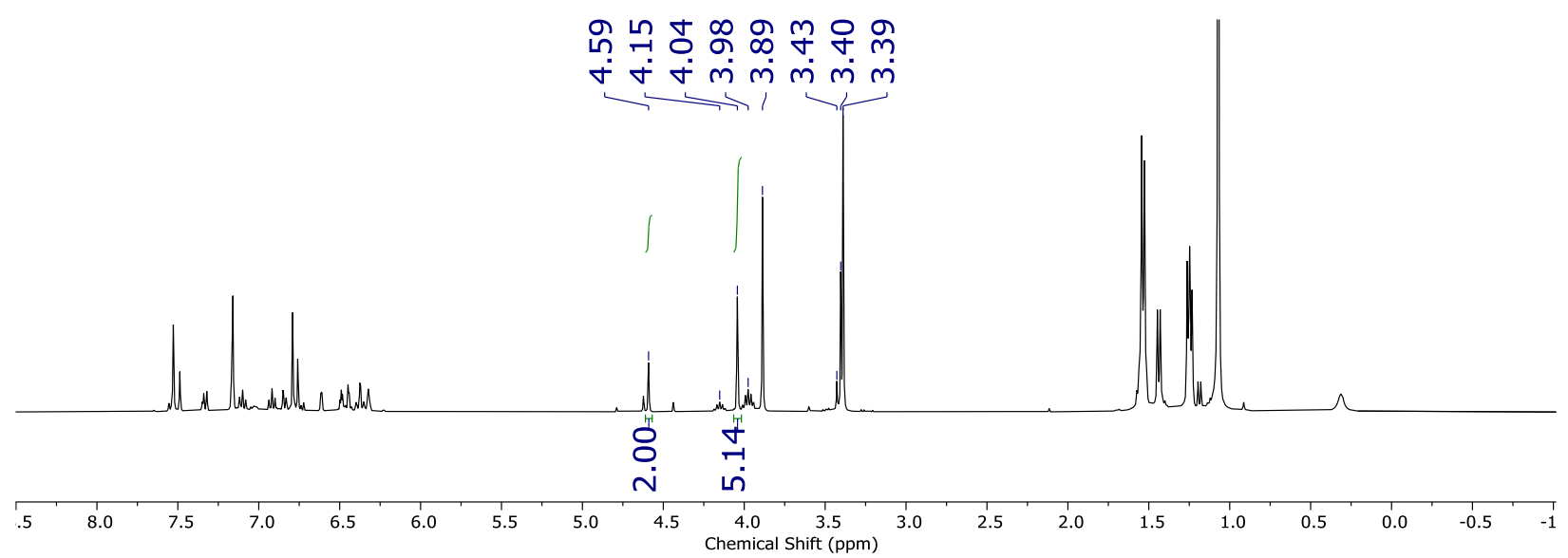

Figure S86. ${ }^{1} \mathrm{H}$ NMR spectrum $\left(400 \mathrm{MHz}, \mathrm{C}_{6} \mathrm{D}_{6}\right)$ of the one-photon photoredox catalysis sample for the reaction of ca. $10 \mathrm{~mol} \% \mathrm{~W}\left(\mathrm{CNDippPh}{ }^{\mathrm{OMe} 3}\right)_{6}$ and 1-(2-iodobenzyl)-pyrrole after 1-h irradiation. The following was determined from relative integration: $72 \%$ conversion, $\mathrm{TON}=6.7$. The resonances for $\mathrm{W}\left(\mathrm{CNDippPh}{ }^{\mathrm{OMe} 3}\right)_{6}\left(3.39 \mathrm{ppm}\right.$ : $\mathrm{OCH}_{3} ; 3.98 \mathrm{ppm}$ : isopropyl methine) are more intense than those of $\mathrm{WI}_{2}\left(\mathrm{CNDippPh}^{\mathrm{OMe} 3}\right)_{5}\left(3.40: \mathrm{OCH}_{3} ; 4.15 \mathrm{ppm}\right.$ : isopropyl methine) and free $\mathrm{CNDippPh}{ }^{\mathrm{OMe} 3}$ (3.43 ppm: $\mathrm{OCH}_{3}$ ), suggesting a significant amount of photocatalyst is still present. 


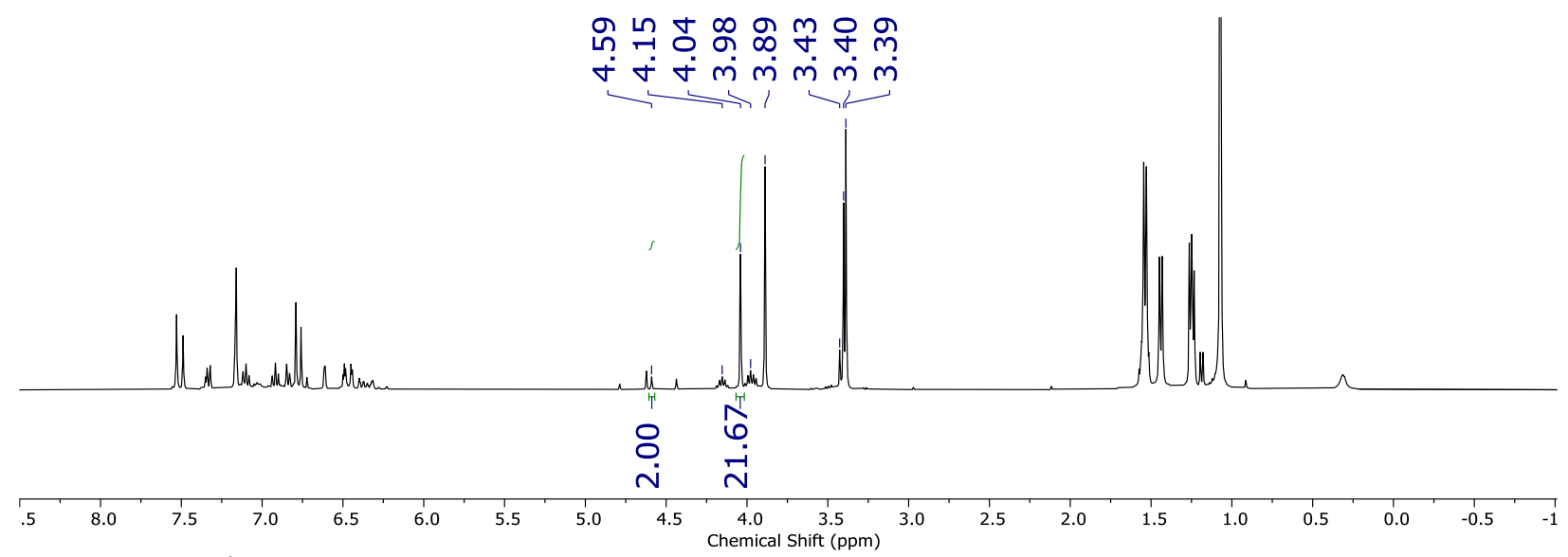

Figure S87. ${ }^{1} \mathrm{H}$ NMR spectrum $\left(400 \mathrm{MHz}, \mathrm{C}_{6} \mathrm{D}_{6}\right)$ of the one-photon photoredox catalysis sample for the reaction of ca. $10 \mathrm{~mol} \% \mathrm{~W}\left(\mathrm{CNDippPh}{ }^{\mathrm{OMe} 3}\right)_{6}$ and 1-(2-iodobenzyl)-pyrrole after 2-h irradiation. The following was determined from relative integration: $92 \%$ conversion, TON = 8.6. The resonances for $\mathrm{W}\left(\mathrm{CNDippPh}{ }^{\mathrm{OMe} 3}\right)_{6}\left(3.39 \mathrm{ppm}\right.$ : $\mathrm{OCH}_{3} ; 3.98 \mathrm{ppm}$ : isopropyl methine) are still more intense than those of $\mathrm{WI}_{2}\left(\mathrm{CNDippPh}^{\mathrm{OMe} 3}\right)_{5}\left(3.40: \mathrm{OCH}_{3} ; 4.15 \mathrm{ppm}\right.$ : isopropyl methine) and free $\mathrm{CNDippPh}{ }^{\mathrm{OMe} 3}$ (3.43 ppm: $\mathrm{OCH}_{3}$ ), suggesting a significant amount of photocatalyst is still present.

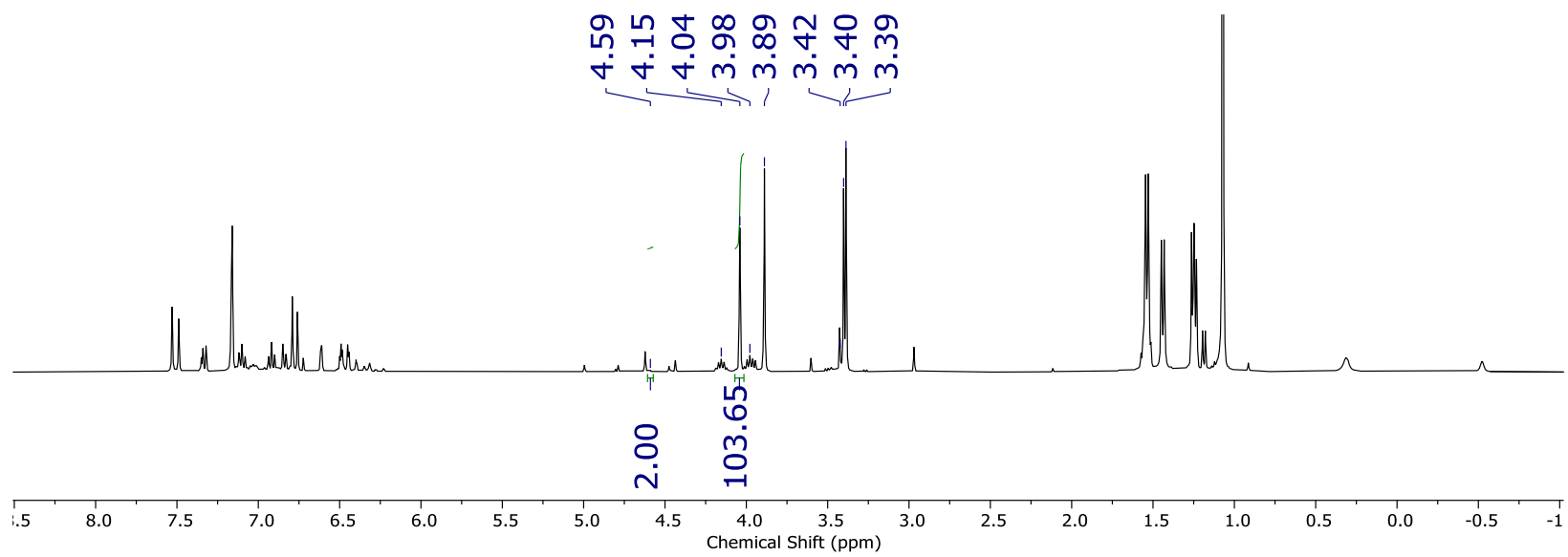

Figure S88. ${ }^{1} \mathrm{H}$ NMR spectrum $\left(400 \mathrm{MHz}, \mathrm{C}_{6} \mathrm{D}_{6}\right)$ of the one-photon photoredox catalysis sample for the reaction of ca. $10 \mathrm{~mol} \% \mathrm{~W}\left(\mathrm{CNDippPh}{ }^{\mathrm{OMe} 3}\right)_{6}$ and 1-(2-iodobenzyl)-pyrrole after 4-h irradiation. The following was determined from relative integration: $98 \%$ conversion, $\mathrm{TON}=9.2$. A significant amount of $\mathrm{W}\left(\mathrm{CNDippPh}{ }^{\mathrm{OMe} 3}\right)_{6}$ photocatalyst is still present. See Figures S89-91 for details. 


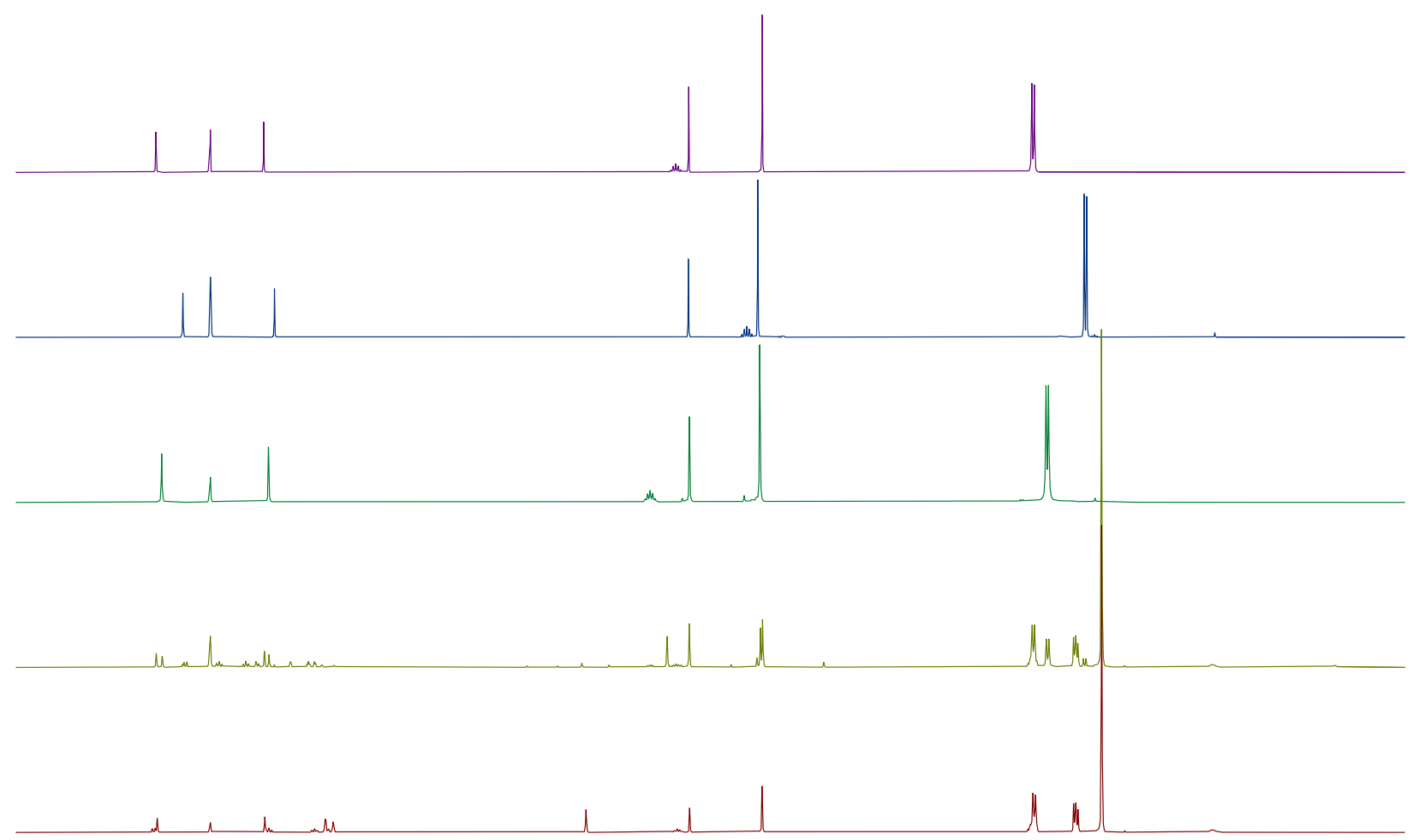

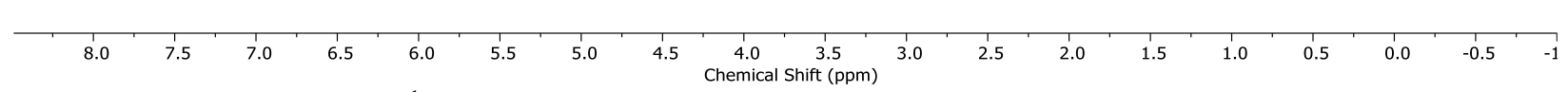

Figure S89. Stacked ${ }^{1} \mathrm{H}$ NMR spectra $\left(400 \mathrm{MHz}, \mathrm{C}_{6} \mathrm{D}_{6}\right)$ of an authentic sample of $\mathrm{W}\left(\mathrm{CNDippPh}{ }^{\mathrm{OMe} 3}\right)_{6}$ (purple), an authentic sample of $\mathrm{CNDippPh}^{\mathrm{OMe} 3}$ (blue), an authentic sample of $\mathrm{WI}_{2}\left(\mathrm{CNDippPh}^{\mathrm{OMe}}\right)_{5}$ (green), the post-photoredox reaction mixture from Figure S88 (yellowgreen), and the pre-irradiated photoredox reaction mixture from Figure S85 (red).
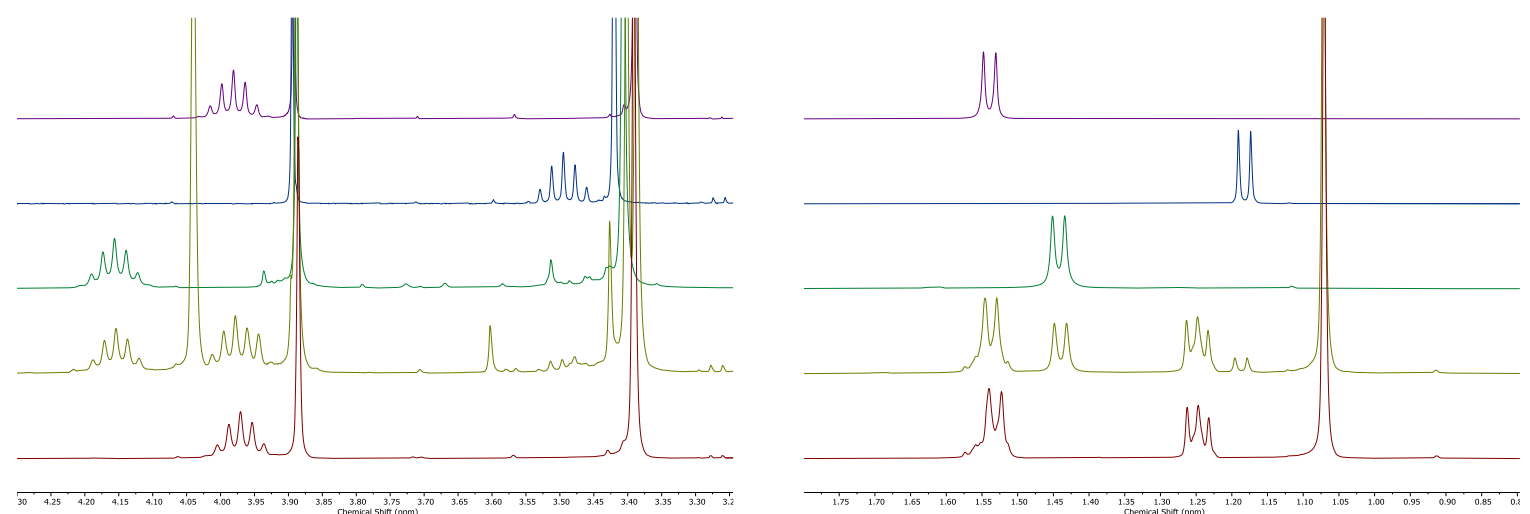

Figure S90. Zoom-ins of the ${ }^{1} \mathrm{H}$ NMR spectra from Figure S89 showing the isopropyl regions. 


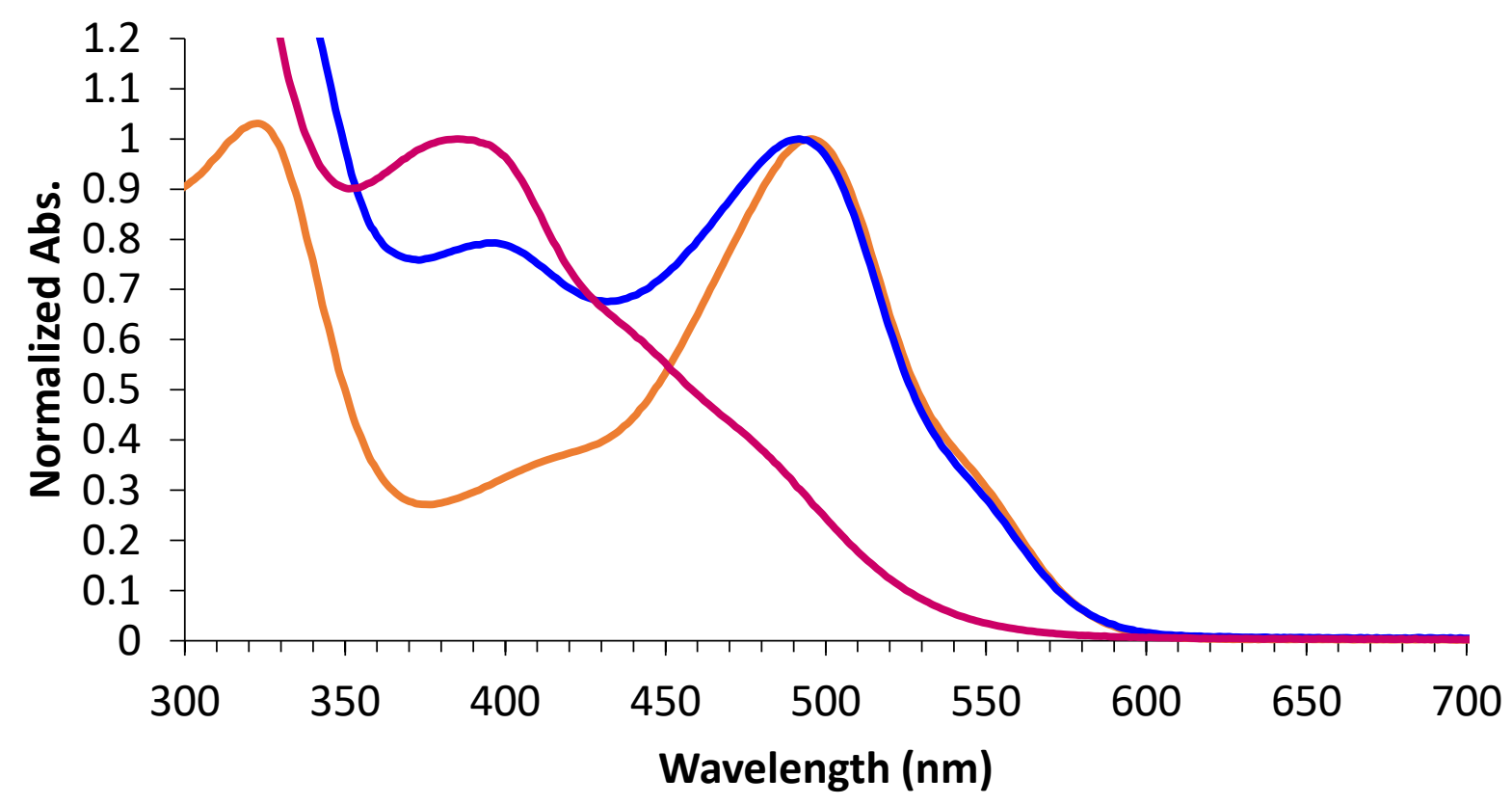

Figure S91. Overlaid UV-visible absorbance spectra of an authentic sample of W(CNDippPh $\left.{ }^{\mathrm{OMe} 3}\right)_{6}$ (orange, toluene), the post-photoredox reaction mixture from Figure S88 (blue, toluene), and an authentic sample of $\mathrm{WI}_{2}\left(\mathrm{CNDippPh}{ }^{\mathrm{OMe} 3}\right)_{5}$ (magenta, benzene).

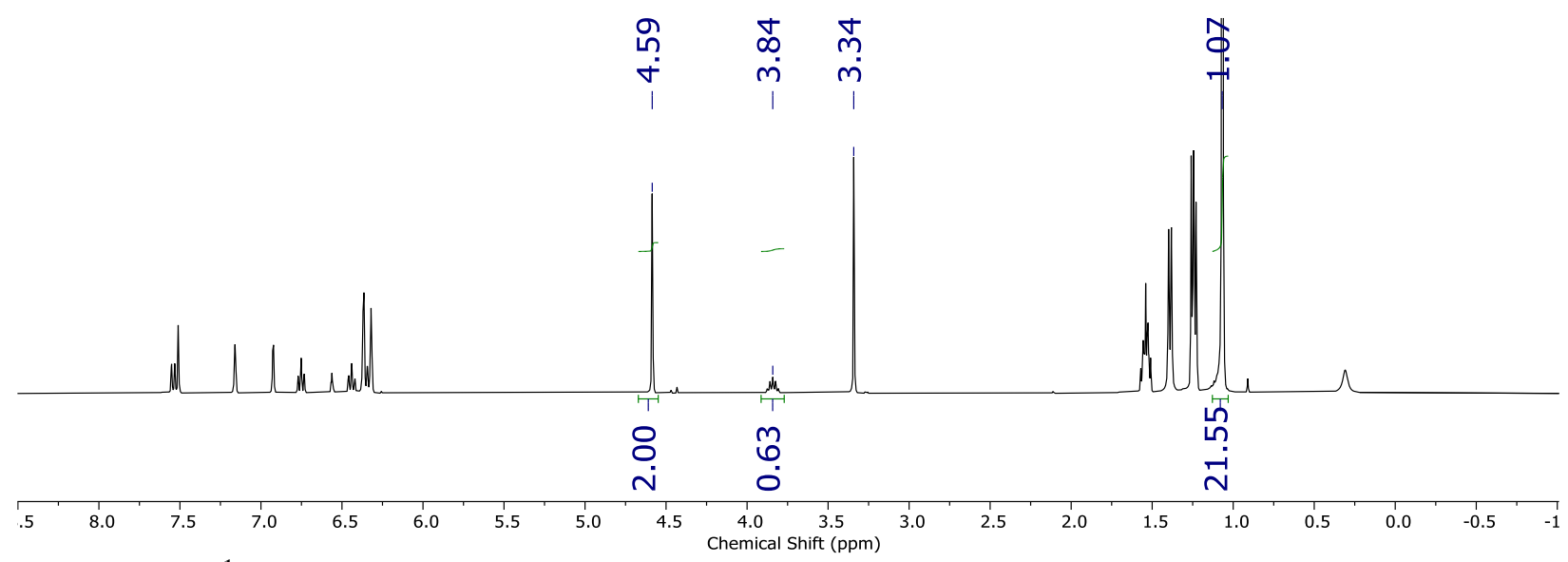

Figure S92. ${ }^{1} \mathrm{H}$ NMR spectrum $\left(400 \mathrm{MHz}, \mathrm{C}_{6} \mathrm{D}_{6}\right)$ of the one-photon photoredox catalysis sample for the reaction of ca. $5 \mathrm{~mol} \% \mathrm{~W}\left(\mathrm{CNDippPh}{ }^{\mathrm{OMe}}\right)_{6}$ and 1-(2-iodobenzyl)-pyrrole prior to irradiation. The following concentrations/stoichiometries were determined from relative integration: $\mathrm{W}\left(\mathrm{CNDippPh}{ }^{\mathrm{OMe} 2}\right)_{6}=2.63 \mathrm{mM}, 5.25 \mathrm{~mol} \%$; TMP $=89.8 \mathrm{mM}, 1.80$ equiv. 


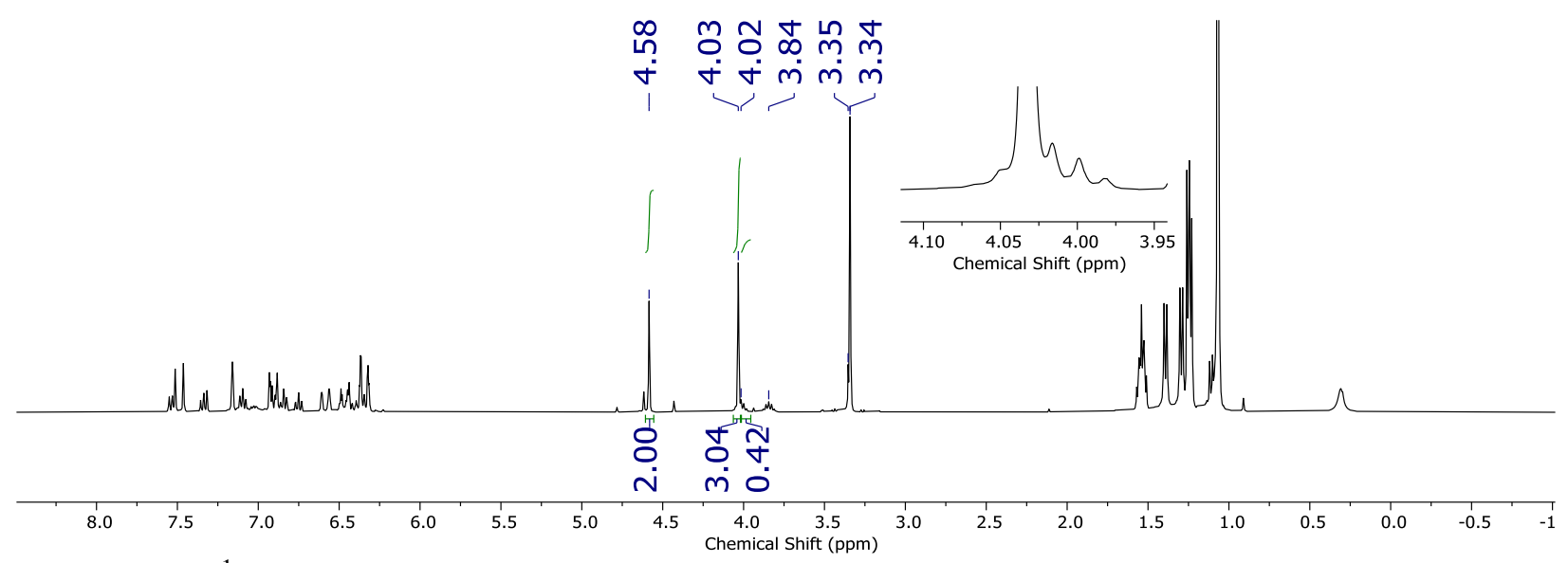

Figure S93. ${ }^{1} \mathrm{H}$ NMR spectrum $\left(400 \mathrm{MHz}, \mathrm{C}_{6} \mathrm{D}_{6}\right)$ of the one-photon photoredox catalysis sample for the reaction of ca. $5 \mathrm{~mol} \% \mathrm{~W}\left(\mathrm{CNDippPh}{ }^{\mathrm{OMe} 2}\right)_{6}$ and 1-(2-iodobenzyl)-pyrrole after 1-h irradiation. The following was determined from relative integration: $57 \%$ conversion, TON $=11$. An isopropyl methine resonance for $\mathrm{W}\left(\mathrm{CNDippPh}{ }^{\mathrm{OMe} 2}\right)_{6}(3.84 \mathrm{ppm})$ suggests the photocatalyst is still present. *Note: As shown in the inset, the benzylic resonance at $4.03 \mathrm{ppm}$ corresponding to the cyclized organic product overlaps with an isopropyl methine resonance centered at $4.02 \mathrm{ppm}$. To calculate the conversion, half of the latter resonance was integrated $(0.42)$ and subtracted from the integration of the former $(3.04-0.42=2.62)$.

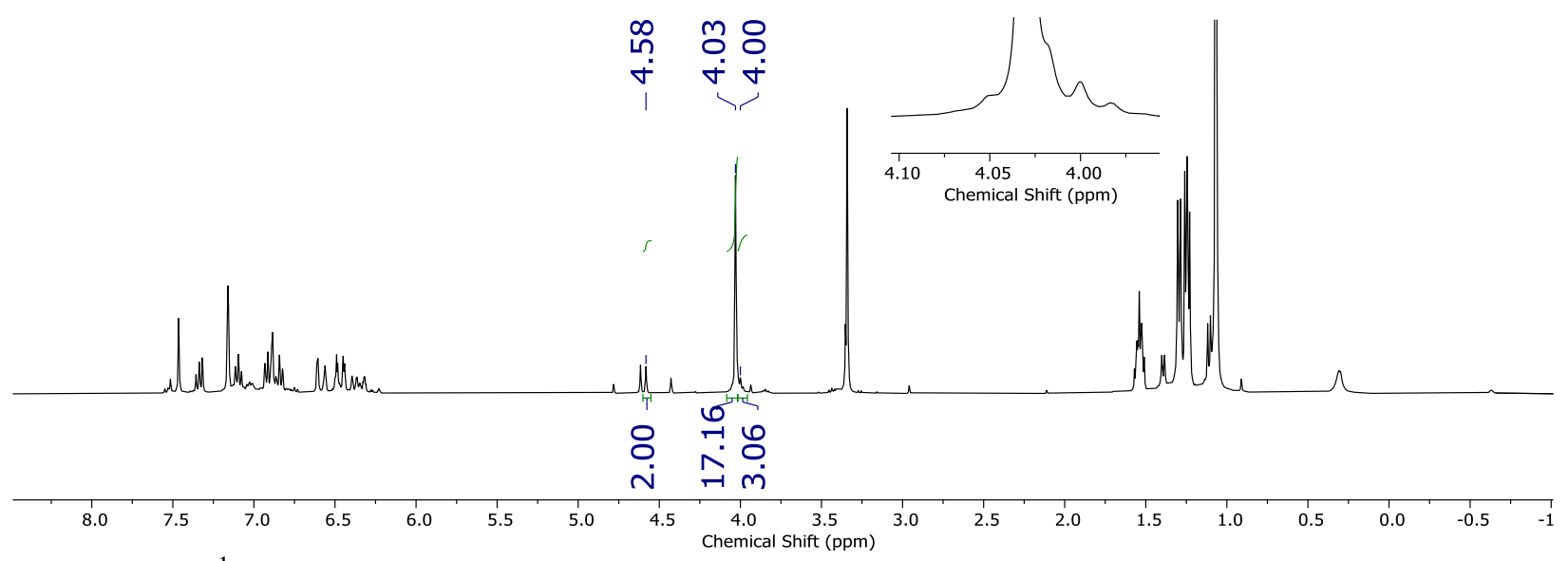

Figure S94. ${ }^{1} \mathrm{H}$ NMR spectrum $\left(400 \mathrm{MHz}, \mathrm{C}_{6} \mathrm{D}_{6}\right)$ of the one-photon photoredox catalysis sample for the reaction of ca. $5 \mathrm{~mol} \% \mathrm{~W}\left(\mathrm{CNDippPh}{ }^{\mathrm{OMe} 2}\right)_{6}$ and 1-(2-iodobenzyl)-pyrrole after 4-h irradiation. The following was determined from relative integration: $88 \%$ conversion, TON $=17$. The isopropyl methine resonance attributable to $\mathrm{W}\left(\mathrm{CNDippPh}{ }^{\mathrm{OMe} 2}\right)_{6}$ is no longer observed, consistent with complete $\mathrm{W}\left(\mathrm{CNDippPh}{ }^{\mathrm{OMe} 2}\right)_{6}$ consumption as suggested by UV-visible absorbance spectroscopy (Figure S95) and loss of sample luminescence. *Note: As shown in the inset, the benzylic resonance at $4.03 \mathrm{ppm}$ corresponding to the cyclized organic product overlaps with an isopropyl methine resonance centered at $4.00 \mathrm{ppm}$. To calculate the conversion, half of the latter resonance was integrated (3.06) and subtracted from the integration of the former $(17.16-3.06=$ 14.10). 


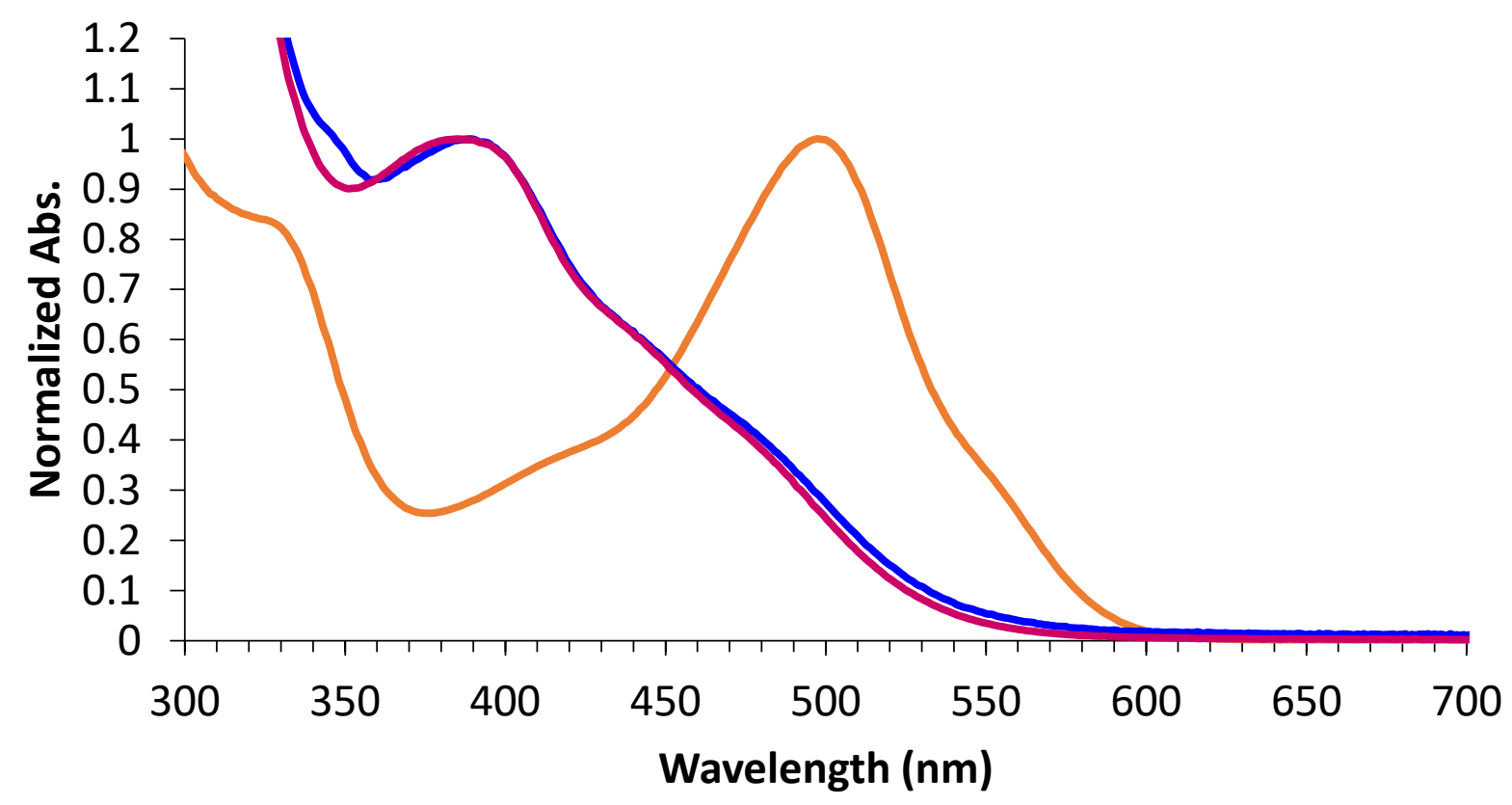

Figure S95. Overlaid UV-visible absorbance spectra of an authentic sample of W(CNDippPh $\left.{ }^{\mathrm{OMe} 2}\right)_{6}$ (orange, toluene), the post-photoredox reaction mixture from Figure S94 (blue, toluene), and an authentic sample of $\mathrm{WI}_{2}\left(\mathrm{CNDippPh}{ }^{\mathrm{OMe} 3}\right)_{5}$ (magenta, benzene).

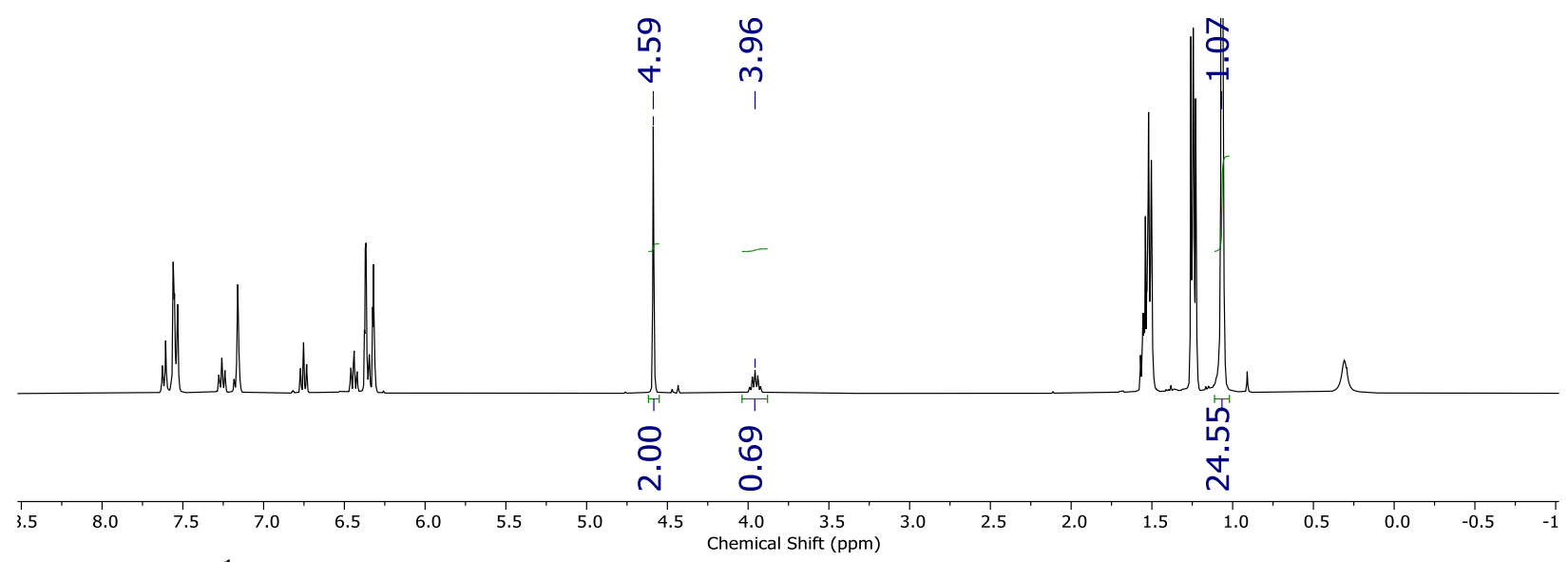

Figure S96. ${ }^{1} \mathrm{H}$ NMR spectrum $\left(400 \mathrm{MHz}, \mathrm{C}_{6} \mathrm{D}_{6}\right)$ of the one-photon photoredox catalysis sample for the reaction of ca. $5 \mathrm{~mol} \% \mathrm{~W}\left(\mathrm{CNDippPh}{ }^{\mathrm{Ph}}\right)_{6}$ and 1-(2-iodobenzyl)-pyrrole prior to irradiation. The following concentrations/stoichiometries were determined from relative integration: $\mathrm{W}\left(\mathrm{CNDippPh}{ }^{\mathrm{Ph}}\right)_{6}=2.88 \mathrm{mM}, 5.75 \mathrm{~mol} \%$; TMP $=102 \mathrm{mM}, 2.05$ equiv. 


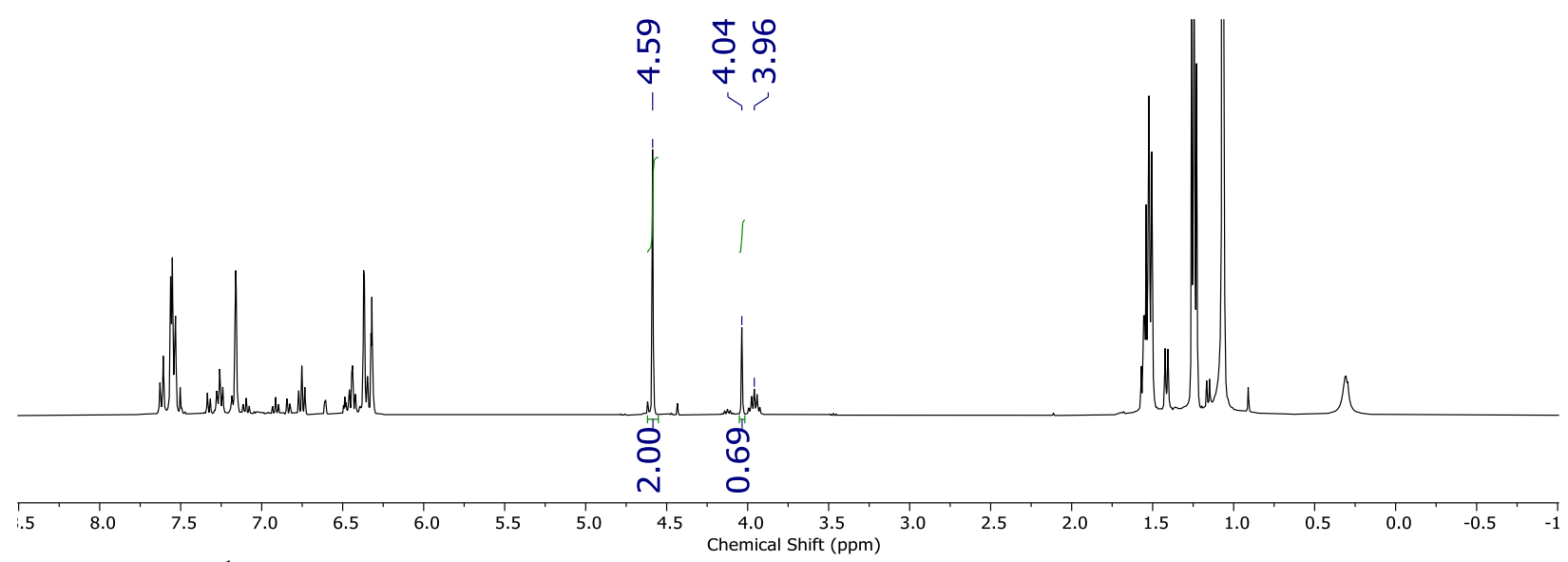

Figure S97. ${ }^{1} \mathrm{H}$ NMR spectrum $\left(400 \mathrm{MHz}, \mathrm{C}_{6} \mathrm{D}_{6}\right)$ of the one-photon photoredox catalysis sample for the reaction of ca. $5 \mathrm{~mol} \% \mathrm{~W}\left(\mathrm{CNDippPh}{ }^{\mathrm{Ph}}\right)_{6}$ and 1-(2-iodobenzyl)-pyrrole after 1-h irradiation. The following was determined from relative integration: $26 \%$ conversion, $\mathrm{TON}=4.5$. An intense isopropyl methine resonance for $\mathrm{W}\left(\mathrm{CNDippPh}{ }^{\mathrm{Ph}}\right)_{6}(3.96 \mathrm{ppm})$ suggests the photocatalyst is still present.

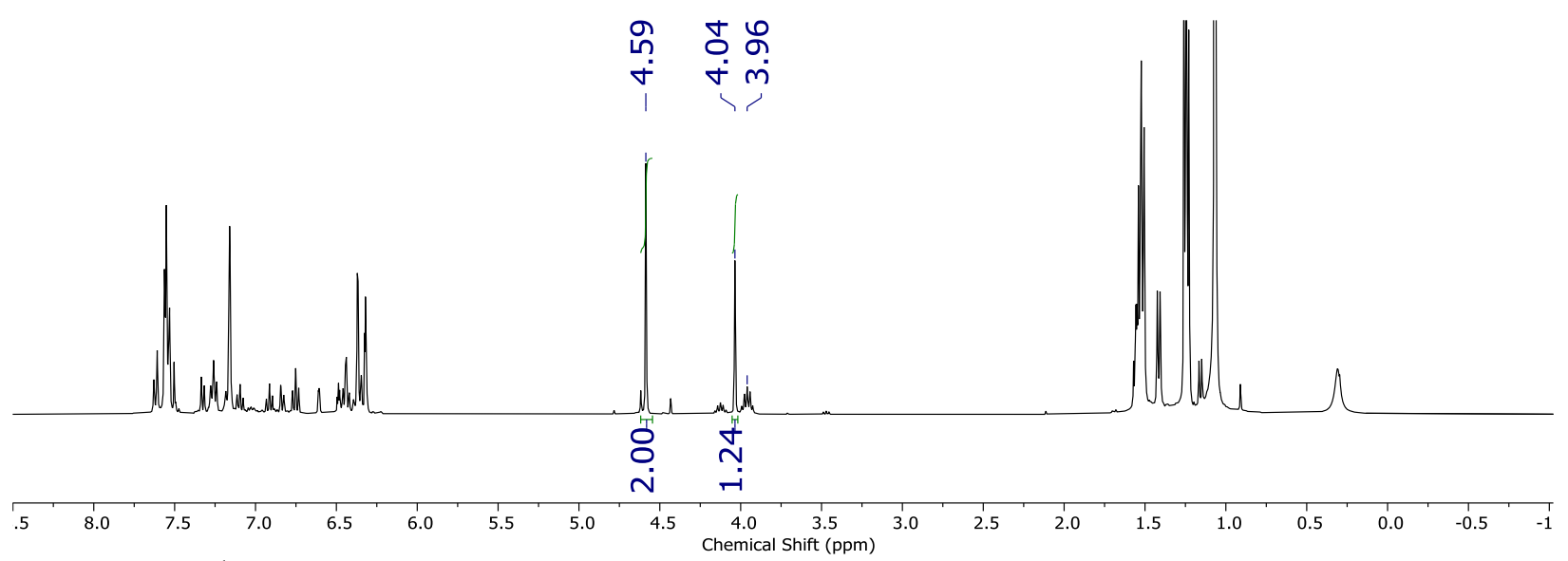

Figure S98. ${ }^{1} \mathrm{H}$ NMR spectrum $\left(400 \mathrm{MHz}, \mathrm{C}_{6} \mathrm{D}_{6}\right)$ of the one-photon photoredox catalysis sample for the reaction of ca. $5 \mathrm{~mol} \% \mathrm{~W}\left(\mathrm{CNDippPh}{ }^{\mathrm{Ph}}\right)_{6}$ and 1-(2-iodobenzyl)-pyrrole after 2-h irradiation. The following was determined from relative integration: $38 \%$ conversion, $\mathrm{TON}=6.7$. An intense isopropyl methine resonance for $\mathrm{W}\left(\mathrm{CNDippPh}{ }^{\mathrm{Ph}}\right)_{6}(3.96 \mathrm{ppm})$ suggests the photocatalyst is still present. 


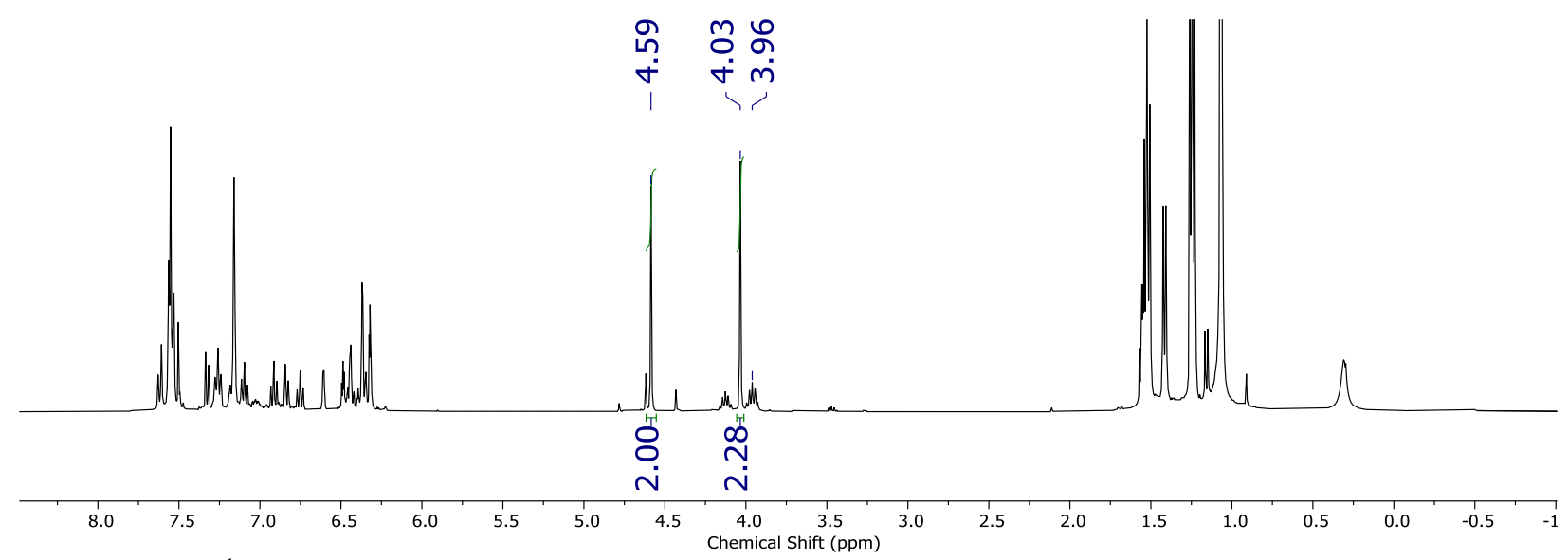

Figure S99. ${ }^{1} \mathrm{H}$ NMR spectrum $\left(400 \mathrm{MHz}, \mathrm{C}_{6} \mathrm{D}_{6}\right)$ of the one-photon photoredox catalysis sample for the reaction of ca. $5 \mathrm{~mol} \% \mathrm{~W}\left(\mathrm{CNDippPh}{ }^{\mathrm{Ph}}\right)_{6}$ and 1-(2-iodobenzyl)-pyrrole after 4-h irradiation. The following was determined from relative integration: $53 \%$ conversion, $\mathrm{TON}=9.3$. An isopropyl methine resonance for $\mathrm{W}\left(\mathrm{CNDippPh}^{\mathrm{Ph}}\right)_{6}(3.96 \mathrm{ppm})$ suggests the photocatalyst is still present.

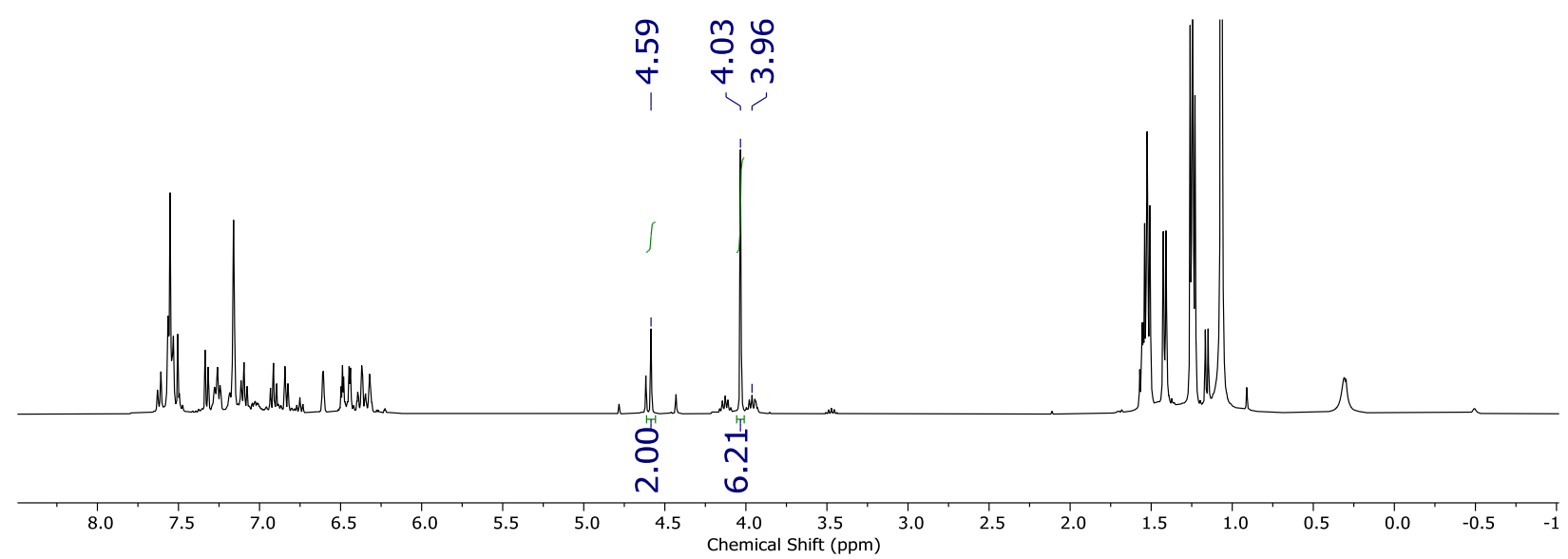

Figure S100. ${ }^{1} \mathrm{H}$ NMR spectrum $\left(400 \mathrm{MHz}, \mathrm{C}_{6} \mathrm{D}_{6}\right)$ of the one-photon photoredox catalysis sample for the reaction of ca. $5 \mathrm{~mol} \% \mathrm{~W}\left(\mathrm{CNDippPh}{ }^{\mathrm{Ph}}\right)_{6}$ and 1-(2-iodobenzyl)-pyrrole after 8-h irradiation. The following was determined from relative integration: $76 \%$ conversion, TON $=13$. An isopropyl methine resonance for $\mathrm{W}\left(\mathrm{CNDippPh}{ }^{\mathrm{Ph}}\right)_{6}(3.96 \mathrm{ppm})$ suggests the photocatalyst is still present. 


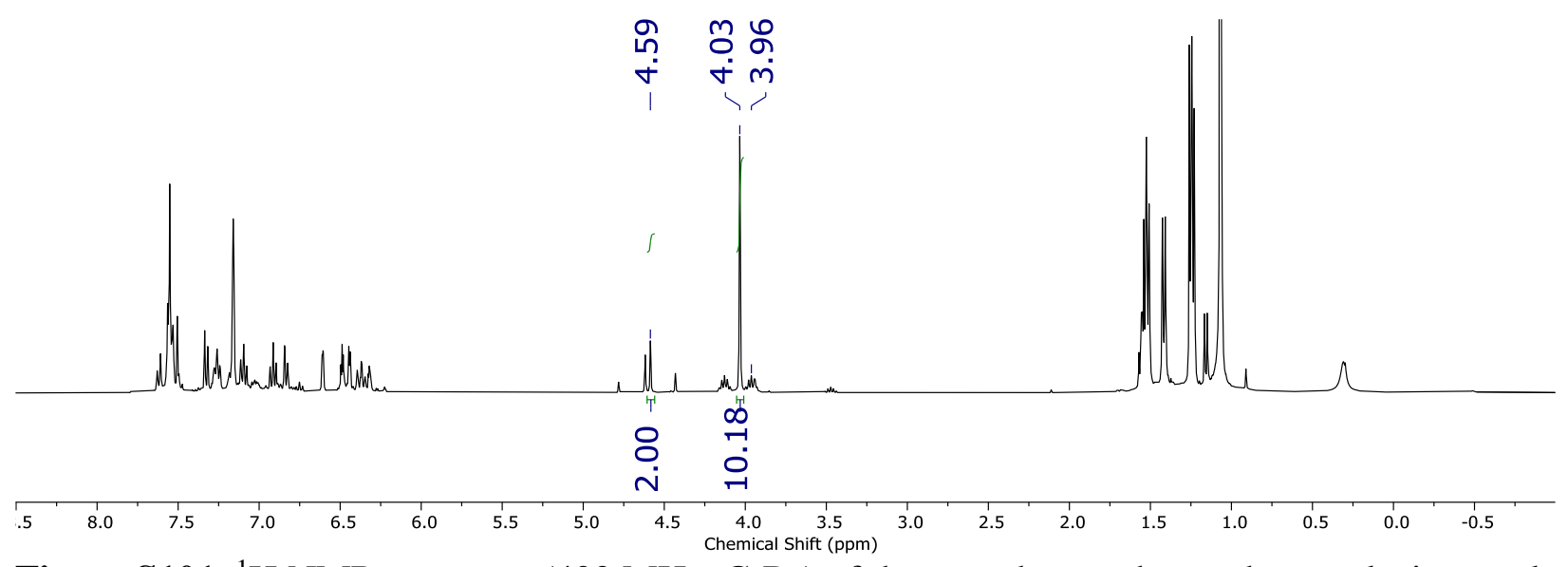

Figure S101. ${ }^{1} \mathrm{H}$ NMR spectrum $\left(400 \mathrm{MHz}, \mathrm{C}_{6} \mathrm{D}_{6}\right)$ of the one-photon photoredox catalysis sample for the reaction of ca. $5 \mathrm{~mol} \% \mathrm{~W}\left(\mathrm{CNDippPh}{ }^{\mathrm{Ph}}\right)_{6}$ and 1-(2-iodobenzyl)-pyrrole after 12-h irradiation. The following was determined from relative integration: $84 \%$ conversion, TON $=15$. An isopropyl methine resonance for $\mathrm{W}\left(\mathrm{CNDippPh}^{\mathrm{Ph}}\right)_{6}(3.96 \mathrm{ppm})$ suggests the photocatalyst is still present and is consistent with the UV-visible absorbance spectrum of the reaction mixture (Figure S102).

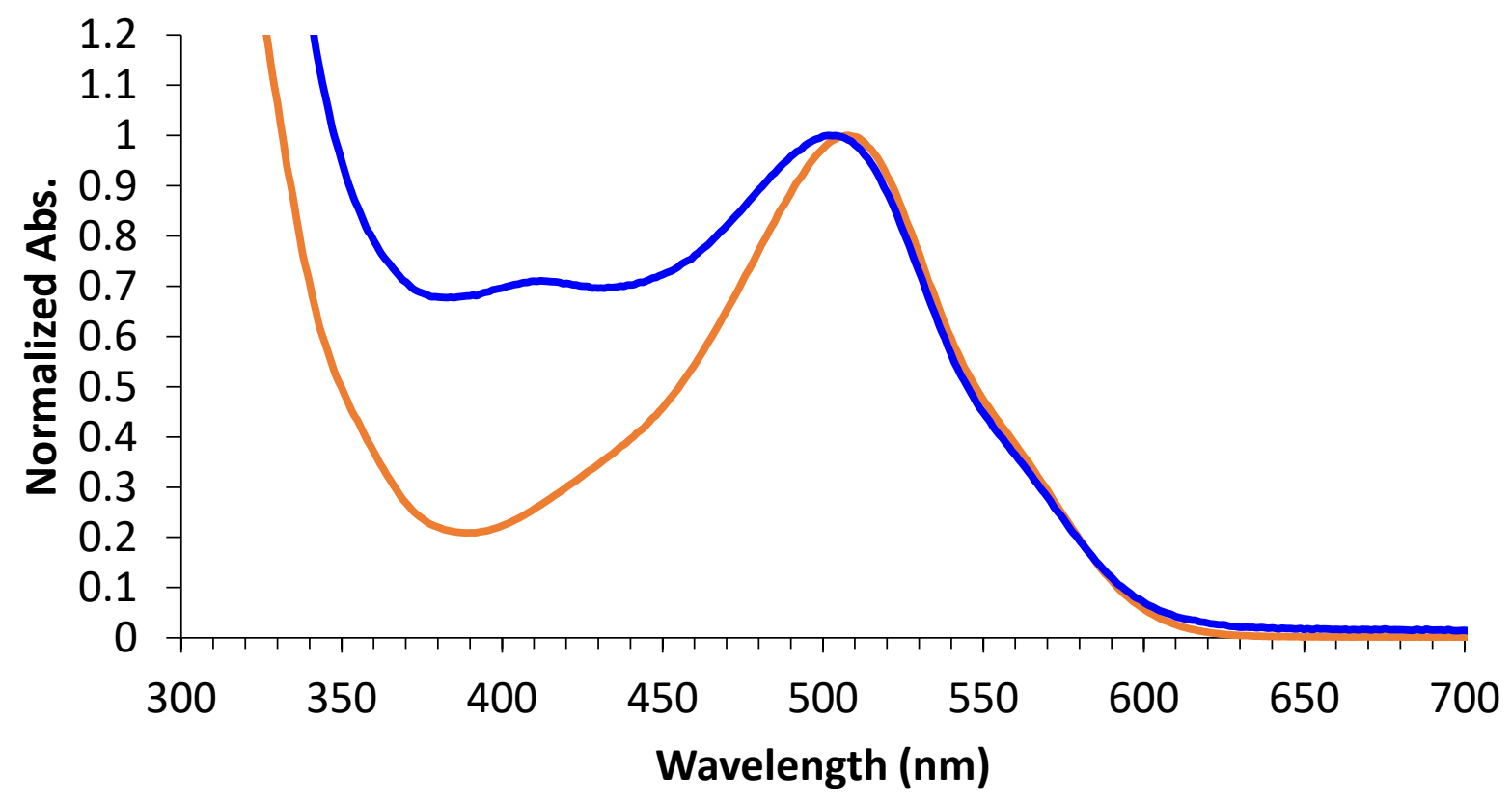

Figure S102. Overlaid UV-visible absorbance spectra of an authentic sample of W(CNDippPh $\left.{ }^{\mathrm{Ph}}\right)_{6}$ (orange, toluene) and the post-photoredox reaction mixture from Figure S101 (blue, toluene). 


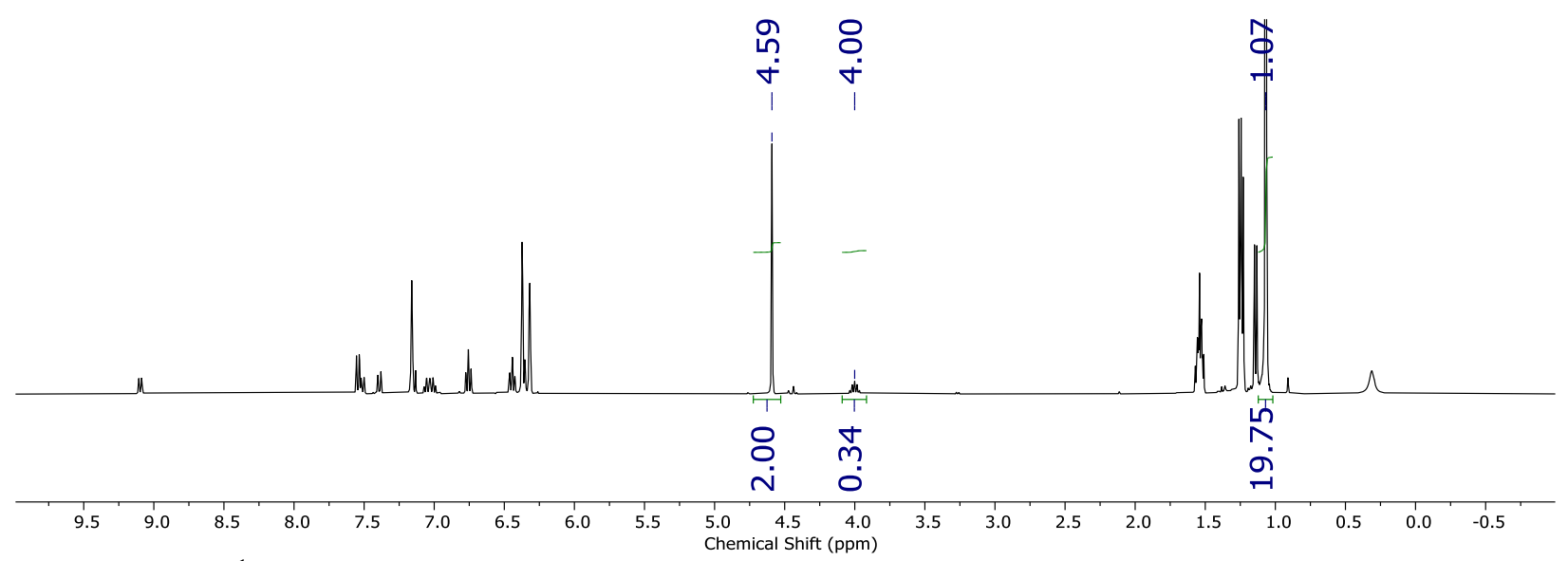

Figure S103. ${ }^{1} \mathrm{H}$ NMR spectrum $\left(400 \mathrm{MHz}, \mathrm{C}_{6} \mathrm{D}_{6}\right)$ of the one-photon photoredox catalysis sample for the reaction of ca. $5 \mathrm{~mol} \% \mathrm{~W}\left(\mathrm{CN}-1-\left(2-{ }^{i} \mathrm{Pr}\right)-\mathrm{Naph}\right)_{6}$ and 1-(2-iodobenzyl)-pyrrole prior to irradiation. The following concentrations/stoichiometries were determined from relative integration: $\mathrm{W}\left(\mathrm{CN}-1-\left(2{ }^{i} \mathrm{Pr}\right)-\mathrm{Naph}\right)_{6}=2.83 \mathrm{mM}, 5.67 \mathrm{~mol} \%$; TMP $=82.3 \mathrm{mM}, 1.65$ equiv.

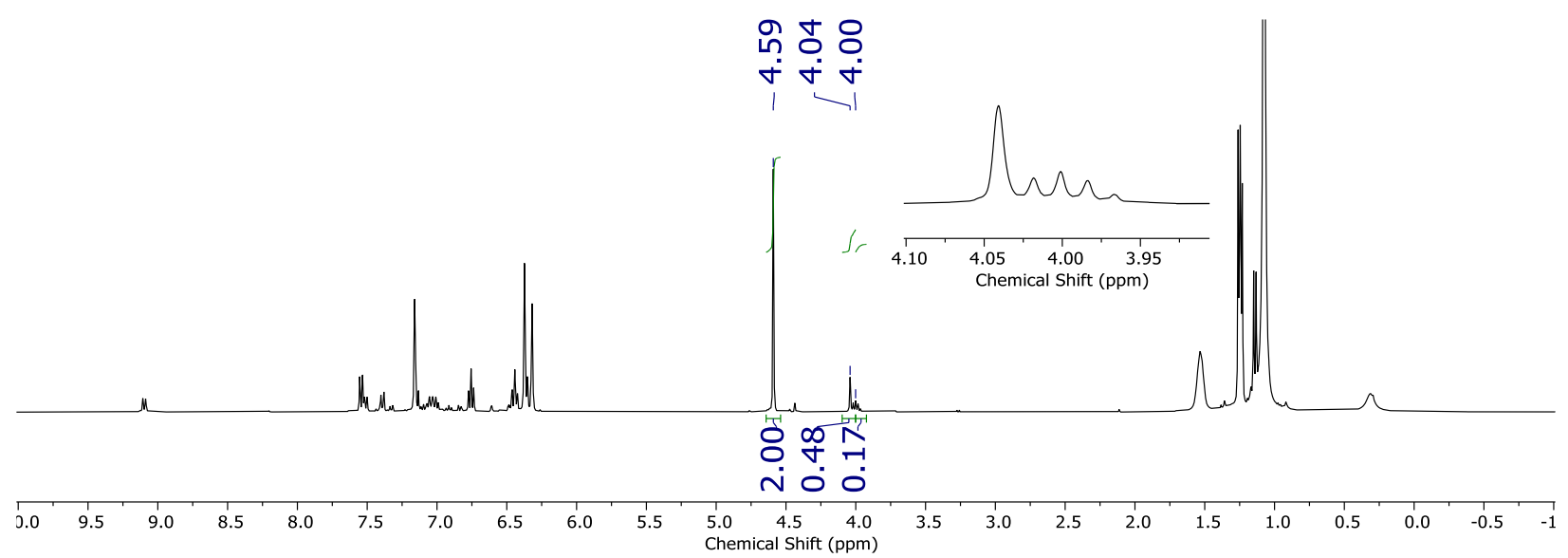

Figure S104. ${ }^{1} \mathrm{H}$ NMR spectrum $\left(400 \mathrm{MHz}, \mathrm{C}_{6} \mathrm{D}_{6}\right)$ of the one-photon photoredox catalysis sample for the reaction of ca. $5 \mathrm{~mol} \% \mathrm{~W}\left(\mathrm{CN}-1-\left(2-{ }^{i} \mathrm{Pr}\right)-\mathrm{Naph}\right)_{6}$ and 1-(2-iodobenzyl)-pyrrole after $1-\mathrm{h}$ irradiation. The following was determined from relative integration: $13 \%$ conversion, TON $=2.4$. An isopropyl methine resonance for $\mathrm{W}\left(\mathrm{CN}-1-\left(2-{ }^{i} \mathrm{Pr}\right)-\mathrm{Naph}\right)_{6}(4.00 \mathrm{ppm})$ suggests the photocatalyst is still present. *Note: As shown in the inset, the benzylic resonance at $4.04 \mathrm{ppm}$ corresponding to the cyclized organic product overlaps with the isopropyl methine resonance for $\mathrm{W}\left(\mathrm{CN}-1-\left(2-{ }^{i} \mathrm{Pr}\right)-\right.$ Naph)6. To calculate the conversion, half of the latter resonance was integrated (0.17) and subtracted from the integration of the former $(0.48-0.17=0.31)$. 


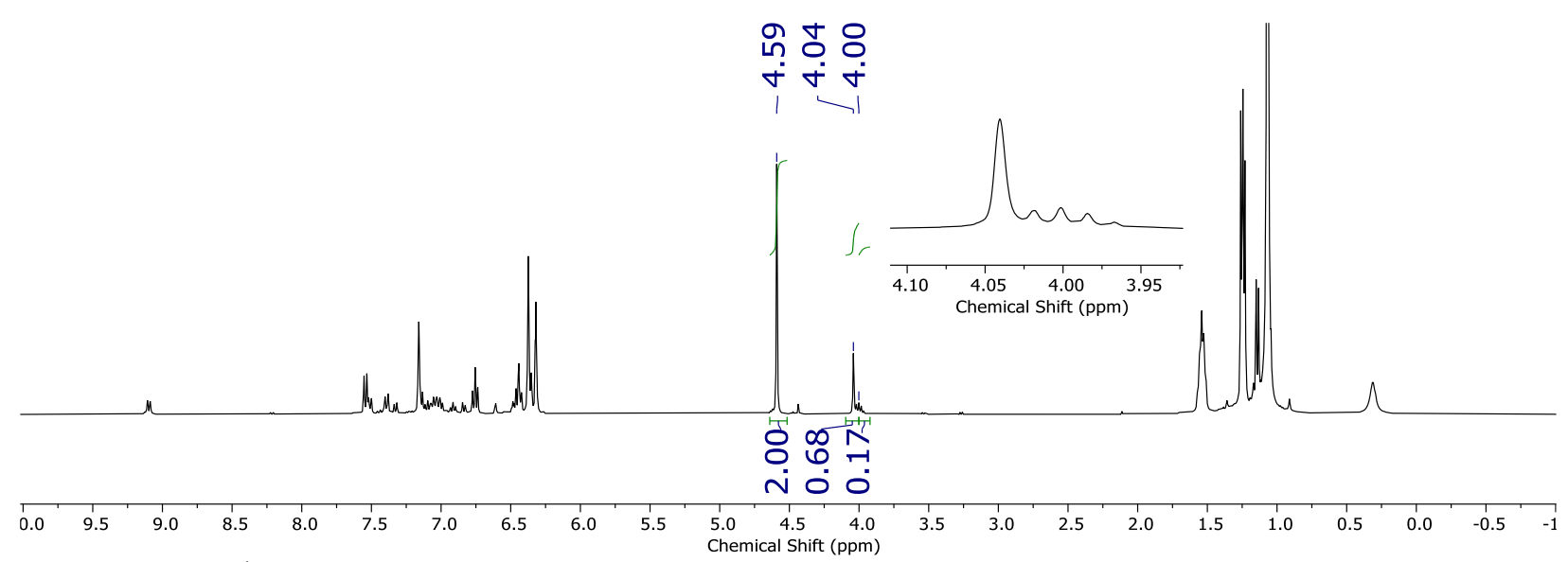

Figure S105. ${ }^{1} \mathrm{H}$ NMR spectrum $\left(400 \mathrm{MHz}, \mathrm{C}_{6} \mathrm{D}_{6}\right)$ of the one-photon photoredox catalysis sample for the reaction of ca. $5 \mathrm{~mol} \% \mathrm{~W}\left(\mathrm{CN}-1-\left(2-{ }^{i} \mathrm{Pr}\right)-\mathrm{Naph}\right)_{6}$ and 1-(2-iodobenzyl)-pyrrole after 2-h irradiation. The following was determined from relative integration: $20 \%$ conversion, $\mathrm{TON}=3.6$. An isopropyl methine resonance for $\mathrm{W}\left(\mathrm{CN}-1-\left(2{ }^{i} \mathrm{Pr}\right)-\mathrm{Naph}\right)_{6}(4.00 \mathrm{ppm})$ suggests the photocatalyst is still present. *Note: As shown in the inset, the benzylic resonance at $4.04 \mathrm{ppm}$ corresponding to the cyclized organic product overlaps with the isopropyl methine resonance for $\mathrm{W}\left(\mathrm{CN}-1-\left(2{ }^{-} \mathrm{Pr}\right)-\right.$ Naph)6. To calculate the conversion, half of the latter resonance was integrated $(0.17)$ and subtracted from the integration of the former $(0.68-0.17=0.51)$.

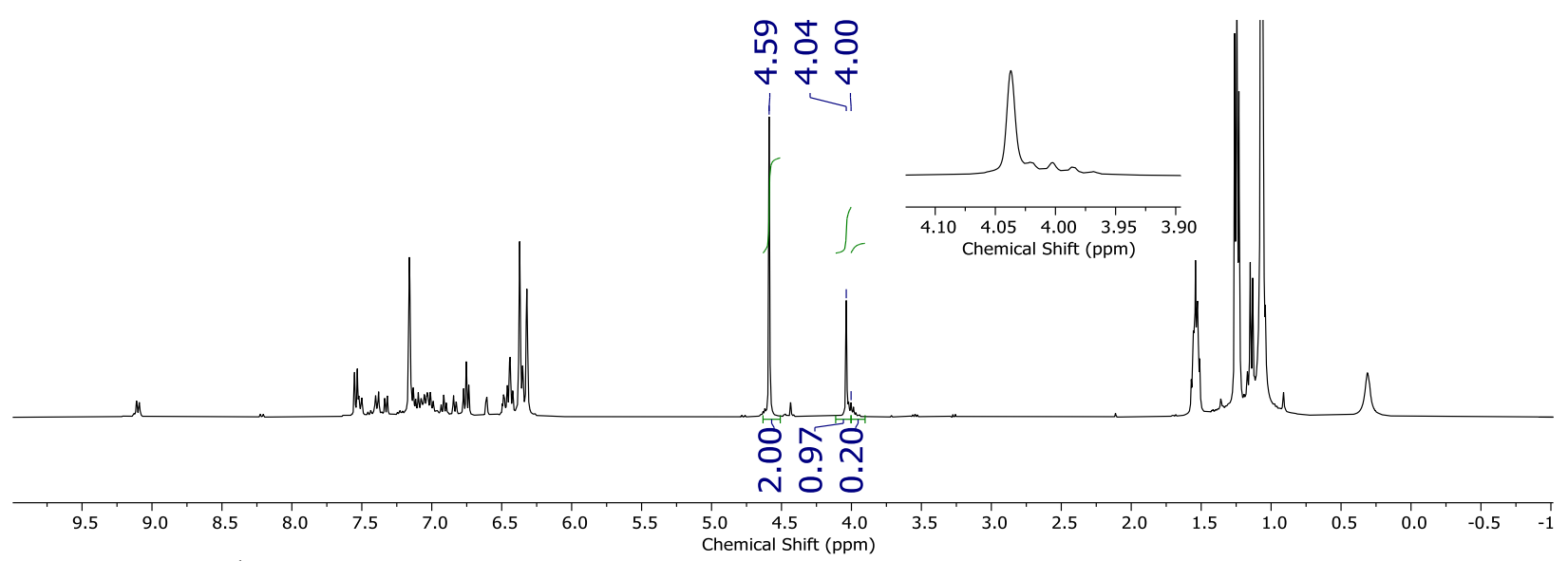

Figure S106. ${ }^{1} \mathrm{H}$ NMR spectrum $\left(400 \mathrm{MHz}, \mathrm{C}_{6} \mathrm{D}_{6}\right)$ of the one-photon photoredox catalysis sample for the reaction of ca. $5 \mathrm{~mol} \% \mathrm{~W}\left(\mathrm{CN}-1-\left(2-{ }^{-} \mathrm{Pr}\right)-\mathrm{Naph}\right)_{6}$ and 1-(2-iodobenzyl)-pyrrole after 4-h irradiation. The following was determined from relative integration: $28 \%$ conversion, $\mathrm{TON}=4.9$. An isopropyl methine resonance for $\mathrm{W}\left(\mathrm{CN}-1-\left(2{ }^{i} \mathrm{Pr}\right)-\mathrm{Naph}\right)_{6}(4.00 \mathrm{ppm})$ suggests the photocatalyst is still present. *Note: As shown in the inset, the benzylic resonance at $4.04 \mathrm{ppm}$ corresponding to the cyclized organic product overlaps with the isopropyl methine resonance for $\mathrm{W}\left(\mathrm{CN}-1-\left(2{ }^{i} \mathrm{Pr}\right)-\right.$ Naph)6. To calculate the conversion, half of the latter resonance was integrated $(0.20)$ and subtracted from the integration of the former $(0.97-0.20=0.77)$. 


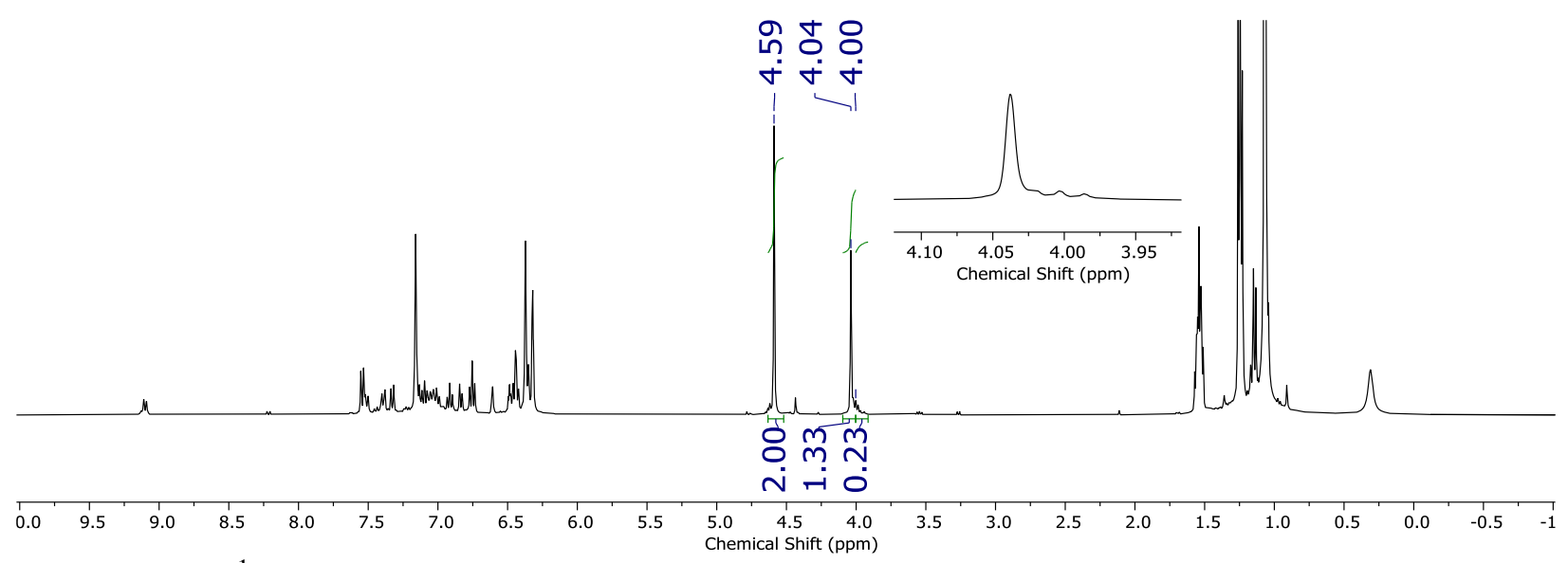

Figure S107. ${ }^{1} \mathrm{H}$ NMR spectrum $\left(400 \mathrm{MHz}, \mathrm{C}_{6} \mathrm{D}_{6}\right)$ of the one-photon photoredox catalysis sample for the reaction of ca. $5 \mathrm{~mol} \% \mathrm{~W}\left(\mathrm{CN}-1-\left(2-{ }^{i} \mathrm{Pr}\right)-\mathrm{Naph}\right)_{6}$ and 1-(2-iodobenzyl)-pyrrole after 8-h irradiation. The following was determined from relative integration: $36 \%$ conversion, $\mathrm{TON}=6.3$. An isopropyl methine resonance for $\mathrm{W}\left(\mathrm{CN}-1-\left(2{ }^{i} \mathrm{Pr}\right)-\mathrm{Naph}\right)_{6}(4.00 \mathrm{ppm})$ suggests the photocatalyst is still present. *Note: As shown in the inset, the benzylic resonance at $4.04 \mathrm{ppm}$ corresponding to the cyclized organic product overlaps with the isopropyl methine resonance for $\mathrm{W}\left(\mathrm{CN}-1-\left(2{ }^{-} \mathrm{Pr}\right)-\right.$ Naph)6. To calculate the conversion, half of the latter resonance was integrated $(0.23)$ and subtracted from the integration of the former $(1.33-0.23=1.10)$.

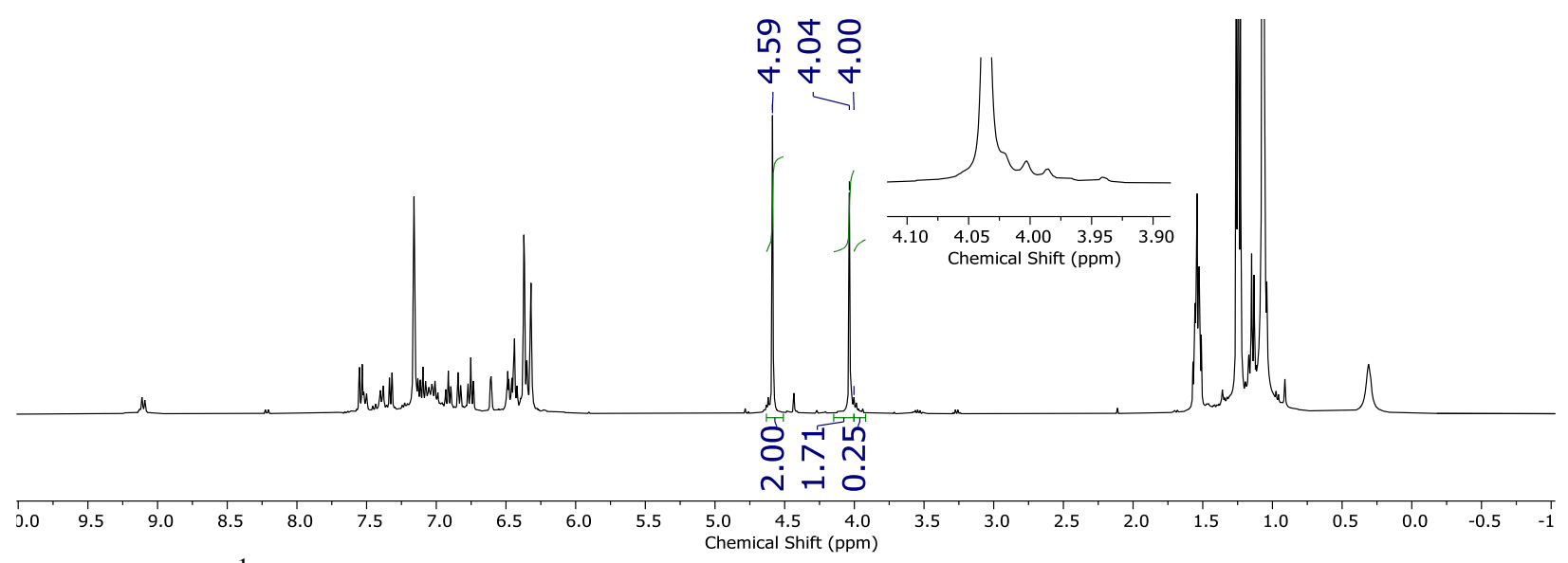

Figure S108. ${ }^{1} \mathrm{H}$ NMR spectrum $\left(400 \mathrm{MHz}, \mathrm{C}_{6} \mathrm{D}_{6}\right)$ of the one-photon photoredox catalysis sample for the reaction of ca. $5 \mathrm{~mol} \% \mathrm{~W}\left(\mathrm{CN}-1-\left(2-{ }^{-} \mathrm{Pr}\right)-\mathrm{Naph}\right)_{6}$ and 1-(2-iodobenzyl)-pyrrole after 8-h irradiation. The following was determined from relative integration: $42 \%$ conversion, $\mathrm{TON}=7.4$. An isopropyl methine resonance for $\mathrm{W}\left(\mathrm{CN}-1-\left(2{ }^{i} \mathrm{Pr}\right)-\mathrm{Naph}\right)_{6}(4.00 \mathrm{ppm})$ suggests the photocatalyst is still present and is consistent with the UV-visible absorbance spectrum of the reaction mixture (Figure S109). *Note: As shown in the inset, the benzylic resonance at $4.04 \mathrm{ppm}$ corresponding to the cyclized organic product overlaps with the isopropyl methine resonance for $\mathrm{W}\left(\mathrm{CN}-1-\left(2{ }^{-} \mathrm{Pr}\right)-\right.$ Naph)6. To calculate the conversion, half of the latter resonance was integrated (0.25) and subtracted from the integration of the former $(1.71-0.25=1.46)$. 


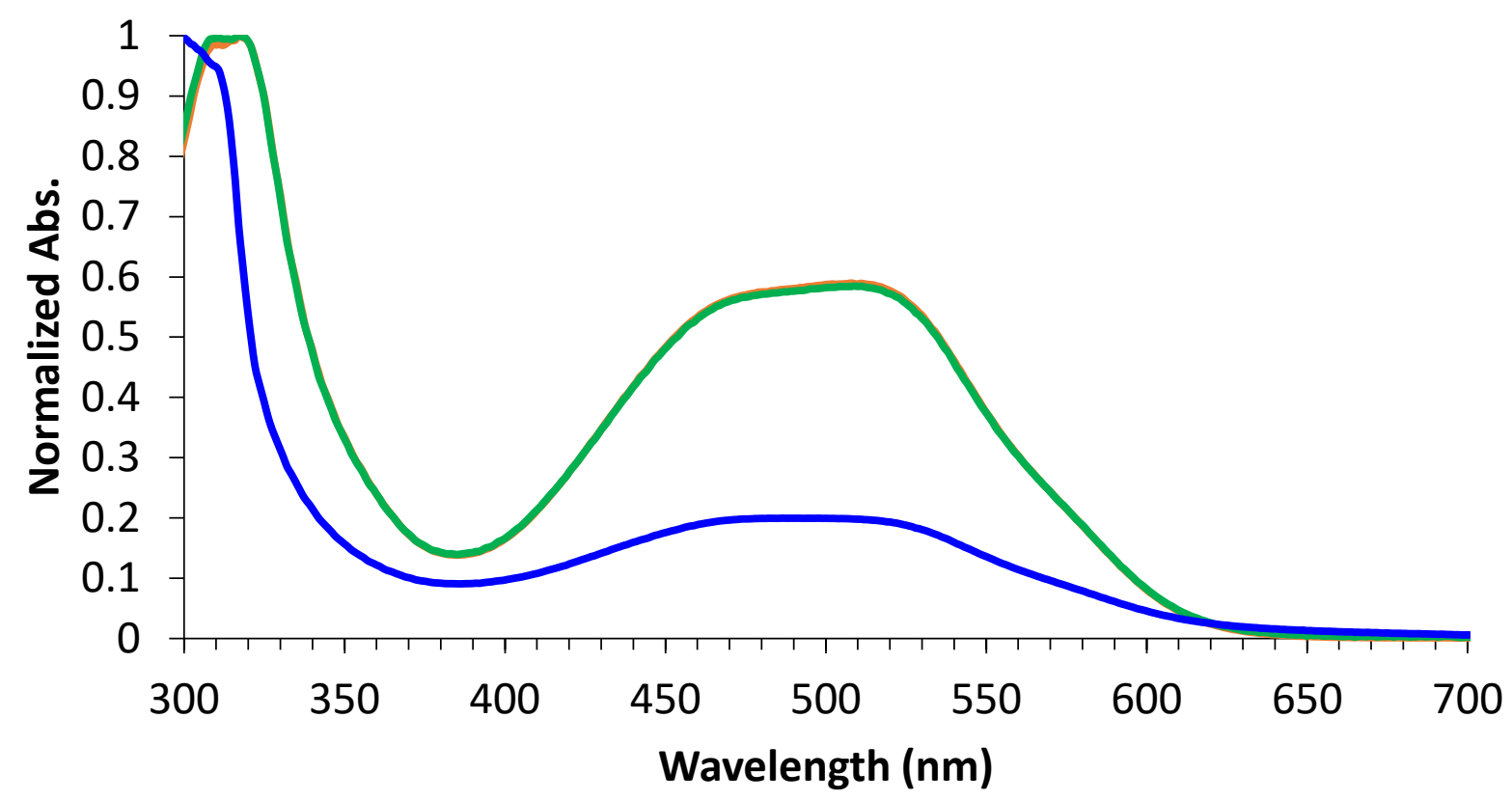

Figure S109. Overlaid UV-visible absorbance spectra of an authentic sample of W(CN-1-(2- $\left.{ }^{i} \mathrm{Pr}\right)-$ $\mathrm{Naph})_{6}$ (orange, toluene), the pre-irradiated photoredox reaction mixture from Figure S103 (green, toluene), and the post-photoredox reaction mixture from Figure S108 (blue, toluene).

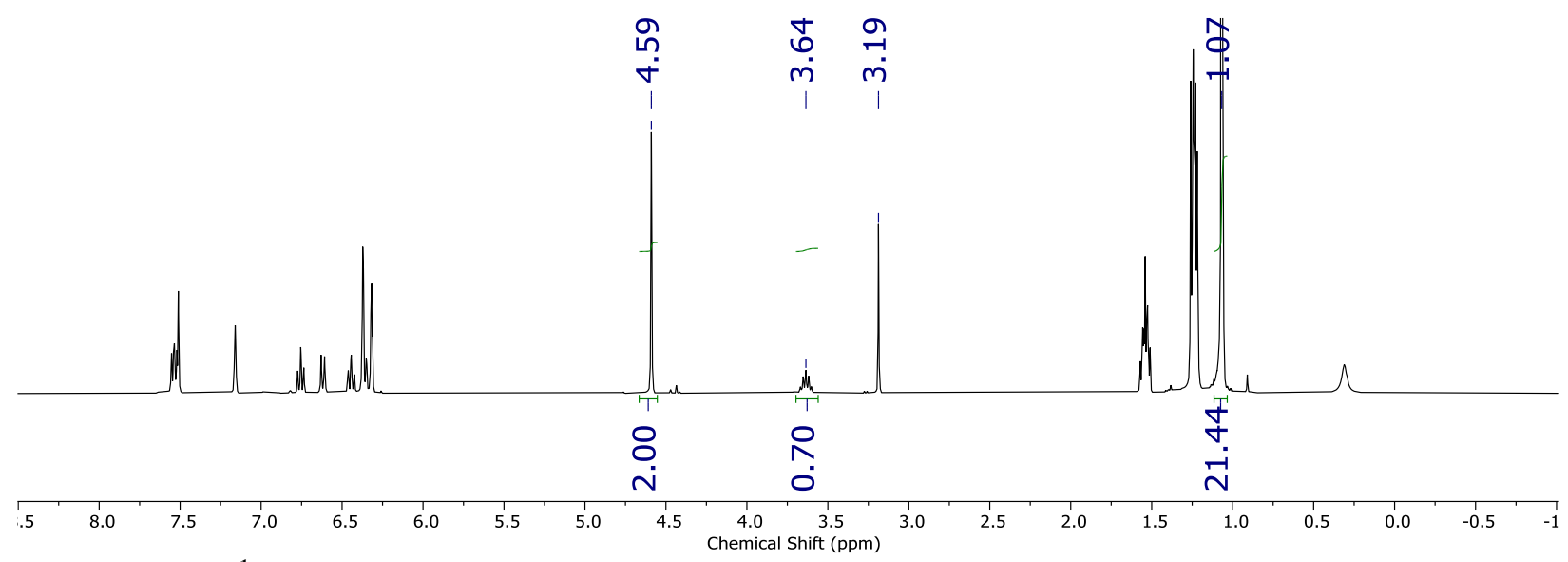

Figure S110. ${ }^{1} \mathrm{H}$ NMR spectrum $\left(400 \mathrm{MHz}, \mathrm{C}_{6} \mathrm{D}_{6}\right)$ of the one-photon photoredox catalysis sample for the reaction of ca. $5 \mathrm{~mol} \% \mathrm{~W}\left(\mathrm{CNDipp}{ }^{\mathrm{CC}} \mathrm{Ph}^{\mathrm{OMe}}\right)_{6}$ and 1-(2-iodobenzyl)-pyrrole prior to irradiation. The following concentrations/stoichiometries were determined from relative integration: $\mathrm{W}\left(\mathrm{CNDipp}{ }^{\mathrm{CC}} \mathrm{Ph}^{\mathrm{OMe}}\right)_{6}=2.92 \mathrm{mM}, 5.83 \mathrm{~mol} \%$; TMP $=89.3 \mathrm{mM}, 1.79$ equiv. 


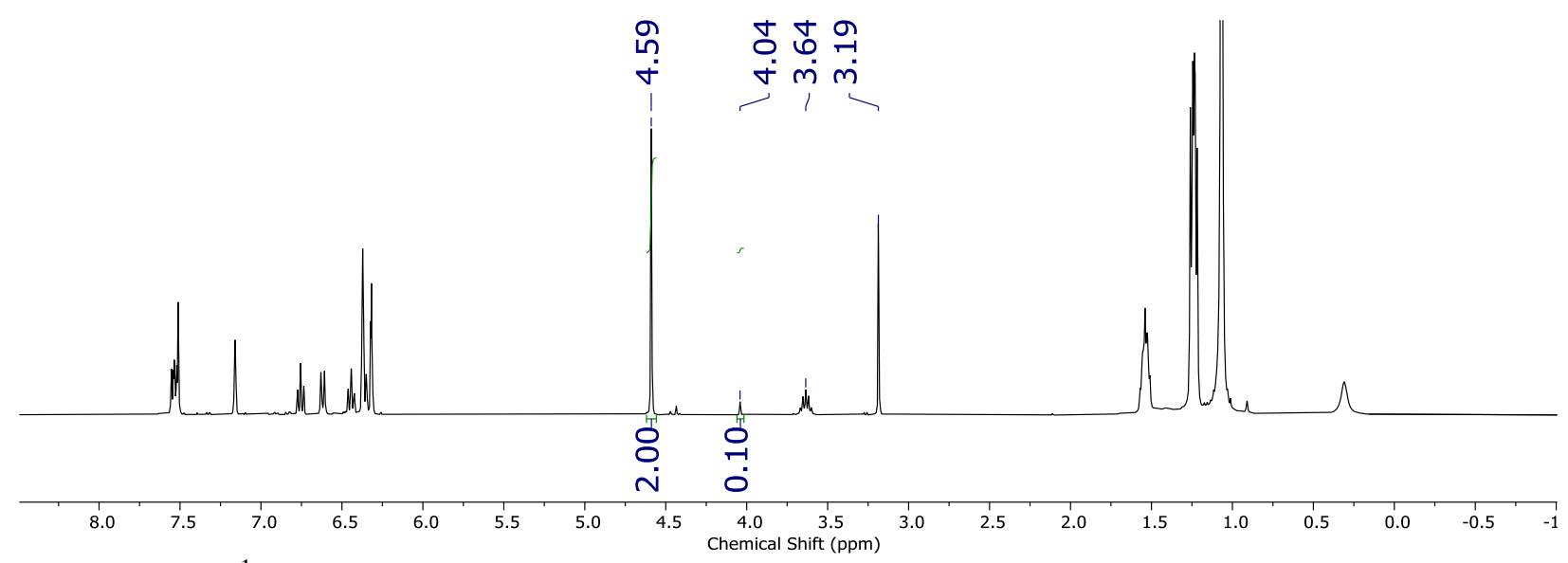

Figure S111. ${ }^{1} \mathrm{H}$ NMR spectrum $\left(400 \mathrm{MHz}, \mathrm{C}_{6} \mathrm{D}_{6}\right)$ of the one-photon photoredox catalysis sample for the reaction of ca. $5 \mathrm{~mol} \% \mathrm{~W}\left(\mathrm{CNDipp}^{\mathrm{CC}} \mathrm{Ph}^{\mathrm{OMe}}\right)_{6}$ and 1-(2-iodobenzyl)-pyrrole after 1-h irradiation. The following was determined from relative integration: $5 \%$ conversion, $\mathrm{TON}=0.8$. Intense resonances for $\mathrm{W}\left(\mathrm{CNDipp}{ }^{\mathrm{CC}} \mathrm{Ph}^{\mathrm{OMe}}\right)_{6}$ are still present $\left(3.19 \mathrm{ppm}\right.$ : $\mathrm{OCH}_{3} ; 3.64 \mathrm{ppm}$ : isopropyl methine), with negligible decomposition observed.

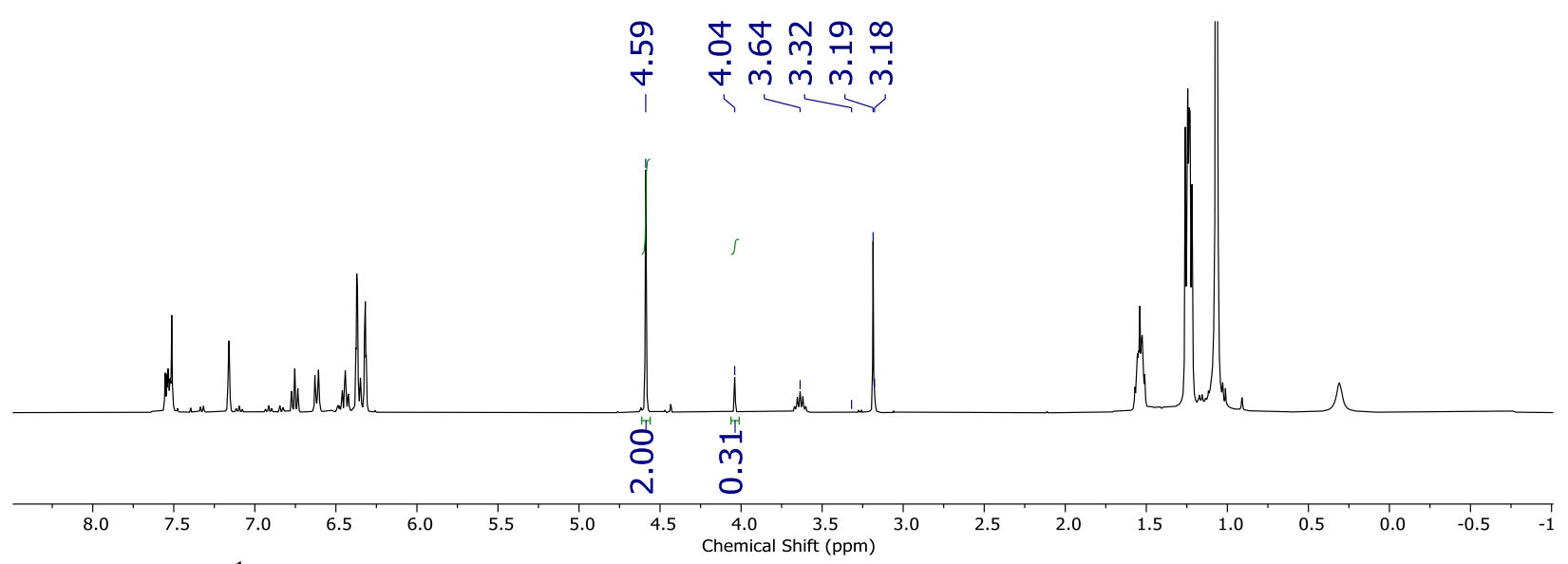

Figure S112. ${ }^{1} \mathrm{H}$ NMR spectrum $\left(400 \mathrm{MHz}, \mathrm{C}_{6} \mathrm{D}_{6}\right)$ of the one-photon photoredox catalysis sample for the reaction of ca. $5 \mathrm{~mol} \% \mathrm{~W}\left(\mathrm{CNDipp}{ }^{\mathrm{CC}} \mathrm{Ph}^{\mathrm{OMe}}\right)_{6}$ and 1-(2-iodobenzyl)-pyrrole after 4-h irradiation. The following was determined from relative integration: $13 \%$ conversion, $\mathrm{TON}=2.3$. Intense resonances for $\mathrm{W}\left(\mathrm{CNDipp}{ }^{\mathrm{CC}} \mathrm{Ph}^{\mathrm{OMe}}\right)_{6}$ are still present $\left(3.19 \mathrm{ppm}\right.$ : $\mathrm{OCH}_{3} ; 3.64 \mathrm{ppm}$ : isopropyl methine), with only a small amount of free $\mathrm{CNDipp}^{\mathrm{CC}} \mathrm{Ph}^{\mathrm{OMe}}$ (3.18 ppm: $\mathrm{OCH}_{3} ; 3.32$ ppm: isopropyl methine) observed. 


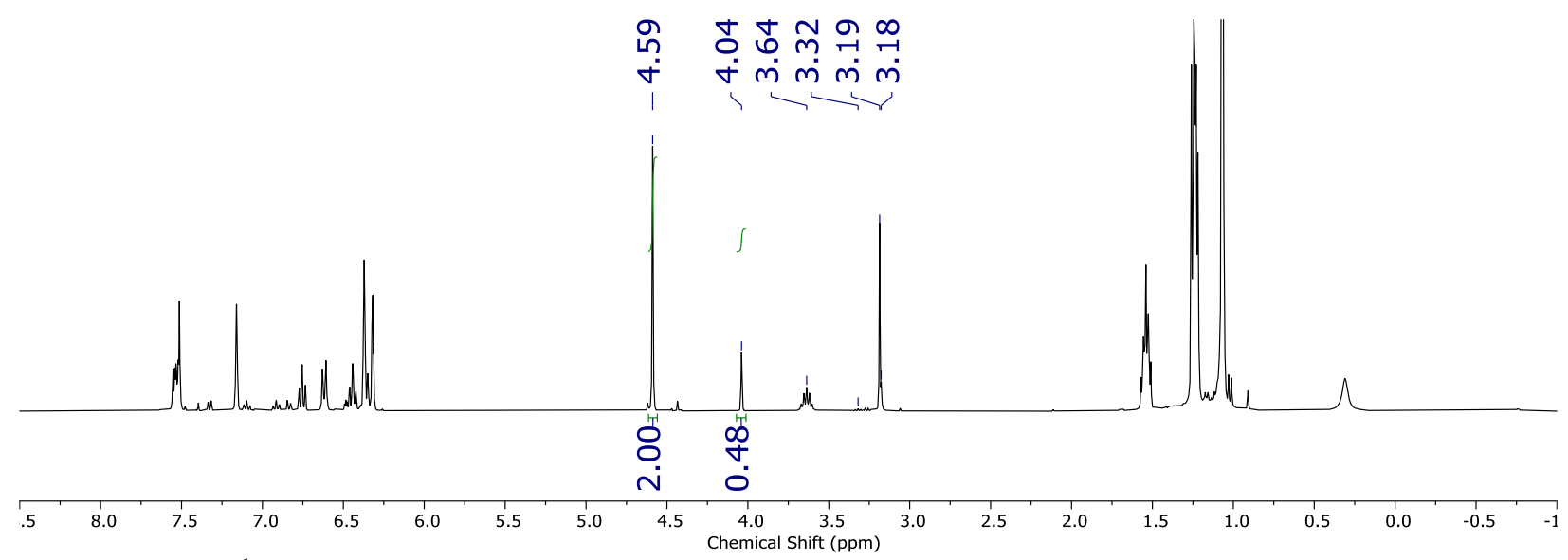

Figure S113. ${ }^{1} \mathrm{H}$ NMR spectrum $\left(400 \mathrm{MHz}, \mathrm{C}_{6} \mathrm{D}_{6}\right)$ of the one-photon photoredox catalysis sample for the reaction of ca. $5 \mathrm{~mol} \% \mathrm{~W}\left(\mathrm{CNDipp}^{\mathrm{CC}} \mathrm{Ph}^{\mathrm{OMe}}\right)_{6}$ and 1-(2-iodobenzyl)-pyrrole after 8-h irradiation. The following was determined from relative integration: $19 \%$ conversion, TON $=3.3$. Intense resonances for $\mathrm{W}\left(\mathrm{CNDipp}^{\mathrm{CC}} \mathrm{Ph}^{\mathrm{OMe}}\right)_{6}$ are still present $\left(3.19\right.$ ppm: $\mathrm{OCH}_{3} ; 3.64 \mathrm{ppm}$ : isopropyl methine), with only a small amount of free $\mathrm{CNDipp}^{\mathrm{CC}} \mathrm{Ph}^{\mathrm{OMe}}$ (3.18 ppm: $\mathrm{OCH}_{3} ; 3.32$ ppm: isopropyl methine) observed.

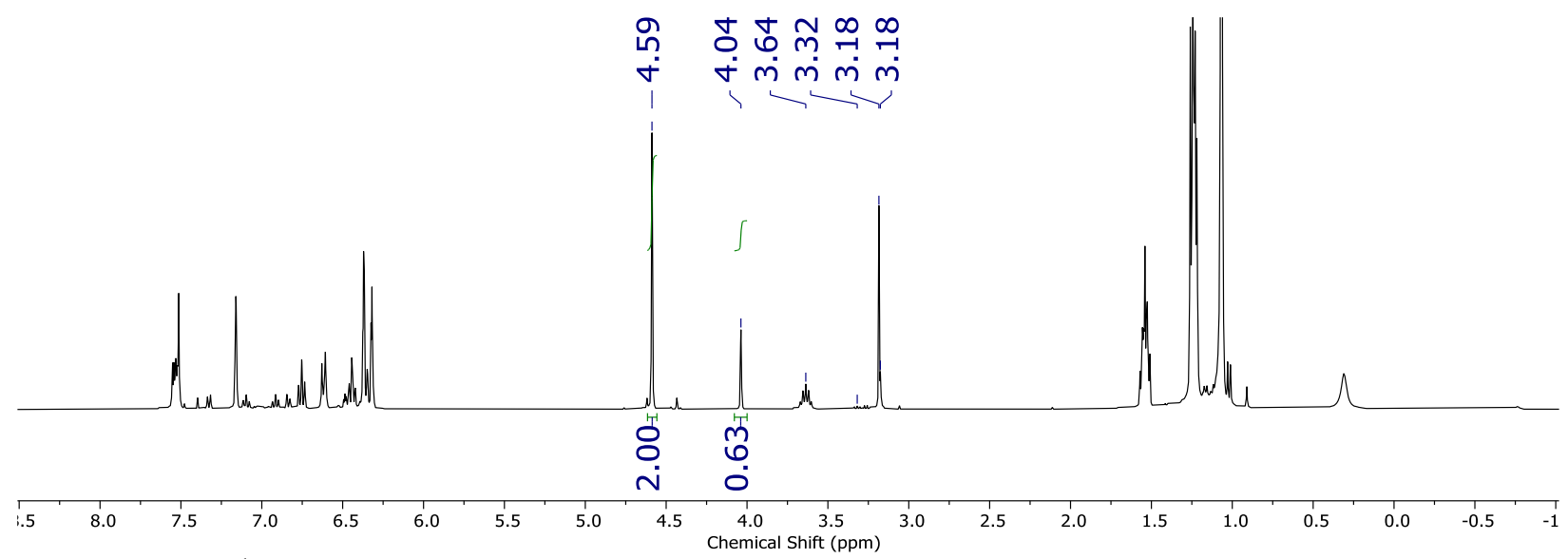

Figure S114. ${ }^{1} \mathrm{H}$ NMR spectrum $\left(400 \mathrm{MHz}, \mathrm{C}_{6} \mathrm{D}_{6}\right)$ of the one-photon photoredox catalysis sample for the reaction of ca. $5 \mathrm{~mol} \% \mathrm{~W}\left(\mathrm{CNDipp}{ }^{\mathrm{CC}} \mathrm{Ph}^{\mathrm{OMe}}\right)_{6}$ and 1-(2-iodobenzyl)-pyrrole after 12-h irradiation. The following was determined from relative integration: $24 \%$ conversion, $\mathrm{TON}=4.1$. Intense resonances for $\mathrm{W}\left(\mathrm{CNDipp}^{\mathrm{CC}} \mathrm{Ph}^{\mathrm{OMe}}\right)_{6}$ are still present $\left(3.19 \mathrm{ppm}\right.$ : $\mathrm{OCH}_{3} ; 3.64 \mathrm{ppm}$ : isopropyl methine), suggesting a significant amount of the photocatalyst is still present, and consistent with the UV-visible absorbance spectrum of the reaction mixture (Figure S115). 


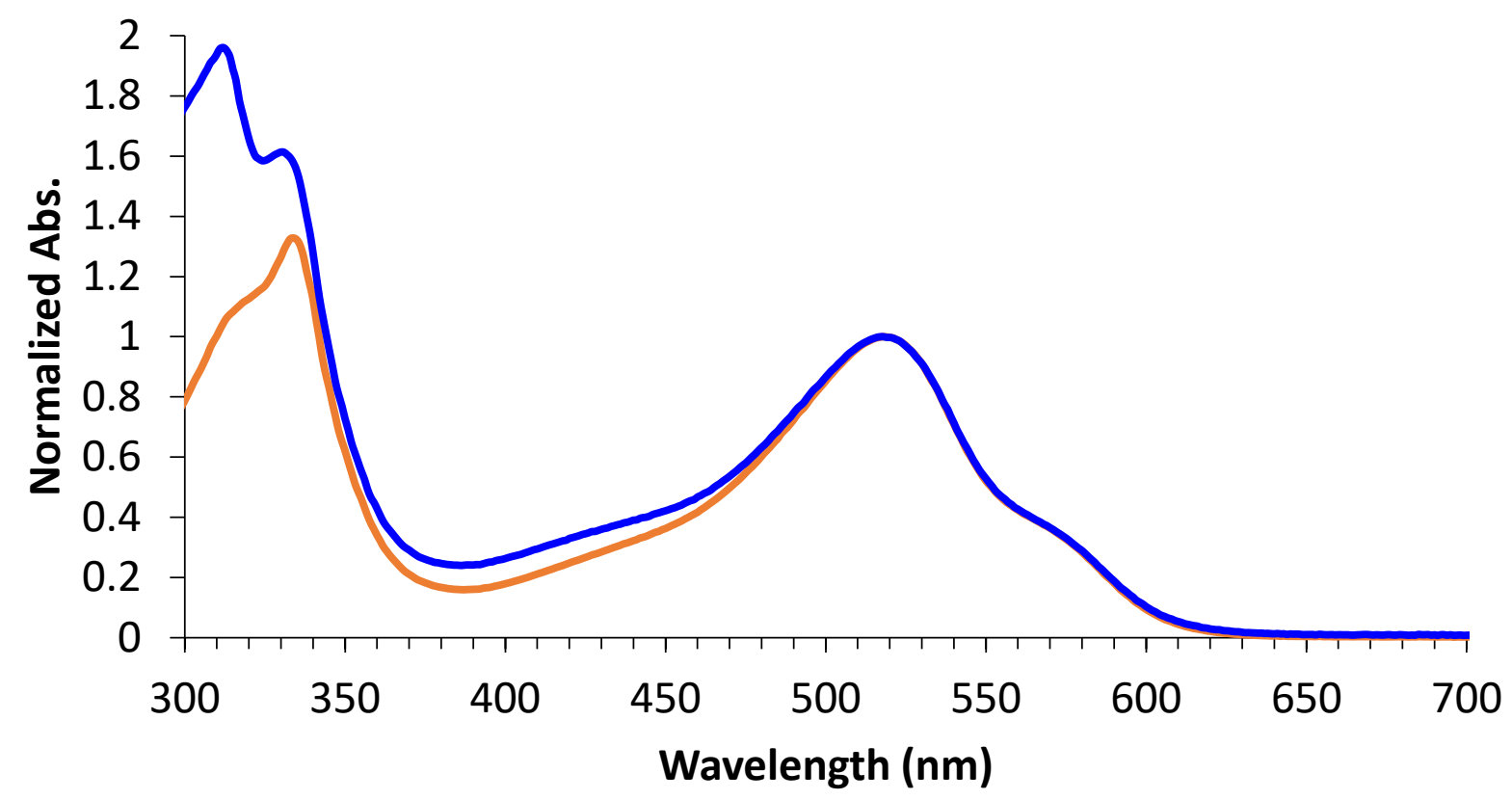

Figure S115. Overlaid UV-visible absorbance spectra of an authentic sample of $\mathrm{W}\left(\mathrm{CNDipp}{ }^{\mathrm{CC}} \mathrm{Ph}^{\mathrm{OMe}}\right)_{6}$ (orange, toluene) and the post-photoredox reaction mixture from Figure S114 (blue, toluene).

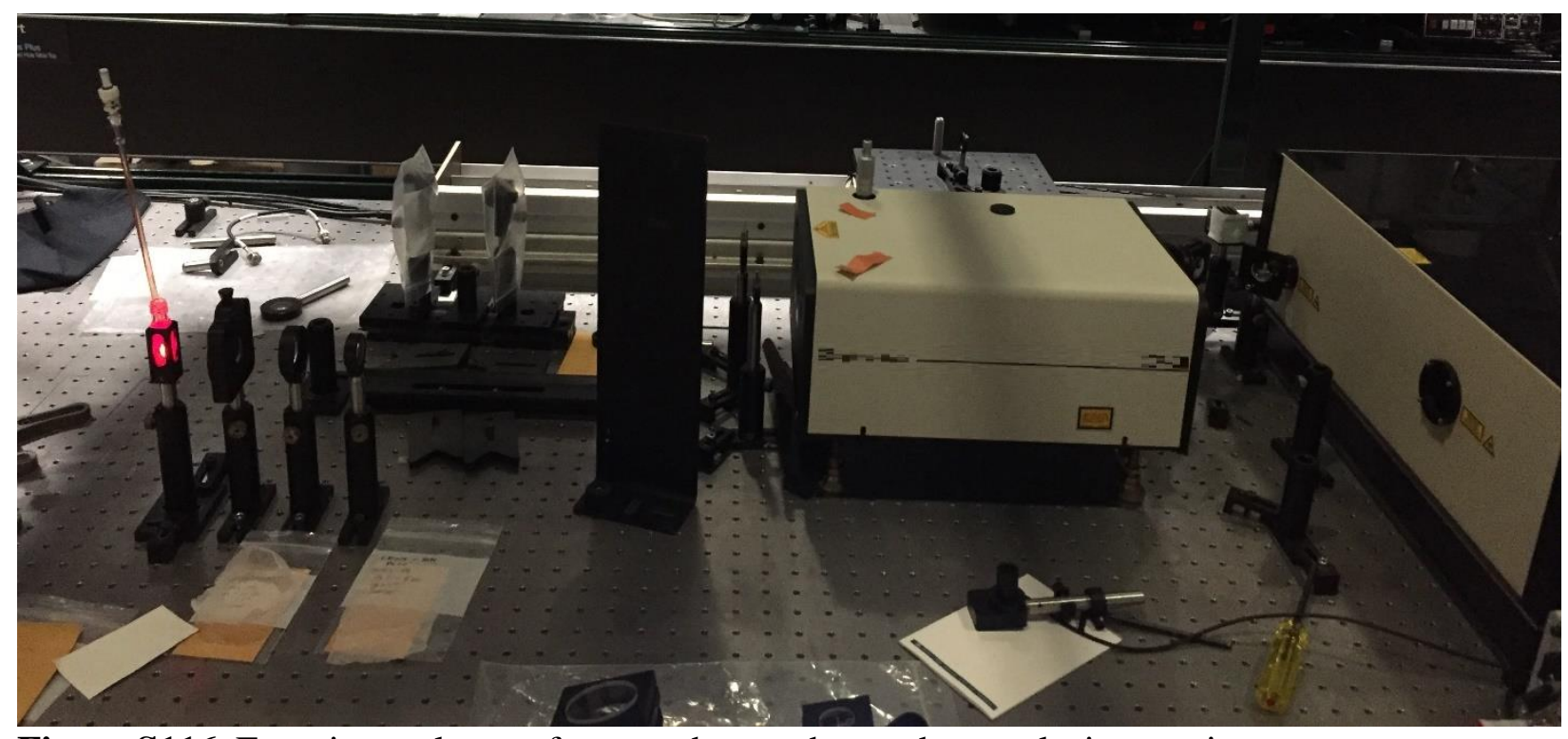

Figure S116. Experimental setup for two-photon photoredox catalysis experiments. 


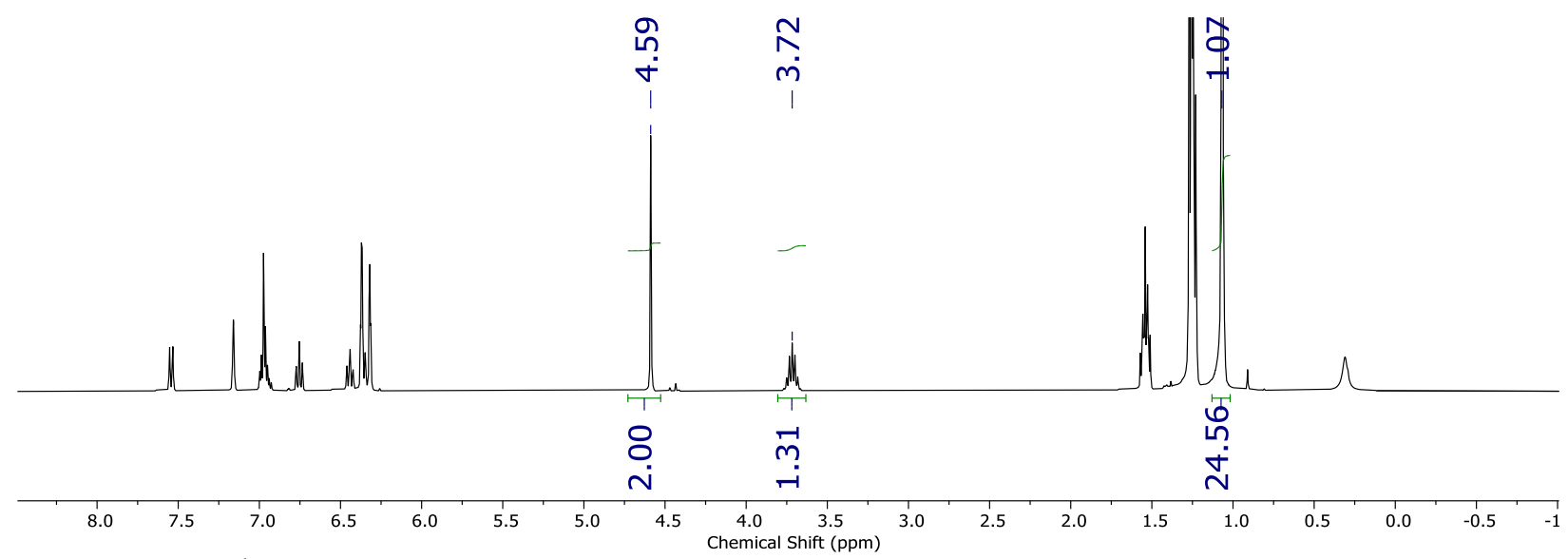

Figure S117. ${ }^{1} \mathrm{H}$ NMR spectrum $\left(400 \mathrm{MHz}, \mathrm{C}_{6} \mathrm{D}_{6}\right.$ ) of the two-photon photoredox catalysis sample for the reaction of ca. $10 \mathrm{~mol} \% \mathrm{~W}(\mathrm{CNDipp})_{6}$ and 1-(2-iodobenzyl)-pyrrole prior to irradiation. The following concentrations/stoichiometries were determined from relative integration: $\mathrm{W}(\mathrm{CNDipp})_{6}=$ $5.46 \mathrm{mM}, 10.9 \mathrm{~mol} \%$; TMP $=102 \mathrm{mM}, 2.05$ equiv.

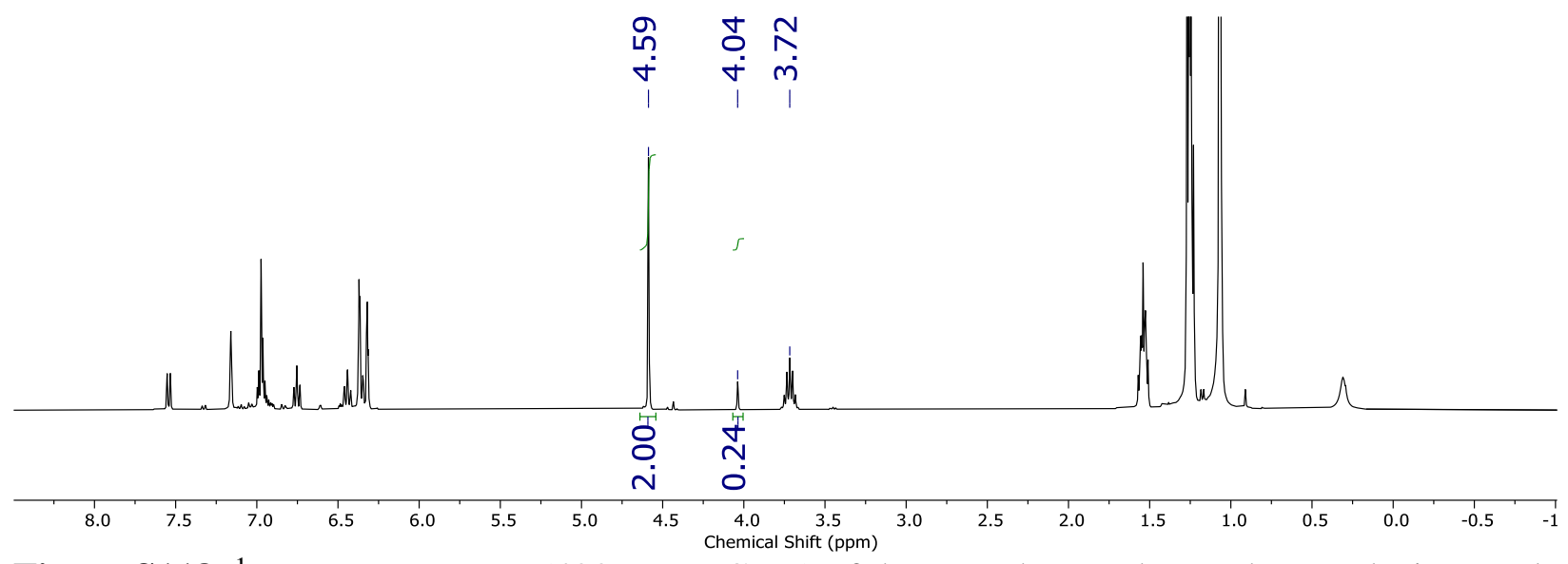

Figure S118. ${ }^{1} \mathrm{H}$ NMR spectrum $\left(400 \mathrm{MHz}, \mathrm{C}_{6} \mathrm{D}_{6}\right.$ ) of the two-photon photoredox catalysis sample for the reaction of ca. $10 \mathrm{~mol} \% \mathrm{~W}(\mathrm{CNDipp})_{6}$ and 1-(2-iodobenzyl)-pyrrole after 1-h irradiation. The following was determined from relative integration: $11 \%$ conversion, $\mathrm{TON}=1.0$. An intense isopropyl methine resonance for $\mathrm{W}(\mathrm{CNDipp})_{6}$ is still present $(3.72 \mathrm{ppm})$, with negligible decomposition observed. 


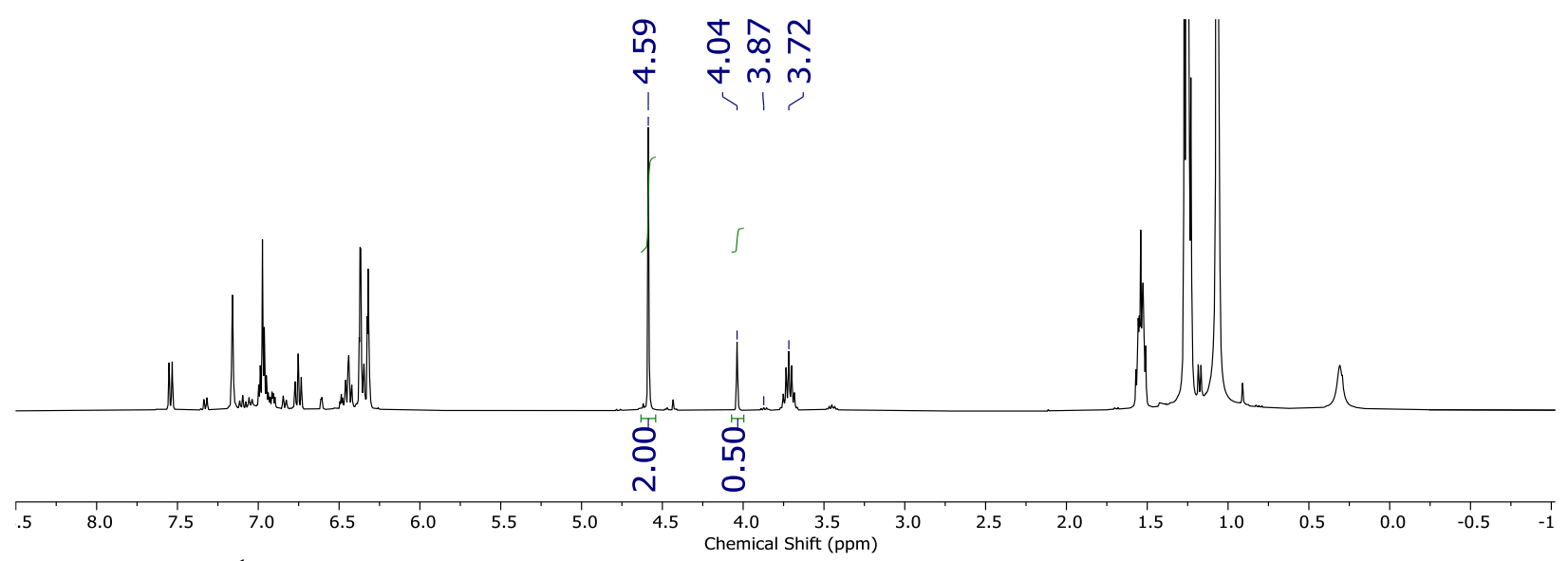

Figure S119. ${ }^{1} \mathrm{H}$ NMR spectrum $\left(400 \mathrm{MHz}, \mathrm{C}_{6} \mathrm{D}_{6}\right.$ ) of the two-photon photoredox catalysis sample for the reaction of ca. $10 \mathrm{~mol} \% \mathrm{~W}(\mathrm{CNDipp})_{6}$ and 1-(2-iodobenzyl)-pyrrole after 2-h irradiation. The following was determined from relative integration: $20 \%$ conversion, $\mathrm{TON}=1.8$. An intense isopropyl methine resonance for $\mathrm{W}(\mathrm{CNDipp})_{6}$ is still present $(3.72 \mathrm{ppm})$, with only a small amount of $\mathrm{WI}_{2}(\mathrm{CNDipp})_{5}$ (3.87 ppm) observed.

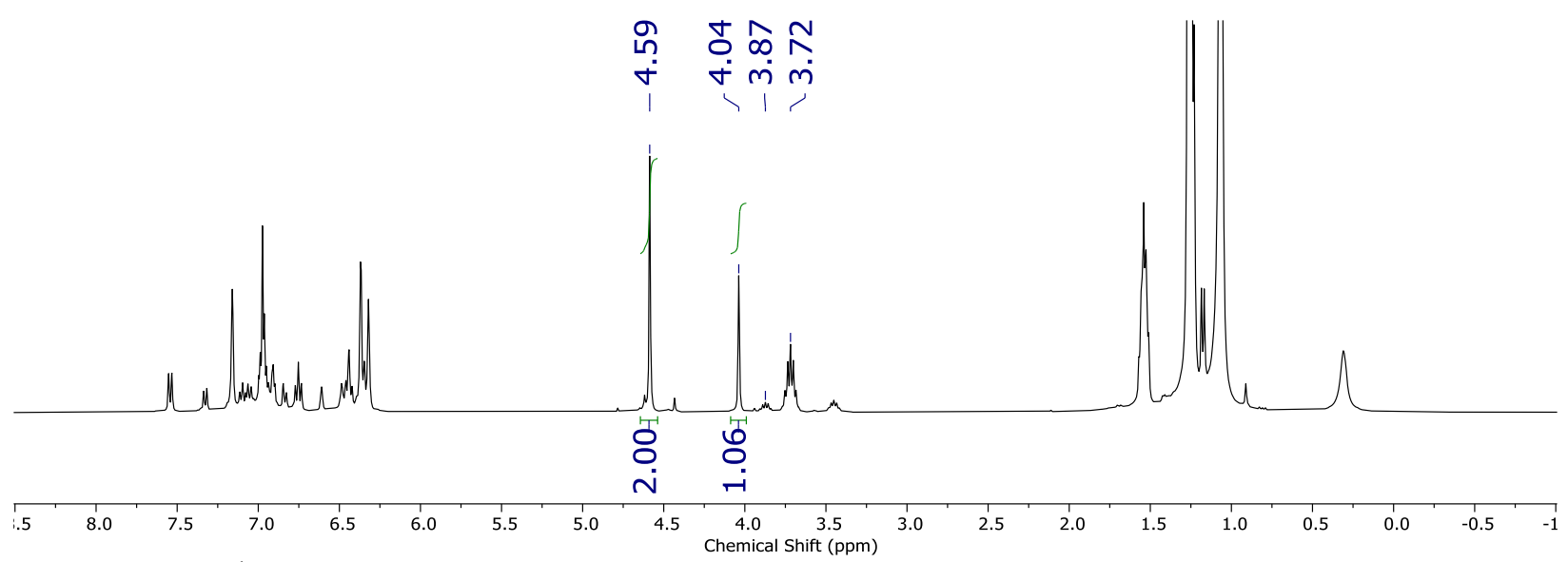

Figure S120. ${ }^{1} \mathrm{H}$ NMR spectrum $\left(400 \mathrm{MHz}, \mathrm{C}_{6} \mathrm{D}_{6}\right)$ of the two-photon photoredox catalysis sample for the reaction of ca. $10 \mathrm{~mol} \% \mathrm{~W}(\mathrm{CNDipp})_{6}$ and 1-(2-iodobenzyl)-pyrrole after 4-h irradiation. The following was determined from relative integration: $35 \%$ conversion, $\mathrm{TON}=3.2$. An intense isopropyl methine resonance for $\mathrm{W}(\mathrm{CNDipp})_{6}$ is still present $(3.72 \mathrm{ppm})$, with only a small amount of $\mathrm{WI}_{2}(\mathrm{CNDipp})_{5}$ (3.87 ppm) observed. 


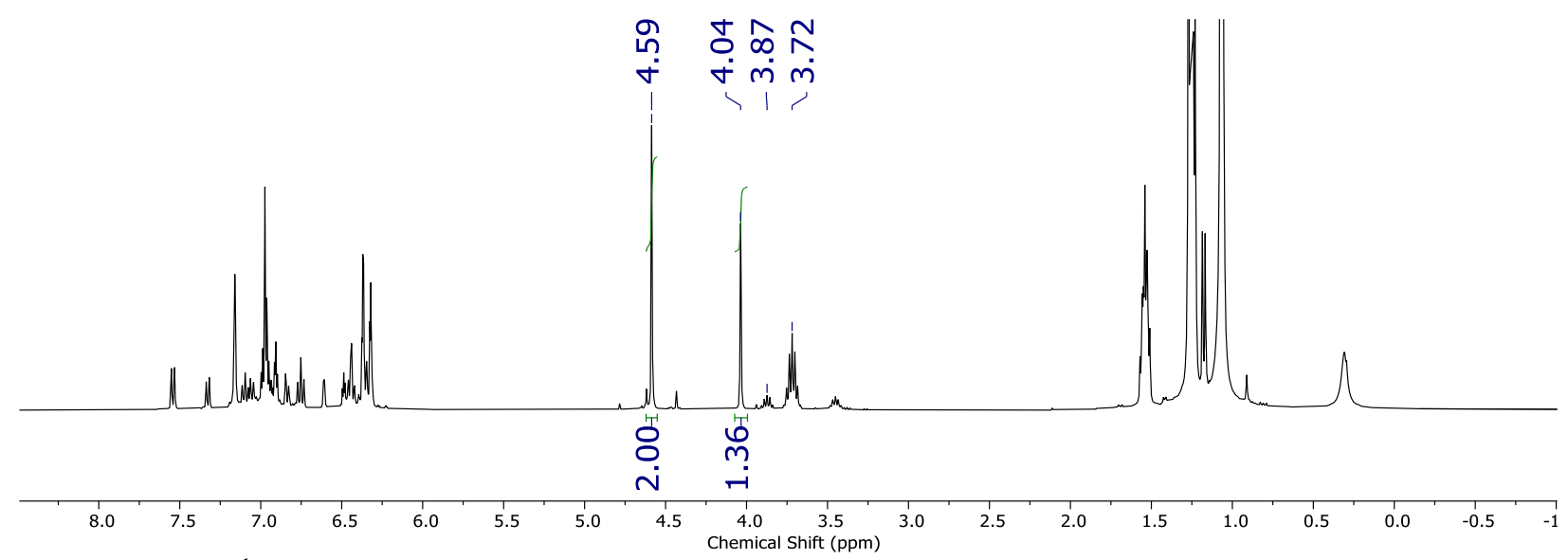

Figure S121. ${ }^{1} \mathrm{H}$ NMR spectrum $\left(400 \mathrm{MHz}, \mathrm{C}_{6} \mathrm{D}_{6}\right.$ ) of the two-photon photoredox catalysis sample for the reaction of ca. $10 \mathrm{~mol} \% \mathrm{~W}(\mathrm{CNDipp})_{6}$ and 1-(2-iodobenzyl)-pyrrole after 5-h irradiation. The following was determined from relative integration: $41 \%$ conversion, $\mathrm{TON}=3.7$. An intense isopropyl methine resonance for $\mathrm{W}(\mathrm{CNDipp})_{6}$ is still present $(3.72 \mathrm{ppm})$, with a small amount of $\mathrm{WI}_{2}$ (CNDipp) 5 (3.87 ppm) observed.

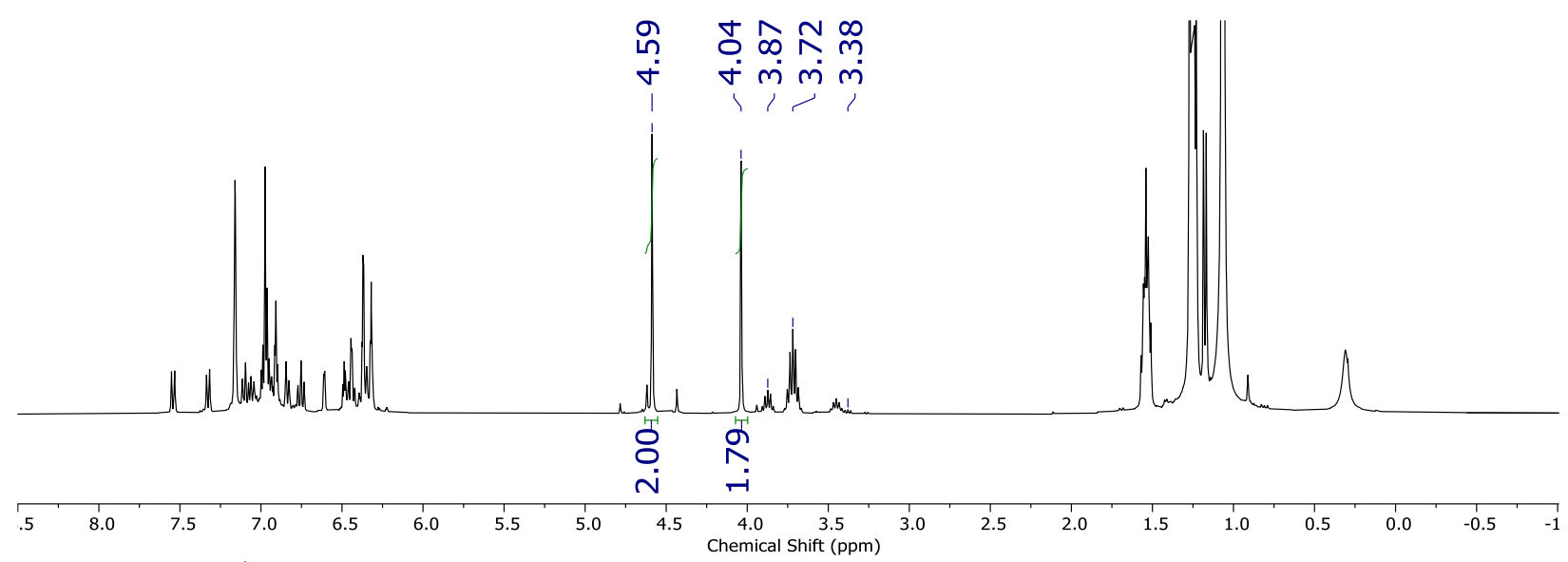

Figure S122. ${ }^{1} \mathrm{H}$ NMR spectrum $\left(400 \mathrm{MHz}, \mathrm{C}_{6} \mathrm{D}_{6}\right)$ of the two-photon photoredox catalysis sample for the reaction of ca. $10 \mathrm{~mol} \% \mathrm{~W}(\mathrm{CNDipp})_{6}$ and 1-(2-iodobenzyl)-pyrrole after 8-h irradiation. The following was determined from relative integration: $47 \%$ conversion, $\mathrm{TON}=4.3$. An intense isopropyl methine resonance for $\mathrm{W}(\mathrm{CNDipp})_{6}$ is still present $(3.72 \mathrm{ppm})$, as well as resonances attributable to $\mathrm{WI}_{2}(\mathrm{CNDipp})_{5}$ (3.87 ppm) and free CNDipp (3.38 ppm). 


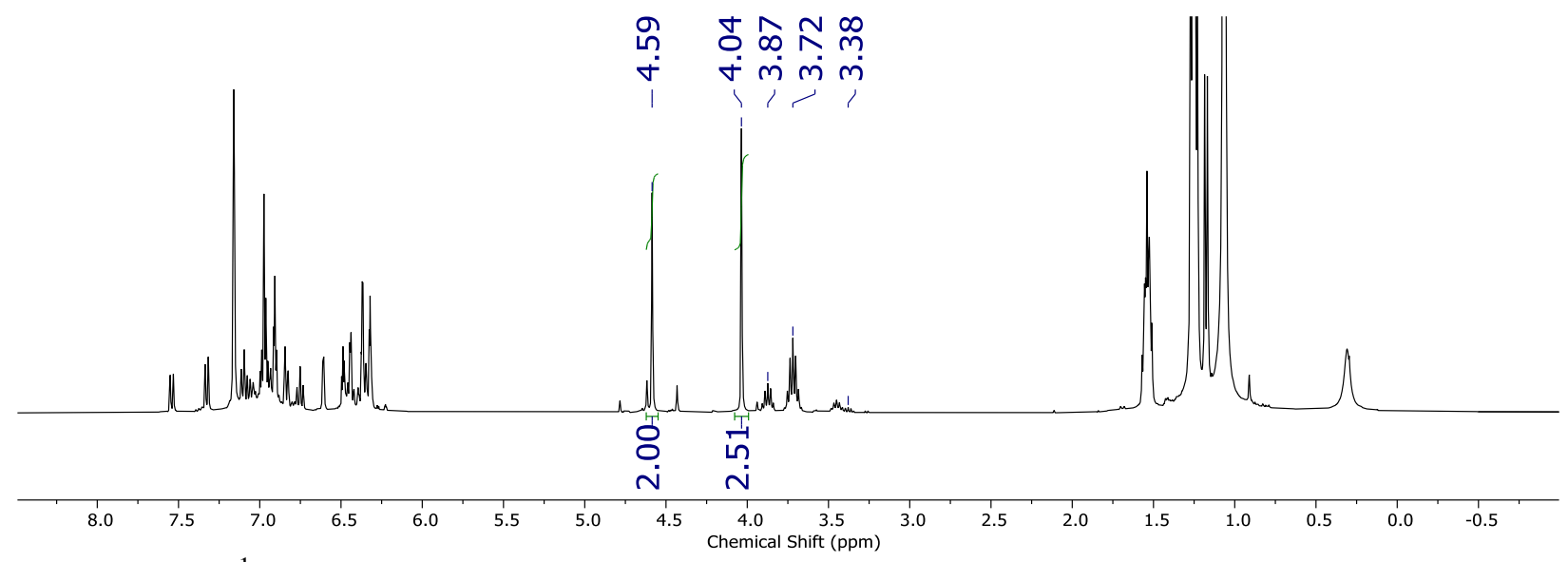

Figure S123. ${ }^{1} \mathrm{H}$ NMR spectrum $\left(400 \mathrm{MHz}, \mathrm{C}_{6} \mathrm{D}_{6}\right.$ ) of the two-photon photoredox catalysis sample for the reaction of ca. $10 \mathrm{~mol} \% \mathrm{~W}(\mathrm{CNDipp})_{6}$ and 1-(2-iodobenzyl)-pyrrole after 12-h irradiation. The following was determined from relative integration: $56 \%$ conversion, $\mathrm{TON}=5.1$. An intense isopropyl methine resonance for $\mathrm{W}(\mathrm{CNDipp})_{6}(3.72 \mathrm{ppm})$ suggests a significant amount of the photocatalyst is still present. Resonances attributable to $\mathrm{WI}_{2}(\mathrm{CNDipp})_{5}(3.87 \mathrm{ppm})$ and free CNDipp (3.38 ppm) are also observed.

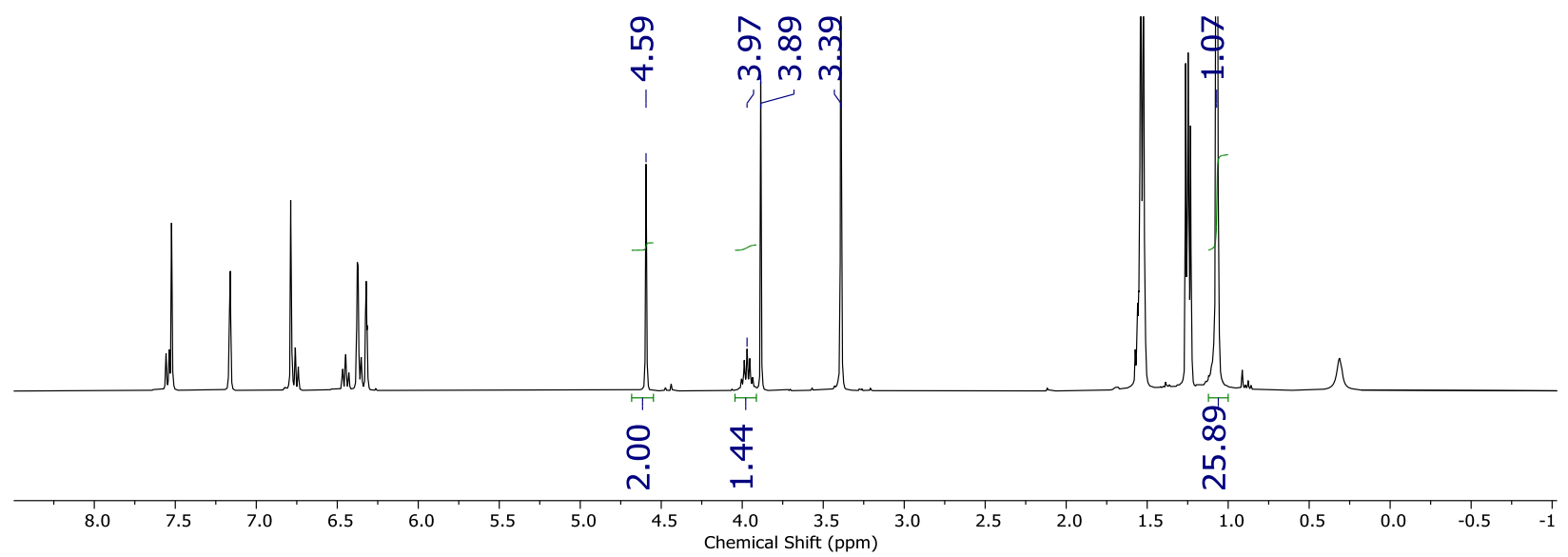

Figure S124. ${ }^{1} \mathrm{H}$ NMR spectrum $\left(400 \mathrm{MHz}, \mathrm{C}_{6} \mathrm{D}_{6}\right)$ of the two-photon photoredox catalysis sample for the reaction of ca. $10 \mathrm{~mol} \% \mathrm{~W}\left(\mathrm{CNDippPh}{ }^{\mathrm{OMe} 3}\right)_{6}$ and 1-(2-iodobenzyl)-pyrrole prior to irradiation. The following concentrations/stoichiometries were determined from relative integration: $\mathrm{W}\left(\mathrm{CNDippPh}{ }^{\mathrm{OMe} 3}\right)_{6}=6.00 \mathrm{mM}, 12.0 \mathrm{~mol} \%$; TMP $=108 \mathrm{mM}, 2.16$ equiv. 


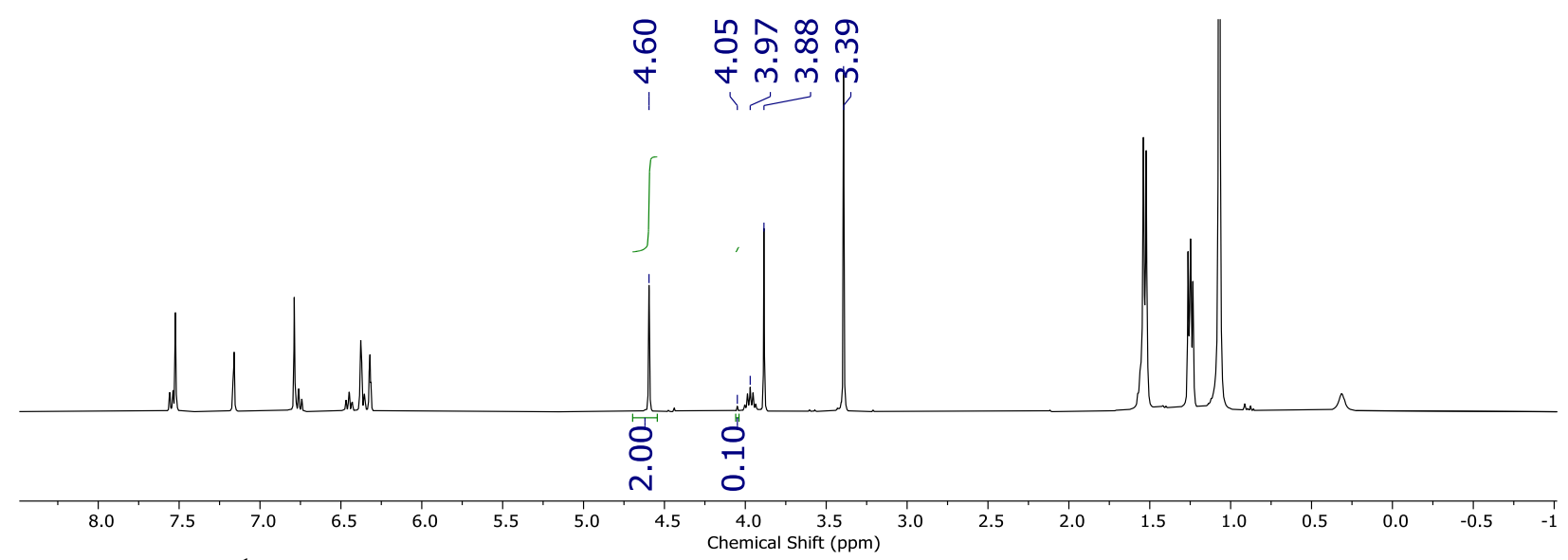

Figure S125. ${ }^{1} \mathrm{H}$ NMR spectrum $\left(400 \mathrm{MHz}, \mathrm{C}_{6} \mathrm{D}_{6}\right)$ of the two-photon photoredox catalysis sample for the reaction of ca. $10 \mathrm{~mol} \% \mathrm{~W}\left(\mathrm{CNDippPh}{ }^{\mathrm{OMe}}\right)_{6}$ and 1-(2-iodobenzyl)-pyrrole after 1-h irradiation. The following was determined from relative integration: $5 \%$ conversion, $\mathrm{TON}=0.4$. Intense resonances for $\mathrm{W}\left(\mathrm{CNDippPh}{ }^{\mathrm{OMe} 3}\right)_{6}$ are still present $\left(3.39,3.88\right.$ ppm: $\mathrm{OCH}_{3} ; 3.97 \mathrm{ppm}$ : isopropyl methine), with negligible decomposition observed.

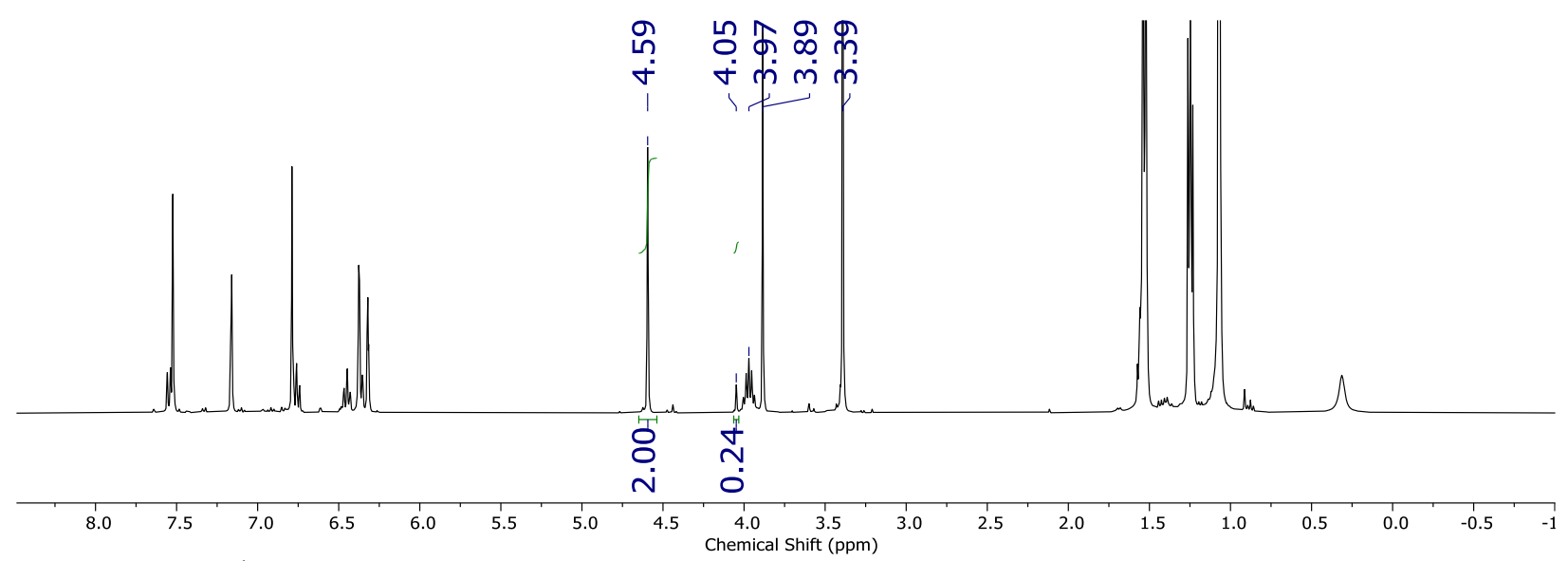

Figure S126. ${ }^{1} \mathrm{H}$ NMR spectrum $\left(400 \mathrm{MHz}, \mathrm{C}_{6} \mathrm{D}_{6}\right)$ of the two-photon photoredox catalysis sample for the reaction of ca. $10 \mathrm{~mol} \% \mathrm{~W}\left(\mathrm{CNDippPh}{ }^{\mathrm{OMe} 3}\right)_{6}$ and 1-(2-iodobenzyl)-pyrrole after 2-h irradiation. The following was determined from relative integration: $11 \%$ conversion, $\mathrm{TON}=0.9$. Intense resonances for $\mathrm{W}\left(\mathrm{CNDippPh}{ }^{\mathrm{OMe} 3}\right)_{6}$ are still present $\left(3.39,3.89\right.$ ppm: $\mathrm{OCH}_{3} ; 3.97 \mathrm{ppm}$ : isopropyl methine), with negligible decomposition observed. 


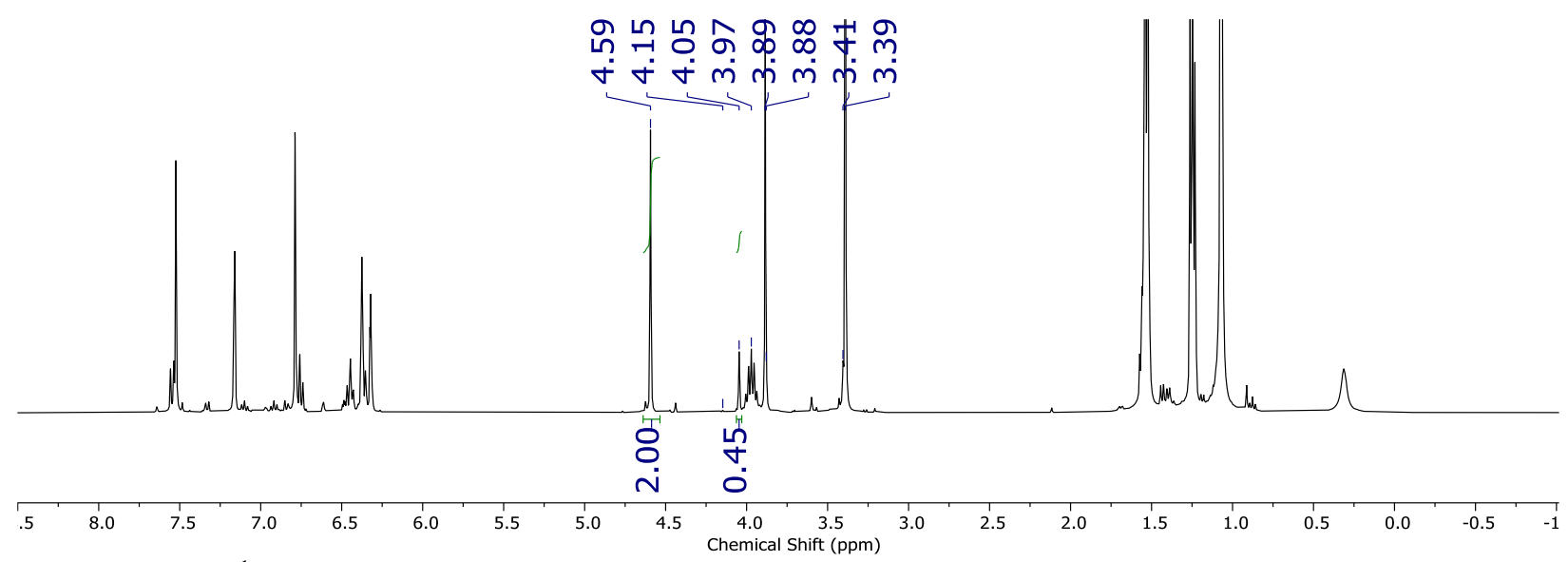

Figure S127. ${ }^{1} \mathrm{H}$ NMR spectrum $\left(400 \mathrm{MHz}, \mathrm{C}_{6} \mathrm{D}_{6}\right)$ of the two-photon photoredox catalysis sample for the reaction of ca. $10 \mathrm{~mol} \% \mathrm{~W}\left(\mathrm{CNDippPh}{ }^{\mathrm{OMe}}\right)_{6}$ and 1-(2-iodobenzyl)-pyrrole after 4-h irradiation. The following was determined from relative integration: $18 \%$ conversion, TON $=1.5$. Intense resonances for $\mathrm{W}\left(\mathrm{CNDippPh}{ }^{\mathrm{OMe} 3}\right)_{6}$ are still present $\left(3.39,3.89 \mathrm{ppm}: \mathrm{OCH}_{3} ; 3.97 \mathrm{ppm}\right.$ : isopropyl methine), with only a small amount of $\mathrm{WI}_{2}\left(\mathrm{CNDippPh}^{\mathrm{OMe} 3}\right)_{5}\left(3.41,3.88 \mathrm{ppm}\right.$ : $\mathrm{OCH}_{3} ; 4.15$ ppm: isopropyl methine) observed.

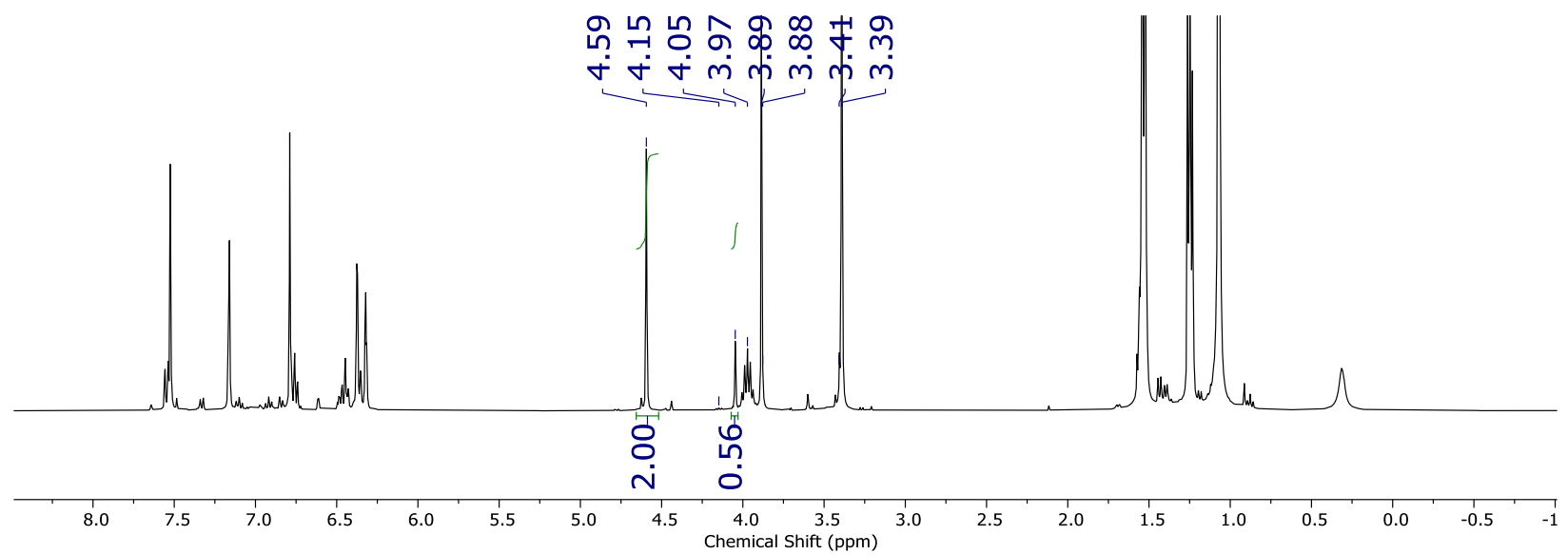

Figure S128. ${ }^{1} \mathrm{H}$ NMR spectrum $\left(400 \mathrm{MHz}, \mathrm{C}_{6} \mathrm{D}_{6}\right)$ of the two-photon photoredox catalysis sample for the reaction of ca. $10 \mathrm{~mol} \% \mathrm{~W}\left(\mathrm{CNDippPh}{ }^{\mathrm{OMe} 3}\right)_{6}$ and 1-(2-iodobenzyl)-pyrrole after 5-h irradiation. The following was determined from relative integration: $22 \%$ conversion, $\mathrm{TON}=1.8$. Intense resonances for $\mathrm{W}\left(\mathrm{CNDippPh}{ }^{\mathrm{OMe} 3}\right)_{6}$ are still present $\left(3.39,3.89 \mathrm{ppm}\right.$ : $\mathrm{OCH}_{3} ; 3.97 \mathrm{ppm}$ : isopropyl methine), with only a small amount of $\mathrm{WI}_{2}\left(\mathrm{CNDippPh}^{\mathrm{OMe} 3}\right)_{5}\left(3.41,3.88 \mathrm{ppm}\right.$ : $\mathrm{OCH}_{3} ; 4.15$ ppm: isopropyl methine) observed. 


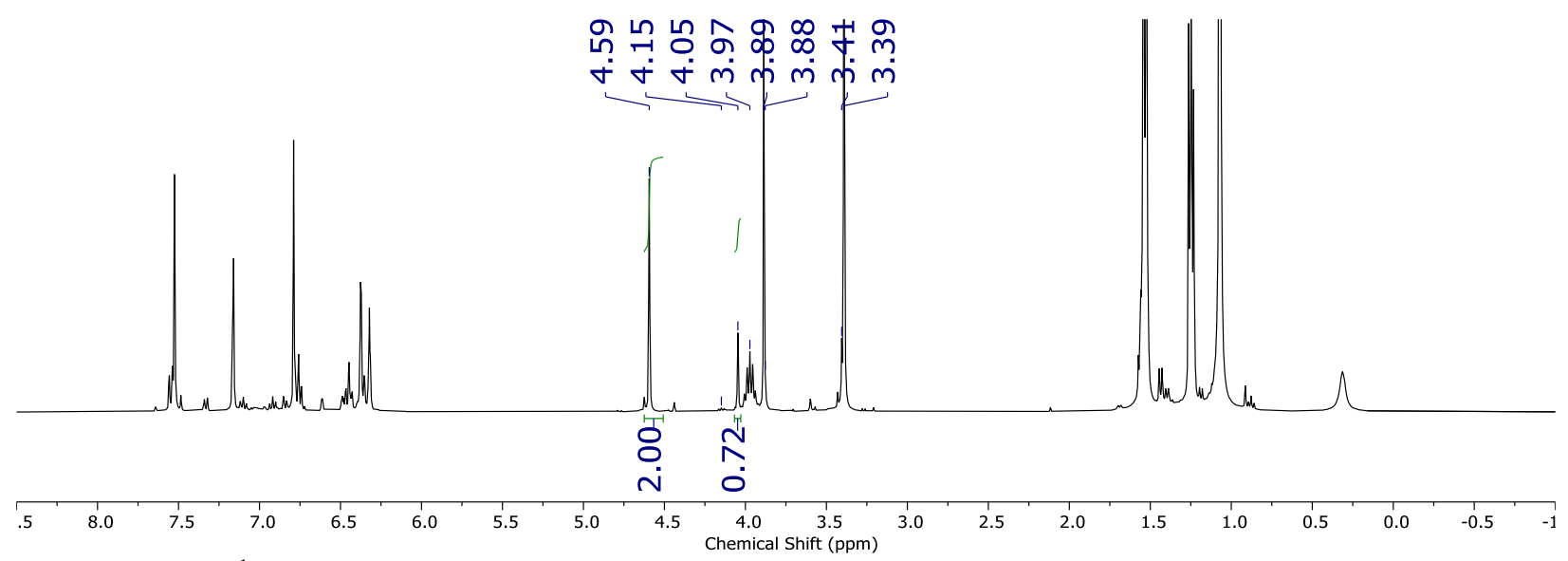

Figure S129. ${ }^{1} \mathrm{H}$ NMR spectrum $\left(400 \mathrm{MHz}, \mathrm{C}_{6} \mathrm{D}_{6}\right)$ of the two-photon photoredox catalysis sample for the reaction of ca. $10 \mathrm{~mol} \% \mathrm{~W}\left(\mathrm{CNDippPh}{ }^{\mathrm{OMe} 3}\right)_{6}$ and 1-(2-iodobenzyl)-pyrrole after 8-h irradiation. The following was determined from relative integration: $27 \%$ conversion, $\mathrm{TON}=2.2$. Intense resonances for $\mathrm{W}\left(\mathrm{CNDippPh}{ }^{\mathrm{OMe} 3}\right)_{6}$ are still present $\left(3.39,3.89 \mathrm{ppm}: \mathrm{OCH}_{3} ; 3.97 \mathrm{ppm}\right.$ : isopropyl methine), with only a small amount of $\mathrm{WI}_{2}\left(\mathrm{CNDippPh}^{\mathrm{OMe} 3}\right)_{5}\left(3.41,3.88 \mathrm{ppm}\right.$ : $\mathrm{OCH}_{3} ; 4.15$ ppm: isopropyl methine) observed.

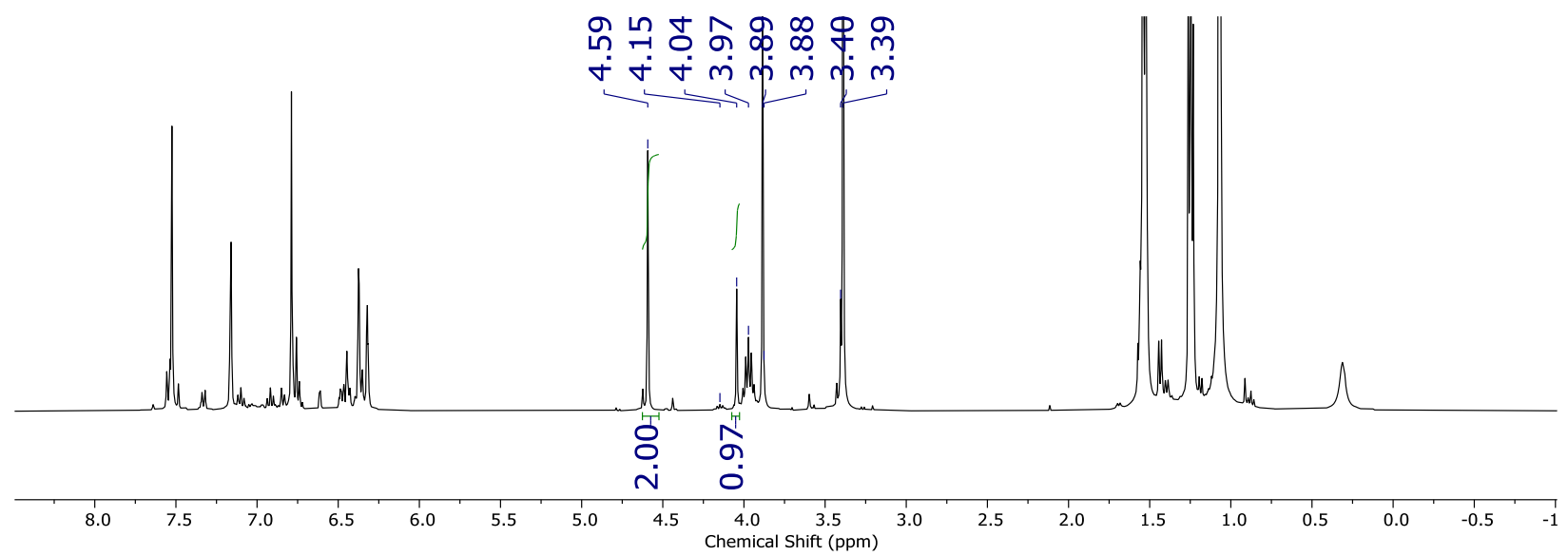

Figure S130. ${ }^{1} \mathrm{H}$ NMR spectrum $\left(400 \mathrm{MHz}, \mathrm{C}_{6} \mathrm{D}_{6}\right)$ of the two-photon photoredox catalysis sample for the reaction of ca. $10 \mathrm{~mol} \% \mathrm{~W}\left(\mathrm{CNDippPh}{ }^{\mathrm{OMe}}\right)_{6}$ and 1-(2-iodobenzyl)-pyrrole after 12-h irradiation. The following was determined from relative integration: $33 \%$ conversion, TON $=2.7$. Intense resonances for $\mathrm{W}\left(\mathrm{CNDippPh}{ }^{\mathrm{OMe} 3}\right)_{6}\left(3.39,3.89 \mathrm{ppm}\right.$ : $\mathrm{OCH}_{3} ; 3.97 \mathrm{ppm}$ : isopropyl methine $)$ suggest a significant amount of the photocatalyst is still present. Only a small amount of $\mathrm{WI}_{2}\left(\mathrm{CNDippPh}{ }^{\mathrm{OMe} 3}\right)_{5}\left(3.40,3.88 \mathrm{ppm}\right.$ : $\mathrm{OCH}_{3} ; 4.15 \mathrm{ppm}$ : isopropyl methine) is observed.

\section{Stern-Volmer Quenching}

Density of 1-(2-iodobenzyl)-pyrrole and 1-(2-bromobenzyl)-pyrrole

1-(2-iodobenzyl)-pyrrole and 1-(2-bromobenzyl)-pyrrole are liquids at room temperature. To facilitate their addition by volume to Stern-Volmer samples, the density of both compounds was determined. Inside the glovebox, 25 or $50 \mu \mathrm{L}$ aliquots of the organic substrate was delivered via microsyringe to a tared vial, and the mass recorded after each addition. The density was extracted from the slope of linear plots of mass versus volume. 


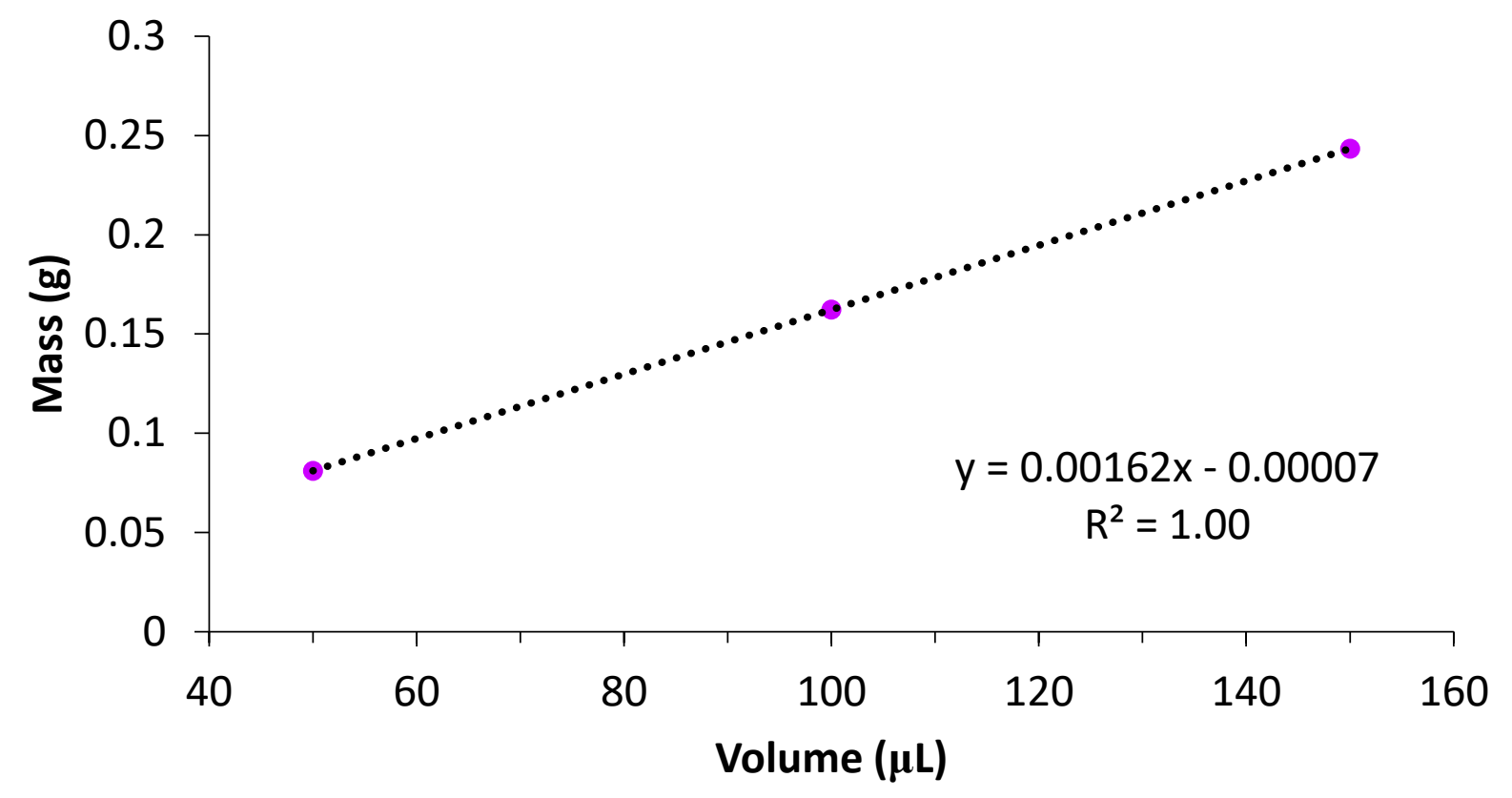

Figure S131. Plot of mass versus volume for 1-(2-iodobenzyl)-pyrrole. From the slope of the linear fit, $\rho=1.62 \mathrm{~g} / \mathrm{mL}$.

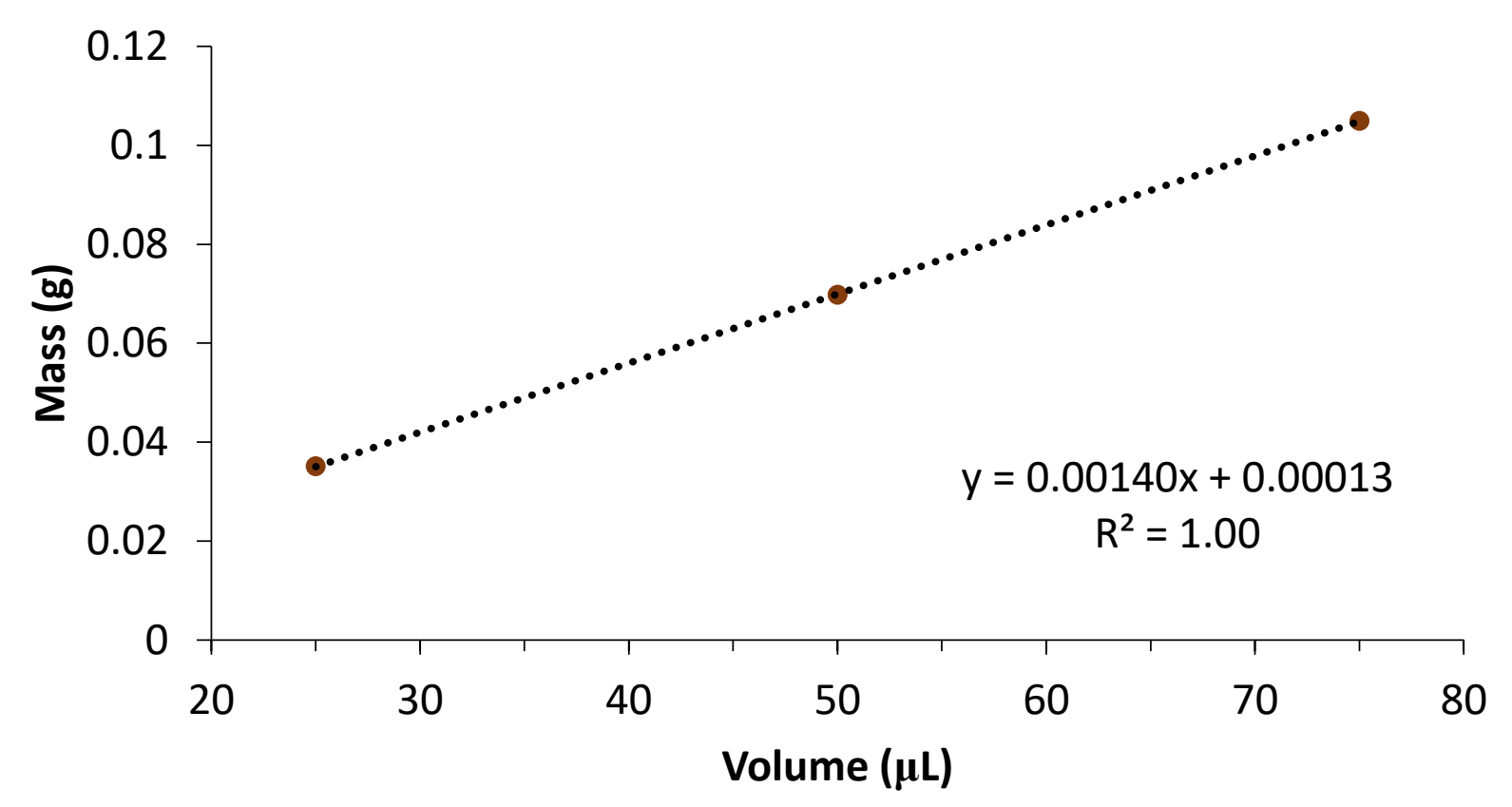

Figure S132. Plot of mass versus volume for 1-(2-bromobenzyl)-pyrrole. From the slope of the linear fit, $\rho=1.40 \mathrm{~g} / \mathrm{mL}$. 


\section{1-(2-iodobenzyl)-pyrrole Quenching of W(CNDipp)6 in Benzene Solution}

Table S2. Samples and results of Stern-Volmer analysis of 1-(2-iodobenzyl)-pyrrole quenching of $\mathrm{W}(\mathrm{CNDipp})_{6}$ in benzene solution $\left(\lambda_{\mathrm{obs}}=580 \mathrm{~nm}\right)$.

$\begin{array}{cccccc}\text { Entry } & \begin{array}{c}{[\mathbf{W}(\mathbf{C N D i p p}) \mathbf{6}]} \\ (\boldsymbol{\mu M})\end{array} & \begin{array}{c}\text { Solvent } \\ 1^{a}\end{array} & \begin{array}{c}{[\mathbf{T M P}]} \\ (\boldsymbol{\mu M})\end{array} & \begin{array}{c}[\mathbf{1 - ( 2 - i o d o b e n z y l ) - p y r r o l e})] \\ (\mathbf{m M})\end{array} & \text { Lifetime }(\mathbf{n s}) \\ 2 & 3.4 & \text { Toluene } & ----- & ---- & 122 \\ 3 & 3.4 & \text { Benzene } & ---- & ---- & 116 \\ 4 & 3.4 & \text { Benzene } & 131 & 9.9 & 126 \\ 5 & 3.4 & \text { Benzene } & ---- & 19.8 & 114 \\ 6 & 3.4 & \text { Benzene } & ---- & 29.7 & 99 \\ 7 & 3.4 & \text { Benzene } & ---- & 39.6 & 92 \\ 8 & 3.4 & \text { Benzene } & ---- & 49.5 & 87\end{array}$

${ }^{a}$ Data from ref. 1.

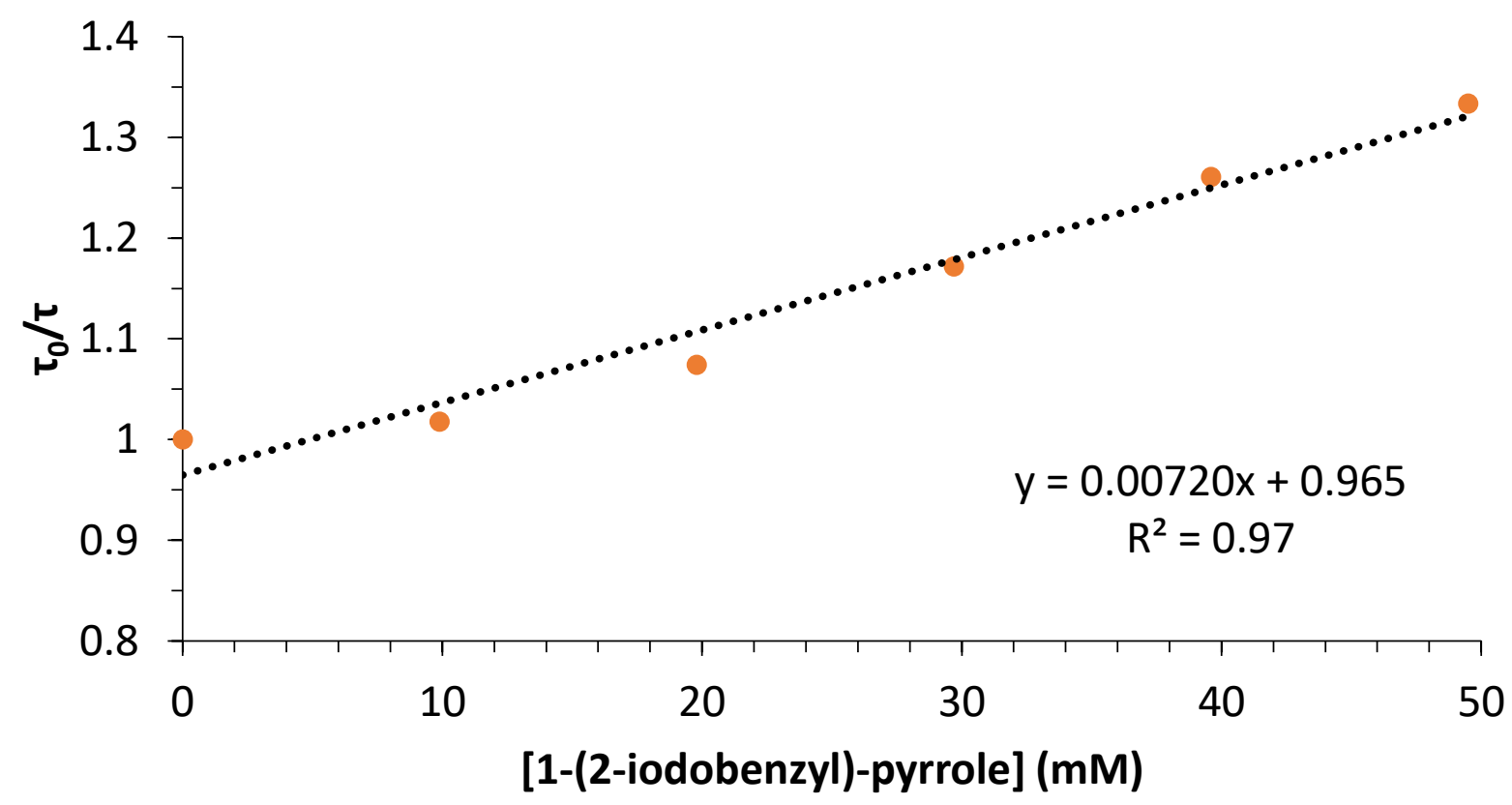

Figure S133. Plot of $\left(\tau_{0} / \tau\right)$ versus 1-(2-iodobenzyl)-pyrrole concentration for W(CNDipp)6. From the slope of the linear fit, the bimolecular quenching constant was determined to be $k_{\mathrm{q}}=6.2 \times 10^{7}$ $\mathrm{M}^{-1} \mathrm{~s}^{-1}$. 


\section{1-(2-bromobenzyl)-pyrrole Quenching of W(CNDipp)6 in Benzene Solution}

Table S3. Samples and results of Stern-Volmer analysis of 1-(2-bromobenzyl)-pyrrole quenching of $\mathrm{W}(\mathrm{CNDipp})_{6}$ in benzene solution $\left(\lambda_{\mathrm{obs}}=580 \mathrm{~nm}\right)$.

$\begin{array}{ccccc}\text { Entry } & \begin{array}{c}{\left[\mathbf{W}(\mathbf{C N D i p p})_{6}\right]} \\ (\boldsymbol{\mu M})\end{array} & \text { Solvent } & \begin{array}{c}\text { [1-(2-bromobenzyl)-pyrrole) }] \\ (\mathbf{m M})\end{array} & \text { Lifetime }(\mathbf{n s}) \\ 1 & 3.4 & \text { Benzene } & ---- & 116 \\ 2 & 3.4 & \text { Benzene } & 385 & 93 \\ 3 & 3.4 & \text { Benzene } & 734 & 76 \\ 4 & 3.4 & \text { Benzene } & 1147 & 57 \\ 5 & 3.4 & \text { Benzene } & 1498 & 47\end{array}$

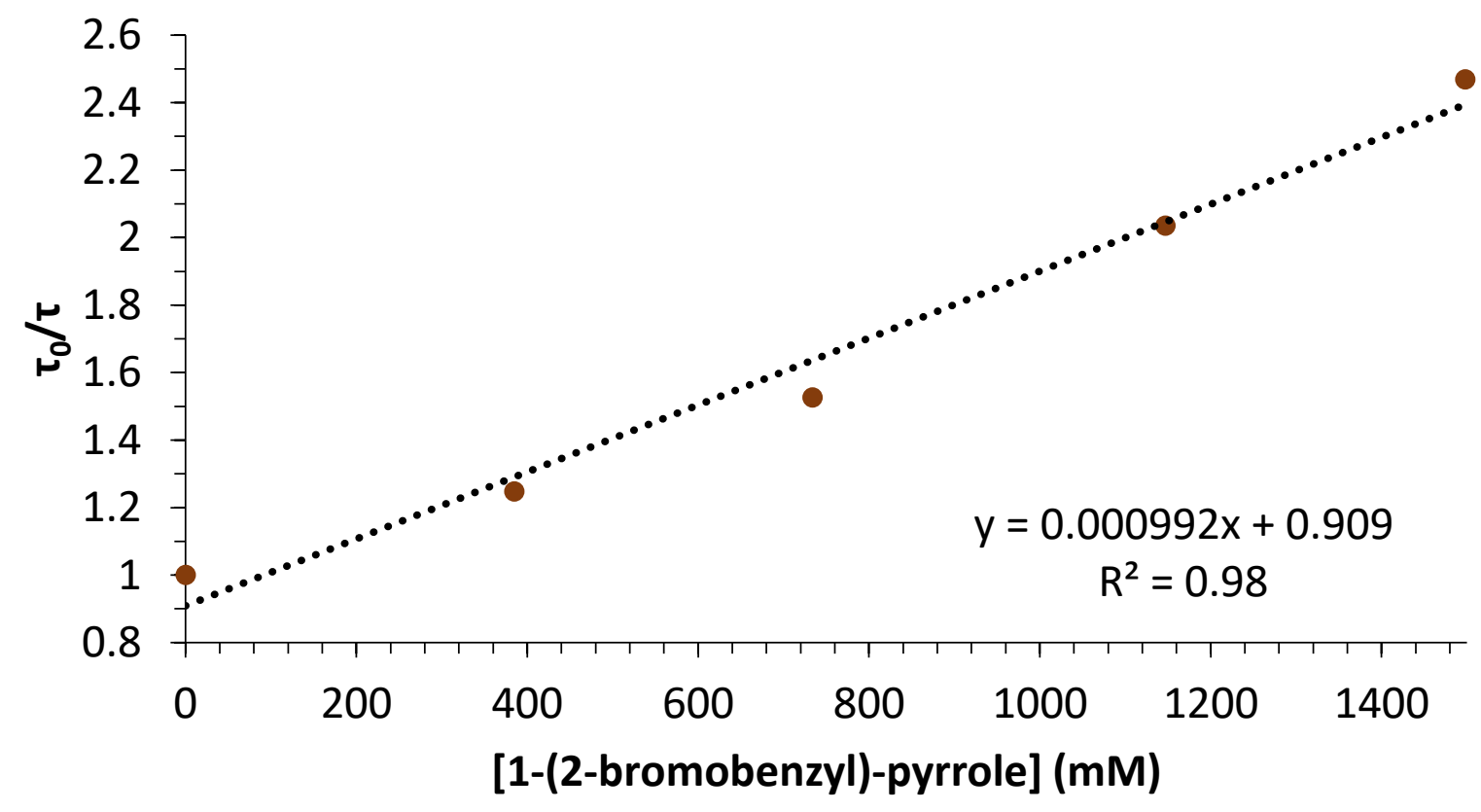

Figure S134. Plot of $\left(\tau_{0} / \tau\right)$ versus 1-(2-bromobenzyl)-pyrrole concentration for W(CNDipp)6. From the slope of the linear fit, the bimolecular quenching constant was determined to be $k_{\mathrm{q}}=8.6 \times 10^{6}$ $\mathrm{M}^{-1} \mathrm{~s}^{-1}$. 
1-(2-iodobenzyl)-pyrrole Quenching of W(CNDippPh $\left.{ }^{\mathrm{OMe}}\right)_{6}$ in Benzene Solution

Table S4. Samples and results of Stern-Volmer analysis of 1-(2-iodobenzyl)-pyrrole quenching of $\mathrm{W}\left(\mathrm{CNDippPh}{ }^{\mathrm{OMe} 3}\right)_{6}$ in benzene solution $\left(\lambda_{\text {obs }}=620 \mathrm{~nm}\right)$.

\begin{tabular}{|c|c|c|c|c|c|}
\hline Entry & $\begin{array}{c}{\left[\mathrm{W}\left(\mathrm{CNDippPh}{ }^{\mathrm{OMe3}}\right)_{6}\right]} \\
(\mu \mathrm{M})\end{array}$ & Solvent & $\begin{array}{l}{[\mathrm{TMP}]} \\
(\mu \mathrm{M})\end{array}$ & $\begin{array}{c}\text { [1-(2-iodobenzyl)-pyrrole) }] \\
(\mathrm{mM})\end{array}$ & Lifetime \\
\hline $1^{a}$ & ---- & Toluene & ---- & ---- & $1.83 \mu \mathrm{s}$ \\
\hline 2 & 1.7 & Benzene & ----- & ----- & $1.76 \mu \mathrm{s}$ \\
\hline 3 & 1.7 & Benzene & 81 & ----- & $1.80 \mu \mathrm{s}$ \\
\hline 4 & 1.7 & Benzene & ----- & 185 & $260 \mathrm{~ns}$ \\
\hline 5 & 1.7 & Benzene & ----- & 370 & $148 \mathrm{~ns}$ \\
\hline 6 & 1.7 & Benzene & ----- & 555 & $122 \mathrm{~ns}$ \\
\hline 7 & 1.7 & Benzene & ----- & 740 & $96 \mathrm{~ns}$ \\
\hline
\end{tabular}

${ }^{a}$ Data from ref. 1.

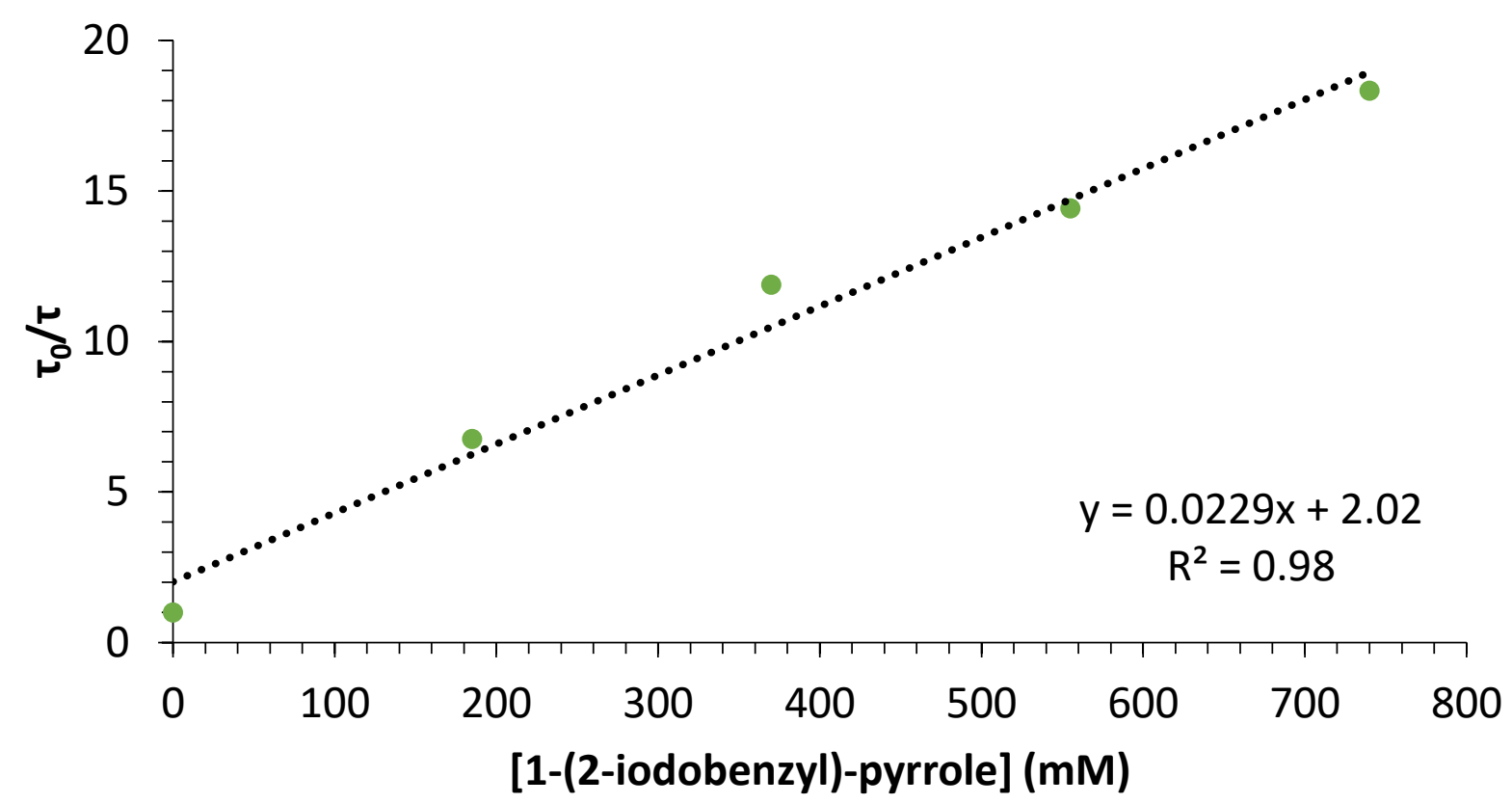

Figure S135. Plot of $\left(\tau_{0} / \tau\right)$ versus 1-(2-iodobenzyl)-pyrrole concentration for $\mathrm{W}\left(\mathrm{CNDippPh}{ }^{\mathrm{OMe} 3}\right)_{6}$. From the slope of the linear fit, the bimolecular quenching constant was determined to be $k_{\mathrm{q}}=1.3 \mathrm{x}$ $10^{7} \mathrm{M}^{-1} \mathrm{~s}^{-1}$. 
1-(2-iodobenzyl)-pyrrole Quenching of W(CN-1-(2-i ${ }^{-}$r)-Naph)6 in Benzene Solution

Table S5. Samples and results of Stern-Volmer analysis of 1-(2-iodobenzyl)-pyrrole quenching of $\mathrm{W}\left(\mathrm{CN}-1-\left(2-{ }^{i} \mathrm{Pr}\right)-\mathrm{Naph}\right)_{6}$ in benzene solution $\left(\lambda_{\mathrm{obs}}=670 \mathrm{~nm}\right)$.

\begin{tabular}{|c|c|c|c|c|c|}
\hline Entry & $\begin{array}{c}{\left[\mathrm{W}\left(\mathrm{CN}-1-\left(2-{ }^{i} \mathrm{Pr}\right)-\mathrm{Naph}\right)_{6}\right]} \\
(\mu \mathrm{M})\end{array}$ & Solvent & $\begin{array}{c}{[\mathrm{TMP}]} \\
(\mu \mathrm{M})\end{array}$ & $\begin{array}{c}\text { [1-(2-iodobenzyl)-pyrrole)] } \\
(\mathbf{m M})\end{array}$ & Lifetime \\
\hline $1^{a}$ & ---- & Toluene & ---- & ----- & $3.83 \mu \mathrm{s}$ \\
\hline 2 & 1.9 & Benzene & ----- & ----- & $3.65 \mu \mathrm{s}$ \\
\hline 3 & 1.9 & Benzene & 81 & ----- & $3.62 \mu \mathrm{s}$ \\
\hline 4 & 1.9 & Benzene & ----- & 185 & $1.84 \mu \mathrm{s}$ \\
\hline 5 & 1.9 & Benzene & ----- & 370 & $1.09 \mu \mathrm{s}$ \\
\hline 6 & 1.9 & Benzene & ----- & 555 & $734 \mathrm{~ns}$ \\
\hline 7 & 1.9 & Benzene & ----- & 740 & $531 \mathrm{~ns}$ \\
\hline 8 & 1.9 & Benzene & ----- & 925 & $459 \mathrm{~ns}$ \\
\hline
\end{tabular}

${ }^{a}$ Data from ref. 2.

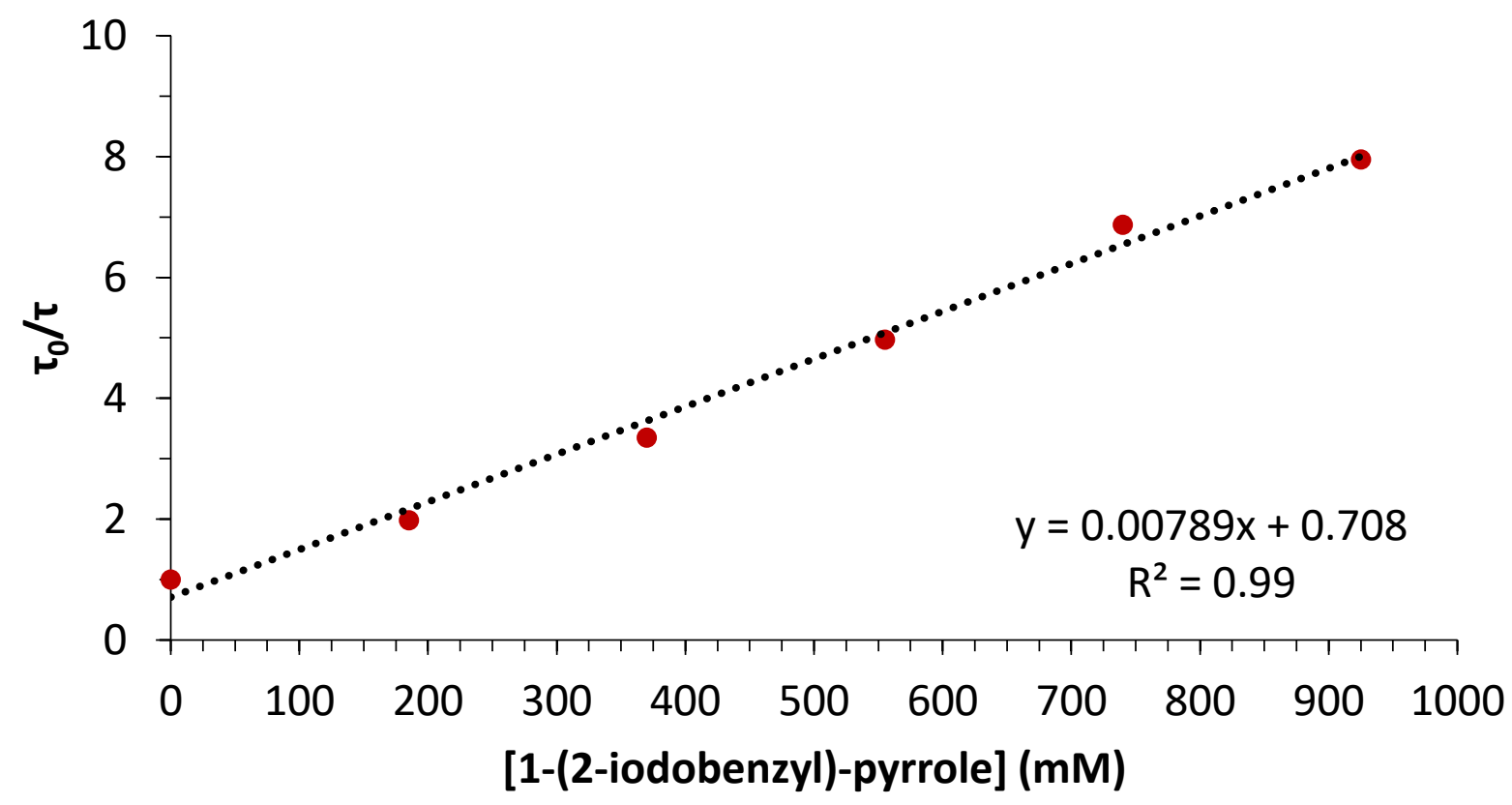

Figure S136. Plot of $\left(\tau_{0} / \tau\right)$ versus 1-(2-iodobenzyl)-pyrrole concentration for $\mathrm{W}\left(\mathrm{CN}-1-\left(2-{ }^{i} \mathrm{Pr}\right)-\right.$ Naph)6. From the slope of the linear fit, the bimolecular quenching constant was determined to be $k_{\mathrm{q}}$ $=2.2 \times 10^{6} \mathrm{M}^{-1} \mathrm{~s}^{-1}$. 


\section{Cyclic Voltammetry}

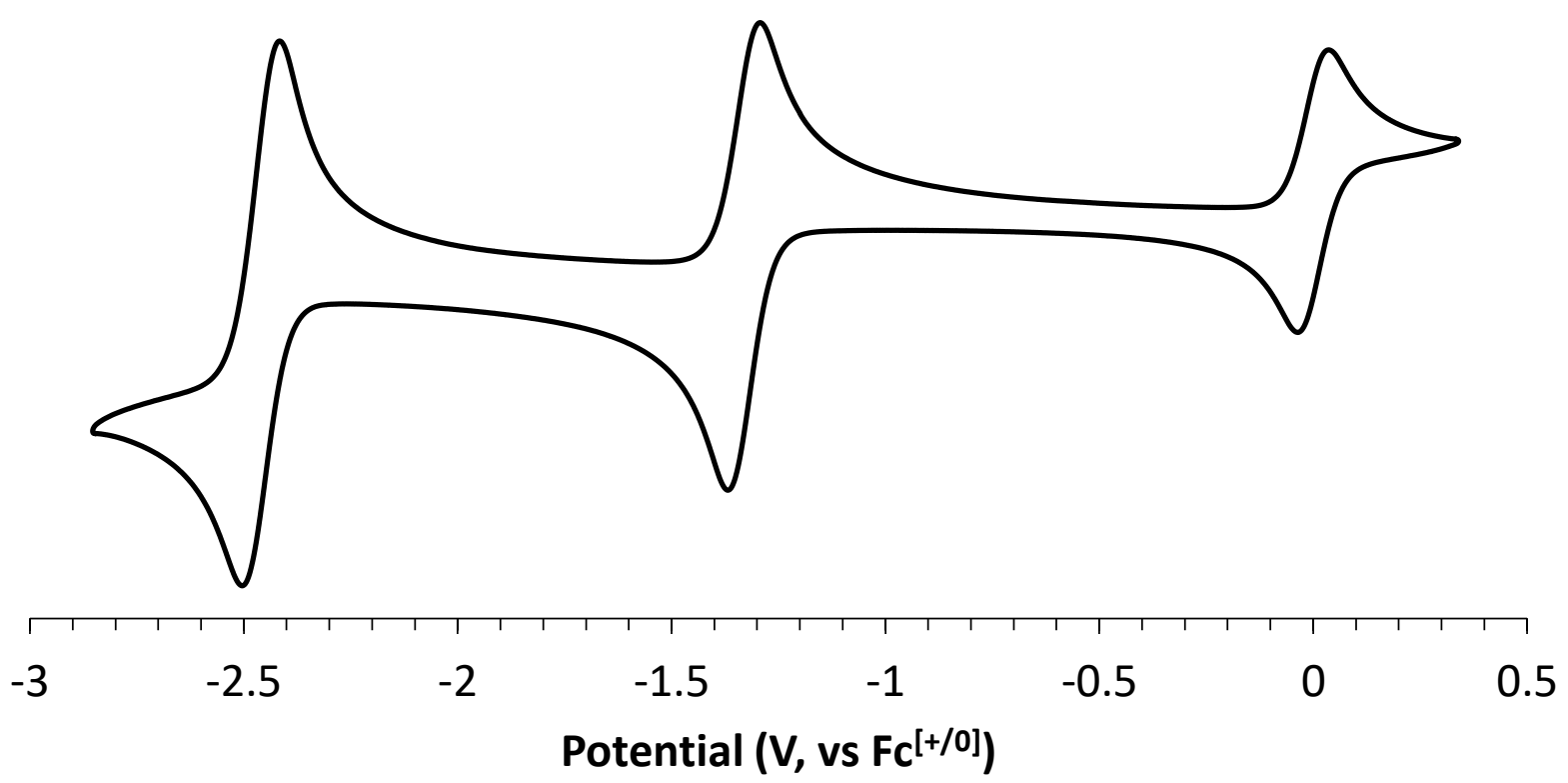

Figure S137. Cyclic voltammogram of $\left[\mathrm{Cp}_{2} \mathrm{Co}\right]\left[\mathrm{PF}_{6}\right]$ in $0.1 \mathrm{M} \mathrm{THF}$ solution of $\left[{ }^{n} \mathrm{Bu}_{4}\right]\left[\mathrm{PF}_{6}\right]$ at a scan rate of $100 \mathrm{mV} / \mathrm{s}$. The $\mathrm{CV}$ contains ferrocene and is referenced versus $\mathrm{Fc}^{[+/ 0]}$.
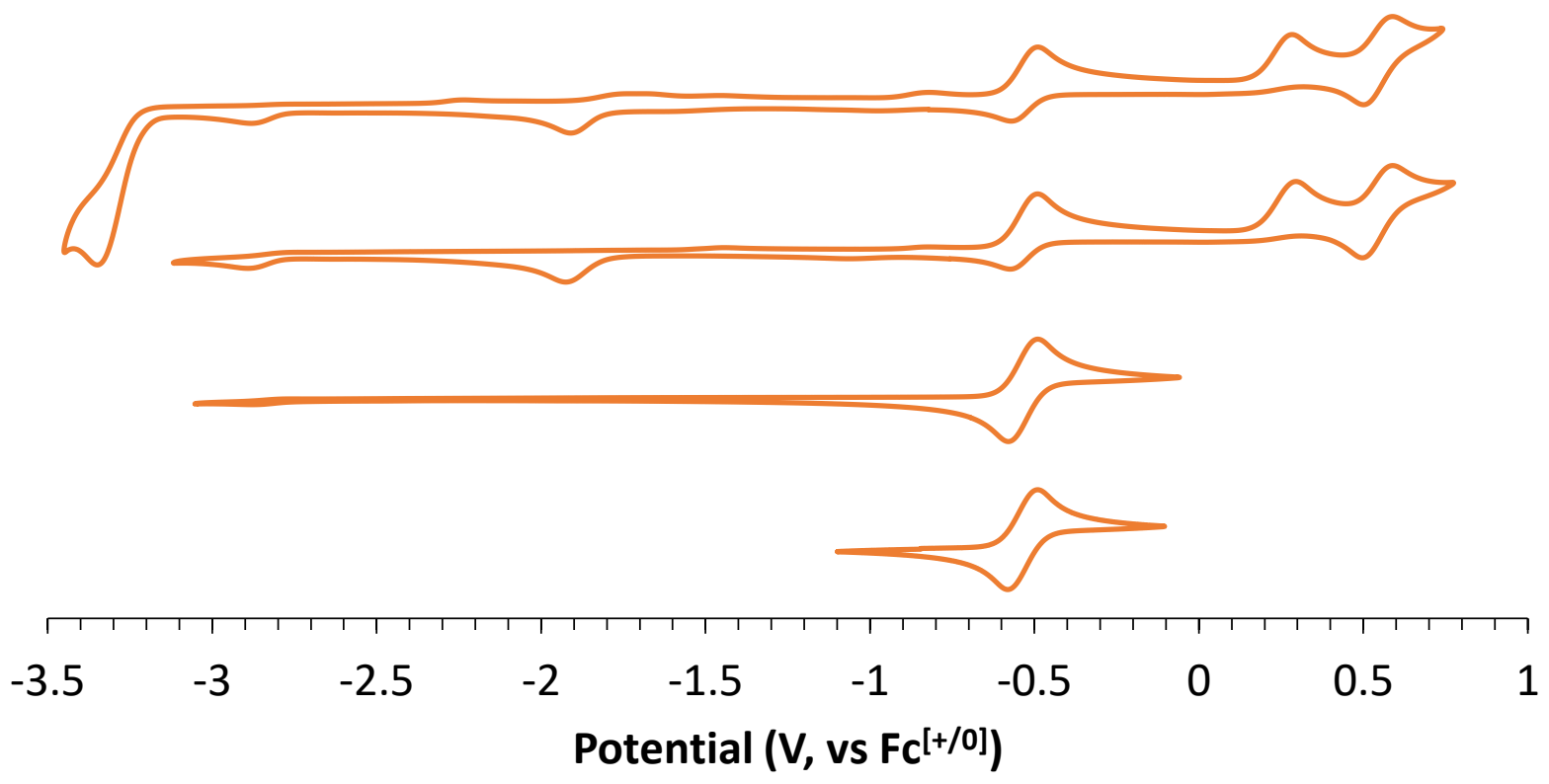

Figure S138. Cyclic voltammograms of $\mathrm{W}(\mathrm{CNDipp})_{6}$ in $0.1 \mathrm{M}$ THF solution of $\left[{ }^{n} \mathrm{Bu}_{4}\right]\left[\mathrm{PF}_{6}\right]$ at a scan rate of $100 \mathrm{mV} / \mathrm{s}$. 

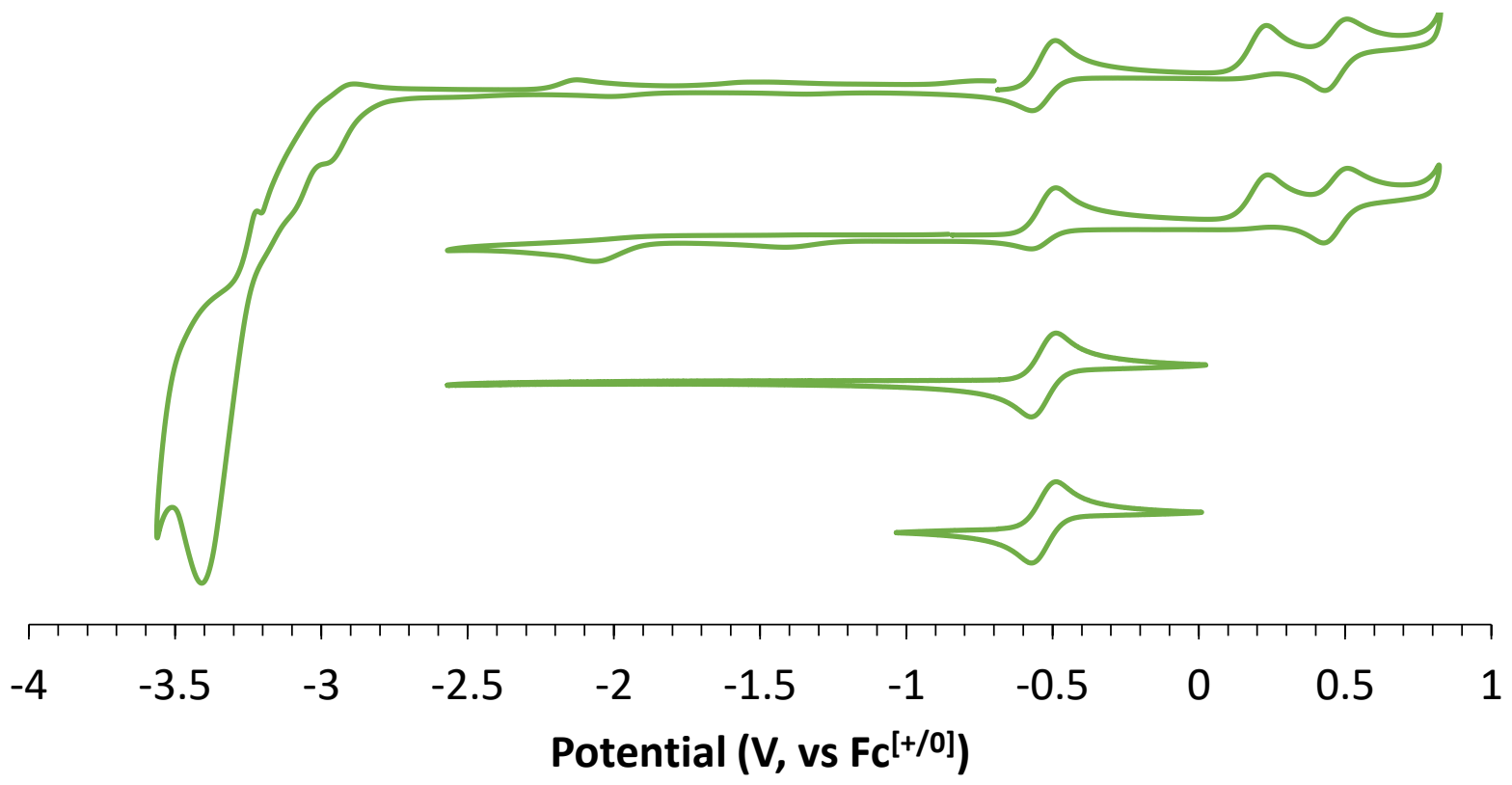

Figure S139. Cyclic voltammograms of $\mathrm{W}\left(\mathrm{CNDippPh}^{\mathrm{OMe} 3}\right)_{6}$ in $0.1 \mathrm{M}$ THF solution of $\left[{ }^{n} \mathrm{Bu}_{4}\right]\left[\mathrm{PF}_{6}\right]$ at a scan rate of $100 \mathrm{mV} / \mathrm{s}$.

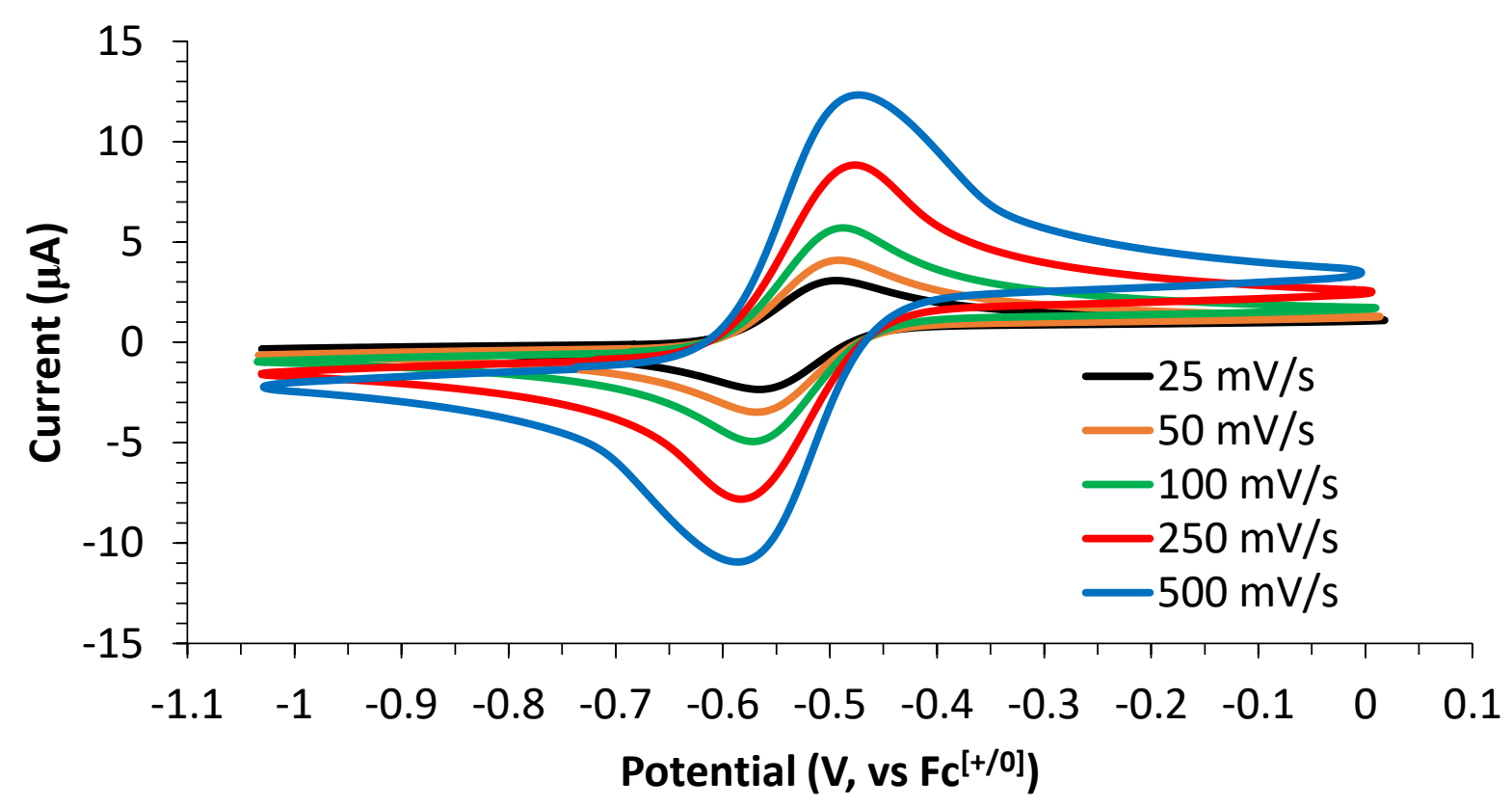

Figure S140. Cyclic voltammograms of the isolated $\mathrm{W}^{[+/ 0]}$ redox couple of $\mathrm{W}\left(\mathrm{CNDippPh}{ }^{\mathrm{OMe} 3}\right)_{6}$ in $0.1 \mathrm{M}$ THF solution of $\left[{ }^{n} \mathrm{Bu}_{4}\right]\left[\mathrm{PF}_{6}\right]$ at different scan rates. 


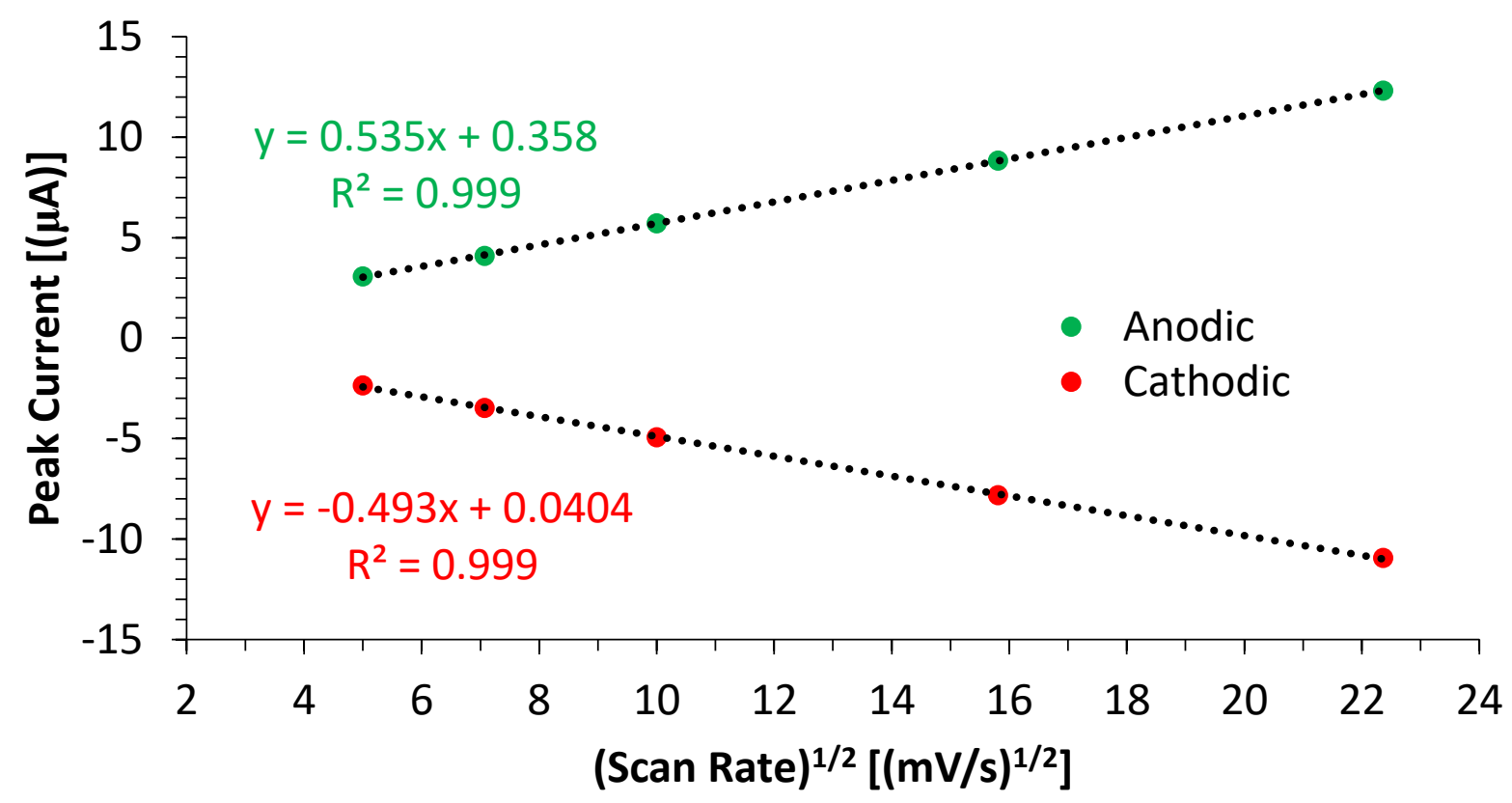

Figure S141. Plot of the cathodic/anodic peak current versus the square root of scan rate for the $\mathrm{W}^{[+/ 0]}$ redox couple of $\mathrm{W}\left(\mathrm{CNDippPh}{ }^{\mathrm{OMe} 3}\right)_{6}$ in $0.1 \mathrm{M}$ THF solution of $\left[{ }^{n} \mathrm{Bu}_{4}\right]\left[\mathrm{PF}_{6}\right]$.
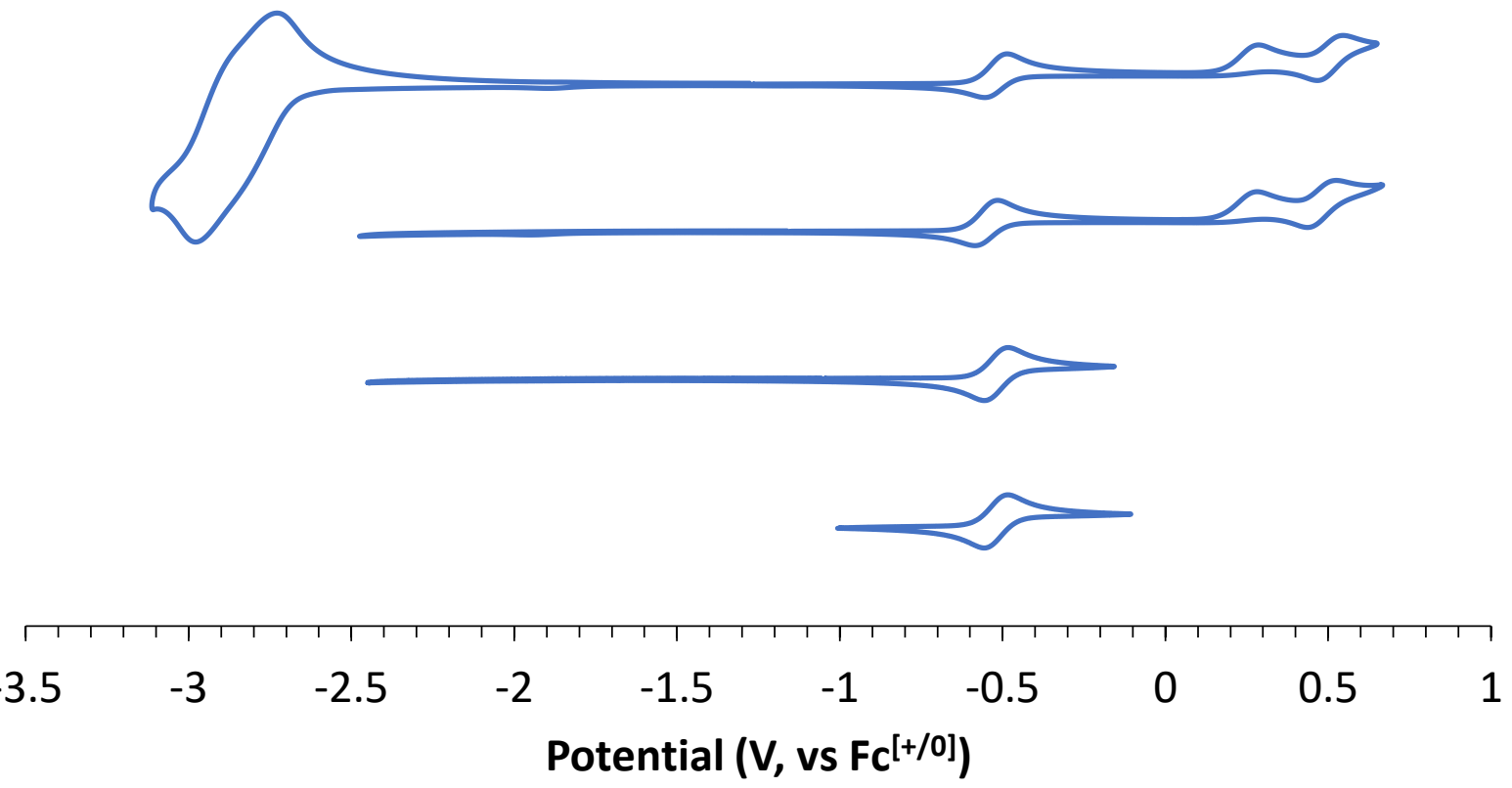

Figure S142. Cyclic voltammograms of $\mathrm{W}\left(\mathrm{CNDippPh}^{\mathrm{Ph}}\right)_{6}$ in $0.1 \mathrm{M}$ THF solution of $\left[{ }^{n} \mathrm{Bu}_{4}\right]\left[\mathrm{PF}_{6}\right]$ at a scan rate of $100 \mathrm{mV} / \mathrm{s}$. 


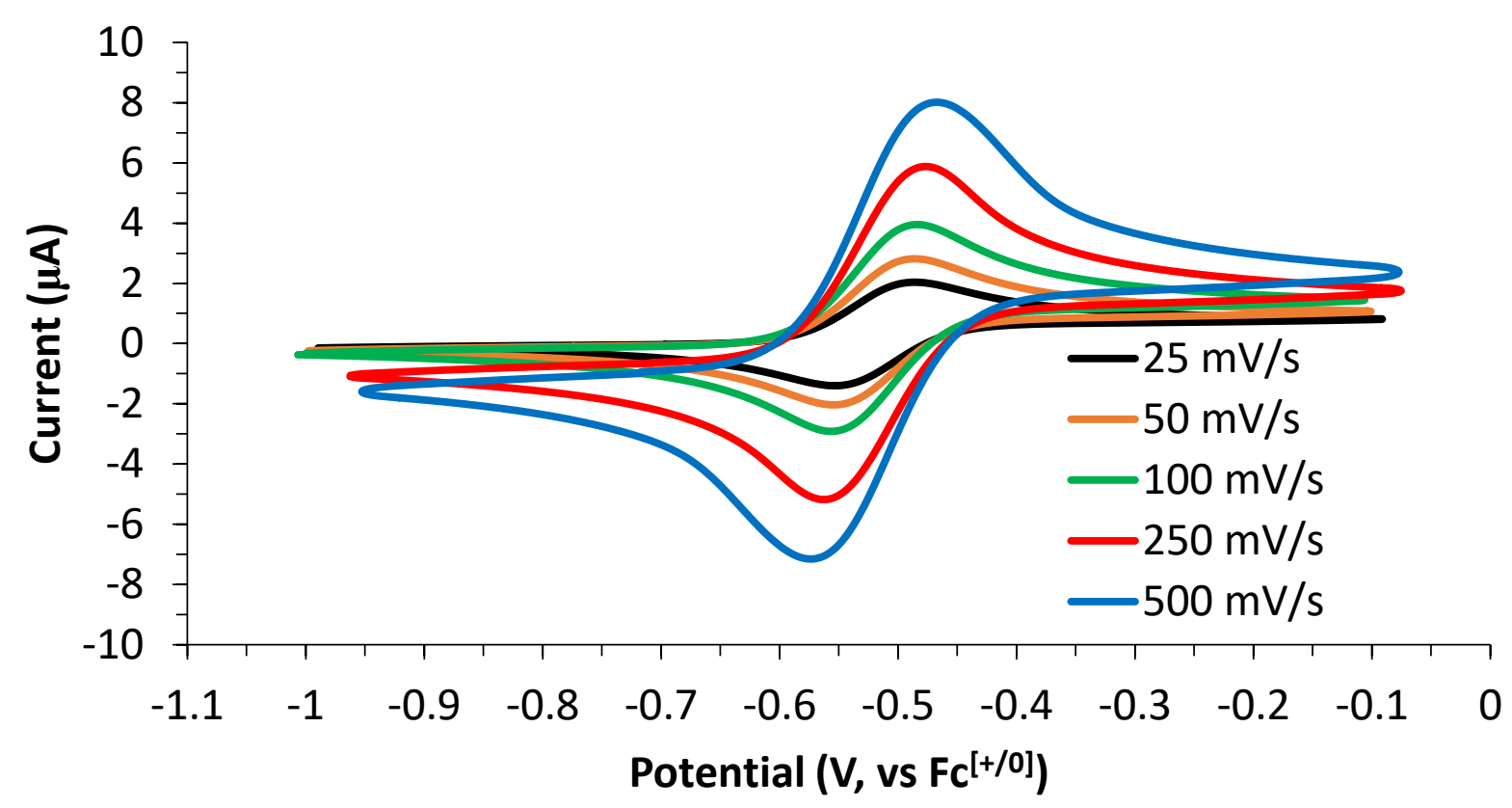

Figure S143. Cyclic voltammograms of the isolated $\mathrm{W}^{[+/ 0]}$ redox couple of $\mathrm{W}\left(\mathrm{CNDippPh}^{\mathrm{Ph}}\right)_{6}$ in 0.1 M THF solution of $\left[{ }^{n} \mathrm{Bu}_{4}\right]\left[\mathrm{PF}_{6}\right]$ at different scan rates.

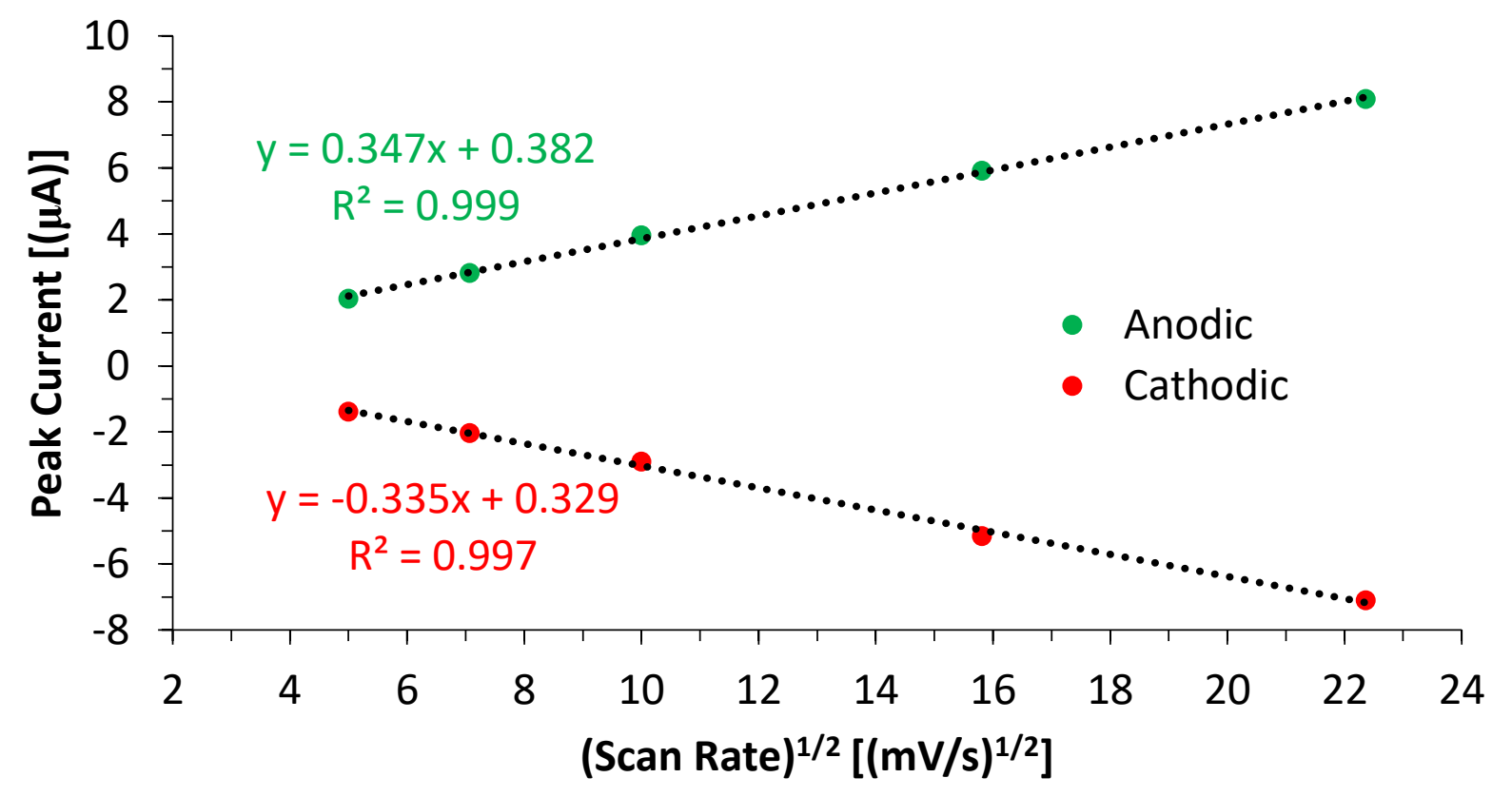

Figure S144. Plot of the cathodic/anodic peak current versus the square root of scan rate for the $\mathrm{W}^{[+/ 0]}$ redox couple of $\mathrm{W}\left(\mathrm{CNDippPh}{ }^{\mathrm{Ph}}\right)_{6}$ in $0.1 \mathrm{M}$ THF solution of $\left[{ }^{n} \mathrm{Bu}_{4}\right]\left[\mathrm{PF}_{6}\right]$. 


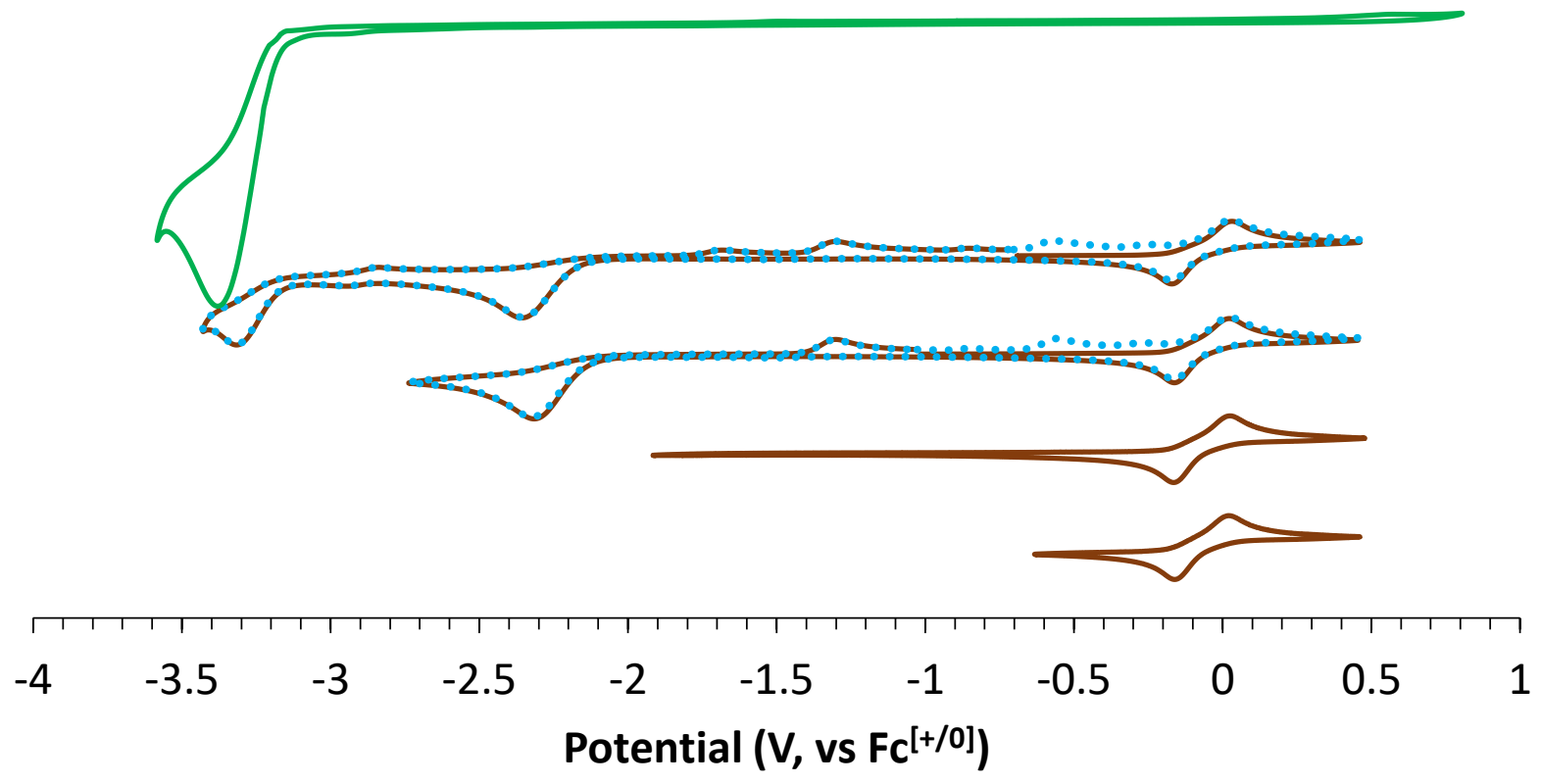

Figure S145. Cyclic voltammograms of $\mathrm{WI}_{2}(\mathrm{CNDipp})_{5}$ (brown; cycles 2 depicted as dotted blue traces) and free CNDipp (green) in $0.1 \mathrm{M} \mathrm{THF}$ solution of $\left[{ }^{n} \mathrm{Bu}_{4}\right]\left[\mathrm{PF}_{6}\right]$ at a scan rate of $100 \mathrm{mV} / \mathrm{s}$.

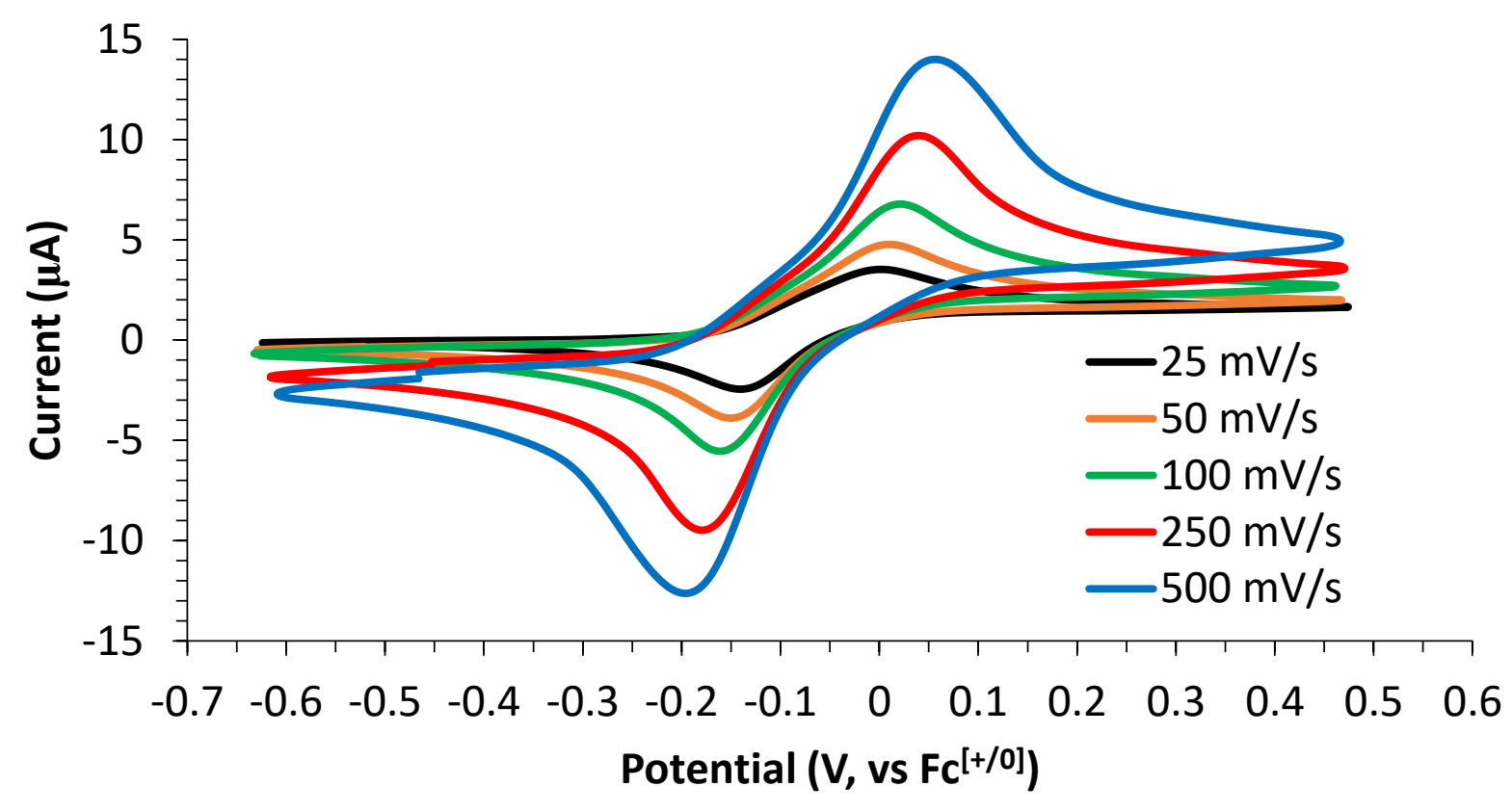

Figure S146. Cyclic voltammograms of the isolated $\mathrm{W}^{[3+/ 2+]}$ redox couple of $\mathrm{WI}_{2}(\mathrm{CNDipp})_{5}$ in 0.1 $\mathrm{M}$ THF solution of $\left[{ }^{n} \mathrm{Bu}_{4}\right]\left[\mathrm{PF}_{6}\right]$ at different scan rates. 


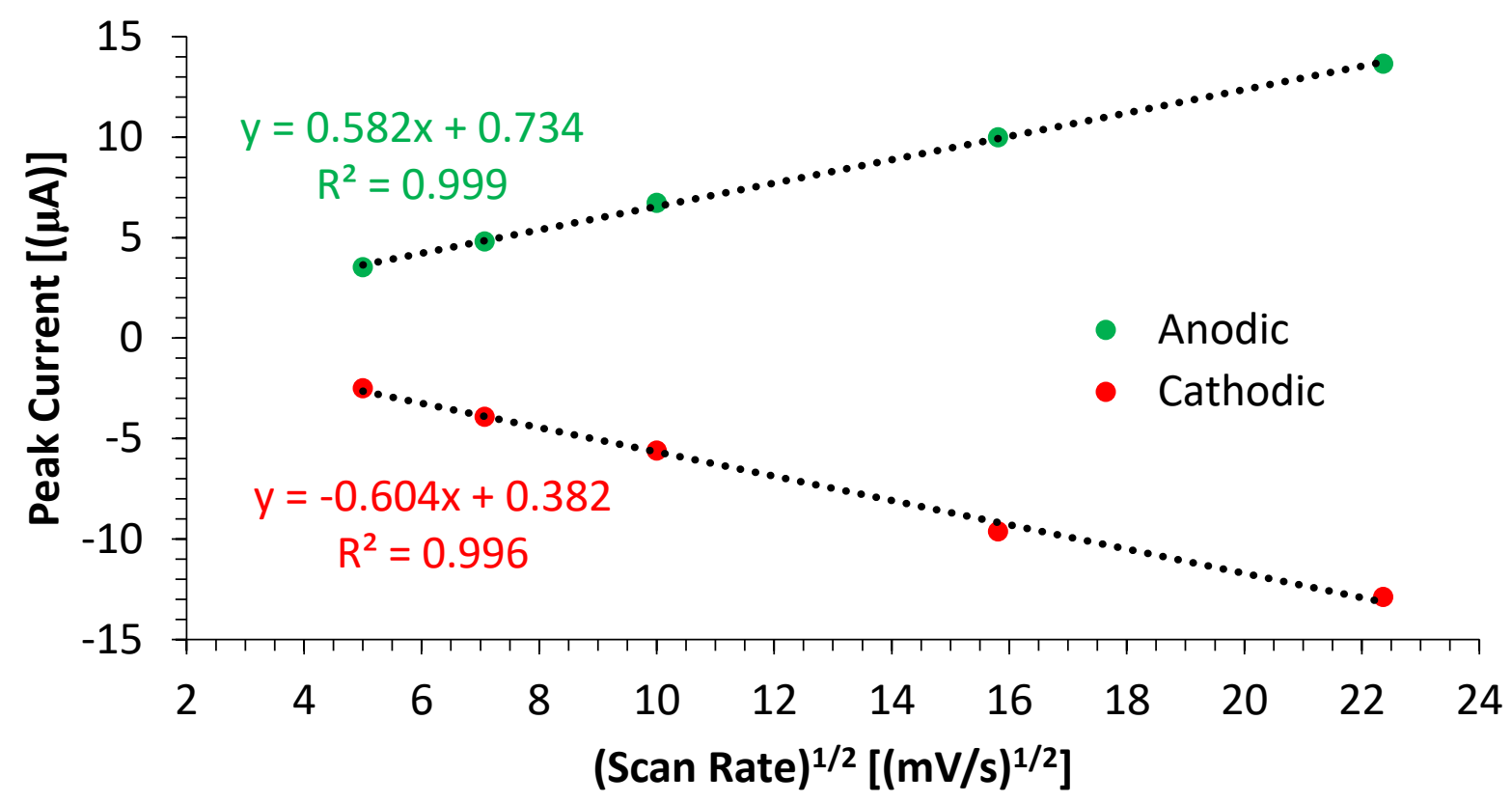

Figure S147. Plot of the cathodic/anodic peak current versus the square root of scan rate for the $\mathrm{W}^{[3+/ 2+]}$ redox couple of $\mathrm{WI}_{2}(\mathrm{CNDipp})_{5}$ in $0.1 \mathrm{M}$ THF solution of $\left[{ }^{n} \mathrm{Bu}_{4}\right]\left[\mathrm{PF}_{6}\right]$.

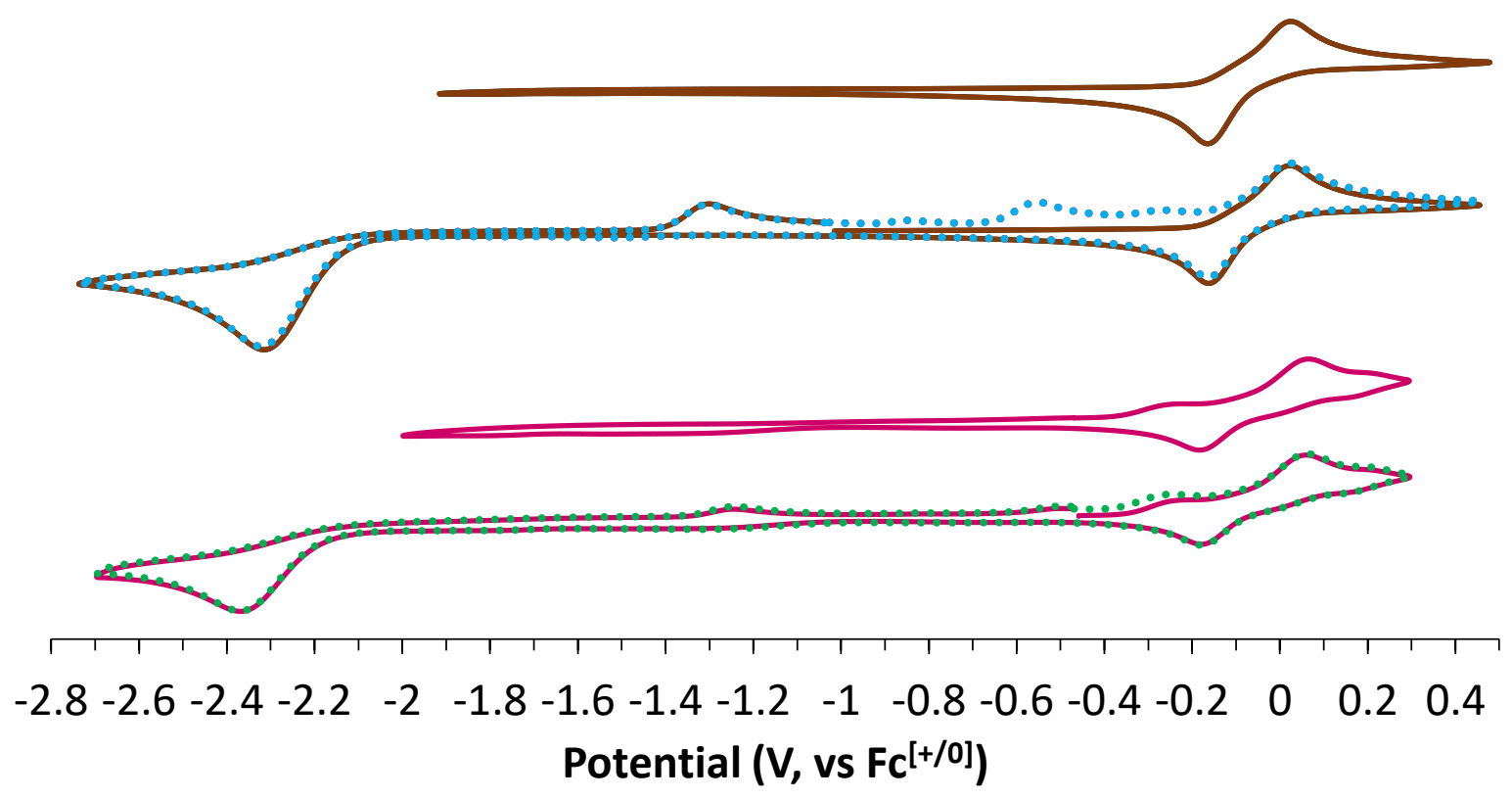

Figure S148. Cyclic voltammograms of $\mathrm{WI}_{2}(\mathrm{CNDipp})_{5}$ (brown; cycle 2 depicted as dotted blue trace) and $\mathrm{WI}_{2}\left(\mathrm{CNDippPh}^{\mathrm{OMe} 3}\right)_{5}$ (magenta; cycle 2 depicted as dotted green trace) in $0.1 \mathrm{M}$ THF solution of $\left[{ }^{n} \mathrm{Bu}_{4}\right]\left[\mathrm{PF}_{6}\right]$ at a scan rate of $100 \mathrm{mV} / \mathrm{s}$. ${ }^{*}$ Note: $\mathrm{WI}_{2}\left(\mathrm{CNDippPh}^{\mathrm{OMe} 3}\right)_{5}$ contains a minor impurity that gives rise to the extra features present in cycle 1 of the CVs. 
Estimation of $E^{o}\left(\mathrm{~W}^{[3+/ 2+]}\right)$ and $E_{\mathrm{p}, \mathrm{c}}^{\mathrm{o}}\left(\mathrm{W}^{[2+/ 0]}\right)$ of $\mathrm{WI}_{2}(\mathrm{CNAr})_{5}$ by Extrapolation of [MI $\left.(\mathrm{CNPh})_{6}\right]^{+}$ and $\left[\mathrm{M}(\mathrm{CNPh})_{7}\right]^{2+}$ Formal/Peak Potentials

Walton and co-workers previously reported the redox chemistry of $\left[\mathrm{Mo}(\mathrm{CNPh})_{7}\right]\left[\mathrm{PF}_{6}\right]_{2}$, $\left[\mathrm{MoI}(\mathrm{CNPh})_{6}\right]\left[\mathrm{PF}_{6}\right]$, and $\left[\mathrm{W}(\mathrm{CNPh})_{7}\right]\left[\mathrm{PF}_{6}\right]_{2}{ }^{13}$ Cyclic voltammograms of all three complexes display a reversible 1-electron $\mathrm{M}^{[3+/ 2+]}$ oxidation and irreversible 2-electron $\mathrm{M}^{[2+/ 0]}$ reduction event at the potentials listed in Table S6. Replacement of an uncharged $\pi$-accepting $\mathrm{CNPh}$ ligand of $\left[\mathrm{Mo}(\mathrm{CNPh})_{7}\right]^{2+}$ by an anionic iodide ligand leads to a cathodic shift $(0.35 \mathrm{~V})$ in the $\mathrm{Mo}^{[3+2+]}$ formal potential of $\left[\mathrm{MoI}(\mathrm{CNPh})_{6}\right]^{+}$, as the halide ligand is better able to stabilize the $\mathrm{Mo}^{3+}$ oxidation state. Similarly, the peak cathodic potential for the $\mathrm{Mo}^{[2+/ 0]}$ couple of $\left[\mathrm{MoI}(\mathrm{CNPh})_{6}\right]^{+}$occurs at $0.26 \mathrm{~V}$ more negative than that of $\left[\mathrm{Mo}(\mathrm{CNPh})_{7}\right]^{2+}$. Making the general assumption that replacement of a $\mathrm{CNPh}$ ligand by $\mathrm{I}^{-}$results in $\Delta E^{\mathrm{o}}\left(\mathrm{M}^{[3+/ 2+]}\right)=-0.35 \mathrm{~V}$ and $\Delta E_{\mathrm{p}, \mathrm{c}}^{\mathrm{o}}\left(\mathrm{M}^{[2+/ 0]}\right)=-0.26 \mathrm{~V}$, extrapolation predicts the potentials shown in Table $\mathrm{S} 6$ for $\left[\mathrm{WI}(\mathrm{CNPh})_{6}\right]^{+}$and $\mathrm{WI}_{2}(\mathrm{CNPh})_{6}$. Although the former compound has been previously prepared, ${ }^{13}$ its electrochemistry was not reported.

The $\mathrm{W}^{[3+/ 2+]}$ oxidation and $\mathrm{W}^{[2+/ 0]}$ reduction events of $\mathrm{WI}_{2}(\mathrm{CNAr})_{5}\left(\mathrm{Ar}=\right.$ Dipp or DippPh $\left.{ }^{\mathrm{OMe} 3}\right)$ occur at slightly more negative potentials than those predicted for $\mathrm{WI}_{2}(\mathrm{CNPh})_{5}$ (Table S6). We attribute these differences to the greater donor strength of 2,6-diisopropylphenylisocyanides versus phenylisocyanide, as well as small uncertainties due to the (1) different experimental conditions under which cyclic voltammograms were collected and (2) use of the approximation $E^{\mathrm{o}}\left(\mathrm{Fc}^{[+/ 0]}\right)=$ $+0.4 \mathrm{~V}$ vs SCE.

Table S6. Reported (black) and extrapolated (red italics) formal/peak potentials for $\left[\mathrm{M}(\mathrm{CNPh})_{7}\right]^{2+}$ and $\left[\mathrm{MI}(\mathrm{CNPh})_{6}\right]^{+}$complexes $(\mathrm{M}=\mathrm{Mo}, \mathrm{W})$.

\begin{tabular}{|c|c|c|}
\hline Complex & $\boldsymbol{E}^{\mathbf{o}}\left(\mathbf{M}^{[3+/ 2+]}\right)(\mathbf{V})$ & $E_{\mathrm{p}, \mathrm{c}}^{\mathbf{o}}\left(\mathbf{M}^{[2+/ 0]}\right)(\mathbf{V})$ \\
\hline$\left[\mathrm{Mo}(\mathrm{CNPh})_{7}\right]^{2+}$ & +1.01 & -1.52 \\
\hline$\left[\mathrm{MoI}(\mathrm{CNPh})_{6}\right]^{+}$ & +0.66 & -1.78 \\
\hline $\mathrm{MoI}_{2}(\mathrm{CNPh})_{5}$ & +0.31 & -2.04 \\
\hline$\left[\mathrm{W}(\mathrm{CNPh})_{7}\right]^{2+}$ & +0.92 & -1.42 \\
\hline$\left[\mathrm{WI}(\mathrm{CNPh})_{6}\right]^{+}$ & +0.57 & -1.68 \\
\hline $\mathrm{WI}_{2}(\mathrm{CNPh})_{5}$ & +0.22 & -1.94 \\
\hline $\mathrm{WI}_{2}(\mathrm{CNDipp})_{5}$ & -0.07 & -2.31 \\
\hline $\mathrm{WI}_{2}\left(\mathrm{CNDippPh} \mathrm{OMe}^{\mathrm{OM}}\right)_{5}$ & -0.06 & -2.35 \\
\hline
\end{tabular}

*Redox potentials for $\left[\mathrm{Mo}(\mathrm{CNPh})_{7}\right]\left[\mathrm{PF}_{6}\right]_{2},\left[\mathrm{MoI}(\mathrm{CNPh})_{6}\right][\mathrm{PF} 6]$, and $\left[\mathrm{W}(\mathrm{CNPh})_{7}\right]\left[\mathrm{PF}_{6}\right]_{2}$ reported in $\mathrm{V}$ vs SCE in ref. 13 were converted to $\mathrm{V}$ vs $\mathrm{Fc}^{[+/ 0]}$ using the approximation $E^{\circ}\left(\mathrm{Fc}^{[+/ 0]}\right)=+0.4 \mathrm{~V}$ vs SCE.

$\underline{\text { W(CNDipp)6 Regeneration from WI2(CNDipp) }}$

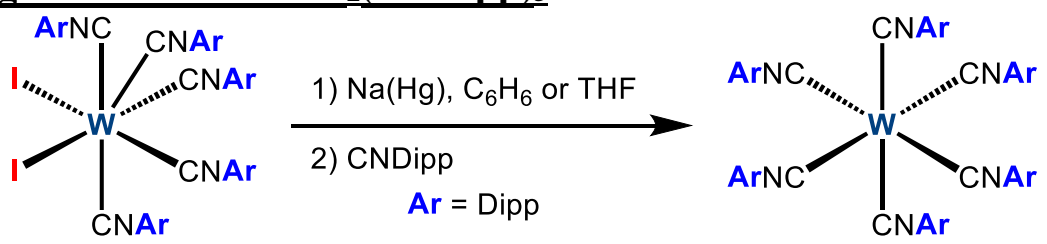

Reduction of $\mathrm{WI}_{2}(\mathrm{CNDipp})_{5}$ with excess $\mathrm{Na}(\mathrm{Hg})$ in room temperature benzene or THF solution, followed by filtration and addition of excess CNDipp, resulted in regeneration of $\mathrm{W}(\mathrm{CNDipp})_{6}$ as determined by ${ }^{1} \mathrm{H}$ NMR and UV-visible absorbance spectroscopies. 


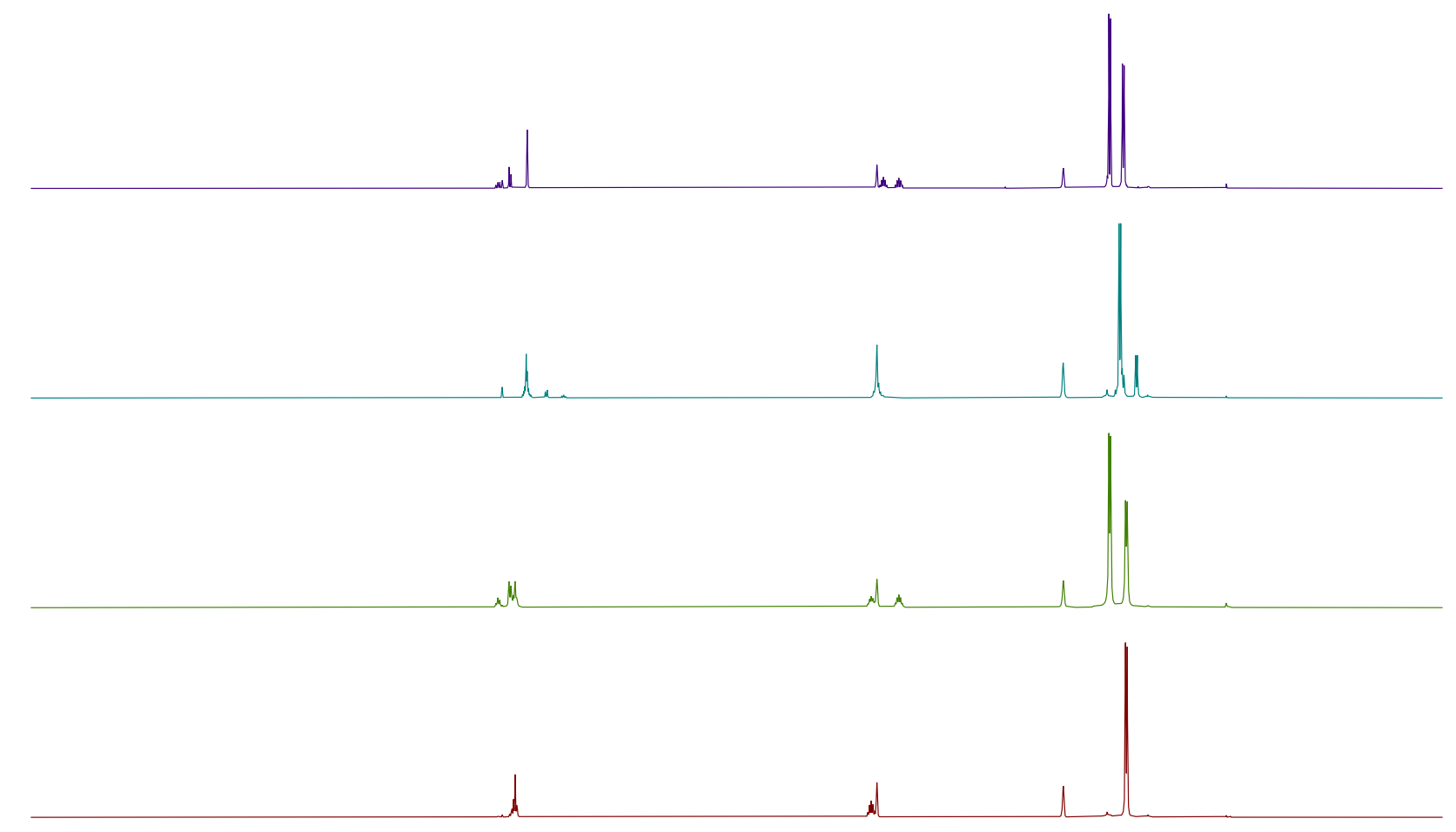

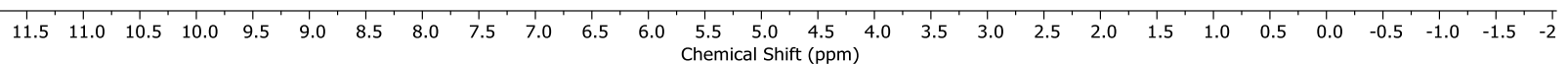

Figure S149. Stacked ${ }^{1} \mathrm{H}$ NMR spectra (400 MHz, THF- $\left.d_{8}\right)$ of $\mathrm{WI}_{2}(\mathrm{CNDipp})_{5}$ (red), a mixture of $\mathrm{WI}_{2}$ (CNDipp)5 and free CNDipp (green), and the reaction mixture from $\mathrm{Na}(\mathrm{Hg})$ reduction of $\mathrm{WI}_{2}$ (CNDipp) 5 prior to (aqua) and after (purple) treatment with excess CNDipp. The spectrum of the mixture of $\mathrm{WI}_{2}(\mathrm{CNDipp})_{5}$ and free CNDipp remains unchanged over the course of 2 days, suggesting that substitution of the iodo ligands of $\mathrm{WI}_{2}(\mathrm{CNDipp})_{5}$ by CNDipp does not take place at ambient temperature in $\mathrm{THF}-d_{8}$ solution. 


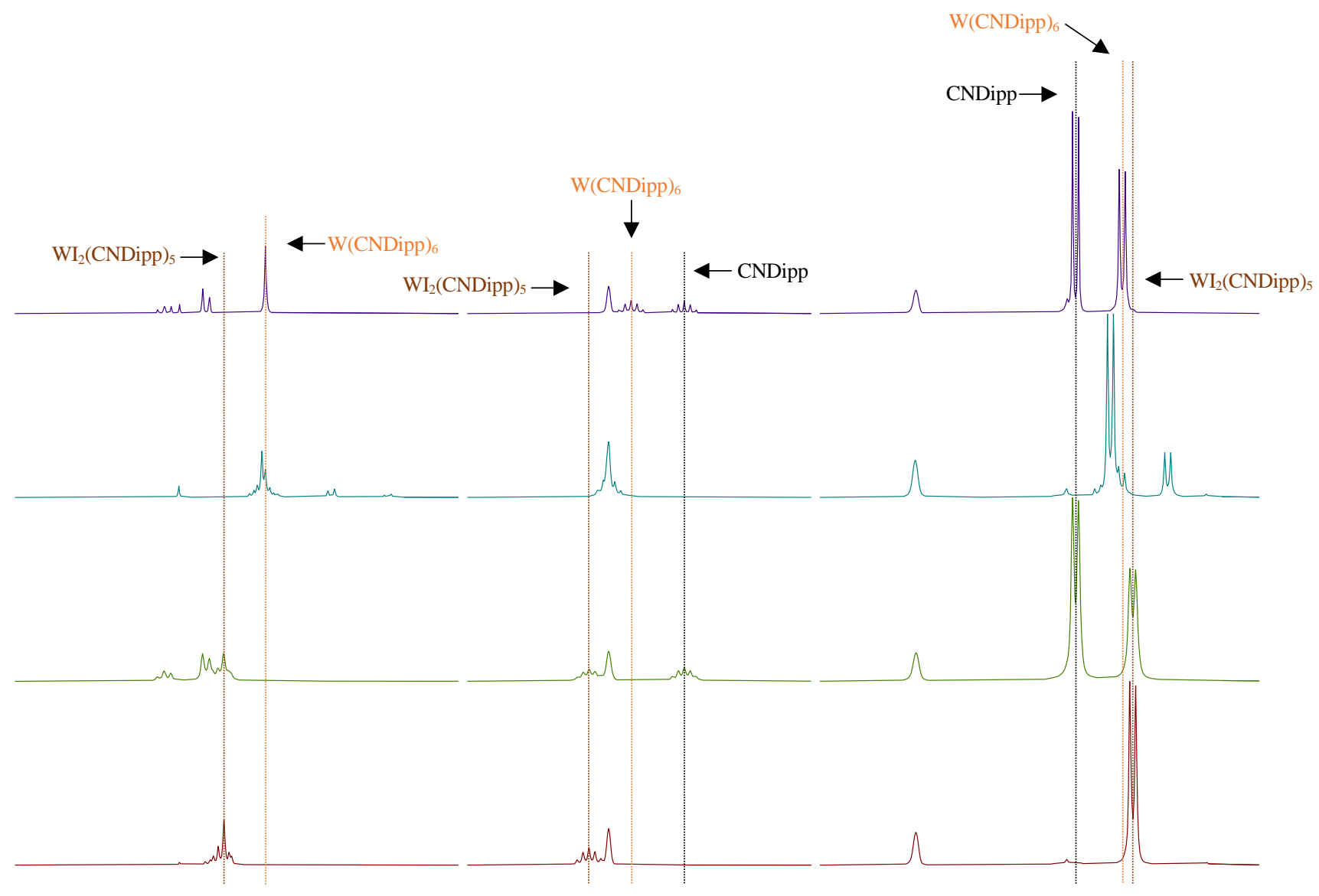

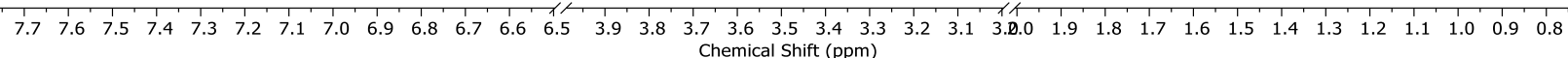
Figure S150. Zoom-ins of the ${ }^{1} \mathrm{H}$ NMR spectra from Figure S149 showing the regions of interest. 


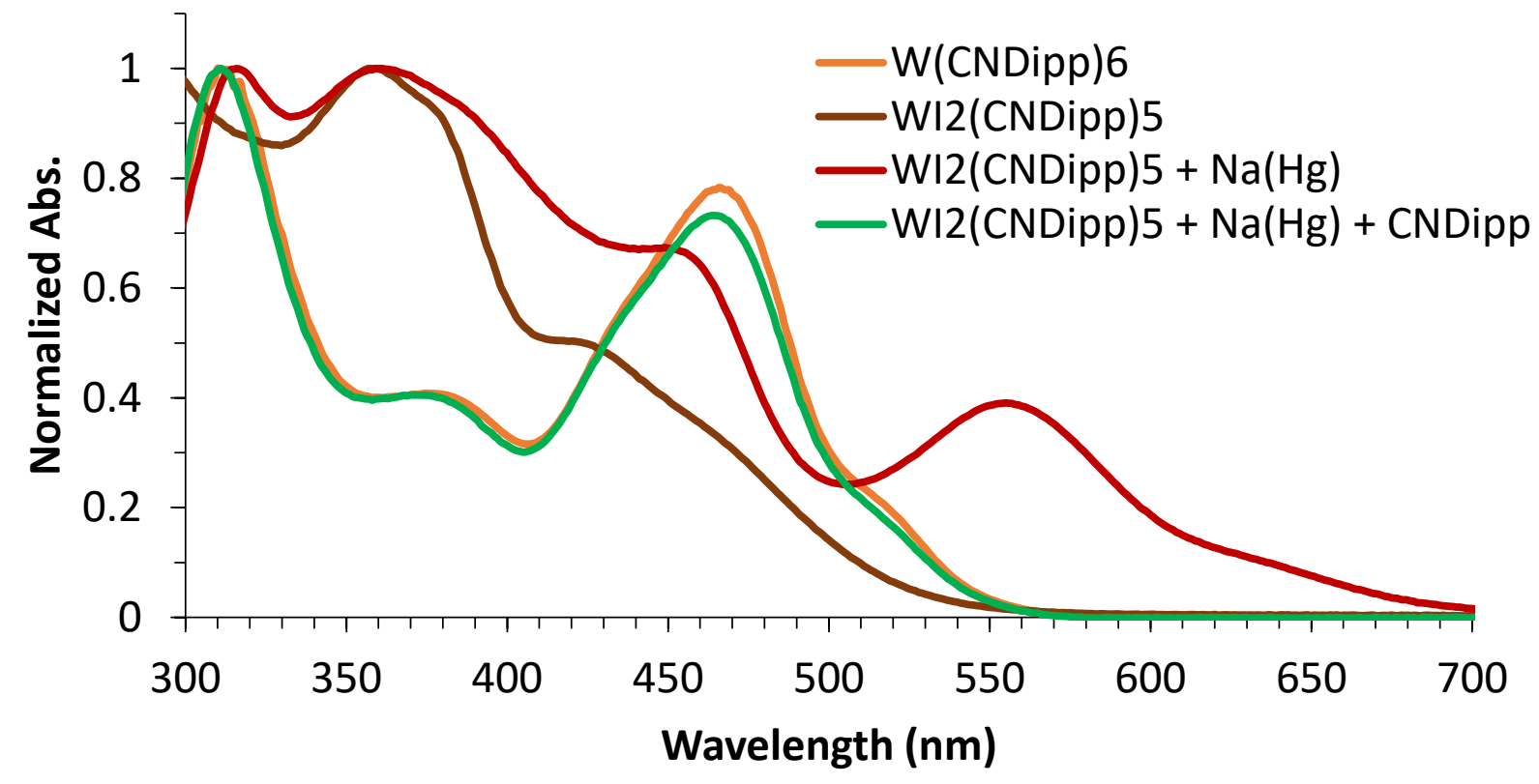

Figure S151. Normalized UV-visible absorbance spectra (THF solution) of W(CNDipp) 6 (orange), $\mathrm{WI}_{2}(\mathrm{CNDipp})_{5}$ (brown), and the reaction mixture from $\mathrm{Na}(\mathrm{Hg})$ reduction of $\mathrm{WI}_{2}(\mathrm{CNDipp})_{5}$ prior to (red) and after (green) treatment with excess CNDipp. The latter two spectra were acquired from the corresponding NMR samples in Figure S149. 


\section{X-Ray Crystallography}

Table S7. Crystal data and structure refinement for $\mathrm{WI}_{2}(\mathrm{CNDipp})_{5}$.

\begin{tabular}{|c|c|}
\hline Compound & $\mathrm{WI}_{2}$ (CNDipp) \\
\hline Empirical formula & $\mathrm{C}_{65} \mathrm{H}_{85} \mathrm{I}_{2} \mathrm{~N}_{5} \mathrm{~W}$ \\
\hline Formula weight & 1374.02 \\
\hline Temperature $[\mathrm{K}]$ & $100(2)$ \\
\hline Crystal Color & Orange \\
\hline Crystal system & Triclinic \\
\hline Space group & $\mathrm{P}-1$ \\
\hline $\mathrm{a}[\AA]$ & $11.967(4)$ \\
\hline $\mathrm{b}[\AA]$ & $12.496(3)$ \\
\hline$c[\AA]$ & $23.240(9)$ \\
\hline$\alpha\left[^{\circ}\right]$ & $75.624(14)$ \\
\hline$\beta\left[^{\circ}\right]$ & $79.57(3)$ \\
\hline$\gamma\left[^{\circ}\right]$ & $68.552(10)$ \\
\hline Volume $\left[\AA^{3}\right]$ & $3117.7(18)$ \\
\hline $\mathrm{Z}$ & 2 \\
\hline$\rho_{\text {calc }}\left[\mathrm{g} / \mathrm{cm}^{3}\right]$ & 1.464 \\
\hline$\mu\left[\mathrm{mm}^{-1}\right]$ & 2.884 \\
\hline $\mathrm{F}(000)$ & 1380 \\
\hline Radiation & $\operatorname{MoK} \alpha(\lambda=0.71073 \AA)$ \\
\hline Reflections collected & 113395 \\
\hline Independent reflections & 19239 \\
\hline Data/restraints/parameters & $19239 / 0 / 678$ \\
\hline Goodness-of-fit on $\mathrm{F}^{2}$ & 1.096 \\
\hline $\mathrm{R}_{1}(\mathrm{I}>2 \sigma(\mathrm{I}))$ & 0.0284 \\
\hline $\mathrm{wR}_{2}(\mathrm{I}>2 \sigma(\mathrm{I}))$ & 0.0524 \\
\hline $\mathrm{R}_{1}$ (all data) & 0.0378 \\
\hline $\mathrm{wR}_{2}$ (all data) & 0.0546 \\
\hline
\end{tabular}




\section{$\underline{\text { References }}$}

(1) Sattler, W.; Henling, L. M.; Winkler, J. R.; Gray, H. B. Bespoke Photoreductants: Tungsten Arylisocyanides. J. Am. Chem. Soc. 2015, 137, 1198-1205.

(2) Fajardo, J.; Schwan, J.; Kramer, W. W.; Takase, M. K.; Winkler, J. R.; Gray, H. B. ThirdGeneration W(CNAr)6 Photoreductants (CNAr = Fused-Ring and Alkynyl-Bridged Arylisocyanides). Inorg. Chem. 2021, 60, 3481-3491.

(3) Nayak, M.; Kang, Y. K.; Kim, I. Altering the Cyclization Modes: Temperature-Dependent Intramolecular 7-Endo-Dig vs 6-Endo-Dig Electrophilic Ring Closures. Org. Lett. 2017, 19, 1474-1477.

(4) Herr, P.; Glaser, F.; Büldt, L. A.; Larsen, C. B.; Wenger, O. S. Long-Lived, Strongly Emissive, and Highly Reducing Excited States in Mo(0) Complexes with Chelating Isocyanides. J. Am. Chem. Soc. 2019, 141, 14394-14402.

(5) Takematsu, K.; Wehlin, S. A. M.; Sattler, W.; Winkler, J. R.; Gray, H. B. Two-Photon Spectroscopy of Tungsten(0) Arylisocyanides Using Nanosecond-Pulsed Excitation. Dalton Trans. 2017, 46, 13188-13193.

(6) Sheldrick, G. M. Phase Annealing in SHELX-90: Direct Methods for Larger Structures. Acta Cryst. 1990, A46, 467-473.

(7) Sheldrick, G. M. Crystal Structure Refinement with SHELXL. Acta Cryst. 2015, C71, 3-8.

(8) Müller, P. Practical Suggestions for Better Crystal Structures. Crystallogr. Rev. 2009, 15, 57-83.

(9) Saper, N. I.; Snider, B. B. 2,2,6,6-Tetramethylpiperidine-Catalyzed, Ortho-Selective Chlorination of Phenols by Sulfuryl Chloride. J. Org. Chem. 2014, 79, 809-813.

(10) Büldt, L. A.; Guo, X.; Prescimone, A.; Wenger, O. S. A Molybdenum(0) Isocyanide Analogue of $\mathrm{Ru}\left(2,2^{\prime}\right.$-Bipyridine $) 3^{2+}$ : A Strong Reductant for Photoredox Catalysis. Angew. Chem., Int. Ed. 2016, 55, 11247-11250.

(11) Reguardati, S. de; Pahapill, J.; Mikhailov, A.; Stepanenko, Y.; Rebane, A. High-Accuracy Reference Standards for Two-Photon Absorption in the 680-1050 nm Wavelength Range. Opt. Express 2016, 24, 9053-9066.

(12) Seybold, P. G.; Gouterman, M.; Callis, J. Calorimetric, Photometric and Lifetime Determinations of Fluorescence Yields of Fluorescein Dyes. Photochem. Photobiol. 1969, 9, 229-242.

(13) Klendworth, D. D.; Welters, W. W.; Walton, R. A. Redox Chemistry of Hexakis(Phenyl Isocyanide) Complexes of Molybdenum and Tungsten: The Synthesis of the Seven-Coordinate 
Cations $\left[\mathrm{M}(\mathrm{CNPh})_{7}\right]^{2+}$ and Their Electrochemistry and Substitution Reactions. Organometallics 1982, 1, 336-343. 